\section{Consejo de Editores (Editors Board)}

Editores Jefe (Editor-in-Chief)

- Dr. Jaime Padilla-Verdugo, Editor Jefe. Universidad Politécnica Salesiana (Ecuador).

- Dra. Verónica Marín-Díaz, Editora Jefe. Universidad de Córdoba (España).

Editores Asociados (Associate Editors)

- Dra. Victoria Jara-Cobos, Editora Asociada. Universidad Politécnica Salesiana (Ecuador).

- Patricio Benavides, Editor Asociado. Universidad Politécnica Salesiana (Ecuador).

Editores temáticos (Thematic Editors)

- Dr. Fernando González Alonso, Universidad Pontificia de Salamanca (España)

- Dra. Azucena Ochoa Cervantes, Universidad Autónoma de Querétaro (México)

- Dr. José Luis Guzón Nestar, Universidad Complutense de Madrid y Universidad Pontificia de Salamanca (España)

Co-Editores internacionales (International Coeditors)

Dr. Geraldo Caliman, Universidade Católica de Brasília, (Brasil)

\section{Consejo Científico (Advisory Board)}

- Dr. Alejandro Rodríguez-Martín, Universidad de Oviedo, España

- Dr. Alfonso Torres Carrillo, Universidad Pedagógica Nacional, Colombia

- Dr. Alfredo Veiga-Neto, Universidade Federal do Rio Grande do Sul, Brasil

- Dra. Ana Castro Zubizarreta, Universidad de Cantabria, España

- Dra. Ana Rosa Arias Gago, Universidad de León, España

- Dr. Antonio Bautista García-Vera, Universidad Complutense de Madrid, España

- Dra. Armanda Matos, Universidad de Coímbra, Portugal

- Dr. Carlos Paladines Escudero, PUCE, Ecuador

- Dra. Carmen Martínez Novo, Universidad de Kentucky, USA

- Dra. Cristina Allemann-Ghionda, Universidad de Colonia, Alemania

- Dr. Daniel Mato, Universidad Nacional Tres de Febrero, Argentina

- Dra. Diana Rivera Rogel, Universidad Técnica Particular de Loja, Ecuador

- Dr. Emilio Álvarez-Arregui, Universidad de Oviedo, España

- Dr. Felipe Trillo Alonso, Universidad de Santiago de Compostela, España

- Dra. Gabriela Borjes, Universidade Federal de Juiz de Fora, Brasil

- Dr. Geraldo Caliman, Universidade Católica de Brasília, Brasil

- Dr. Gunther Dietz, Universidad Veracruzana, México

- Dr. Jairo Lugo-Ocando, Northwestern University in Qatar, Qatar

- Dr. Javier Loredo Enríquez, Universidad Iberoamericana, México

- Dr. Jesús María Salinas Ibáñez, Universidad de las Islas Baleares, España

- Dr. Jorge Maldonado Mahauad, Universidad de Cuenca, Ecuador

- Dr. José Antonio Caride Gómez, Universidad de Santiago de Compostela, España

- Dr. José Joaquín Brunner, Universidad Diego Portales, Chile

- Dr. José Manuel Castellano Gil, Universidad Nacional de Educación, Ecuador
- Dr. José Tejada Fernández, Universidad Autónoma de Barcelona, España

- Dr. Juan Silva Quiroz, Universidad de Santiago de Chile, Chile

- Dr. Julio Cabero-Almenara, Universidad de Sevilla, España

- Dr. Lorenzo Cantoni, Università della Svizzera Italiana, Suiza

- Dr. Luis Miguel Pedrero Esteban, Universidad Pontificia de Salamanca, España

- Dr. Manuel Area, Universidad de La Laguna, España

- Dra. María Caridad Valdés Rodríguez, Universidad de las Ciencias Informáticas, Cuba

- Dra. María Isabel Punín Larrea, Universidad Técnica Particular de Loja, Ecuador

- Dra. María Teresa Bejarano Franco, Universidad de Castilla La Mancha, España

- Dra. María-Soledad Ramírez-Montoya, TEC de Monterrey, México

- Dr. Maurice Tardif, Universidad de Montreal, Canadá

- Dra. Mercedes González-Sanmamed, Universidad de La Coruña, España

- Dra. Natalia González Fernández, Universidad de Cantabria, España

- Dra. Paloma Antón Ares, Universidad Complutense de Madrid, España

- Dra. Paula Renés Arellano, Universidad de Cantabria, España

- Dr. Peter McLaren, Chapman University, USA

- Dra. Pilar Arnáiz Sánchez, Universidad de Murcia, España

- Dr. Rafael Tejeda Díaz, Universidad Técnica de Manabí, Ecuador

- Dr. Ronaldo Zacharias, Centro Universitário Salesiano de São Paulo, Brasil

- Dra. Rosa Bruno-Jofré, Queen’s University, Canadá

- Dra. Soraya Ferreira Vieira, Universidade Federal de Juiz de Fora, Brasil

- Dra. Sylvia Schmelkes del Valle, INEE, México

- Dr. Vicent Gozálvez Pérez, Universidad de Valencia, España

Consejo Internacional de Revisores (International Board of Reviewers)

- Dra. Adelina de Oliveira Novaes, Universidade Cidade de São Paulo, Brasil

- Dra. Adir Casaro Nascimento, Universidade Catolica Dom Bosco, Brasil

- Dra. Águeda Delgado-Ponce, Universidad de Huelva, España

- Dra. Aleksandra Jablonska, Universidad Pedagógica Nacional, México

- Dra. Alessandra Diehl, Universidade de Ribeirão Preto, Brasil

- Dra. Alethia Fernández de la Reguera, UNAM, México

- Dr. Alexandre Godoy Dotta, Centro Universitário Autônomo do Brasil, Brasil

- Dr. Alexandre Martins, Marquette University, USA

- Dra. Alicia Inés Villa, Universidad Nacional de La Plata, Argentina

- Dra. Alma Rosa Hernández Mondragón, Universidad La Salle, México

- Álvaro Guaymás, Universidad Nacional de Salta (UNSa), Argentina

- Dr. Amauris Laurencio Leyva, Universidad de La Habana, Cuba

- Dra. Amelia Gort Almeida, Universidad de La Habana, Cuba 
- Dra. Amneris Chaparro Martínez, UNAM, México

- Ana Cristina Canosa, Centro Universitário Salesiano de São Paulo, Brasil

- Dra. Ana Lucia Braz, Universidade do Grande ABC, Brasil

- Dra. Ana Lupita Chaves, Universidad de Costa Rica, Costa Rica

- Ana Marcela Castellanos Guzmán, Universidad La Salle, México

- Dra. Ana María Eyng, Pontificia Universidad Católica de Paraná, Brasil

- Dra. Ana Pérez-Escoda, Universidad Internacional de La Rioja, España

- Dr. André Boccato de Almeida, Pontifícia Universidade Católica de São Paulo, Brasil

- Dra. Ángela Santamaría Chavarro, Universidad del Rosario de Bogotá, Colombia

- Dra. Anita Gramigna, Università degli Studi di Ferrara, Italia

- Dra. Annachiara Del Prete, Universidad Rovira y Virgili, España

- Anne Köster, European University Viadrina, Alemania

- Dra. Antonella Cagnolati, Università degli Studi di Foggia, Italia

- Dra. Antonia Ramírez-García, Universidad de Córdoba, España

- Dr. Antonio Hilario Aguilera, Universidade Federal de Mato Grosso do Sul, Brasil

- Dr. Antônio Igo Barreto Pereira, Universidade Federal do Acre, Brasil

- Dr. Aristeo Santos López, Universidad Autónoma del Estado de México, México

- Dra. Azucena Ochoa Cervantes, Universidad Autónoma de Querétaro, México

- Dra. Beatriz Gualdieri, Universidad Nacional de Luján, Argentina

- Dra. Bianca Thoilliez Ruano, Universidad Autónoma de Madrid, España

- Dra. Carla Förster Marín, Pontificia Universidad Católica de Chile, Chile

- Dra. Carmen Marta-Lazo, Universidad de Zaragoza, España

- Dra. Cecilia Dolores Correa de Molina, Universidad Simón Bolívar, Colombia

- Dra. Claudia Araújo de Lima, Universidade Federal de Mato Grosso do Sul, Brasil

- Dra. Claudia del Pilar Vélez, Universidad de San Buenaventura de Cali, Colombia

- Dra. Claudia Moreno Standen, Universidad de Chile, Chile

- Dra. Constantina Xavier Filha, Universidade Federal de Mato Grosso do Sul, Brasil

- Dr. Cristian Desbouts, Università Pontificia Salesiana, Italia

- Dra. Damia Mendoza-Zambrano, Universidad Laica Eloy Alfaro de Manabí, Ecuador

- Dr. Daniel Leonidas Loncón, Universidad Nacional de la Patagonia, Argentina

- Dr. Daniel Llanos Erazo, Universidad Politécnica Salesiana, Ecuador

- Diana Ávila, Universidad Politécnica Salesiana, Ecuador

- Dr. Eduardo Fabara Garzón, Universidad Andina "Simón Bolívar", Ecuador

- Dr. Eduardo Mercado Cruz, ISCEEM, México

- Dra. Elena Guadalupe Rodríguez-Roa, Universidad La Salle, México
- Dra. Elisabete Oliveira, ECOS - Comunicação em Sexualidade, Brasil

- Dra. Elsa Celina Gatti García, Universidad de la República, Uruguay

- Dra. Emiko Saldivar, University of California - Santa Barbara, USA

- Dr. Emiliano Gil Blanco, Universidad San Francisco de Quito, Ecuador

- Dr. Enrique Arturo Parra Marín, Universidad de Chile, Chile

- Dr. Enrique Sánchez Rivas, Universidad de Málaga, España

- Dr. Ernesto Guerra García, Universidad Autónoma Indígena de México, México

- Dr. Felipe de Jesús Perales Mejía, Universidad Pedagógica Nacional, México

- Dr. Fernando Lara, PUCE, Ecuador

- Dr. Fernando González Alonso, Universidad Pontificia de Salamanca, España

- Fernando Paladines Jaramillo, PUCE, Ecuador

- Dra. Flor Marina Bermúdez-Urbina, Universidad de Ciencias y Artes de Chiapas, México

- Dr. Francisco Javier Merchán Iglesias, Universidad de Sevilla, España

- Dra. Gema Sáez Rodríguez, Universidad Francisco de Vitoria, España

- Dr. Gersem José dos Santos Luciano, Universidade Federal do Amazonas, Brasil

- Dra. Gina Benavides Llerena, Universidad Andina “Simón Bolívar", Ecuador

- Giovanna Barroca de Moura, Universidade Estadual da Paraíba, Brasil

- Dr. Greby Uriel Rioja Montaño, Universidad Mayor de San Simón, Bolivia

- Dr. Henry Chero Valdiviezo, Universidad Católica Los Ángeles de Chimbote, Perú

- Dra. Herminia Hernández, Universidad de La Habana, Cuba

- Dr. Hugues Ribeiro, Universidade Estadual Paulista Júlio de Mesquita Filho, Brasil

- Dra. Irene Melgarejo Moreno, Universidad Católica de Murcia, España

- Dra. Irina Salcines Talledo, Universidad de Cantabria, España

- Dra. Isabel-Maria Gallardo Fernández, Universitat de Valencia, España

- Dr. Ivar César Oliveira de Vasconcelos, Universidade Católica de Brasília, Brasil

- Dr. Jaime Rivas Castillo, Universidad Don Bosco, El Salvador

- Dr. Jean Carlos García Zacarías, Pontificia Universidad Católica del Ecuador, Ecuador

- Dra. Jennie Brand Barajas, Universidad La Salle, México

- Dr. José Andrés García Méndez, Escuela Nacional de Antropología e Historia, México

- Dr. José Antonio Fernández Bravo, Universidad Camilo José Cela, España

- Dr. José Antonio Trasferetti, Pontifícia Universidade Católica de Campinas, Brasil 
- Dr. José Francisco Alvarado García, Universidad Iberoamericana, México

- Dr. José Guilherme dos Santos Fernandes, Universidade Federal do Pará, Brasil

- Dr. José Luis Guzón Nestar, CES Don Bosco, UCM y San Pío X, UPSA, España

- Dr. José Luis Moral, Università Pontificia Salesiana, Italia

- Dr. José Raúl Jiménez Ibáñez, Universidad de La Salle, Colombia

- Dra. Josiane Peres Gonçalves, Universidade Federal de Mato Grosso do Sul, Brasil

- Dr. Juan José Leiva Olivencia, Universidad de Málaga, España

- Dr. Juan Vicente Ortiz Franco, Fundación Universitaria Los Libertadores, Colombia

- Dra. Kathie Njaine, Fundação Oswaldo Cruz, Brasil

- Laura Liliana Rosso, Universidad Nacional de Nordeste, Argentina

- Dra. Laura Sánchez Blanco, Universidad Pontificia de Salamanca, España

- Dra. Laura Selene Mateos-Cortés, Universidad Veracruzana, México

- Dra. Leonor Buendía Eisman, Universidad de Granada, España

- Dra. Liliana Inés Ávila Garzón, Universidad Pedagógica y Tecnológica de Colombia, Colombia

- Dra. Liliana Mayer, Universidad Metropolitana para la Educación y el Trabajo, Argentina

- Dra. Lisset Coba Mejía, Facultad Latinoamericana de Ciencias Sociales, Ecuador

- Dra. Lorena Pastor Gil, Universidad Complutense de Madrid, España

- Dr. Luis Antonio Reyes Ochoa, Universidad Católica Silva Henríquez, Chile

- Dr. Luis Enrique Sime Poma, Pontificia Universidad Católica del Perú, Perú

- Dr. Luis Fernando Cuji Llugna, Universidad Nacional de Tres de Febrero, Argentina

- Luis Fernando García Álvarez, Instituto Nacional de Antropología e Historia, México

- Dr. Luis Huerta-Charles, New Mexico State University, USA

- Dra. Marcela Rosario Salazar Ibáñez, Universidad La Salle, México

- Dr. Márcio Roberto de Lima, Universidade Federal de São João Del-Rei, Brasil

- Dra. Maria Alfredo Lopes Moreira, Universidade do Minho, Portugal

- Dra. María Bertha Fortoul Ollivier, Universidad La Salle, México

- Dra. Maria de Fátima Pereira, Universidade do Porto, Portugal

- Dra. María del Mar Rodríguez Rosell, Universidad Católica de Murcia, España

- Dra. María Domingo Coscollola, Universitat Internacional de Catalunya, España

- Dra. María Elena Ortiz, Universidad Politécnica Salesiana, Ecuador

- Dra. María Inés Copello Danzi, Universidad de la República, Uruguay
- Dra. Maria Inês Millen, Centro de Ensino Superior de Juiz de Fora, Brasil

- Dra. María José Batista Pinto, Universidade Federal de Minas Gerais, Brasil

- María Margarita Marhx Bracho, Universidad La Salle, México

- Dra. María Sol Villagómez, Universidad Politécnica Salesiana, Ecuador

- Dra. María Teresa Prieto Quezada, Universidad de Guadalajara, México

- Dra. Maria-Carmen Caldeiro-Pedreira, Universidad Pública de Navarra, España

- Dra. Mariana Coralina Carmo, Universidade Estadual de Campinas, Brasil

- Dra. Maribel Enaida Alegre Jara, Universidad Nacional del Santa Perú

- Dra. Maribel Pinto, Instituto Politécnico de Viseu, Portugal

- Dr. Mário Marcelo Coelho, Pontifícia Universidade Católica de São Paulo, Brasil

- Dr. Marlécio Maknamara, Universidade Federal da Bahia, Brasil

- Dra. Meireluci Costa Ribeiro, Universidade Federal de São Paulo, Brasil

- Dra. Milagros Elena Rodríguez, Universidad de Oriente, Venezuela

- Dra. Mirtes Lira, Universidade de Pernambuco, Brasil

- Dra. Mistli López Pérez, Universidad Autónoma del Estado de Morelos, México

- Dra. Mónica Cecilia Sáenz Amaguaya, Universidad Politécnica Salesiana, Ecuador

- Dra. Mónica Montenegro, Universidad de Buenos Aires, Argentina

- Nelson Rubén Martínez Reyes, Universidad Don Bosco, El Salvador

- Dra. Noelia Ceballos López, Universidad de Cantabria, España

- Dra. Olga Alegre de la Rosa, Universidad de La Laguna, España

- Dra. Olga Espinoza Aros, Pontificia Universidad Católica de Chile, Chile

- Pablo Gómez Jiménez, Universidad Juárez Autónoma de Tabasco, México

- Dra. Patricia Hora Correia, Universidade do Estado da Bahia, Brasil

- Dra. Patricia Muñoz Borja, Universidad Santiago de Cali, Colombia

- Dr. Paulo César Nodari, Universidade de Caxias do Sul, Brasil

- Dr. Pierre André Garcia Pires, Universidade Federal do Acre, Brasil

- Raimundo França, Universidade Federal de Alagoas, Brasil

- Dr. Ramon Luis de Santana Alcântara, Universidade Federal do Maranhão, Brasil

- Dra. Regina Ferreira Barra, Universidade Federal de Juiz de Fora, Brasil

- Dra. Renata Nunes Vasconcelos, Universidade Federal de Alfenas, Brasil

- Dra. Rita Gomes do Nascimento, Ministério da Educação, Brasil

- Dr. Robério Barreto, Universidade do Estado da Bahia, Brasil

- Roberto López Chila, Universidad Politécnica Salesiana, Ecuador 
- Dra. Romilda Teodora Ens, Pontifícia Universidade Católica do Paraná, Brasil

- Dra. Ruth Aguilar Feijoo, Universidad Técnica Particular de Loja, Ecuador

- Dra. Ruth Amanda Cortes, IDEP, Colombia

- Dra. Salomé Sola-Morales, Universidad de Santiago de Chile, Chile

- Dra. Sandra Alves da Silva Santiago, Universidade Federal da Paraíba, Brasil

- Dra. Sandra Liliana Londoño Calero, Pontificia Universidad Javeriana, Colombia

- Dr. Sebastián Granda Merchán, Universidad Politécnica Salesiana, Ecuador

- Sergio Enrique Hernández Loeza, UNAM, México

- Dra. Shirlei Rezende Sales, Universidade Federal de Minas Gerais, Brasil

- Dra. Shirley Silva, Universidade de São Paulo, Brasil

- Dra. Silvia Barco, Universidad Nacional del Comahue, Argentina

- Dra. Sílvia Ester Orrú, Universidade de Brasília, Brasil

- Dra. Sonia Koehler, Centro Universitário Salesiano de São Paulo, Brasil

- Dra. Sonia Liliana Ivanoff, Universidad Nacional de la Patagonia, Argentina

- Dra. Sonia Sampaio, Universidad Federal de Bahía, Brasil

- Susana Barco, Universidad Nacional del Comahue, Argentina

- Dra. Suyai Malen García Gualda, Universidad Nacional del Comahue, Argentina

- Dra. Suzana dos Santos Gomes, Universidade Federal de Minas Gerais, Brasil

- Dra. Tânia Regina Dantas, Universidade do Estado da Bahia, Brasil

- Dra. Tania Suely Azevedo Brasileiro, Universidade Federal do Oeste do Pará, Brasil

- Dra. Teresa Laura Artieda, Universidad Nacional del Nordeste, Argentina

- Dr. Tiago Duque, Universidade Federal de Mato Grosso do Sul, Brasil

- Dra. Vanessa Figueiredo, Universidade Federal de Mato Grosso do Sul, Brasil

- Dra. Vania Tanira Biavatti, Universidade Regional de Blumenau, Brasil

- Dra. Victoria Jara, Universidad Politécnica Salesiana, Ecuador

- Dra. Wedja Maria Oliveira Leal, Pontifícia Universidade Católica de São Paulo, Brasil

- Dr. Wellington de Oliveira, UFVJM, Brasil

- Dr. Welson Barbosa Santos, Universidade Federal de Goiás, Brasil

- Willy Chambi Zabaleta, Universidad Salesiana de Bolivia, Bolivia

- Dra. Ximena Vélez Calvo, Universidad del Azuay, Ecuador

- Dra. Yamila Irupé Núñez, Universidad Nacional de Misiones, Argentina

- Dra. Yamirlis Gallar Pérez, Universidad Internacional SEK, Ecuador

- Dra. Yolanda Castro Robles, Pontificia Universidad Javeriana, Colombia

\section{Consejo Técnico (Board of Management)}

- Dr. Ángel Torres-Toukoumidis

- Soledad Aguilar

- Wilson Verdugo (Soporte OJS)

- Marco Gutiérrez (Soporte OJS)

- Paulina Torres (Redacción y estilo)

- Raysa Andrade (Maquetación)

- Adriana Curiel (Traducción)

- Jessica Rivadeneira-Peñafiel (Asistente editorial)

\section{Edita (Published by)}

Universidad Politécnica Salesiana www.ups.edu.ec

Consejo de Publicaciones (Board of Publications)

- Dr. Juan Cárdenas Tapia, Rector - Presidente

- Dr. Juan Pablo Salgado, Vicerrector de Investigación

- Dr. José Juncosa Blasco, Editorial Universitaria Abya-Yala

- Dr. René Unda Lara, Editor de Universitas

- Dr. Jaime Padilla Verdugo, Editor de Alteridad

- MSc. Sheila Serrano Vincenti, Editora de La Granja

- MSc. Jorge Cueva Estrada, Editor de Retos

- Dr. John Calle Sigüencia, Editor de Ingenius

- Dra. Floralba Aguilar Gordón, Editora de Sophia

- MSc. Betty Rodas Soto, Editora de Utopía

- MSc. Mónica Ruiz Vásquez, Editora del Noti-Ups

- Dra. Paola Ingavélez Guerra, Editora Revista Virtual-Cátedra Unesco

- MSc. David Armendáriz González, Editor Web

- Dr. Luis Álvarez Rodas, Editor General

\section{Editorial Universitaria Abya-Yala}

(Quito, Ecuador)

Hernán Hermosa (Coordinación General)

Av. 12 de Octubre N23-116 y Wilson, Bloque A, UPS

Casilla 17-12-7-19

Teléfono: (593-2)3962-800 ext. 2638

E-mail: editorial@ayayala.org.ec

Portal electrónico: http://www.abyayala.org 


\section{ALTERIDAD}

p-ISSN: 1390-325x / e-ISSN: 1390-8642

Vol. 16, No. 1/ enero-junio 2021

\section{Índice}

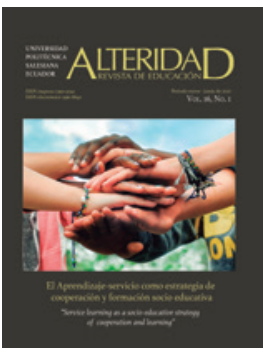

\section{El aprendizaje-servicio como estrategia de cooperación y formación socio educativa}

"Service learning as a socio-educative strategy of cooperation and learning"

\section{Editores Temáticos}

Dr. Fernando González Alonso, Universidad Pontificia de Salamanca (España)

Dra. Azucena Ochoa Cervantes, Universidad Autónoma de Querétaro (México)

Dr. José Luis Guzón Nestar, Universidad Complutense de Madrid y

Universidad Pontificia de Salamanca (España)

Editorial

SECCIÓN MONOGRÁFICA (MONOGRAPHIC SECTION)

DRA. XUS MARTÍN-GARCÍA, BRENDA BÄR-KWAST, DRA. MÓNICA GIJÓN-CASARES,

DR. JOSEP MARÍA PUIG-ROVIRA Y DRA. LAURA RUBIO-SERRANO

El mapa de los valores del aprendizaje-servicio

The service learning values map

DR. JOSÉ SANDOVAL-DIAZ, DAVID CUADRA-MARTÍNEZ Y CRISTIAN ORELLANA-FONSECA

Diagnóstico comunitario ante desastres climáticos: Una experiencia de aprendizaje-servicio

Community assessment in the face of climatic disasters: A Service-Learning experience

DRA. PALOMA CANDELA-SOTO, DRA. MARÍA CARMEN SÁNCHEZ-PÉREZ

Y DRA. MERCEDES ÁVILA-FRANCÉS

Aprendizaje-servicio en la enseñanza de la Sociología a futuros docentes

Service-Learning in the teaching of Sociology for future teachers

DR. FRANCISCO GANGA-CONTRERAS, ESTELA RODRIGUEZ-QUEZADA

Y NATALY GUIÑEZ-CABRERA

Metodología de aprendizaje-servicio en un proyecto integrado de costos y marketing

Service-learning methodology in an integrated cost and marketing project

DRA. LILIANA MAYER Y WANDA PEROZZO-RAMÍREZ

Aprendizaje-servicio en escuelas argentinas de Bachillerato Internacional

Service Learning enactment in International Baccalaureate Schools in Argentina

\section{SECCIÓN MISCELÁNEA (MISCELLANEOUS SECTION)}

DR. JULIO JUVENAL ALDANA-ZAVALA, DR. PATRICIO ALFREDO VALLEJO-VALDIVIESO

Y DR. JOSIA ISEA

Investigación y aprendizaje: Retos en Latinoamérica hacia el 2030

Research and learning: Challenges in Latin America towards 2030

DRA. YANET AMANDA MAQUERA-MAQUERA, DR. SAÚL BERMEJO-PAREDES Y ÉRIKA OLIVERA-CONDORI

Intervención familia-aula para el desarrollo de habilidades grafomotrices

Family-classroom intervention for the development of graphomotor skills

CRISTIAN OYARZÚN-MALDONADO Y RODOLFO SOTO-GONZÁLEZ

La improcedencia de estandarizar el trabajo docente: Un análisis desde Chile

The inadmissibility of standardizing the teaching work: An analysis from Chile

MAURICIO ANDRÉS VALDÉS-PINO, DRA. MARÍA ISABEL CALVO-ÁLVAREZ

Y DR. FERNANDO MARTÍNEZ-ABAD

Formación inclusiva del profesorado de primaria en tres regiones chilenas

Inclusive training of elementary teachers in three chilean regions

XIMENA PATRICIA VIZUETE-SALAZAR Y DR. ALEXANDER RAMÓN LÁREZ-LÁREZ

Perspectiva de género en educación Básica Superior y Bachillerato

Gender perspective in Superior Basic Education and High School

Normas de Publicación en "Alteridad" 


\section{ALTERIDAD}

p-ISSN: 1390-325x / e-ISSN: 1390-8642

Vol. 16, No. 1/ enero-junio 2021

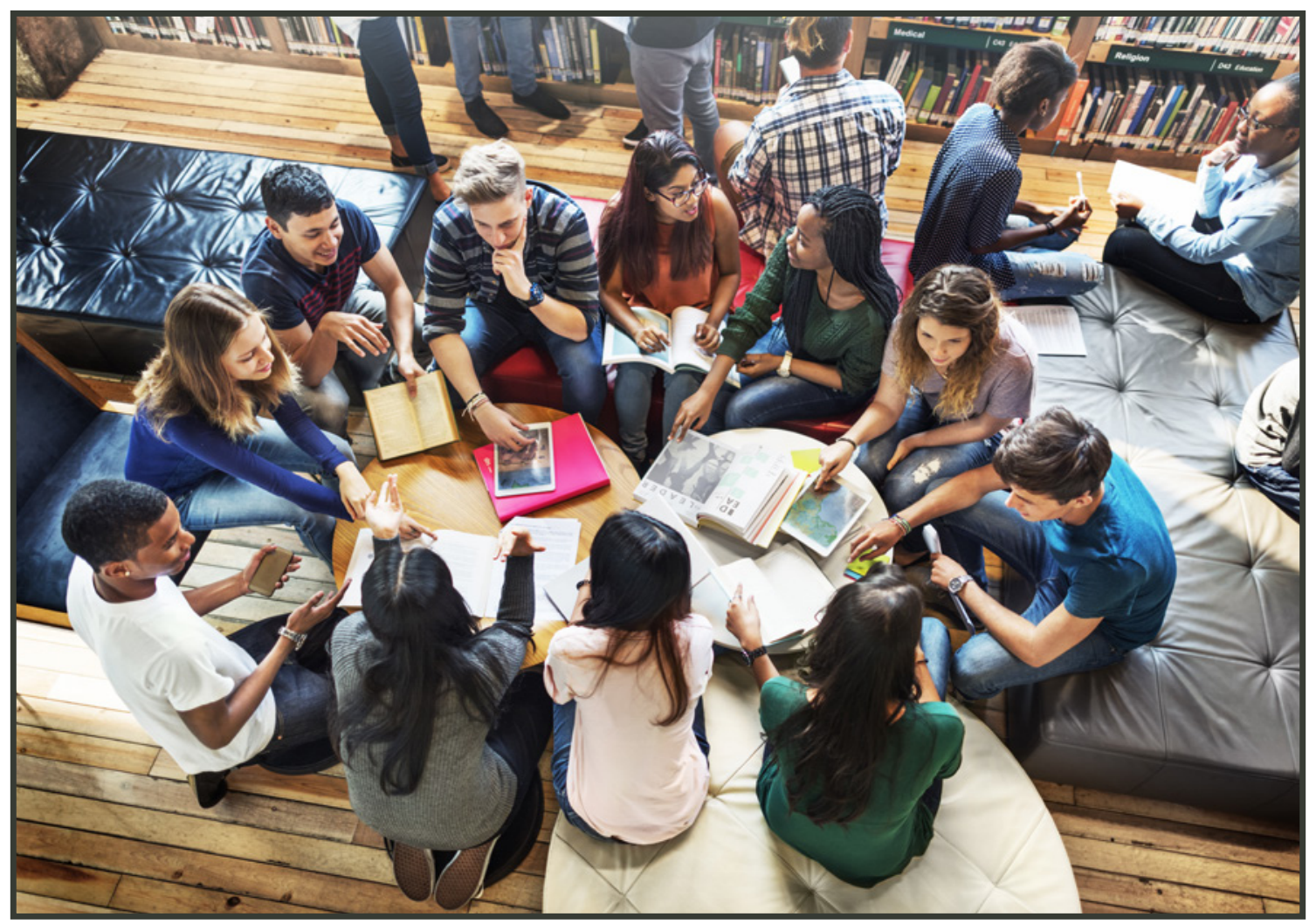

Fuente https:/ / www.shutterstock.com/es/image-photo/classmate-classroom-sharing-international-friend-concept-402458263

\section{Aprendizaje-Servicio}

Aprendizaje-Servicio [ApS] es una práctica de innovación educativa, una herramienta de transformación social, que conjuga el aprender haciendo mientras se ayuda a los demás; es una metodología activa que incentiva el cambio mientras se consolida el aprendizaje en el encuentro con el otro, en el compartir ideas, pensamientos, sentimientos y el saber ser solidario, empático y sencillo para mejorar realidades, producir conocimientos, cambiar sistemas y beneficiar a la sociedad. 


\section{Editorial}

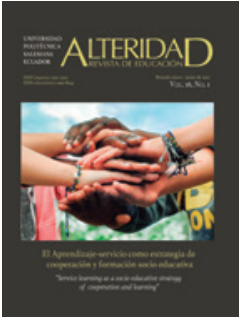

EdTores Temáticos

- Dr. Fernando González Alonso, Universidad Pontificia de Salamanca (España)

- Dra. Azucena Ochoa Cervantes, Universidad Autónoma de Querétaro (México)

- Dr. José Luis Guzón Nestar, Universidad Complutense de Madrid y Universidad Pontificia de Salamanca (España)

EDITOR JEFE

- Dr. Jaime Padilla-Verdugo, Universidad Politécnica Salesiana (Ecuador)

Desde el siglo XIX los diversos postulados de la escuela activa advertían, que el aprendizaje se construye mediante la experiencia, como mecanismo que permite al alumnado reflexionar y construir conocimientos. Implica canalizar propuestas pedagógicas que articulen experiencia, acción y aprendizaje, y así alcanzar el desarrollo cognitivo, afectivo-social y político de los estudiantes.

El aprendizaje-servicio (ApS) es una propuesta pedagógica que modula lo anterior. Se concreta como un proyecto donde los alumnos son los agentes que ayudan a la comunidad en sus necesidades, habiendo planificado y mejorando sus propios aprendizajes. El ApS es la expresión del aprendizaje basado en la experiencia y el servicio a la comunidad, contando con el apoyo institucional y de redes implicadas.

El proyecto de ApS responde a la realidad analizada con el diseño, ejecución y evaluación de este, posicionando al alumnado como personas capaces de transformar su entorno, desde la formación ciudadana y la puesta en práctica de valores de acuerdo a la región y a los objetivos particulares que se persigan. La participación activa del alumnado en experiencias de ApS, fomenta su aprendizaje, implicación, protagonismo y sensibilización en las necesidades socio-educativas detectadas en la comunidad.

En este número de "Alteridad", en la Sección Monográfica: El aprendizaje-servicio como estrategia de cooperación y formación socio-educativa, se muestran los resultados de experiencias y estudios que dan cuenta de la importancia, interés y actualidad del ApS como estrategia pedagógica y solidaria.

El primer artículo titulado El mapa de los valores del aprendizaje-servicio, proporciona un marco general para observar la potencia de esta metodología en el campo de la formación moral. Los autores, realizan una revisión amplia de los valores que activan el ApS. Para hacer esta propuesta, realizan una vinculación con los niveles de aprendizaje de valores que se despliegan en esta práctica. El resultado final es un mapa de valores que tiene al menos tres finalidades: una es visibilizar la diversidad de valores que se activan más allá de los ampliamente reconocidos como la cooperación o el altruismo; la segunda es concienciar a quienes hacen uso del ApS sobre la potencia moral de esta práctica y la tercera, orientar sobre la intencionalidad de las tareas, con el fin de incrementar la calidad formativa de esta experiencia.

En segundo lugar, se nos ofrece el artículo Diagnóstico comunitario ante desastres climáticos: Una experiencia de aprendizaje-servicio, que describe una experiencia de ApS realizada en la Universidad de Atacama (Chile), con estudiantes de octavo semestre de la carrera de Psicología, con el fin de atender a una comunidad que sufría los estragos de un evento hidrometeorológico 
extraordinario. La experiencia ApS se llevó a cabo dentro de la asignatura Diagnóstico Psicosocial. Este presenta una clara vinculación entre los aprendizajes curriculares y las necesidades reales, mostrando que, a partir de la experiencia no solo se mejoraron los saberes prácticos y teóricos, también se adquirieron competencias profesionales situadas en un contexto real. Otro elemento interesante a destacar es que se muestra la oportunidad del trabajo interdisciplinar, favoreciendo prácticas pedagógicas acordes a una formación universitaria que debe dar respuesta a los problemas cada vez más complejos.

La tercera propuesta hace balance de las contribuciones del ApS a la docencia universitaria, en concreto, a la formación inicial del profesorado. A partir de la evaluación de un proyecto de innovación docente llevado a cabo en la Facultad de Educación de la Universidad de Castilla La Mancha (UCLM), se profundiza en la percepción de los estudiantes sobre la utilidad del ApS en el aprendizaje académicocompetencial y en las experiencias vividas en escenarios escolares reales donde han observado y aplicado sus aprendizajes teóricos. La valoración de la adquisición de competencias concretas del Grado, la disposición y desempeño para comprender problemas sociales que afrontarán en su futuro profesional, así como los sentimientos y emociones experimentadas, son algunos de los objetivos que guían el manuscrito. Se trata de un estudio empírico de metodología mixta, que revela la elevada satisfacción del alumnado participante en la adquisición de competencias profesionales y personales próximas al desempeño competencial y formativo de las futuras maestras y los futuros maestros.

Un acercamiento también muy novedoso es el que nos llega de la mano de otros autores chilenos con su artículo Metodología de aprendizaje-servicio en un proyecto integrado de costos y marketing. En el artículo se destaca la necesidad de ir más allá de los procesos tradicionales de enseñanza. De aquí que ellos propongan el ApS como un método pedagógico que integra el aprendizaje y el servicio comunitario de los estudiantes en un entorno real. La finalidad principal de su estudio es describir la experiencia del diseño, la implementación y la gestión de la metodología de ApS en un proyecto integrado que contempla las asignaturas de costos y marketing, en un programa de negocios en una universidad estatal del centro-sur de Chile. El trabajo se sustenta en la sistematización de la experiencia de ApS, basada en tres fases de implementación. El proceso del diseño, la implementación y la gestión de un proyecto de estas características podría servir de guía en futuras aplicaciones por parte de los profesores o las instituciones, que se encuentren interesados en la innovación de los procesos de la enseñanza y el aprendizaje.

Autoras argentinas nos acercan a una visión del ApS en las escuelas de su país en Bachillerato Internacional, en el área metropolitana de Buenos Aires. Mediante un estudio cualitativo, que combina entrevistas, análisis documental y observaciones, estudian los diversos sentidos de las actividades que estudiantes, docentes y directivos realizan para el componente CAS (Creatividad, Acción y Servicio) del Programa Diploma, el más popular. Los resultados del trabajo muestran conclusiones diferentes, cuando se trata de escuelas privadas asociadas a otras públicas de sectores medios y medio-altos. Del artículo se deduce la importancia de los agentes institucionales en la promoción de estos proyectos, donde los jóvenes son los protagonistas y la habilitación para su realización dependerá de los adultos.

Es así que, con los artículos mostrados en este número temático, queda clara no sola la pertinencia de esta metodología sino la necesidad de implementarla en los distintos niveles escolares para asegurar el aprendizaje y formar mejores personas.

En la Sección Miscelánea, los artículos tratan diversos temas vinculados al proceso de enseñanza-aprendizaje, abriendo discusiones y planteando alternativas que respondan a los nuevos desafíos de los estudiantes, padres de familia, instituciones educativas y sociedad en general. El artí- 
culo, Investigación y aprendizaje: Retos en Latinoamérica hacia el 2030, de Aldana, Vallejo e Isea, hace referencia a una educación diferente al modelo tradicional. A partir de una revisión bibliográfica, sostiene que la investigación constituye un factor clave para la formación, no solo por sistematizar propuestas de investigación y generar nuevos conocimientos, sino porque facilita el aprendizaje a lo largo de la vida, e identifica factores pertinentes para un proceso de formación transversal orientado al logro de los Objetivos de Desarrollo Sostenible, constituyéndose a nivel latinoamericano en retos para el 2030; y por lo mismo, en algo que está pendiente de trabajar.

La propuesta de Maquera-Maquera, Bermejo-Paredes, y Olivera-Condori, Intervención familia-aula para el desarrollo de habilidades grafomotrices, constituye un aporte significativo para el nivel de educación inicial. Para responder a las exigencias de los padres de familia y las expectativas de la sociedad actual, abre la discusión, por una parte, de la relación entre "motricidad fina" y "habilidad grafomotriz"; y por otra, del intercambio de experiencias y conocimientos entre docentes y padres de familia. Se convierte en un desafío tanto para el profesorado de educación inicial cuanto para los padres de familia, ambos, corresponsables de la educación de la niñez, de ir más allá de sus creencias, y transformar las prácticas de educación inicial.

Oyarzún-Maldonado y Soto-González en el artículo, La improcedencia de estandarizar el trabajo docente: Un análisis desde Chile, presentan una temática de gran relevancia, colocando en el centro de la discusión un tema crítico, álgido y necesario para cualquier contexto. En la misma dirección de quienes buscan mejorar la equidad y calidad educativa, desde la propuesta de Mintzberg, analizan la pertinencia de los diferentes mecanismos de estandarización de los procesos y resultados de enseñanza-aprendizaje. Consideran que la teoría del comportamiento organizacional hegemónico es insuficiente para una evaluación integral, y discuten la pertinencia de otros mecanismos en los que prevalezcan el desarrollo de habilidades situadas, el trabajo colaborativo, la formación en valores socioeducativos, entre otros.

Bajo el título, Formación inclusiva del profesorado de primaria en tres regiones chilenas de Valdés-Pino, Calvo-Álvarez y Martínez-Abad, tratan un tema de interés, de actualidad y de alta relevancia, como es la educación inclusiva y la consecuente necesidad de formación de los docentes como principales mediadores del proceso de enseñanza-aprendizaje. El artículo se propone analizar e identificar esas necesidades formativas en inclusión desde la visión del profesorado, evidenciando la necesidad de formación particularmente en aspectos metodológicos y estratégicos que permitan promover, por una parte, un proceso de enseñanza aprendizaje centrado en la persona, el diseño de planes educativos individuales, el autoaprendizaje, el trabajo colaborativo y el uso de espacios virtuales; y por otra, la importancia de los recursos humanos y el trabajo interdisciplinar y colaborativo.

La sección miscelánea de este número se cierra con el artículo Perspectiva de género en educación Básica Superior y Bachillerato de Vizuete-Salazar y Lárez-Lárez. Un tema relevante, dada la necesidad de debatir sobre el mismo en el contexto escolar. En este es normal que los adolescentes se relacionen de acuerdo a sus concepciones culturales o estereotipos aprendidos en el hogar o sus diversos entornos, evidenciándose la desigualdad, discriminación y violencia aprendidas. El artículo presenta la percepción de los estudiantes sobre igualdad de género, demostrando que si bien, existe una actitud adaptativa que incide positivamente en un trato de igualdad y equidad, queda todavía actitudes estereotipadas. Los autores concluyen que el ambiente escolar constituye un espacio idóneo para eliminar tales estereotipos. Se ofrece al lector la posibilidad de analizarlo no solo en otros contextos, sino también en otros problemas y cuestiones que deben ser transformadas.

La pandemia del Covid-19 condujo rápidamente a la suspensión de clases y al cierre de universidades, colegios y escuelas en todo el mundo. Debido a las restricciones y recomendaciones emitidas 
por los centros de prevención de enfermedades y otras organizaciones nacionales, los gobiernos, instituciones educativas, padres de familia, docentes y estudiantes, hemos tenido que salir al encuentro de un proceso de enseñanza-aprendizaje remoto y/o en línea, provocando cambios vertiginosos en la acción educativa. La situación es potencialmente perjudicial para la educación. Nada está definido. El desafío para los sistemas educativos es grande: dar continuidad y mantener la calidad de la acción educativa mientras se vela por la seguridad de educadores, estudiantes y las respectivas familias. Pero la emergencia educativa consiste en qué hacer en tan poco tiempo y en cómo abordar de manera remota las necesidades de los estudiantes por área de estudio y por nivel.

Si bien, no existe un reemplazo total del aprendizaje experiencial, surgen nuevas iniciativas para mantener la calidad educativa, que incluyen el modelo de aula invertida, el uso de videoconferencias, la simulación de procedimientos, juegos de roles, el uso de videos educativos procedimentales, entre otros. Se adoptaron una combinación de modos de enseñanza-aprendizaje en línea sincrónicos y asincrónicos. El modo sincrónico implica lecciones en vivo en tiempo real impartidas a través del software de videoconferencia. El asincrónico implica subir los recursos didácticos a plataformas virtuales, con instrucciones procedimentales.

Se considera que el uso de las tecnologías podría ayudar a cerrar la brecha educativa; sin embargo, no siempre es real en todos los contextos. Se requiere el apoyo de organismos gubernamentales y no gubernamentales para que, sobre todo los estudiantes de los sectores marginales, puedan contar con el equipamiento y la conexión a Internet requerida. Continúan surgiendo nuevas necesidades, como el rediseño de los programas educativos, la capacitación a los docentes en el uso de las TIC, y la sistematización de las mejores experiencias educativas que respondan a estos nuevos desafíos.

Si consideramos que, como dice el poeta Brecht, "lo nuevo no acaba de nacer y lo viejo no acaba de morir", debemos aprender a reaccionar con prontitud y profesionalidad a los nuevos desafíos educativos.

Para continuar reflexionando la educación, se les invita a enviar sus manuscritos para ser arbitrados en Alteridad, Revista de Educación que ocupa el primer lugar entre las Revistas Científicas de Ecuador, de acuerdo con el Ranking de la Red Iberoamericana de Innovación y Conocimiento Científico (REDIB). 


\section{A}

p-ISSN: 1390-325x / e-ISSN: 1390-8642

Vol. 16, No. 1/ enero-junio 2021

\section{Sección Monográfica \\ (Monographic section)}

El aprendizaje-servicio como estrategia de cooperación y formación socio educativa

"Service learning as a socio-educative strategy of cooperation and learning"

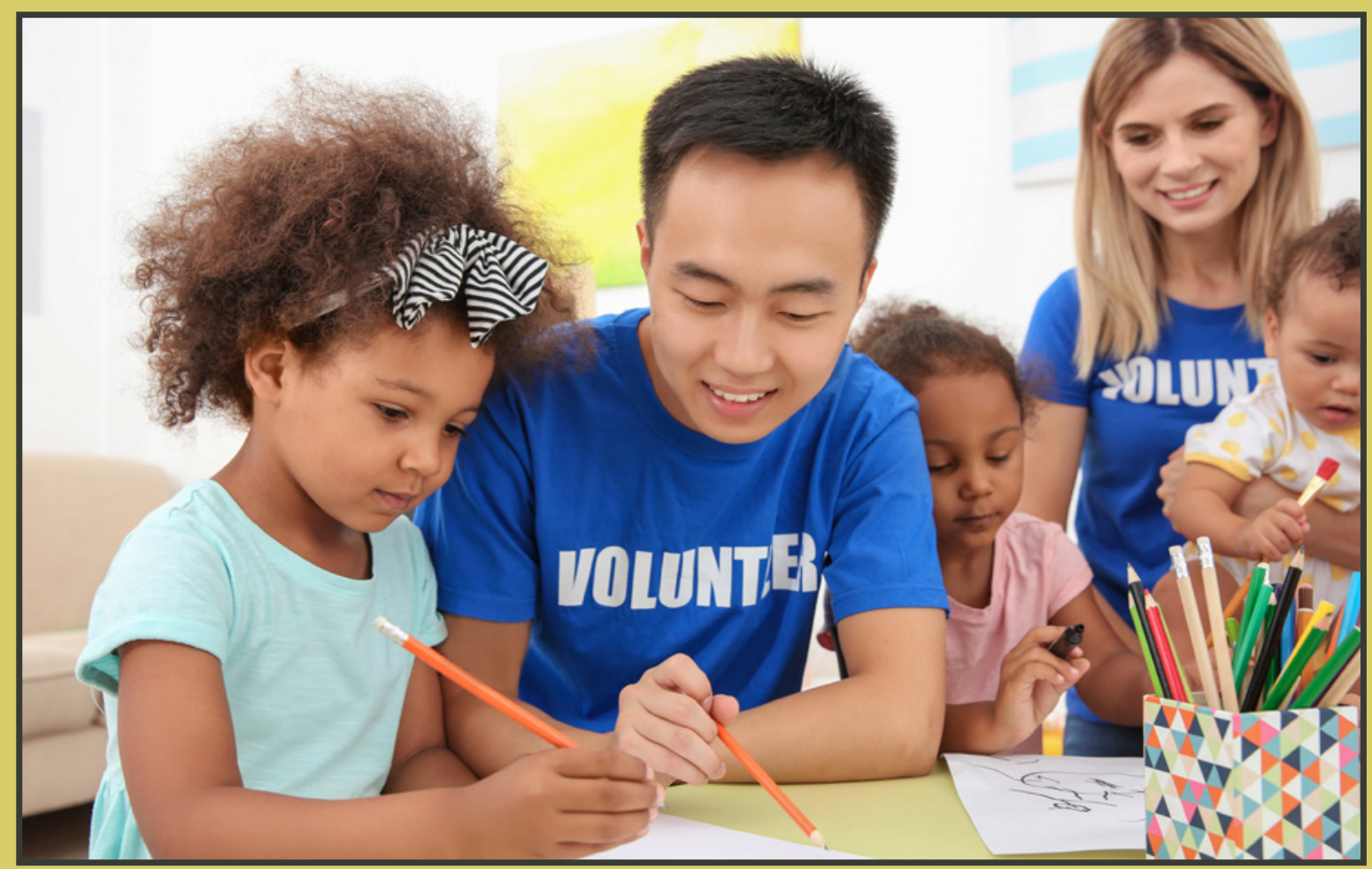

Fuente: https:/ / www.shutterstock.com/es/image-photo/young-male-volunteer-drawing-little-children-772558447 


\title{
EAIRRDAD $\quad$ El mapa de los valores del aprendizaje-servicio
}

\author{
The service learning values map
}

D Dra. Xus Martín-García es docente titular de la Universidad de Barcelona (España) (xusmartin@ub.edu) (https://orcid.org/0000-0003-4404-1026)

D Brenda Bär-Kwast es doctoranda en la Universidad de Barcelona (España) (brendabar@ub.edu) (https://orcid.org/0000-0002-4263-4007)

(D) Dra. Mónica Gijón-Casares es docente agregada Serra Hunter de la Universidad de Barcelona (España) (mgijon@ub.edu) (https://orcid.org/0000-0002-2696-6415)

(D) Dr. Josep María Puig-Rovira es catedrático jubilado de la Universidad de Barcelona (España) (joseppuig@ub.edu) (https://orcid.org/0000-0002-0168-6628)

(D) Dra. Laura Rubio-Serrano es docente agregada de la Universidad de Barcelona (España) (Irubio@ub.edu (https://orcid.org/0000-0002-5170-4564)

Recibido: 2020-06-13 / Revisado: 2020-11-30 / Aceptado: 2020-12-02 / Publicado: 2021-01-01

\section{Resumen}

A pesar de que la bibliografía especializada reconoce el aprendizaje-servicio como una metodología relevante de educación en valores, no se dispone todavía de una relación suficientemente completa de la pluralidad de valores que activa. El objetivo de este artículo es construir un mapa fiable de los valores que propone esta metodología. Para conseguirlo se definirán los niveles de aprendizaje que se superponen en una práctica educativa compleja y luego se determinarán los valores que se trabajan en cada uno de los niveles de la práctica del aprendizaje-servicio. Para conseguirlo se ha realizado un trabajo de reconstrucción racional basado en la optimización recíproca conseguida entre una selección de buenas experiencias de aprendizaje-servicio y la teoría de las prácticas morales y del aprendizaje-servicio. Esta metodología ha permitido establecer tres niveles simultáneos de aprendizaje -la práctica, las acciones y las tareas - así como un elenco de los valores que cristalizan en cada uno de ellos: un mapa completo de la variedad y riqueza de valores que se ponen en juego en el aprendizaje-servicio. Un resultado que, en los procesos de formación del profesorado, ayudará a tomar conciencia de la fuerza moral de esta metodología y a activarla durante su desempeño profesional.

Descriptores: Aprendizaje-servicio, educación en valores, práctica moral, mapa de valores, formación del profesorado.

\section{Abstract}

Despite the fact that the specialized bibliography recognizes service learning as a relevant methodology for values education, a sufficiently complete list of the plurality of values that it activates, is not yet available. The objective of this article is to build a reliable map of the values that service learning proposes. In order to achieve it, the levels of learning that overlap in a complex educational practice will be defined and then the values that works at each level of service-learning practices will be determined. To achieve this, a rational reconstruction work based on the reciprocal optimization achieved between a selection of good servicelearning experiences and the theory of moral practices and service-learning has been carried out. This methodology has allowed us to establish three simultaneous levels of learning - practice, actions and tasks - as well as a list of the values that crystallize in each of them: a complete map of the variety and richness of values that are put into play in service learning. A result that, in the processes of teacher training, will help to raise awareness of the moral strength of this methodology and to activate it during their professional performance.

Keywords: Service learning, values education, moral practice, values map, teacher training.

Forma sugerida de citar: Martín-García, X., Bär-Kwast, B., Gijón-Casares, M., Puig-Rovira, J.M., \& Rubio-Serrano, L. (2021). El mapa de los valores del aprendizaje-servicio. Alteridad, 16(1), 12-22. https://doi.org/10.17163/alt.v16n1.2021.01 


\section{Introducción}

Una de las características relevantes del aprendizaje-servicio es ser una excelente metodología de educación en valores. Cuando se afirma que es una propuesta que combina los aprendizajes con el servicio a la comunidad (Furco, 2002; Puig et al., 2015; Tapia, 2001; Martín \& Rubio, 2010), se reconoce tanto la adquisición de conocimientos curriculares, como la formación en valores que proporciona la preparación y la realización del servicio. Respecto a esta segunda cuestión, con frecuencia se asegura que el aprendizaje-servicio forma en valores como el altruismo, la cooperación, el compromiso, la solidaridad y el espíritu crítico (Eyler \& Giles, 1999; Rafols, 2004). Sin embargo, esta lista y otras parecidas están lejos de dar cuenta de la riqueza en valores de esta metodología. No muestra la cantidad y la variedad de valores presentes en cada experiencia. Se aplica una metodología de educación en valores sin tener una imagen completa de los valores que activa. El objetivo de este artículo es presentar el mapa de los valores del aprendizaje-servicio.

En relación con este objetivo, es apropiado definir el aprendizaje-servicio como una práctica educativa compleja que transmite valores. Esta afirmación se sustenta en conocimientos disponibles sobre las prácticas educativas, la naturaleza de los valores y en lo que se entenderá por transmisión en este contexto.

Una práctica educativa es un curso ordenado de pasos o acciones encadenadas que persiguen objetivos formativos bien establecidos $y$ bien conocidos por los participantes, al menos por el profesorado, y que se han ido pautando por la comunidad pedagógica. (Miller \& Goodnow, 1995; Wenger, 2001). Además, en cualquier práctica, como afirma MacIntyre (1987), "se realizan los bienes inherentes a la misma mientras se intenta lograr los modelos de excelencia que le son apropiados a esa forma de actividad..." (p. 233). Es decir, las prácticas expresan valores que los participantes activan durante su desarrollo y al actualizarlos los van asimilando (Puig, 2003).
El aprendizaje-servicio es una práctica compleja que expresa valores y que los hace vivir y adquirir a sus participantes.

Las prácticas educativas expresan y transmiten valores, pero ¿qué son los valores y cuál es su naturaleza? El debate ha sido largo y encendido (Perry, 1950; Scheler, 1941; Dewey, 2008). Hoy es posible afirmar que los valores son cualidades estructurales incorporadas en la realidad (Frondizi, 1958, 1977). Aunque los valores se pueden conceptualizar y se pueden elaborar teorías sobre ellos, su naturaleza original no está en el mundo de las ideas intangibles. Por otra parte, los valores se pueden elegir porque interesan a quienes los detectan, pero no son preferencias subjetivas. Los valores son cualidades o propiedades que los seres humanos hemos ido creando durante la evolución biológica y cultural (Cela-Conde, 1989; Tomasello, 2010, 2016; De Waals, 2007; Wilson, 2012). Cualidades que han surgido y quedado impregnadas en la realidad: en las cosas, las formas establecidas de relación y comportamiento, las instituciones públicas, las normas sociales o las disposiciones de carácter de los individuos. El aprendizaje-servicio activa conductas que manifiestan cualidades que consideramos valiosas.

El aprendizaje-servicio es una práctica que transmite valores, donde la transmisión se refiere al paso de los valores desde el espacio social y donde se activa la práctica al espacio interno de la mente de los alumnos participantes (Bourdieu, 1997, 1980; Piaget, 1999; Rogoff, 1993; Wertsch, 1988). Lo que Vygotsky (1979) explicó como el doble aprendizaje de las funciones superiores: primero se aprenden de manera interpsicológica - los valores se realizan entre varias personasy luego se dominan de forma intrapsicológica — cada sujeto es capaz de impulsar y sostener por iniciativa propia la realización de los valores. La metodología del aprendizaje-servicio activa socialmente la realización de valores y facilita que cada participante los vaya convirtiendo en su modo de ser y de actuar habitual. Nos interesa dejar apuntada la idea de transmisión para ver 
cómo en las prácticas de aprendizaje-servicio se realiza el paso de lo social a lo mental, aunque este tema no se aborda en la presente investigación.

El objetivo que se persigue en este artículo es trazar un mapa de los valores del aprendizaje-servicio. Este objetivo parte de lo que ya conocemos: el aprendizaje-servicio como una práctica que transmite valores y una concepción de los valores como cualidades que se expresan en las prácticas y que los sujetos aprenden. Sin embargo, para trazar el mapa de los valores del aprendizaje-servicio, pese a contar con investigaciones sobre esta temática (Puig, 2016), no disponemos de una relación amplia, hecha con voluntad exhaustiva, de los diferentes valores que se activan en el aprendizaje-servicio, así como en otras prácticas complejas. Tampoco disponemos de conocimiento suficiente sobre los distintos espacios y niveles de aprendizaje de los valores en las prácticas educativas $y$, naturalmente, la misma falta se aprecia en el caso del aprendizajeservicio. Por lo tanto, trazar un mapa de los valores del aprendizaje-servicio supone perseguir por este orden dos objetivos complementarios: 1) Definir los niveles de aprendizaje de valores en una práctica educativa compleja, y en el aprendizaje servicio. 2) Formular un inventario organizado de los valores que se activan en las prácticas de aprendizaje-servicio.

Además de la relevancia que puedan tener los resultados que se alcancen para el mejor conocimiento del aprendizaje-servicio y de los niveles de aprendizaje de las prácticas educativas complejas, quizás el resultado de mayor relieve sea contribuir a que el profesorado pueda usar el mapa de valores del aprendizaje-servicio para tomar conciencia de la riqueza de esta práctica e implementarla con toda la potencia formativa que ofrece. Un aspecto de futuro que no se abordará en este artículo.

\section{Metodología}

A nivel metodológico, construir el mapa de valores del aprendizaje-servicio ha supuesto una secuencia de acciones que pautan el proceso basado en el enfoque de la reconstrucción racional. Dicho enfoque invita a reflexionar entre la experiencia y la teoría para construir propuestas vinculadas a la realidad que, combinadas con referentes teóricos, permiten una fundamentación sólida de las mismas.

El proceso se inicia con la creación de un equipo de investigación que cumple dos condiciones: la diversidad entre sus miembros y la experiencia de cada uno de ellos en la temática del aprendizaje-servicio. Para garantizar el primer aspecto, se convoca a ocho investigadores vinculados a entornos educativos donde el aprendizaje-servicio tiene una presencia significativa: educación primaria, educación secundaria, tiempo libre, educación social, intervención socioeducativa y, ámbito universitario, principalmente. Se valoró que entre todos los participantes quedaban representados los principales ámbitos educativos y podía recogerse un amplio abanico de experiencias. La segunda condición de calidad exigía que los miembros del equipo investigador conocieran ampliamente la metodología del aprendizaje-servicio y hubieran estado implicados, previamente, en investigaciones vinculadas a la educación en valores y el aprendizaje-servicio.

Para elaborar el mapa de valores se han tenido en cuenta materiales que sistematizan las fases y acciones recomendadas para construir proyectos de calidad de aprendizaje- servicio (Puig et al., 2009; Martín, 2016, Tapia, 2006), así como la Rúbrica de evaluación de proyectos de aprendizaje-servicio que recoge un conjunto completo de todos los dinamismos pedagógicos de este tipo de prácticas (GREM, 2015). Asimismo se han seleccionado experiencias de calidad detectadas por algún miembro del equipo investigador en su ámbito de conocimiento y sistematizaciones previas ya existentes, muchas de ellas recogidas en espacios como los siguientes: el Centre Promotor de l'Aprenentatge Servei (https://bit. ly/2JzmDfp); Zerbikas (https://bit.ly/3g5RvQF), Red Española Aprendizaje Servicio (https://bit. 
ly/2JKd65a) y CLAYSS, Centro Latinoamericano de Aprendizaje y Servicio Solidario en el ámbito de América Latina (https://bit.ly/3lFs49A).

Se realizaron ocho sesiones de trabajo del equipo de investigación orientadas a la puesta en común del trabajo individual y a la reflexión conjunta. En ellas se discutieron aportaciones bibliográficas, así como otros materiales teóricos surgidos a lo largo del debate. Se recogieron notas y grabaciones de cada sesión. Fruto del trabajo colaborativo se construyó el marco conceptual y gráfico que determinaría la forma de presentar los resultados: el mapa de los valores. A partir de ese momento el trabajo conjunto se orientó a determinar las diez fases presentes en las experiencias de aprendizaje-servicio, las cinco tareas principales que implican cada una de ellas y los dos valores prioritarios que cristalizan en cada uno de estos momentos. A lo largo del proyecto se definieron, asimismo, las finalidades últimas que persigue toda propuesta de aprendizaje-servicio.
Las aportaciones teóricas, prácticas y los debates surgidos en las sesiones se fueron incorporando progresivamente hasta construir y completar la propuesta que aquí se presenta. Una idea que, inspirada en la cartografía social pedagógica (Barragán, 2016; Novak 1998), camina hacia la construcción de un mapa cognitivo de los valores presentes en las experiencias de aprendizaje-servicio. La propuesta de organización en un modelo de mapa que considera las ideas de Novak y Gowin (1988) sobre cómo las personas construyen los aprendizajes y cómo los mapas ayudan a estructurarlos.

Como se puede comprobar en la tabla 1 la propuesta metodológica de la reconstrucción racional (Habermas, 1985) en la que se basa la investigación ha exigido un meta-análisis de las prácticas de aprendizaje-servicio a la luz de distintos referentes teóricos, lo que ha permitido definir el contenido de cada nivel de estructura del mapa.

\section{Tabla 1. Fases del proceso de elaboración}

\begin{tabular}{|c|c|}
\hline Fase & Defínición \\
\hline Preparación & $\begin{array}{l}\text { - Trabajo de recogida de información la construcción de los valores en las experiencias de } \\
\text { aprendizaje-servicio. } \\
\text { - Construir un equipo investigador diverso. } \\
\text { - Concretar el objetivo y un formato compartido. }\end{array}$ \\
\hline Revisión sistemática & $\begin{array}{l}\text { - Buscar, acceder y compartir elementos presentes en buenas prácticas de aprendizaje-servicio. } \\
\text { - Analizar, sistematizar y comparar herramientas existentes sobre la construcción de proyec- } \\
\text { tos de aprendizaje-servicio. }\end{array}$ \\
\hline $\begin{array}{c}\text { Enriquecimiento } \\
\text { teórico }\end{array}$ & $\begin{array}{l}\text { - Aportar información teórica sobre la metodología del aprendizaje servicio. } \\
\text { - Detectar y sistematizar la información teórica sobre el proceso de construcción de valores } \\
\text { en el aprendizaje-servicio. }\end{array}$ \\
\hline $\begin{array}{l}\text { Reconstrucción } \\
\text { racional }\end{array}$ & $\begin{array}{l}\text { Determinar y definir: } \\
\text { - Las fases de los proyectos de aprendizaje-servicio. } \\
\text { - Las tareas principales que se dan en cada una de las anteriores fases. } \\
\text { - Los valores que cristalizan en cada fase y las finalidades últimas que persigue el } \\
\text { aprendizaje-servicio. }\end{array}$ \\
\hline Redacción & $\begin{array}{l}\text { - Analizar las formas de presentación del trabajo realizado. } \\
\text { - Redactar los diferentes niveles del mapa y el material complementario para su comprensión } \\
\text { y uso. }\end{array}$ \\
\hline
\end{tabular}




\begin{tabular}{|c|l|}
\hline Fase & \multicolumn{1}{c|}{ Definición } \\
\hline Corrección & $\begin{array}{l}\text { - Evaluar el conjunto del trabajo en su fondo y en su forma e introducir las modificaciones } \\
\text { oportunas. }\end{array}$ \\
\hline Formas de uso & - Definir las distintas maneras de utilizar el mapa de valores e iniciar su aplicación y difusión. \\
\hline Publicación & - Publicar el mapa en forma de guía fácil y en formato póster. \\
\hline
\end{tabular}

Fuente: Elaboración propia.

\section{Resultados}

Los resultados obtenidos en la investigación se concretan en el diseño de un mapa de los valores del aprendizaje-servicio. En él se da respuesta a los dos objetivos planteados inicialmente. Por un lado, se definen los niveles de aprendizaje de valores en el aprendizaje-servicio y por otro, se propone un inventario organizado de los valores que se activan en dicha práctica.

Se trata de un resultado que aporta una imagen gráfica de un tema que hasta el momento no se había abordado de manera sistemática: el desarrollo y la adquisición de valores por parte de los educandos mientras se implican en una práctica altamente compleja como es el aprendizaje-servicio. Si en estudios anteriores se había puesto de manifiesto la diversidad de dinamismos que se activan durante un proyecto y la complejidad de tareas que requieren por parte del profesorado (GREM, 2015), la presente investigación recoge la riqueza y complejidad de valores que los jóvenes movilizan en una acti- vidad. El mapa visibiliza una batería de valores vinculados a las distintas fases del proyecto y otros que tienen una presencia destacada durante todo el proceso. Asimismo, la imagen que se aporta permite tomar conciencia de los aprendizajes de valores inherentes a esta metodología.

\subsection{Estructura y niveles de aprendi- zaje en el mapa de los valores}

Tal y como puede observarse en la figura 1, el mapa se estructura en tres niveles de elementos, cada uno de los cuales expresa valores y, en consecuencia, facilita que el alumnado los adquiera. El primer nivel, el nuclear, se refiere al conjunto de la práctica y recoge las finalidades referidas a valores del aprendizaje-servicio; el segundo nivel, las fases o pasos de la actividad, está constituido por un conjunto ordenado de acciones que encarnan valores; $y$ en el tercer nivel se explicitan las múltiples tareas que incorpora el desarrollo de cada fase y el conjunto de la práctica. A su vez, cada una de estas tareas se realizan de acuerdo con orientaciones de valor.

Tabla 2. Niveles de aprendizaje en el mapa de los valores

\begin{tabular}{|c|l|l|}
\hline Práctica & $\begin{array}{l}\text { Conjunto organizado de acciones que tienen un objetivo operativo, encar- } \\
\text { nan valores y los transmiten al alumnado. }\end{array}$ & Finalidades de valor. \\
\hline Acciones & $\begin{array}{l}\text { Designan cada una de las fases o pasos cuya articulación compone y da } \\
\text { sentido a una práctica socio-cultural compleja. }\end{array}$ & $\begin{array}{l}\text { Valores encarnados en la } \\
\text { acción. }\end{array}$ \\
\hline Tareas & $\begin{array}{l}\text { Conductas que manifiestan competencias que se deben activar para reali- } \\
\text { zar cada una de las acciones que constituyen una práctica. }\end{array}$ & Orientación a valores. \\
\hline
\end{tabular}

Fuente: Elaboración propia. 
El primer nivel de la estructura se corresponde con las finalidades de valor del aprendizaje-servicio. Un nivel que en el mapa se encuentra situado en el centro, con la voluntad de destacar la función nuclear que desempeña. Los tres ejes de valores que lo forman -altruismo y cooperación, participación ciudadana y aprendizaje transformador - tienen una presencia transversal en las distintas fases, y dan sentido a la actividad en su conjunto. Son valores inherentes a la metodología y proponen un horizonte de valor del aprendizaje-servicio.

En el segundo nivel de estructura se recogen las diez acciones o fases en las que se desa- rrolla un proyecto de aprendizaje-servicio y los valores más destacados que emergen en cada una de ellas. Las fases marcan una secuencia en el desarrollo de las actividades, pero no se limitan a trazar un recorrido. A pesar de su carácter procedimental, plasman acciones en las que cristalizan valores. Son, por tanto, acciones "de valor" en la medida que exigen a los estudiantes ejercitarse y entrenar determinados valores -en el mapa únicamente se destacan dos por cada fase - vinculados a los diez momentos en los que se desarrolla la actividad.

Figura 1. Mapa de los valores del aprendizaje-servicio

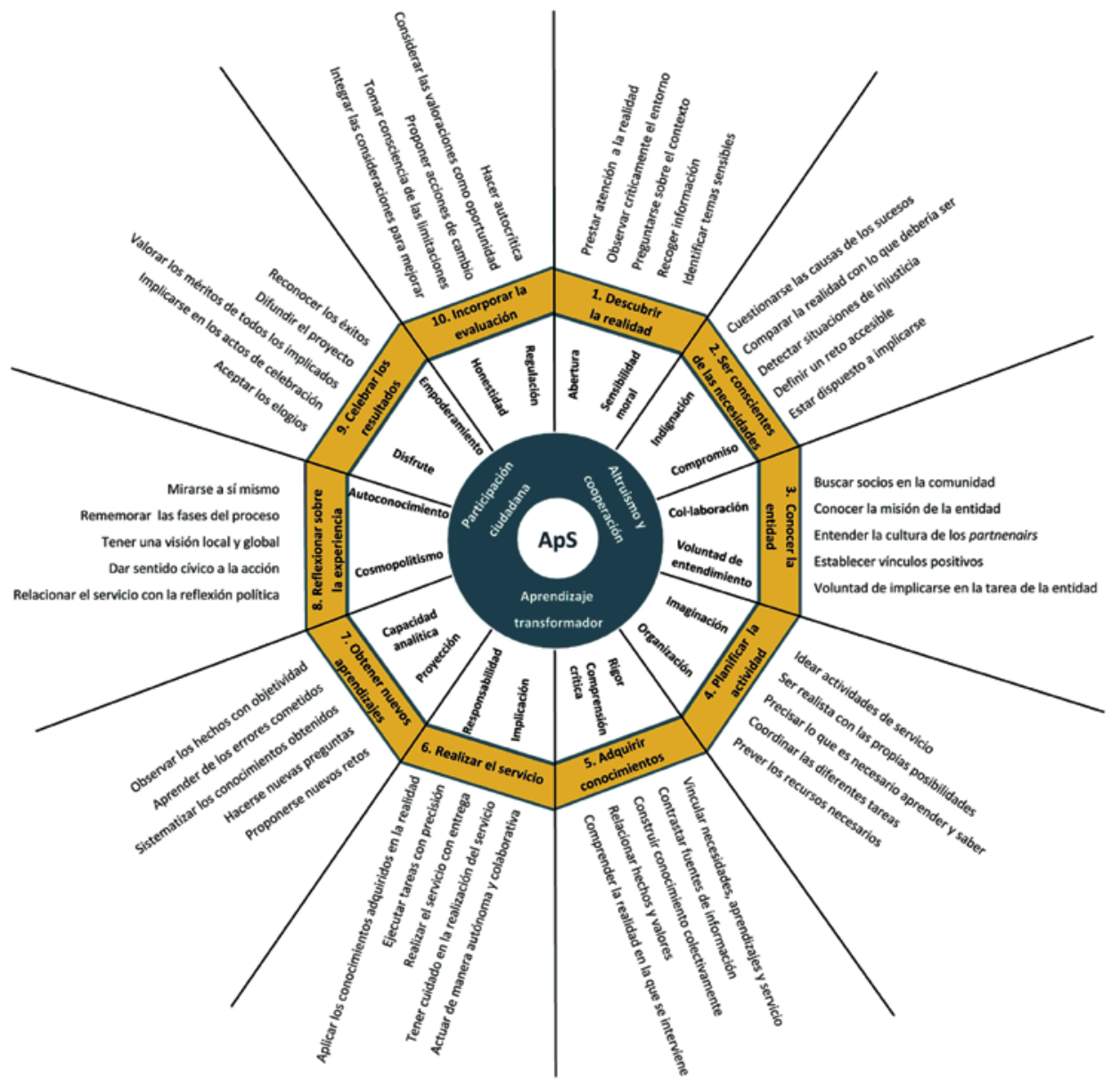

Fuente: Elaboración propia. 
La figura circular del mapa invita a aplicar con flexibilidad la secuencia que se propone. Si bien hay fases propias de momentos iniciales y otras que, de manera generalizada, cierran un proyecto, la entrada a un aprendizaje-servicio tiene distintas posibilidades en función de la singularidad de cada experiencia. Pero las fases no remiten únicamente a acciones, también apuntan a valores. El segundo nivel del mapa tiene dos elementos: la formulación de las diez fases y los valores que con mayor intensidad los estudiantes practican mientras realizan la acción. No se trata de valores únicos, pero sí los más relevantes.

El tercer nivel de estructura lo conforman las tareas, o conductas competentes, que exige la participación en una actividad de aprendizaje-servicio. En el gráfico aparecen en la parte exterior, ubicadas en relación con cada fase. Las cincuenta tareas que se recogen dan cuenta de la complejidad de la metodología atendiendo al trabajo realizado por los estudiantes. Estos llevan a cabo un sinfín de cometidos de distinta envergadura mientras aprenden trabajando en necesidades reales del entorno. A cada fase se la ha asignado las cinco tareas más comunes a todos los proyectos de aprendizaje-servicio, si bien estas no agotan el trabajo de los estudiantes. La naturaleza de las tareas varía de manera significativa y el mapa recoge desde tareas simples a otras más complejas, que apuntan directamente al desarrollo de competencias de distinta índole.

\subsection{Inventario de valores en el aprendizaje-servicio}

El segundo de los objetivos planteados en el artículo, el inventario de valores de los proyectos de aprendizaje-servicio, se explica con los distintos niveles de valor de la estructura circular. Por un lado, las finalidades que orientan el desarrollo de la práctica $y$, por otro, aquellos valores que cristalizan en cada una de las fases.

Los valores que se encuentran en el centro del mapa corresponden a los propósitos que impulsan y dotan de sentido la realización del aprendizaje-servicio. Se han descrito tres horizontes valóricos, el altruismo y la cooperación; la participación ciudadana; y el aprendizaje transformador. El altruismo y la cooperación se refiere al desarrollo de conductas que se alejan de lógicas de interés individual y se basan en la ayuda mutua, la hospitalidad y la necesaria interdependencia de los miembros de una colectividad. La participación ciudadana se refiere a promover la incorporación de los estudiantes como ciudadanos activos en su comunidad, un protagonismo que les permita contribuir al bien común. El aprendizaje transformador se refiere a la voluntad de dotar de sentido cívico al conocimiento, que sea útil para mejorar la realidad y permita a los estudiantes transformar el mundo en el que viven.

Los valores que se activan en las fases no son solo buenas ideas que conviene trabajar en el aula, sino resultado de la experimentación de tareas por parte de los estudiantes. Cada fase contempla cinco tareas y dos valores. Para explicarlos se han elegido tres de las fases del mapa: ser consciente de las necesidades, realizar el servicio y, celebrar los resultados.

\subsubsection{Ser consciente de las necesidades. Indignación y compromiso}

En la segunda fase de los proyectos se invita a los jóvenes a detectar necesidades, situaciones de carencia y aspectos mejorables de la vida de las personas, los colectivos o el medio ambiente. Ser consciente de las necesidades apunta a dos valores, indignación y compromiso. Un proceso de análisis crítico que permite a los estudiantes comprender que esas necesidades son causadas por una situación de injusticia que exige denuncia y reparación. Sin embargo, la indignación no es suficiente, requiere también del compromiso para asumir una responsabilidad individual y colectiva en la mejora de la realidad.

Ambos valores, indignación y compromiso, se activan cuando los educadores proponen las siguientes tareas. 
Tabla 3. Los valores en la segunda fase

\begin{tabular}{|l|l|}
\hline \multicolumn{1}{|c|}{ Ser consciente de las necesidades } \\
\hline Valores & Indignación. Compromiso. \\
\hline & $\begin{array}{l}\text { - Cuestionarse las causas de los hechos. } \\
\text { - Comparar la realidad con lo que debería ser. }\end{array}$ \\
\hline Tareas & $\begin{array}{l}\text { - Detectar situaciones de injusticia. } \\
\text { - Definir un reto accesible. }\end{array}$ \\
\hline
\end{tabular}

\section{Fuente: Elaboración propia.}

Los educadores promueven que los estudiantes realicen un análisis crítico de la realidad cuando se cuestionan las causas de los hechos, y para ello atienden tanto a aspectos sistémicos como a elementos contextuales y territoriales. Cuando los jóvenes comparan la realidad con lo que debería ser pueden realizar una valoración que apunta a una mirada esperanzada. Detectar situaciones de injusticia implica construir con argumentos fundamentados cómo se encarnan las necesidades en la vida de las personas que las sufren. Una fase que no concluye con el análisis, sino que incorpora dos tareas orientadas a asumir responsabilidades. Una, definir un reto accesible que permite a los jóvenes concretar acciones de denuncia y reparación en una propuesta realista y motivadora. Y dos, estar dispuesto a implicarse, lo que supone concretar el reto anterior en un compromiso individual y colectivo.

\subsubsection{Realizar el servicio. Responsabilidad e implicación}

La sexta fase de la práctica implica la ejecución de acciones solidarias y altruistas por parte de los jóvenes. Tareas que tienen una estrecha relación con el análisis crítico de la realidad y los aprendizajes adquiridos en fases anteriores. Realizar un servicio apunta a dos valores, responsabilidad e implicación. El primero permite aplicar lo aprendido en el proyecto para mejorar la realidad de las personas y realizar con compromiso las tareas de servicio. Una obligación que adquiere sentido junto a la implicación, ya que el aprendizaje-servicio no busca solamente una ejecución eficiente, sino que requiere, también, colaboración y entrega.

Ambos valores, responsabilidad e implicación, se experimentan cuando los educadores proponen las siguientes tareas en el proyecto.

Tabla 4. Los valores en la sexta fase

\section{Realizar el servicio}

\begin{tabular}{|l|l|}
\hline Valores & Responsabilidad. Implicación. \\
\hline Tareas & - Aplicar los conocimientos adquiridos en la realidad. \\
& - Ejecutar tareas con precisión. \\
& - Realizar el servicio con entrega. \\
& - Tener cuidado en la realización del servicio. \\
\hline
\end{tabular}

Fuente: Elaboración propia. 
Los educadores invitan a los jóvenes a aplicar los conocimientos adquiridos en la realidad; saberes y habilidades que se han entrenado en fases anteriores. La realización del servicio exige a los jóvenes rigor y minuciosidad para ejecutar tareas con precisión. La utilidad del conocimiento y la precisión en la realización se contemplan en tres de las tareas propuestas. Realizar el servicio con entrega, que permite a los estudiantes experimentar dedicación y dar sentido a su acción. Tener cuidado en la realización del servicio, que exige realizar las tareas solidarias con atención, sensibilidad y solidaridad. Y actuar de manera autónoma y colaborativa incrementa el valor del servicio en la media que se tiene conciencia de estar trabajando por el bien común.

\subsubsection{Celebrar los resultados. Empoderamiento $y$ disfrute}

En la penúltima fase de los proyectos se valora el proceso altruista y colaborativo realizado, así como la capacidad de los estudiantes de aportar a la comunidad. Una fase que permite integrar de manera positiva los éxitos personales y colectivos vividos durante el proyecto. Celebrar los resultados implica dos valores, empoderamiento y disfrute. El primero es el resultado de tareas realizadas en fases anteriores, pero especialmente, de la difusión y celebración que se realiza cuando concluye el proyecto. El segundo adquiere sentido con el valor del disfrute, que se concreta en la alegría y el placer de integrar los elogios y aceptar la huella que dejan en la identidad.

Ambos valores, empoderamiento y disfrute, se activan cuando se ponen en juego las siguientes tareas en el proyecto.

Tabla 5. Los valores en la novena fase

\begin{tabular}{|l|l|}
\hline \multicolumn{1}{|c|}{ Celebrar los resultados } \\
\hline Valores & Empoderamiento. Disfrute. \\
\hline & - Reconocer los éxitos. \\
& - Difundir el proyecto. \\
Tareas & - Valorar los méritos de todos los implicados. \\
& - Implicarse en los actos de celebración. \\
& - Aceptar los elogios. \\
\hline
\end{tabular}

Fuente: Elaboración propia.

Los educadores reconocen los éxitos de los jóvenes y el beneficio a la comunidad del servicio realizado. Difundir el proyecto permite visibilizar y divulgar las experiencias, los aprendizajes de los jóvenes y los logros colectivos. Un reconocimiento que va más allá del grupo clase y que supone reconocer y agradecer el papel de todos los participantes en el proyecto. Por un lado, implicarse en los actos de celebración permite a los estudiantes expresar gratitud a la comunidad. Por otro, acoger los elogios exige integrar el reconocimiento de los otros, una tarea que no siempre es fácil pero que ayuda a avanzar hacia la autorrealización.

\section{Discusión y conclusiones}

El mapa de los valores presentado en el artículo recoge dos aportaciones básicas. La primera consiste en la propuesta de una estructura organizada en niveles de aprendizaje que dan forma a las actividades de aprendizaje-servicio. Estos niveles, que se activan de manera simultánea, son tres: la práctica, las acciones y las tareas. La segunda aportación se focaliza en la detección y definición de los 
valores que los estudiantes desarrollan atendiendo a cada uno de los tres niveles. Así, se explicitan los valores que dan sentido a la práctica en su conjunto, y aquellos otros cuya presencia se intensifica en cada una de las diez fases o acciones que marcan la secuencia de un proyecto.

Con la mirada puesta en el rol del estudiante, el mapa recoge tres finalidades, diez fases, cincuenta tareas y una veintena de valores que permiten a los jóvenes descubrir la realidad, investigar para construir conocimiento útil a la comunidad y participar en la sociedad de forma altruista. El resultado de la investigación refuerza la idea defendida desde las pedagogías progresistas (Freinet, 1972; Dewey, 1964) de que la adquisición de valores no se consigue a partir de la transmisión oral, sino que los valores se viven, se experimentan y se aprenden en la acción.

En los resultados de la investigación destaca la cantidad y diversidad de valores que durante las actividades de aprendizaje-servicio se activan. Algunos de estos valores son ampliamente conocidos y citados con asiduidad en la literatura pedagógica sobre el tema. Cooperación, bien común, altruismo o participación son valores morales que se asocian de manera casi automática a la práctica del aprendizaje-servicio. Sin embargo, durante la revisión sistemática de las actividades emergió una cantidad nada despreciable de nuevos valores que a pesar de no tener un reconocimiento generalizado aparecían reiteradamente en la mayoría de experiencias. Algunos de ellos —rigor, disfrute, o capacidad analítica- no tienen un carácter marcadamente moral, pero son asimismo valores deseables que los estudiantes entrenan y cuya activación mejora su experiencia formativa.

En relación con la cantidad y diversidad de valores detectados en el mapa, la hipótesis del equipo de investigación es que, si bien el aprendizaje-servicio invita por sí mismo al ejercicio de valores, la toma de conciencia por parte de los educadores del potencial moral de esta práctica puede incrementar el aprendizaje de los estudiantes.
Un mapa del aprendizaje-servicio como el que aquí se presenta, permite a los docentes intensificar los valores, visibilizarlos, generar reflexión sobre ellos o incrementar la atención en algunas tareas, de manera que su conocimiento sobre los valores que están en juego revierta en la calidad formativa de la práctica. Conocimiento y toma de conciencia a la que el mapa de los valores pretende contribuir aportando un análisis fiable y sistemático sobre el tema.

\section{Referencias bibliográficas}

Barragán, D. (2016). Cartografía social pedagógica: entre teoría y metodología. [Social Pedagogical Cartography: between Theory and Methodolgy]. Revista colombiana de educación, 70, pp. 247-285, Universidad Pedagógica Nacional, Bogotá. https://bit.ly/2VtWPno

Bourdieu, P. (1980). Le sens pratique. Les editions de Minuit.

Bourdieu, P. (1997). Meditations pascaliennes. Éditions du Seuil.

Cela-Conde, C.J. (1989). El naturalismo contemporáneo: de Darwin a la sociobiología. En V. Camps (Ed.), Historia de la ética. 3. La ética contemporánea (pp. 601-634). Editorial Crítica.

De Waals, F. (2007). Primates y filósofos. La evolución de la moral del simio al hombre. Paidós.

Dewey, J. (1964). Naturaleza humana y conducta. Fondo de Cultura Económica.

Dewey, J. (2008). Teoría de la valoración. Editorial Biblioteca Nueva.

Eyler, J., \& Giles, D.E. (1999). Where's the Learning in Service-Learning? Jossey-Bass

Freinet, C. (1972). La educación moral y cívica. Laia.

Frondizi, R. (1958). ¿Qué son los valores? Fondo de Cultura Económica.

Frondizi, R. (1977). Introducción a los problemas fundamentales del hombre. Fondo de Cultura Económica.

Furco, A. (2002). Is service-Learning really better than community service? In A. Furco, \& S.H. Billing (Ed.), Service-Learning. The essence of the Pedagogy (pp. 23-50). Information Age Publishing. 
GREM (2015) Rúbrica para la autoevaluación y la mejora de los proyectos de aprendizajeservicio. Fundació Jaume Bofill. https://bit.ly/33FhY2F

Habermas, J. (1985). Conciencia moral y acción comunicativa. Península.

MacIntyre, A. (1987). Tras la virtud. Crítica.

Martín, X., \& Rubio, L. (2010). Prácticas de ciudadanía. Octaedro.

Martín, X. (2016). Proyectos con alma. Trabajo por proyectos con servicio a la comunidad. Barcelona, Graó.

Miller, P.J., \& Goodnow, J.J. (1995). Cultural practices: Toward an Integration of Culture and Development. In J.J. Goodnow, P.J. Miller, \& F. Kessel (Ed.), Cultural Practices as Contexts for Development (pp. 5-16). Jossey-Bass Publishers.

Novak, J.D., \& Gowin, D.B. (1988): Aprendiendo a aprender. Martínez Roca.

Novak, J.D. (1998): Conocimiento y aprendizaje. Los mapas conceptuales como herramientas facilitadoras para escuelas y empresas. Alianza Editorial.

Perry, R.B. (1950). General Theory of Value. Harvard University Press.

Piaget, J. (1999). De la pedagogía. Paidós.

Puig, J.M. (2003). Prácticas morales. Una aproximación a la educación moral. Paidós.
Puig, J.M. (Coord.) (2009). Aprendizaje servicio (ApS). Educación y compromiso cívico. Graó.

Puig, J.M. (Coord.) (2015). 11 ideas clave. ¿Cómo realizar un proyecto de aprendizaje servicio? Graó.

Puig, J. (2016). Aprendizaje servicio y educación en valores. Convives, (16), 12-19. https://bit.ly/2JxGcVp

Rogoff, B. (1993). Aprendices del pensamiento. El desarrollo cognitivo en el contexto social. Paidós.

Scheler, M. (1941). Ética. Revista de Occidente.

Tapia, N. (2001). La solidaridad como pedagogía. El aprendizaje-servicio en la escuela. Ciudad Nueva.

Tapia, N. (2006). Aprendizaje y servicio solidario. En el sistema educativo y las organizaciones juveniles. Ciudad Nueva.

Tomasello, M. (2010). ¿Por qué cooperamos? Katz.

Tomasello, M. (2016). A Natural History of Human Morality. Harvard University Press.

Vygotsky, L.S. (1979). El desarrollo de los procesos psicológicos superiores. Crítica.

Wenger, E. (2001). Comunidades de práctica. Aprendizaje, significado e identidad. Paidós.

Wertsch, J.V. (1988). Vygotsky y la formación social de la mente. Paidós.

Wilson, E.O. (2012). La conquista social de la tierra. Debate. 


\section{EALTERIDAD Diagnóstico comunitario ante desastres climáticos: Una experiencia de aprendizaje-servicio}

\section{Community assessment in the face of climatic disasters: A Service-Learning experience}

(D) Dr. José Sandoval-Díaz ${ }^{1}$ es docente e investigador de la Universidad del Bío Bío (Chile) (jsandoval@ubiobio.cl) (https://orcid.org/0000-0001-7247-7113)

(D) David Cuadra-Martínez es docente e investigador de la Universidad de Atacama (Chile) (david.cuadra@uda.cl) (https://orcid.org/0000-0002-0810-2795)

(D) Cristian Orellana-Fonseca es docente e investigador de la Universidad del Bío Bío (Chile) (corellana@ubiobio.cl) (https://orcid.org/0000-0001-8614-8011)

(D) Eduardo Sandoval-Obando es docente e investigador de la Universidad Autónoma de Chile (https://orcid.org/0000-0001-7471-6536)

Recibido: 2020-05-14 / Revisado: 2020-12-09 / Aceptado: 2020-12-10 / Publicado: 2021-01-01

\section{Resumen}

El incremento de eventos extremos - a causa del cambio climático - conlleva no solo a la necesidad local de fortalecer las capacidades de afrontamiento y de resiliencia a nivel comunitario, sino también, al replanteo sobre la idoneidad de los planes formativos universitarios en el desarrollo de profesionales competentes ante estos nuevos riesgos emergentes. Bajo este contexto, el presente trabajo tuvo como objetivo valorar la implementación de un proceso de diagnóstico de necesidades comunitarias ante un desastre climático, esto mediante la aplicación metodológica de la estrategia de aprendizaje-servicio (ApS) en un curso de estudiantes de psicología en Chile. Para esto seleccionamos un estudio de caso representativo de gestión comunitaria ante un desastre climático en el norte de Chile, esto bajo un diseño de investigación acción-participativa (IAP). Los datos son producidos mediante la triangulación intermétodo de seis técnicas, esquematizando los resultados del proceso de aprendizaje en cuatro áreas: i) teórico-conceptual, ii) metodológica, iii) práctica y iv) ético-política. Los resultados relevan el uso de ApS en el proceso de enseñanza-aprendizaje del diagnóstico comunitario, identificando tanto ventajas como limitaciones en el desarrollo de competencias disciplinares, transversales profesionales y del servicio entregado. Se concluye con la importancia de integrar estrategias horizontales, participativas y situadas en los procesos de enseñanza profesional, esto acorde al tipo de formación universitaria integral que requiere la problemática psicosocial compleja del cambio climático.

Descriptores: Aprendizaje-servicio, diagnóstico comunitario, formación profesional, investigación acción participativa, cambio climático, Chile.

\begin{abstract}
The increase of extreme events caused by climate change has lead no only to the local need for strengthen the coping and resilience capacity at a community level, but also, to rethink about the suitability of the university study programs in order to develop competent professionals in the face of these new emerging risks. In this context, the objective of this study was to assess the implementation of a community needs assessment process before a climate disaster through the methodological implementation of the Service-Learning strategy (ApS) in a course of psychology students in Chile. To do so, we selected a representative case study of community management in the face of a climate disaster in the north of Chile, using a participatory action research design (PAR). The data were produced using an inter-method triangulation of six techniques, creating a four areas scheme of the learning process results. These areas were: i) theoretical-conceptual, ii) methodological, iii) practical and iv) ethical-political.The results showed the use of ApS in the teaching-learning process of the community assessment, identifying both advantages and limitations in the development of disciplinary, transversal and professional competences, as well as those competences related to the service provided. This study concludes that it is important to integrate horizontal, participative strategies, and use them in the process of professional training and education, according to the integral type of university education required to face the complex psychosocial problem of climate change.

Keywords: Service-learning, community assessment, professional training, participatory action research, climate change, Chile.
\end{abstract}

Forma sugerida de citar: Sandoval-Díaz, J., Cuadra-Martínez, D., Orellana-Fonseca, C., \& Sandoval-Obando, E. (2021). Diagnóstico comunitario ante desastres climáticos: Una experiencia de aprendizaje-servicio. Alteridad, 16(1), 23-37. https://doi.org/10.17163/alt.v16n1.2021.02 


\section{El cambio climático y rol formativo universitario}

La adaptación al cambio climático se ha convertido en uno de los principales objetivos para el Desarrollo sostenible a escala global (Intergovernmental Panel on Climate Change [IPCC], 2014). En América Latina, el cambio ambiental global no solo ha conllevado la emergencia de nuevos riesgos socionaturales, tales como (i) pérdida de biodiversidad, (ii) subida del nivel del mar, (ii) olas de calor y (iv) aumento de peligros hidrometeorológicos, como sequías e inundaciones; sino que, a su vez, ha amplificado e intensificado la vulnerabilidad social de los territorios (Griselda-Günther \& Gutiérrez, 2017; Sánchez \& Reyes, 2015).

En términos de impacto, solo considerando el año 2018, los eventos hidrometeorológicos afectaron a un total de 57,3 millones de personas, siendo liderado por las inundaciones, con un promedio de 35,4 millones de afectados (UN Office for Disaster Risk Reduction [UNDRR], 2019).

Estos intempestivos eventos, ha conllevado la reconfiguración de las estrategias gubernamentales de reducción del riesgo desastre (RRD), las cuales han desplazado el foco desde la respuesta institucional hacia el fortalecimiento de capacidades locales y de resiliencia comunitaria (Gaillard et al., 2019; Sandoval-Díaz, 2020).

En relación con esto, el artículo seis de la Convención Marco de las Naciones Unidas sobre el Cambio Climático (CMNUCC) releva el papel de la educación, formación y sensibilización ante este riesgo, requiriendo no solo su integración curricular, sino repensar el rol de la educación ante la "alfabetización climática" (IPCC, 2014). De acuerdo con esto, paulatinamente, diversos países han ido incorporando contenidos curriculares, tanto en educación formal primaria y/o secundaria (United Nations Educational, Scientific, and Cultural Organization [UNESCO], 2015). En tanto, si bien a nivel universitario esta problemática se encuentra en expansión, predominantemente en disciplinas y posgrados vinculados a ciencias ambientales, es en el campo profesional de las ciencias sociales donde se requiere de colaboradores comprometidos para fortalecer capacidades adaptativas de resiliencia comunitaria (García-Lirios et al., 2014; Ricardo et al., 2019).

Por lo tanto, es importante repensar el rol educativo de las universidades ante estas problemáticas emergentes, con el objetivo de que no solo se ocupen de su desarrollo investigativo básico, sino también, en la facilitación de espacios formativos aplicados que contribuyan al desarrollo de profesionales competentes ante el diagnóstico e intervención de estas problemáticas (De Castro \& Domínguez, 2018).

Para el caso de la formación profesional en Chile, ser competente a nivel institucional se define como:

La capacidad de un individuo para movilizar, tanto sus recursos internos (conocimientos, habilidades y actitudes), como aquellos externos disponibles en el entorno de su área de desempeño, para solucionar problemas complejos que se presenten en el desarrollo de su profesión o actividad. (Comisión Nacional de Acreditación de Chile [CNA], 2015 p. 4)

En el campo formativo universitario, y en las ciencias humanas en particular, un recurrente problema son las dificultades de los estudiantes para transferir, generalizar y aplicar los contenidos teóricos aprendidos al interior de las aulas, hacia situaciones prácticas reales (BarrónTirado, 2009; Cuadra et al., 2018), conllevando no solo dificultades en el cómo proceder operativamente ante contextos diferenciados, sino también, en el cómo favorecer la implicación y participación activa por parte de las propias comunidades involucradas (Stringer, 2008).

A su vez, esta dificultad en la transferencia, no se remite solo a las asignaturas que tributan a los ámbitos de potencial desempeño profesional — sino también - en aquellas asignaturas formativas vinculadas a la reflexividad y metodologías investigativas-científicas (Bassi, 2015; 
Orellana-Fonseca et al., 2019). Desde el imaginario universitario aquellas asignaturas de carácter investigativo solo adquieren "sentido" ante el potencial desarrollo de la tesis de grado o para la escritura de "papers" (si es que los estudiantes presentan interés por el ámbito académicouniversitario), ignorando muchas veces (al igual que sus profesores), las potenciales ventajas que esta forma de racionalidad científica entrega ante situaciones de desempeño profesional concreto, tales como son los procesos de diagnóstico e intervención social (Muñoz-Arce et al., 2017).

Estos procesos de diagnóstico e intervención social, desde una perspectiva transdiciplinaria, tienen como objetivo no solo (i) delimitar y evaluar necesidades psicosociales ante una problemática particular, para posteriormente (ii) desplegar acciones fundamentadas para solucionar dicha problemática, sino también, (iii) posibilitar espacios inclusivos y colaborativos con y desde las propias comunidades implicadas, esto con el objetivo de mediatizar la adquisición reflexiva de capacidades transformadoras de los contextos vulnerados (Freire, 2012; Ortega, 2015).

En línea con esto último, sostenemos que la formación de competencias ante el diagnóstico de problemáticas sociales deben superar el binarismo conocer-hacer de la formación disciplinariaprofesional convencional (Matus, 2002), integrando sostenidamente estrategias y procedimientos indagatorios dialogantes situados, que consideren no solo las competencias técnicas sino también, la subjetividad reflexiva y lógica subyacente al quehacer investigativo como práctica transdisciplinar transformadora (Cuadra-Martínez et al., 2018; Muñoz-Arce et al. 2017; Ortega, 2015), esto acorde a una formación universitaria integral de competencias profesionales y existenciales ante la actual emergencia de problemáticas complejas a escala global (Morin, 2016).

En función de esto, relevamos el papel práctico y heurístico del proceso de investigación aplicado al campo profesional, comprendido como una potencial caja de herramientas para fundamentar reflexivamente decisiones de diagnóstico e intervención social (Bassi, 2015; Orellana-Fonseca et al. 2019), más en los casos donde se torna necesario el levantamiento y análisis de datos de problemáticas complejas, como el cambio climático (García-Lirios et al., 2014; Ricardo et al., 2019).

En síntesis, este desarrollo formativo de competencias investigativas aplicadas al ámbito profesional nos lleva a replantear las formas convencionales de enseñanza-aprendizaje, incitándonos a la incorporación de metodologías participativas e implicativas-activas, que no solo tributen al buen desempeño "declarativo teórico", sino también a su potencial aplicación reflexiva en contextos problemáticos situados (López-Noguero, 2017). De acuerdo con esto, una potencial estrategia formativa para este cometido es el aprendizaje-servicio (ApS).

\subsection{El aprendizaje-servicio}

La formación profesional requiere de espacios educativos que logren trasferir el conocimiento desde el aula hacia la realidad concreta, esto bajo la adquisición y desarrollo de competencias transversales $^{2}$ y disciplinares (Wendler, 2012; Cuadra-Martínez et al., 2018). No obstante, bajo este nuevo contexto de incertidumbre, se sostiene la necesaria implementación de metodologías experienciales-activas, por sobre el mero aprendizaje reproductivo sin valor de uso, requiriendo la mixtura de la reflexión del aprender haciendo constante (Dewey, 1985), y el compromiso social activo con las necesidades vitales de las comunidades más desposeídas (Freire, 2012).

Es así como la metodología del ApS permitiría desarrollar competencias, transferir conocimientos a las comunidades, educar en valores, desarrollar un mayor autoconocimiento, un fuerte sentido de responsabilidad social y de compromiso ciudadano (Rodríguez, 2014), esto bajo el contexto actual que desafía cada vez más a los profesionales (Pizarro \& Hasbún, 2019). A su vez, esta propuesta articula simultáneamente la responsabilidad socioeducativa, la innovación 
pedagógica y el activo protagonismo estudiantil, tanto en el territorio a intervenir, como en los propios procesos de enseñanza-aprendizaje (Mayor, 2019). En la actualidad existen más de 147 nociones de ApS, las cuales se materializan en (i) variados contextos sociocultuales, (ii) instituciones con distinta dependencia administrativa, (iii) intersectorialidad en cuanto al tipo de servicio, (iv) implementación curricular variada, (v) disciplinas distintas, (vi) múltiples niveles y edades de sus participantes (Mayor, 2019).

Para Furco (2011), uno de los principales autores del área, el ApS es "una pedagogía de enseñanza por la que los estudiantes adquieren una mejor comprensión del contenido académico, aplicando competencias y conocimientos para el beneficio de la sociedad" (p. 23). Por otro lado, en términos aplicados, la Red Nacional de Aprendizaje Servicio de Chile (REASE), creada el 2011, lo concibe como:

Un enfoque pedagógico de enseñanza-aprendizaje aplicado en cursos, prácticas y tesis, utilizado para la resolución de problemáticas sociales reales y sentidas, mediante un servicio de calidad, en el que de manera integrada y colaborativa los tres actores centrales del proceso (docentes, estudiantes y socios comunitarios) se vinculan y trabajan en conjunto. (Claire et al., 2019 p. 38)

Si bien existen dificultades para homogenizar esta práctica educativa bajo una misma expresión, existe cierto consenso en tres criterios fundamentales: (i) Servicio comunitario con el objetivo de responder a problemáticas sociales, (ii) pedagogía activa que requiere el protagonismo del estudiantado y cuerpo académico, y (iii) planificación integrada de contenidos curriculares con actividades de servicio comunitario que posibiliten la adquisición de competencias (Montes, Tapia \& Yaber, 2011). Respecto a la arquitectura pedagógica de la ApS se han identificado cinco dimensiones centrales: i) aprendizaje, ii) servicio, iii) participación, iv) actividad de utilidad social y v) reflexión, las cuales, si bien no se expresan de igual manera y énfasis, manifiestan un estado final deseable (Mayor, 2009).

De acuerdo con estos antecedentes, el presente trabajo tiene como objetivo general valorar la implementación de un proceso de diagnóstico de necesidades comunitarias ante un desastre climático, esto mediante la aplicación metodológica de ApS en estudiantes universitarios de psicología en Chile. Como objetivos específicos de aprendizaje buscamos: i) Identificar las ventajas de aprendizaje en las áreas teórico-conceptuales, metodológicas, prácticas y ética-políticas del diagnóstico de necesidades comunitarias bajo el ApS, ii) Identificar las limitaciones de aprendizaje en las cuatro áreas mencionadas anteriormente; mientras que para el ámbito de servicios se busca iii) Generar un diagnostico participativo de necesidades psicosociales ante el desastre.

\subsection{Características del caso de estudio}

La carrera de psicología de la Universidad de Atacama (UDA) surge con el objetivo de iniciar la formación regional de profesionales cuyas competencias científicas-prácticas son el diagnóstico, la evaluación y la intervención en procesos que involucran a personas, grupos y organizaciones, con capacidad de discernimiento ético $y$ respeto por la naturaleza humana en el ejercicio de la profesión (Departamento de Psicología UDA, 2015).

En línea con el modelo educativo universitario, de corte constructivista, y en concordancia con la propuesta 2008-2011 de homologación de competencias curriculares de psicólogos por parte de la red de universidades estatales de Chile, ${ }^{3}$ esta carrera enfatiza la formación de competencias transversales y específicas en diez semestres (Juliá, 2013).

Es así cómo esta formación por competencias incorpora a lo largo de su currículo cuatro asignaturas de taller de integración práctica-profesional: i) acercamiento al campo profesional (segundo semestre); ii) áreas de desa- 
rrollo e inserción profesional (cuarto semestre); iii) diagnóstico psicosocial (sexto semestre) e iv) intervención psicosocial (octavo semestre), esto como previas inducciones a la práctica profesional final (Departamento de Psicología UDA, s.f.).

Bajo este marco formativo, se decide incorporar ApS a la asignatura taller de integración III (diagnóstico psicosocial), esto a partir de la inquietud de un grupo de académicos, quienes, a raíz de un desastre climático ocurrido el 2015 (ver apartado 1.4), buscan no solo responder a la solicitud de apoyo de una comunidad afectada, sino también, reforzar la comprensión aplicada de algunas herramientas metodológicas de investigación previamente enseñadas de forma teórica.

Atendiendo a lo anterior, previo al inicio del segundo semestre del año 2016, se diseña y planifica la incorporación de la estrategia de ApS al taller de integración III, ante lo que se inicia la búsqueda de colaboradores territoriales llegando a la junta vecinal $\mathrm{N}^{\circ} 36$ de la localidad de Paipote, quienes se encontraban en pleno diseño del plan de reconstrucción habitacional posdesastre. En función de esto, se realizaron una serie de reuniones entre profesores y dirigentes comunitarios para aunar objetivos recíprocos y plausibles a desarrollar, donde se consensuó desarrollar un diagnóstico de necesidades comunitarias.

En el presente trabajo entendemos diagnóstico de necesidades como el proceso de elaboración y sistematización de información que permite conocer la problemática y requisitos psicosociales dentro de un contexto, permitiendo jerarquizar necesidades, y como consecuencia, potenciales estrategias de intervención procurando dar viabilidad para su implementación (Aguilar-Idañez \& Ander-Egg, 2001). Los requisitos que debe cumplir este tipo de diagnóstico es que debe ser amplio (para esto se incorporan distintas estrategias de investigación cualitativas y cuantitativas), en lenguaje sencillo, preciso y oportuno, para el presente caso la potencial reconstrucción habitacional posdesastre.

\subsection{El desastre climático en Atacama}

Un evento hidrometeorológico extremo, el 25 de marzo del 2015 (25M), producto de una baja segregada asociada a precipitaciones, causó lluvias torrenciales en 17 quebradas en Atacama, Chile. En Copiapó, capital regional, las lluvias arrastraron gran cantidad de agua enterrando la ciudad bajo una capa de sedimentos de $31 \mathrm{~cm}$ de espesor, dejando a más del 50\% de las viviendas sin sistema de alcantarillado. En cuanto a la afectación, se registraron 22 personas fallecidas, 28000 damnificados, 2000 viviendas destruidas y 5000 con daño mayor, conllevando un impacto económico superior a 46 millones de USD (Izquierdo et al., 2018).

En términos de impacto psicosocial los grupos expuestos-susceptibles que presentaron una significativa severidad subjetiva fueron los adulto/as mayores, personas con discapacidad/ enfermedad crónica, de sexo femenino, con bajos ingresos económicos y sin educación superior, sumándose quienes se encuentran en la condición de daño parcial-total en su vivienda y no recibieron apoyo para la reconstrucción habitacional (Sandoval-Díaz \& Cuadra-Martínez, 2020).

En términos físicos-materiales, la altura media de afectación fue de $45 \mathrm{~cm}$, identificándose cuatro sectores de la ciudad en los que la inundación superó el metro de lámina de agua, siendo uno de ellos la localidad de Paipote, zona cero del desastre. De acuerdo con Izquierdo et al. (2018), las inundaciones causadas por flujos de derrubios y fango constituyen un riesgo a escala global, especialmente en zonas de grandes desniveles y clima árido, como es el caso de Paipote (Ver figura 1). Esta localidad residencial de 20 000 habitantes, fundada en 1913, se ubica entre la conurbación de las comunas de Tierra Amarilla y Copiapó, a 8 kilómetros de esta última. 
Figura 1. Diagrama aéreo del caso de estudio

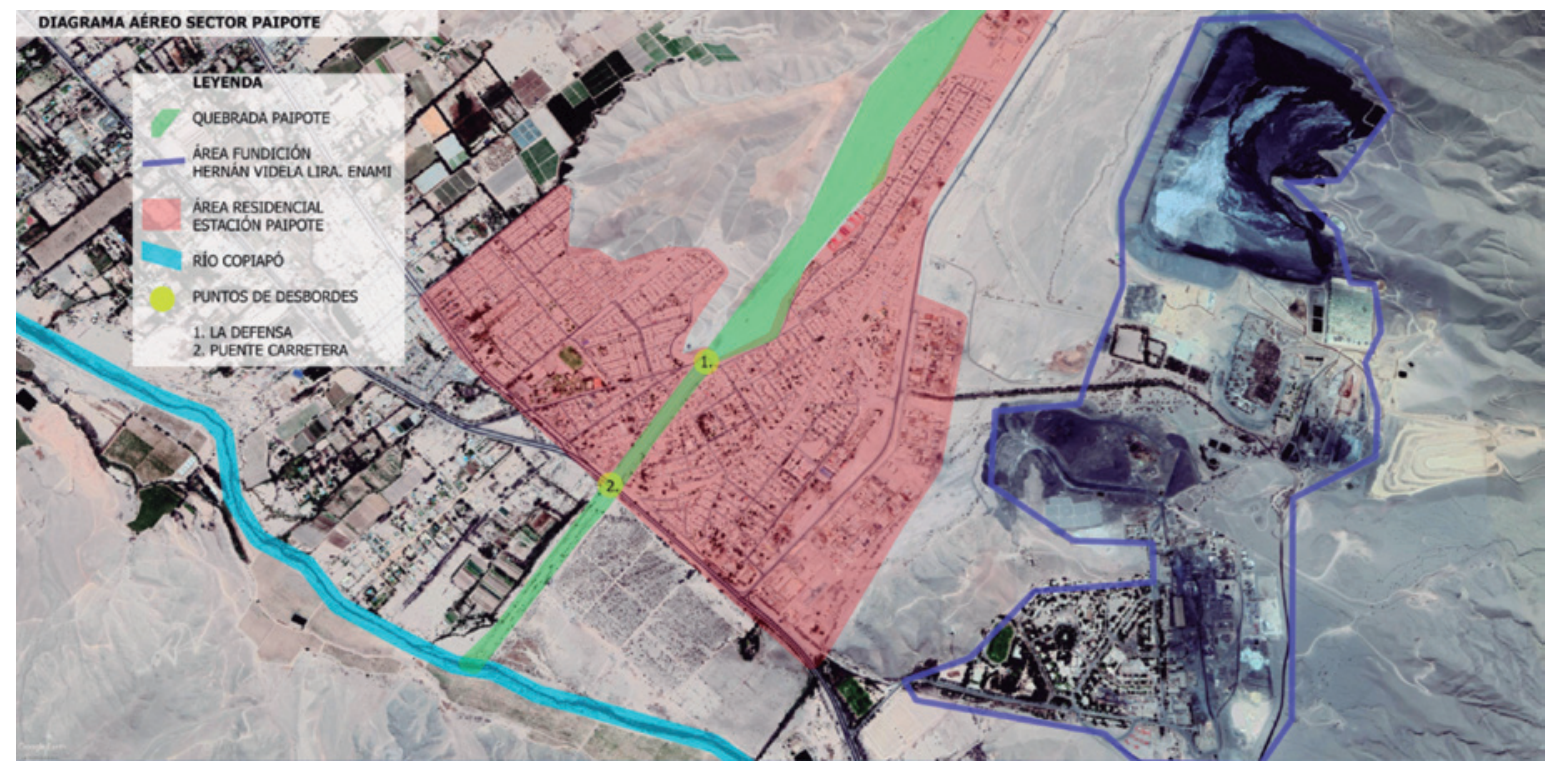

Fuente: Astudillo-Pizarro y Sandoval-Díaz (2019, p. 315).

A fines del año 2016, los dirigentes vecinales de la junta vecinal $\mathrm{N}^{\circ} 36$ de Paipote intentan organizarse para acelerar la lenta reconstrucción de sus barrios y viviendas devastados por el desastre (ocurrido hace más de un año y medio), así como también para solicitar apoyo a actores tanto gubernamentales como de la sociedad civil, como fue el caso del Departamento de psicología de la UDA. Ante esto, un grupo de docentes diseñaron un programa formativo en diagnóstico de necesidades psicosociales a nivel comunitario. La implementación de dicho programa se realizó con la finalidad de responder a dos objetivos: levantar un diagnóstico en conjunto con la junta vecinal, y fortalecer herramientas de formación profesional de estudiantes de octavo semestre.

\section{Metodología}

Se utilizó un estudio de caso ${ }^{4}$ de gestión comunitaria ante un desastre climático, para esto se seleccionó intencionadamente la localidad de Paipote de Atacama como un caso representativo (Gerring, 2007). Se implementó un diseño de Investigación Acción Participativa [IAP], con el objetivo de enfatizar la participación y acción de la comunidad afectada (Stringer, 2008). Fundamental a la IAP es la fase de sensibilización, involucramiento y producción de información, vinculada a la experiencia participativa directa de los profesores responsables del curso a lo largo del ciclo del desastre, alternando instancias de colaboración con la comunidad por medio de la participación en asambleas intersectoriales vinculadas a la reconstrucción habitacional y organización de actividades recreativas en conjunto. Por último, con el fin de que los estudiantes aplicaran técnicas investigativas enseñadas en asignaturas previas, se incorporó la "triangulación de métodos"5 como criterio de validación cruzada (Flick, 2014), esto con el objetivo que utilizaran tanto estrategias cuantitativas como cualitativas (CUAN-CUAL) de producción de datos orales, escritos y visuales, las cuales serán descritas en el apartado de técnicas (ver imagen 1).

Respecto a los socios colaboradores, se utilizó un muestreo intencionado a escala vecinal, procediendo "según la relevancia de los casos, en lugar de hacerlo por su representatividad 
cuantitativa" (Flick, 2007, p. 80). Con base en lo presentado se trabajó en la junta vecinal $\mathrm{N}^{\circ} 36$ de Paipote, asentada en la zona cero del desastre, la que contaba con 174 familias con distintos grados de afectación habitacional.

Figura 2. Aplicación de la técnica de la deriva en la localidad de Paipote

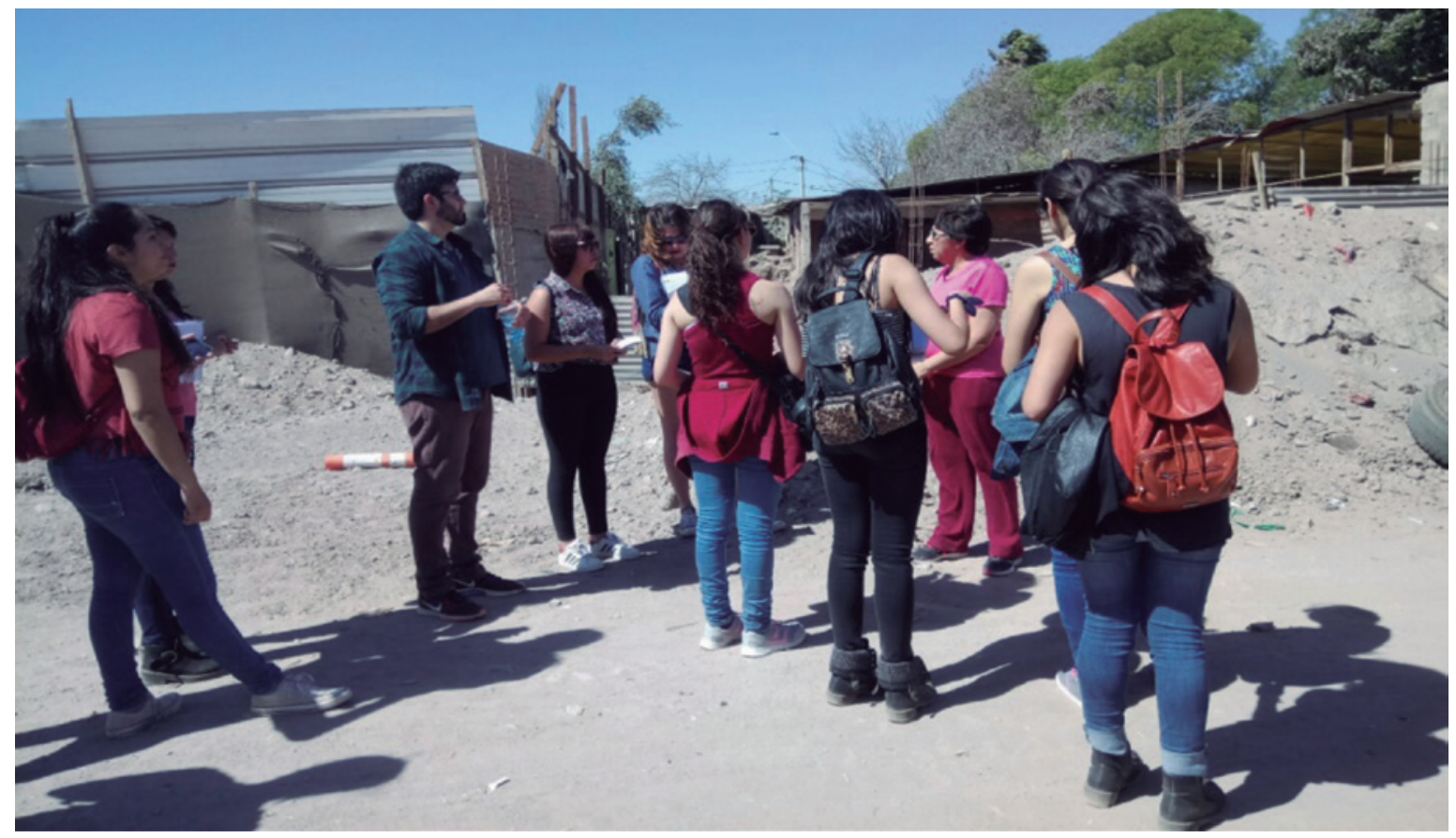

Fotografía: José Sandoval-Díaz.

\subsection{Procedimientos}

La implementación del ApS se realizó desde mediados de julio hasta fines diciembre del año 2016. El taller de integración III contaba con 34 estudiantes inscritos de octavo semestre de psicología. A nivel de servicio, previo inicio de la asignatura, se realizaron dos reuniones de coordinación con dirigentes vecinales, con el objetivo de: consensuar los productos, periodicidad y procedimientos del diagnóstico, y conocer la historia local y experiencia vinculada al desastre climático, posibilitando un primer acercamiento territorial al contexto y la problemática a abordar. Posterior a esta coordinación, junto a la informante clave (dirigente vecinal) se tomó contacto con algunas familias damnificadas, con el objetivo de difundir el potencial trabajo a realizar.
A nivel de aprendizaje, inicialmente, se establecieron sesiones teórico-prácticas semanales con una duración aproximada de una hora y media cronológica (duración del bloque de la asignatura), las que se ampliaban a tres horas si se realizaba en terreno. Para el desarrollo de la asignatura, los estudiantes se auto-agruparon por afinidades personales, (en un máximo de cuatro personas), con el objetivo de priorizar un trabajo en equipo basado en el conocimiento previo. En total se implementaron 13 sesiones (más dos sesiones recreativas junto a la comunidad), las cuales se realizaron tanto en terreno como en las aulas universitarias. Las sesiones son descritas brevemente en la siguiente tabla. 
Tabla 1. Sesiones de actividades implementadas en el taller de integración III

\begin{tabular}{|c|c|c|c|}
\hline Fecha & Actividad & $\begin{array}{l}\text { Tipo de } \\
\text { actividad }\end{array}$ & Breve descripción \\
\hline $\begin{array}{l}15 / 07 \\
24 / 07\end{array}$ & $\begin{array}{l}\text { Reuniones de coordinación previa } \\
\text { con la comunidad. }\end{array}$ & $\begin{array}{l}\text { Práctica de } \\
\text { terreno }\end{array}$ & $\begin{array}{l}\text { Reuniones del cuerpo académico con dirigentes vecinales } \\
\text { para delimitación de objetivos y procedimientos. }\end{array}$ \\
\hline 06/08 & Diseño IAP. & Teórica & $\begin{array}{l}\text { Presentación en aula del diseño, sintetizando sus compo- } \\
\text { nentes teóricos, prácticos y procedimentales. }\end{array}$ \\
\hline $30 / 08$ & Primera inducción al campo. & $\begin{array}{l}\text { Práctica en } \\
\text { Terreno }\end{array}$ & $\begin{array}{l}\text { A nivel grupal se realizó un recorrido a pie por la locali- } \\
\text { dad, utilizando un diario de campo para anotar primeras } \\
\text { impresiones. }\end{array}$ \\
\hline $13 / 09$ & Observación guiada: la deriva. & $\begin{array}{l}\text { Práctica de } \\
\text { terreno }\end{array}$ & $\begin{array}{l}\text { Aplicación de una técnica de observación participante } \\
\text { guiada por los propios dirigentes vecinales. }\end{array}$ \\
\hline $30 / 09$ & $\begin{array}{l}\text { Primera jornada gestión local del } \\
\text { riesgo de desastre UDA. }\end{array}$ & $\begin{array}{l}\text { Seminario- } \\
\text { conversa- } \\
\text { torio }\end{array}$ & $\begin{array}{l}\text { Realizado con distintos expertos locales sobre la temática } \\
\text { de gestión de riesgo de desastre, del que participaron tan- } \\
\text { to dirigentes vecinales como estudiantes. }\end{array}$ \\
\hline $04 / 10$ & $\begin{array}{l}\text { Diagnóstico de necesidades obser- } \\
\text { vadas: estáticas y dinámicas. }\end{array}$ & Teórica & $\begin{array}{l}\text { Presentación en aula del diagnóstico de necesidades psico- } \\
\text { sociales, sintetizando sus componentes teórico-prácticos. }\end{array}$ \\
\hline $11 / 10$ & Diseño de una escala cuantitativa. & $\begin{array}{l}\text { Teórica- } \\
\text { aplicada }\end{array}$ & $\begin{array}{l}\text { En el aula los estudiantes diseñaron preguntas cerradas } \\
\text { de opción i) dicotómica, ii) politómica y de iii) escala Likert; } \\
\text { esto de acuerdo con las impresiones cualitativas recogi- } \\
\text { das en terreno. }\end{array}$ \\
\hline $25 / 10$ & Aplicación de escalas cuantitativas. & $\begin{array}{l}\text { Práctica de } \\
\text { terreno }\end{array}$ & $\begin{array}{l}\text { Aplicación en terreno de escalas psicométricas y pregun- } \\
\text { tas cerradas (consensuadas y seleccionadas en la clase } \\
\text { anterior), esto vía muestreo probabilístico de viviendas por } \\
\text { manzana. }\end{array}$ \\
\hline $08 / 11$ & $\begin{array}{l}\text { Estrategias participativas: Ecomapa } \\
\text { y cartografía social. }\end{array}$ & Teórica & $\begin{array}{l}\text { Presentación introductoria de técnicas participativas sinte- } \\
\text { tizando sus ventajas y limitaciones teórico-prácticas. }\end{array}$ \\
\hline $29 / 11$ & $\begin{array}{l}\text { Matriz de sistematización de diag- } \\
\text { nóstico de necesidades. }\end{array}$ & $\begin{array}{l}\text { Teórica- } \\
\text { aplicada }\end{array}$ & $\begin{array}{l}\text { Presentación teórica de matriz de capacidades y vulnera- } \\
\text { bilidades comunitarias (MCV). }\end{array}$ \\
\hline $06 / 12$ & $\begin{array}{l}\text { Presentación de avances grupales } \\
\text { (Matrices). }\end{array}$ & $\begin{array}{l}\text { Teórica- } \\
\text { expositiva }\end{array}$ & $\begin{array}{l}\text { Presentación grupal de avance de matriz MCV, la que fue } \\
\text { retroalimentada por docentes y pares estudiantiles. }\end{array}$ \\
\hline $13 / 12$ & Entrega de informe final de síntesis. & Teórica & $\begin{array}{l}\text { Con la retroalimentación realizada, los grupos de trabajo } \\
\text { debían elaborar un informe final. }\end{array}$ \\
\hline $\begin{array}{l}10 / 08 \\
21 / 12 \\
\end{array}$ & $\begin{array}{l}\text { Actividades recreativas: i) Celebra- } \\
\text { ción del día del niño/a y ii) Apoyo } \\
\text { celebración navidad comunitaria. }\end{array}$ & $\begin{array}{l}\text { Actividades } \\
\text { recreativas }\end{array}$ & $\begin{array}{l}\text { Realización y apoyo de dos actividades recreativas junto } \\
\text { al cuerpo académico, estudiantes y comunidad. }\end{array}$ \\
\hline
\end{tabular}

Fuente: Elaboración propia

\subsection{Técnicas de producción de datos}

Con los objetivos de a) fortalecer el aprendizaje aplicado investigativo, así como también, b) aumentar la validez del proceso de diagnóstico de necesidades, se utilizó la estrategia de triangulación de métodos CUAN-CUAL (Flick, 2014). Estas técnicas —en primer lugar- fueron enseñadas en sesiones de clase (ver tabla 1), para posteriormente, aplicarse en el trabajo de campo.
La enseñanza de estas técnicas se realizó flexiblemente, esto de acuerdo con los tiempos y características de las sesiones respectivas, considerando para esto: a) temáticas tratadas y emergentes en los terrenos, b) disposición de los estudiantes, c) características del aula y de los recursos a utilizar, por mencionar solo algunos aspectos. La tabla 2 describe las técnicas utilizadas, con su respectivo objetivo, justificación y etapa de utilización. 
Tabla 2. Descripción de las técnicas enseñadas y aplicadas por los estudiantes para el diagnóstico

\begin{tabular}{|c|c|c|c|}
\hline $\begin{array}{l}\text { Contexto de } \\
\text { uso }\end{array}$ & Técnica & Objetivo & Justificación \\
\hline Terreno práctico & $\begin{array}{l}\text { Entrevista narrati- } \\
\text { va (Flick, 2007). }\end{array}$ & $\begin{array}{l}\text { Conocer la historia local, como } \\
\text { los antecedentes y característi- } \\
\text { cas del desastre. }\end{array}$ & $\begin{array}{l}\text { Primer acercamiento cara a cara con la co- } \\
\text { munidad desde una perspectiva situada. }\end{array}$ \\
\hline Terreno práctico & $\begin{array}{l}\text { La deriva (Pellicer } \\
\text { et al., 2013). }\end{array}$ & $\begin{array}{l}\text { Explorar los significados y senti- } \\
\text { dos espaciales ante la experien- } \\
\text { cia de desastre. }\end{array}$ & $\begin{array}{l}\text { Técnica de observación guiada que terri- } \\
\text { torializó las narrativas emergentes de la } \\
\text { entrevista, esto a través de un recorrido en } \\
\text { la zona de exposición al riesgo. }\end{array}$ \\
\hline $\begin{array}{l}\text { Aplicación } \\
\text { práctica aula }\end{array}$ & $\begin{array}{l}\text { Cartografía social } \\
\text { participativa (Vé- } \\
\text { lez et al., 2012). }\end{array}$ & $\begin{array}{l}\text { Producir un mapa, a escala } \\
\text { barrial, de potenciales amena- } \\
\text { zas, vulnerabilidades y espa- } \\
\text { cios de seguridad ante riesgos } \\
\text { climatológicos. }\end{array}$ & $\begin{array}{l}\text { Técnica dialógica que grafica el uso y } \\
\text { apropiación espacial, en la que se dibujan } \\
\text { lugares expuestos-susceptibles y de segu- } \\
\text { ridad ante riesgos. }\end{array}$ \\
\hline $\begin{array}{l}\text { Aplicación } \\
\text { práctica aula }\end{array}$ & $\begin{array}{l}\text { Ecomapa (Fernán- } \\
\text { dez et al., 2011). }\end{array}$ & $\begin{array}{l}\text { Producir un mapa relacional de } \\
\text { actores sociales identificando el } \\
\text { grado de cercanía o distancia } \\
\text { percibido. }\end{array}$ & $\begin{array}{l}\text { Técnica ecológica que grafica las rela- } \\
\text { ciones de cercanía, distancia o ausencia } \\
\text { entre comunidad e instituciones públicas/ } \\
\text { privadas a lo largo del ciclo del desastre. }\end{array}$ \\
\hline $\begin{array}{l}\text { Terreno } \\
\text { práctico }\end{array}$ & $\begin{array}{l}\text { Muestreo y apli- } \\
\text { cación de escalas } \\
\text { de impacto psico- } \\
\text { social (Sandoval- } \\
\text { Díaz \& Cuadra- } \\
\text { Martínez, 2020). }\end{array}$ & $\begin{array}{l}\text { Aplicar competencias de } \\
\text { muestreo y recogida de datos } \\
\text { cuantitativos }\end{array}$ & $\begin{array}{l}\text { Los estudiantes aplicaron un cuadernillo } \\
\text { de escalas psicosociales previo entrena- } \\
\text { miento. Posteriormente analizaron los re- } \\
\text { sultados de forma general vía estadística } \\
\text { descriptiva. }\end{array}$ \\
\hline $\begin{array}{l}\text { Sistematización } \\
\text { en aula }\end{array}$ & $\begin{array}{l}\text { Matriz de capaci- } \\
\text { dades y vulnerabi- } \\
\text { lidades (Anderson } \\
\text { \& Woodrow, 1989). }\end{array}$ & $\begin{array}{l}\text { Sistematizar la información le- } \\
\text { vantada, utilizando una matriz } \\
\text { MCV }\end{array}$ & $\begin{array}{l}\text { A nivel grupal los estudiantes debieron } \\
\text { sistematizar la información levantada para } \\
\text { elaborar un diagnóstico comunitario para } \\
\text { las áreas a) físico-material, b) organizacio- } \\
\text { nal y c) motivacional. }\end{array}$ \\
\hline
\end{tabular}

Fuente: Adecuación propia de Sandoval et al. (2018).

\section{Resultados}

Los resultados se esquematizan en las tablas 3 y 4, según los objetivos específicos del estudio, identificando tanto ventajas como limitaciones de aprendizaje en las áreas i) teórico-conceptuales, ii) metodológicas, iii) prácticas y iv) ética-políticas del diagnóstico de necesidades comunitarias bajo ApS.

Tabla 3. Ventajas en la enseñanza-aprendizaje del diagnóstico psicosocial bajo ApS

\begin{tabular}{|c|c|c|c|}
\hline Teórico conceptual & Metodológica & Práctico & Ético-político \\
\hline $\begin{array}{l}\text { Aplicación a una situación } \\
\text { real de estrategias de levan- } \\
\text { tamiento de datos CUAN- } \\
\text { CUAL revisadas solo de } \\
\text { forma teórica en asignaturas } \\
\text { previas. }\end{array}$ & $\begin{array}{l}\text { Sensibilización sobre la importan- } \\
\text { cia del diseño flexible de la IAP (en } \\
\text { términos de anticipación frente a } \\
\text { situaciones emergentes no contem- } \\
\text { pladas), lo cual no debe ser confun- } \\
\text { dido con decisiones "espontáneas" o } \\
\text { "voluntaristas". }\end{array}$ & $\begin{array}{l}\text { Fortalecimiento de } \\
\text { habilidades sociales } \\
\text { transversales, tales } \\
\text { como: a) trabajo en } \\
\text { equipo, b) escucha ac- } \\
\text { tiva, c) capacidad de } \\
\text { síntesis, d) comunica- } \\
\text { ción asertiva, e) empa- } \\
\text { tía y f) negociación. }\end{array}$ & $\begin{array}{l}\text { Concienciación ante } \\
\text { la experiencia ne- } \\
\text { gativa de la comuni- } \\
\text { dad afectada por el } \\
\text { desastre, la cual se } \\
\text { arrastra más allá de } \\
\text { la contingencia del } \\
\text { evento. }\end{array}$ \\
\hline
\end{tabular}


Problematización conceptual-empírica ante la problemática concreta abordada (ruptura tanto con el empirismo ingenuo [Afectados como meras víctimas] o el imperialismo de la teoría [Comunidades resilientes ante el desastre]).

Incorporación de procesos de autorreflexión grupales los cuales posibilitaron no solo la incorporación de las propias narrativas estudiantiles sino también el señalamiento colectivo de prejuicios u obstaculizadores del proceso.
Desarrollo y aplicación procedimental de estrategias CUAL-CUAN de acuerdo con una problemática de relevancia social.

Relevo de la importancia de la horizontalidad de la IAP en pos de desarrollar soluciones colaborativas.

Fortalecimiento de la criticidad metodológica, por ejemplo: a) Adecuación de la técnica según las características de la población objetivo; b) Pertinencia del tipo de técnica según la naturaleza del dato; b) Limitaciones del diseño y/o formato de los instrumentos según el contexto (Problemas en la comprensión de la escala Likert en adultos mayores y/o uso limitado escalas de auto aplicación en personas que no saben leer).
Aplicación de conocimientos disciplinares a través de un trabajo de campo guiado por una problemática real.
Desarrollo de un posicionamiento investigativo-reflexivo e implicativociudadano ante la problemática.
Retroalimentación comunitaria continua para incorporar estrategias/ procedimientos de acuerdo con las necesidades emergentes.
Continuidad con el trabajo comunitario post asignatura (algunos estudiantes siguieron vinculados a la comunidad).

Fuente: Elaboración propia.

Tabla 4. Limitaciones en la enseñanza-aprendizaje del diagnóstico psicosocial bajo ApS

Teórico conceptual

Abordaje superficial sobre el componente interventivo de la gestión comunitaria ante desastres, esto debido a los tiempos acotados de la asignatura. competencias profesionales enseñadas y las competencias desplegadas ante la problemática psicosocial concreta esto debido a las características de cada contexto.

\section{Metodológica}

Falta de sistematicidad y de análisis profundo de los datos levantados (tanto en términos estadísticos como de contenido cualitativo), esto tanto por los tiempos acotados de la asignatura, como por los vacíos metodológicos previos (desconocimiento en el manejo de software).

Falta de incorporación de criterios de rigurosidad y calidad de las técnicas utilizadas.

\section{Práctico}

Ético - Político

Limitación temporal, en términos de duración semestral (solo 13 sesiones) como por la cantidad de horas asignadas a estas (dos horas aprox.).

Limitación de recursos económicos (transporte y materiales-tecnológicos para el levantamiento de datos) así como humanos (tanto de los profesores como de la comunidad).

Parte de la comunidad desconfía ante el trabajo de organizaciones externas.
En algunos casos, baja disposición y motivación por parte del estudiantado, debido al interés profesional en otras áreas profesionales (ej. clínica, laboral, educacional).

Incompatibilidad, en algunos casos, entre las necesidades sentidas de la comunidad (quienes estaban más interesadas en la reconstrucción habitacional) como en las necesidades a satisfacer en la asignatura (diagnóstico psicosocial).

Fuente: Elaboración propia 


\section{Discusión y conclusiones}

En primer lugar, valoramos de forma positiva el uso de ApS en el proceso de enseñanza-aprendizaje del diagnóstico comunitario ante el riesgo de desastre, identificando tanto ventajas como limitaciones en la adquisición y desarrollo i) teórico-conceptual, ii) metodológico, iii) práctico y iv) ético-político de competencias disciplinares y transversales a nivel profesional en ciencias sociales.

En el proceso de enseñanza-aprendizaje, estas ventajas se tradujeron, no solo en el fortalecimiento práctico de habilidades, conocimientos $\mathrm{y}$ actitudes, en término de competencias profesionales (CNA, 2015; Departamento de psicología, 2015; Juliá, 2013), sino también para el relevo heurístico de distintas técnicas investigativas utilizadas para el diagnóstico. En esta línea, relevamos la importancia de ampliar los horizontes prácticos de la enseñanza convencional metodológica en contextos formativos universitarios, la cual solo tiende a cobrar sentido al momento de cursar la tesis de grado, escindiéndose de las competencias técnicas disciplinares necesarias para el desarrollo de diagnósticos e intervenciones de carácter psicosocial (Bassi, 2015; LópezNoguero, 2017; Orellana-Fonseca et al., 2019). Es por esto, que por medio de la metodología ApS logramos que ciertos conocimientos conceptuales-abstractos e investigativos enseñados en aula, fuesen traducidos y trasladados a una situación problemática concreta, posibilitando no solo el manejo procedimental de las distintas técnicas utilizadas [habilidad], sino también, un autoanálisis crítico reflexivo respecto su uso [actitud] (Cuadra-Martínez et al., 2018).

Otro elemento importante para destacar es el complemento entre estrategias activas de enseñanza y el aprendizaje aplicado y horizontal del proceso de investigación. Es así como el ApS permitió al estudiantado no solo posibilitar una aproximación situada al conocimiento profesional, sino también conocer la importancia de la horizontalidad participativa propia de la IAP tanto para i) posibilitar diálogos de saberes rea- les entre expertos y comunidades, como para ii) posicionar a estos últimos como un actor protagónico en los procesos de cambio autogestionados y sostenibles en el tiempo (Stringer, 2008). De esta forma, los estudiantes pudieron no solo integrar contextualmente teoría y práctica, además de desarrollar competencias profesionales ante problemáticas societales emergentes, sino que - además - el servicio ofertado logró sentido y utilidad para la comunidad, siendo esto un factor clave para los procesos de cambio intersubjetivo (Sandoval-Díaz et al., 2020). Esta complementariedad podría fortalecer la metodología de la ApS, disminuyendo las limitaciones que se producen cuando comunidades e interventores parten desde supuestos inconmensurables sobre el potencial servicio.

Respecto al objetivo del servicio para/ con la comunidad, se logró concretar incipientemente un círculo virtuoso entre intencionalidad pedagógica y social (Furco, 2011; Pizarro \& Hasbún, 2019), posibilitando una negociación continua entre necesidades sentidas comunitarias y los objetivos de aprendizaje esperados, teniendo como meta viable clara el diagnóstico social. Sin embargo, si bien se logró alcanzar este objetivo pedagógico en los tiempos esperados, muchas de las necesidades sociales emergentes del servicio desarrollado no pudieron ser abordadas, dado que algunas obedecían estrictamente o a la dimensión física-material de la reconstrucción de viviendas y espacio público, como a decisiones institucionales que emanaban de los gobiernos locales (estrategias de mitigación ante la exposición de riesgos (Anderson \& Woodrow, 1989). Otro aspecto pendiente fue la incorporación de estrategias interventivas para la reducción de la vulnerabilidad social territorial (Freire, 2012), así como también el empoderamiento y fortalecimiento de capacidades resistentesresilientes (Sandoval et al., 2018).

En lo práctico, en términos de limitaciones, de acuerdo con los cuadrantes del ApS del Service-learning Center de la Universidad de Stanford, nuestra experiencia pedagógica estu- 
vo más cercana a una mixtura de trabajo de campo y servicio comunitario, por la ausencia del componente de retroalimentación por parte de la comunidad, esto debido a los factores de (i) temporalidad acotada de la intervención, (ii) articulación incipiente pero no sistemática entre interventores y socios colaboradores, (ii) baja implicancia y empoderamiento territorial y iii) alta desconfianza hacia agentes externos. A estas limitaciones se suman la carencia de activos materiales y humanos adecuados para una intervención de mediana escala, así como también la ausencia de actores gubernamentales, los cuales eran centrales para las decisiones y tiempos para la reconstrucción posdesastre (Mayor, 2019). Por tanto, futuros trabajos debiesen incorporar la propuesta planteada en el marco de Acción de Sendai (2015), bajo la cual:

Las organizaciones comunitarias deben participar, en colaboración con las instituciones públicas, para, entre otras cosas, proporcionar conocimientos específicos y orientación pragmática en el contexto de elaboración y aplicación de marcos normativos, estándares y planes para la RRD. (UNDRR, 2015, p. 23)

Por lo tanto, mejorar las capacidades, requiere una transferencia de poder en beneficio de la población local reconociéndolos como actores informados, hábiles e ingeniosos (Gaillard et al., 2019). No obstante, a pesar de esta limitación, desde el punto de vista formativo profesional, esta experiencia pedagógica exploratoria posibilitó ir más allá de los enfoques convencionales centrados en el desastre, posibilitando el adentrarnos en la anticipación, respuesta y recuperación local ante riesgos climáticos, bajo la articulación pragmática de distintas estrategias investigativas-interventivas (Anderson \& Woodrow, 1989; Sandoval et al., 2018). En síntesis, afirmamos el uso de la ApS como una metodología participativa para el fortalecimiento no solo de competencias profesionales-disciplinares, sino también, transversales como el pensamiento crítico, el trabajo en equipo y la sensibilidad ciu- dadana (Muñoz-Arce et al., 2017; Ortega, 2015), esto acorde al tipo de formación universitaria integral que requieren las emergentes problemáticas psicosociales complejas (Morin, 2016).

\section{Notas}

1 Trabajo financiado por la Agencia Nacional de Investigación y Desarrollo (ANID) en el marco de la ejecución del FONDECYT de Iniciación N 11200683 "Riesgos socionaturales intensificados por el cambio climático: Análisis de la vulnerabilidad-resiliencia social a escala local" (2020 a 2023)

2 En Chile como competencias transversales se identifican las capacidades de comunicación oral y escrita, resolución de problemas, trabajo en equipo, compromiso ético, creatividad, liderazgo, entre otras (CNA, 2015 p. 5).

3. Proyecto MECESUP ULS 0601 “Mejoramiento de la formación general y especifica de los profesionales psicólogos del consorcio de las universidades del estado (CUECH) mediante el diseño e implementación de un marco curricular basado en competencias".

4. Un caso es un fenómeno (o unidad) espacialmente delimitado, observado en un solo punto del tiempo o a través de un determinado periodo de tiempo (Gerring, 2007 p. 19).

5. Utilización de distintas técnicas que se encuadran en métodos de investigación diferentes, y se combinan para analizar un mismo objeto de estudio con el objetivo de aumentar calidad investigativa.

\section{Referencias bibliográficas}

Anderson, M., \& Woodrow, P. (1989). Rising from the ashes: development strategies in times of disaster. Westview Press.

Astudillo-Pizarro, F., \& Sandoval-Díaz, J. (2019). Justicia espacial, desastres socionaturales y políticas del espacio. Dinámicas sociopolíticas frente a los aluviones y proceso de recuperación en Copiapó, Chile [Spatial Justice, Socio-Natural Disasters, and Spatial Policies: Sociopolitical Dynamics in view of the Floods and Recovery Processes in Copiapó, Chile]. Cuadernos de Geografía: Revista Colombiana de Geografía, 28(2), 303-321. https://doi.org/10.15446/rcdg.v28n2.73520

Aguilar-Idañez, M., \& Ander-Egg, E. (2001). Diagnóstico social: Conceptos y metodología. Lumen.

Barrón-Tirado, M. (2009). Docencia universitaria y competencias didácticas [Teaching at the University and educational competences]. Perfiles educativos, 31(125), 76-87. 
https://doi.org/10.22201/

iisue.24486167e.2009.125.18849

Bassi, J. (2015). Formulación de proyectos de tesis en ciencias sociales. Manual de supervivencia para estudiantes de pre-y posgrado. FACSO/ El buen aire.

Claire, M., Dintrans, P., Santander, G., \& Valenzuela, G. (2019). Aprendizaje servicio: Origen y trayectoria en Chile. Red Nacional de aprendizaje servicio Chile. En V. Pizarro \& B. Hasbún, B. (Eds.), Aprendizaje-Servicio en la Educación Superior Chilena. Ediciones CEAFEN Universidad de Chile. https://bit.ly/3ad0EWE

Cuadra-Martínez, D., Castro, P., \& Juliá, M. (2018). Tres saberes en la formación profesional por competencias: Integración de teorías subjetivas, profesionales y científicas [Three Types of Knowledge in Competency Based Professional Education: The Integration of Subjective, Professional, and Scientific Theories]. Formación universitaria, 11(5), 19-30. https://dx.doi.org/10.4067/S0718-50062018000500019

Comisión Nacional de Acreditación de Chile [CNA]. (2015, octubre). Glosario de términos complementarios criterios de acreditación de pregrado. https://bit.ly/2IQ1cGG

De Castro, A., \& Domínguez, E. (2018). Transformar para educar 6: Aprendizaje servicio. Editorial Universidad del Norte. https://bit.ly/2JXaqlb

Departamento de Psicología UDA (s.f.). Malla curricular de psicología. https://bit.ly/2Kpjv6a

Departamento de Psicología UDA (2015, Julio 9). Definición de la carrera. https://bit.ly/389LoY3

Dewey, J. (1985). Democracia y escuela. Eumo.

Fernández, J., Escalante, E., \& Richard, F. (2011). Revisitando algunas herramientas de evaluación sistémica [Revisiting some tools of systemic evaluation]. Psicoperspectivas, 10(1), 190-208. https://bit.ly/3gNkmcV

Flick, U. (2007). Introducción a la investigación cualitativa. Morata.

Flick, U. (2014). La gestión de la calidad en la investigación cualitativa. Morata.

Freire, P. (2012). Pedagogía del oprimido (2a ed.). Siglo XXI.

Furco, A. (2011). El aprendizaje-servicio: un enfoque equilibrado de la educación experiencial
[Service-Learning: A Balanced Approach to Experiential Education]. Revista Educación Global, 0, 64-70. https://bit.ly/2K01zPI

Gaillard, J., Cadag, J., \& Rampengan, M. (2019). People's capacities in facing hazards and disasters: an overview. Natural Hazards, 95(3), 863-876. https://doi.org/10.1007/s11069-018-3519-1.

García-Lirios, C., Carreón-Guillén, J., \& HernándezValdés, J. (2014). La formación profesional de capital humano en la civilización del cambio climático [Vocational training in human capital civilization of climate change]. Revista Internacional de Investigación en Ciencias Sociales. Revista Internacional de Investigación en Ciencias Sociales, 10(1), 107125. https://bit.ly/3oRTWJO

Gerring, J. (2007). What is a case study and what is it good for? American Political Science Review, 98(2), 341-354. https://doi.org/10.1017/ S0003055404001182

Griselda-Günther, M., \& Gutiérrez, R. (2017). La política del ambiente en América Latina. Una aproximación desde el cambio ambiental global. CLACSO.

Intergovernmental Panel on Climate Change [IPCC]. (2014). AR5 Climate Change 2014: Impacts, Adaptation, and Vulnerability. Cambridge University Press.

Izquierdo, T., Abad, M., Justo, B., Bernárdez., E., \& Arancibia, M. (2018). El evento hidrometeorológico del 25M en la ciudad de Copiapó: análisis de la inundación y los daños en el casco urbano. En G. Vargas, S. Pérez \& P. Aldunce (Eds.), Aluviones y resiliencia en atacama: construyendo saberes sobre riesgos $y$ desastres (pp. 117-135). Social-Ediciones.

Juliá, M. (2013). Competencias del psicólogo en Chile: Propuesta desde las universidades estatales. Editorial Universidad de La Serena.

López-Noguero, F. (2017). Metodología participativa en la enseñanza universitaria. Ediciones de la U.

Matus, T. (2002). Propuestas contemporáneas en trabajo social: hacia una intervención polifónica. Espacio Editorial

Mayor, D. (2019). Dimensiones pedagógicas que configuran las prácticas de aprendizaje-servicio [Pedagogical Dimensions that Configure 
Service-Learning Practices]. Páginas de Educación, 12(2), 23-42. https://dx.doi. org/10.22235/pe.v12i2.1834

Montes, R., Tapia, M., \& Yaber, L. (2011). Manual para docentes y estudiantes solidarios. CLAYSS. https://bit.ly/37ni8hn

Morin, E. (2016). Enseñar a vivir: Manifiesto para cambiar la educación. Paidós.

Muñoz-Arce, G., Hernández-Mary, N., \& VélizBustamante, C. (2017). La relación entre investigación e intervención social: voces desde el trabajo social chileno [The relationship between research and social intervention: voices from chilean social work]. Trabajo Social Global. Revista de Investigaciones en Intervención Social, 7(12), 3-24. https://bit. ly/3gQXmcN

Orellana-Fonseca, C., Salazar-Jiménez, R., FaríasOlavarría, F., Martínez-Labrin, S., \& PérezDíaz, G. (2019). Valoraciones que estudiantes de un posgrado de profesión docente tienen sobre la formación en metodología de la investigación recibida en el pregrado y su uso en la práctica docente [Postgraduate Teaching Students' Evaluation of the Training in Research Methodology Received During Their Degree, and its Use in Teaching Practice]. Revista Electrónica Educare, 23(1), 342-366. https://dx.doi.org/10.15359/ree.23-1.17

Ortega, M. (2015). Trabajo social como transdisciplina: hacia una teoría de la intervención [Social work as transdiscipline: towards a theory of intervention]. Cinta de moebio, (54), 278-289. https://dx.doi.org/10.4067/S0717-554X2015000300005

Pellicer, I., Vivas-Elias, P., \& Rojas, J. (2013). La observación participante y la deriva: dos técnicas móviles para el análisis de la ciudad contemporánea. El caso de Barcelona [a observación participante y la deriva: dos técnicas móviles para el análisis de la ciudad contemporánea. El caso de Barcelona]. EURE, 39(116), 119-139. https://doi.org/10.4067/S0250-71612013000100005

Pizarro, V., \& Hasbún, B. (2019). Aprendizaje Servicio en la Educación Superior Chilena. Ediciones CEA-FEN Universidad de Chile. https://doi.org/10.34720/WCC5-5184

Ricardo, D., Guerra, M., Morales, C., \& Rifa, J. (2019). La Universidad y la educación para el cambio climático [The university and the education for the climate change]. Humanidades Médicas, 19(3), 427-442. https://bit.ly/3r0JeCI

Rodríguez, M. (2014). Aprendizaje-Servicio como estrategia metodológica en la Universidad [Service-learning as a methodological strategy at University]. Revista Complutense de Educación, 25(1), 95-113. https://doi.org/10.5209/rev_RCED.2014.v25.n1.41157

Sánchez, L., \& Reyes, O. (2015, diciembre). Medidas de adaptación y mitigación frente al cambio climático en América Latina y el Caribe. Una revisión general. Estudios del Cambio Climático en América Latina. CEPAL. https://bit.ly/3aejY5O

Sandoval-Díaz, J. (2020). Vulnerabilidad-resiliencia ante el proceso de riesgo-desastre: Un análisis desde la ecología política [Vulnerabilityresilience to the risk-disaster process: An analysis from the political ecology]. Polis (Santiago), 19(56), 214-239. https://dx.doi.org/10.32735/s0718-6568/2020-n56-1527 Sandoval-Díaz, J., \& Cuadra-Martínez, D. (2020). Vulnerabilidad social, severidad subjetiva y crecimiento postraumático en grupos afectados por un desastre climatológico [Social vulnerability, subjective severity and posttraumatic growth in groups affected by a climate disaster]. Revista de Psicología, 29(1), $1-15$. https://dx.doi.org/10.5354/0719-0581.2020.58002 Sandoval-Díaz, J., Cuadra-Martínez, D., PalaciosDíaz, D., \& Ligueño-Espinoza, S. (2020). La investigación-acción como promotora de la formación ciudadana en/desde la escuela: tres propuestas investigativas-interventivas. En C. Orellana., R. Salazar \& V. Hasse (Eds.), Formación ciudadana en la escuela: conceptualización, herramientas de intervención socioeducativa y propuestas didácticas (pp. 173-191). Ril Editores.

Sandoval., J, Rojas, L., Villalobos, M., Sandoval, C., Moraga, F., \& Aguirre, N. (2018). De organización vecinal hacia la gestión local del riesgo: diagnóstico de vulnerabilidad y capacidad [From the local organization towards local risk management: diagnosis of vulnerability and capacity]. Revista INVI, 33(92), 155-180. 
http://dx.doi.org/10.4067/S0718-83582018000100155

Stringer, E. (2008). Action research in education (2nd ed.). Pearson Prentice Hall.

Vélez, I., Rátiva, S., \& Varela, D. (2012). Cartografía social como metodología participativa y colaborativa de investigación en el territorio afrodescendiente de la cuenca alta del río Cauca [Social Cartography as a Participative and Collaborative Research Methodology in the Upper Basin of the Cauca River]. Cuadernos de Geografía, 21(2), 59-73. https://doi.org/10.15446/rcdg.v21n2.25774

Wendler, R. (2012). Human subject's protection: A source for ethical service-learning practi- ce. Michigan Journal of Community Service Learning, 2(18), 29-39.

https://bit.ly/34dhQY8

UN Office for Disaster Risk Reduction [UNDRR]. (2015). Sendai Framework for Disaster Risk Reduction 2015-2030. UNDRR. https://bit.ly/3oS2TCU

UN Office for Disaster Risk Reduction (2019 enero 23). 2018: 60 millones de personas resultaron afectadas por diversos eventos meteorológicos extremos. https://bit.ly/3oUa1hZ

United Nations Educational, Scientific, and Cultural Organization [UNESCO]. (2015). Not just hot air: Putting climate change education into practice. UNESCO https://bit.ly/3nr7LP2 


\section{=ALTERIDAD Aprendizaje-servicio en la enseñanza de la Sociología a futuros docentes}

\section{Service-Learning in the teaching of Sociology for future teachers}

Dra. Paloma Candela-Soto es docente e investigadora de la Universidad de Castilla-La Mancha (España) (Paloma.Candela@ uclm.es) (https://orcid.org/0000-0002-4857-8747)

(D) Dra. María Carmen Sánchez-Pérez es docente titular e investigadora de la Universidad de Castilla-La Mancha (España) (Mariacarmen.Sanchez@uclm.es) (https://orcid.org/0000-0002-7195-7446)

(D) Dra. Mercedes Ávila-Francés es docente e investigadora de la Universidad de Castilla-La Mancha (España) (Mercedes.Avila@ uclm.es) (https://orcid.org/0000-0003-4253-4345)

Recibido: 2020-07-11 / Revisado:: 2020-12-07 / Aceptado: 2020-12-09 / Publicado: 2021-01-01

\section{Resumen}

Este artículo reflexiona y hace balance de las contribuciones del aprendizaje-servicio (ApS) a la docencia universitaria y, en concreto, a la formación inicial del profesorado. A partir de la evaluación de un proyecto de innovación docente llevado a cabo en las Facultades de Educación de la Universidad de Castilla La Mancha (UCLM), se profundiza en la percepción de los estudiantes sobre la utilidad del ApS en el aprendizaje académicocompetencial y en las experiencias vividas en escenarios escolares reales donde han observado y aplicado sus aprendizajes teóricos. La valoración de la adquisición de competencias concretas del Grado, la disposición y desempeño para comprender problemas sociales que deberán afrontar en su futuro profesional, así como los sentimientos y emociones experimentadas, son algunos de los objetivos que guían nuestro trabajo. Se trata de un estudio empírico de metodología mixta, mediante un cuestionario online y el análisis de las narraciones reflexivas de los estudiantes con una muestra de 167 alumnos y alumnas. Los resultados revelan la elevada satisfacción del alumnado participante, especialmente en variables vinculadas con la adquisición de competencias profesionales y personales, destacando las destrezas críticas y reflexivas que favorecen el aprendizaje significativo de la Sociología. Con todo, la investigación corrobora el carácter renovador del ApS en la enseñanza superior, una metodología que se adapta con idoneidad al desempeño competencial y formativo de las futuras maestras y maestros.

Descriptores: Aprendizaje-Servicio, Sociología de la Educación, innovación docente, competencias profesionales, percepciones de los estudiantes, responsabilidad social universitaria.

\section{Abstract}

This paper reflects and gives an account of the Service-Learning (S-L) contributions to university teaching and, more specifically, to the initial teacher training. It is part of an innovation project carried out in the Faculties of Education in the University of Castilla-La Mancha (UCLM). It deepens into students' perceptions about $S-L$ benefits for academic and skill learning. It also studies students' experiences at schools, where they were able to observe and apply their theoretical learning. Some of the objectives guiding this study are to assess the Degree skills acquisition, their ability to understand social problems that they will have to face in their professional future, as well as the feelings and emotions experienced. This empirical mixed methodology study (by an online questionnaire and student narratives analysis) reaches a 167 students sample. Results verify their high level of satisfaction with the S-L project, especially in those variables linked to the professional and personal skills, highlighting the critical and reflective skills that promote a significant learning in Sociology. All in all, this study verifies the renewing power of $S-L$ in higher education, as this methodology effectively adapts to future teachers' competence and training performance.

Keywords: Service-Learning, Sociology of Education, teaching innovation, professional skills, students' perceptions, university social responsibility.

Forma sugerida de citar: Candela-Soto, P., Sánchez-Pérez, M.C., \& Ávila-Francés-M. (2021). Aprendizaje-servicio en la enseñanza de la Sociología a futuros docentes. Alteridad, 16(1), 38-50. https://doi.org/10.17163/alt.v16n1.2021.03 


\section{Introducción}

Este artículo parte de los resultados obtenidos en el proyecto de innovación docente desarrollado por las Facultades de Educación de la Universidad de Castilla-La Mancha (UCLM), orientado a implantar la metodología de AprendizajeServicio en la formación de los futuros docentes. Con un marcado carácter interdisciplinar, ha estado liderado desde sus comienzos (en el curso académico 2017-18) por profesoras del Área de Sociología en los Grados de Educación Infantil y Primaria. El proyecto buscaba dotar a las asignaturas de mayor contenido práctico, ofreciendo al alumnado la posibilidad de participar en proyectos altruistas en contextos de aprendizaje reales, que contribuyesen a la trasformación social y al bienestar de la comunidad. Al tiempo, perseguía promover una relación ética y moral de los estudiantes con el entorno. Este proyecto de aprendizaje-servicio (en adelante ApS) se fundamenta en la esencial relevancia que tienen en la formación de futuros y futuras profesionales de la educación competencias como: la innovación docente, la responsabilidad social universitaria, la calidad académica y la ética (Pérez-Gómez, 1993). A lo largo de los tres años de recorrido del proyecto, en el que se han implicado más de trescientos estudiantes de primer y segundo curso de los Grados de Educación y veinte profesores y profesoras, se ha podido constatar la motivación y el sentido del aprendizaje que representa el ApS, acercando a futuros maestros y maestras a escenarios reales donde observar y aplicar los aprendizajes teóricos de las asignaturas implicadas.

Desde la Sociología, más específicamente, los objetivos se orientaron a identificar situaciones de desigualdad en el contexto escolar y reflexionar sobre ellas; analizar el impacto que la educación tiene en la sociedad y viceversa e identificar los procesos sociales que están influyendo. Todo ello desde un aprendizaje de doble flujo: académico y vivencial. De ahí que la adquisición de competencias y contenidos de Sociología, así como el desarrollo de destrezas asociadas a los fundamentos del pensamiento y la acción sociológica centren el interés de nuestro estudio.

La metodología ApS, tras un proceso de desarrollo y consolidación (Tapia, 2008), llega a nuestros días con una relativa institucionalización, como demuestran tanto las numerosas redes nacionales e internacionales, extendidas en los distintos continentes, como los congresos, eventos y publicaciones específicas. Furco (2004) indica la existencia de más de doscientas definiciones diferentes de ApS publicadas tan solo en inglés y Tapia (2014) identifica como ApS aquellas prácticas que reúnen simultáneamente al menos tres de las siguientes características: la prestación de un servicio solidario a la comunidad, el protagonismo de los propios estudiantes en la ejecución del proyecto, una clara articulación de las actividades solidarias con el aprendizaje y la aplicación de saberes y competencias curriculares explícitas.

De este modo, el potencial renovador del ApS ha empezado a dejar huella también en la docencia universitaria, dotándola de un modelo educativo que combina la formación de profesionales de calidad y de ciudadanos activos, capaces de contribuir a la mejora y transformación de la sociedad. A su apuesta por una formación académica de calidad, que vaya más allá de aprender contenidos y desarrollar competencias, incorpora la preocupación por formar al estudiante en un contexto social y real, capacitándolo para analizar el impacto social, ético y ciudadano que su ejercicio comporta (Rubio \& Escofet, 2017, p. 20; Gutiérrez \& Moreno, 2018). Así mismo, se plantea como una metodología idónea para trabajar las competencias (Ferrán-Zubillaga \& Guinot-Viciano, 2012).

El trabajo que aquí se presenta focaliza su atención en dos aspectos esenciales: la contribución de la Sociología a la formación inicial del profesorado y su interrelación con el ApS. Se trata de una aportación de gran originalidad y relevancia, pues son escasas las aportaciones en este ámbito.

El objetivo general ha sido conocer la percepción de los estudiantes del Grado en Maestro 
de la UCLM sobre las contribuciones del ApS a su formación inicial docente, partiendo de las competencias y aprendizajes profesionales que maestras y maestros deberán enfrentar en el futuro. Más concretamente, se investigaron los siguientes ámbitos: (1) su percepción sobre la aportación de la metodología ApS al aprendizaje de la Sociología de la Educación; (2) en qué medida percibían que las destrezas que trabaja la metodología ApS pueden favorecer la adquisición de competencias del Grado de Maestro, (en concreto, las relativas a trabajo en equipo y el desarrollo de habilidades personales y profesionales); (3) los sentimientos asociados a su experiencia ApS y (4) la satisfacción general de los estudiantes con el proyecto ApS.

Si bien la Sociología tiene una presencia periférica en los planes de estudio de los actuales Grados de Educación, son muchos los análisis y especialistas que destacan su valiosa aportación a la formación docente (McNamara,1972; Daine \& Foster, 1976, en Loubet-Orozco, 2018, p. 9; Perrenoud, 2002; Guerrero-Serón, 2007; Venegas, 2012). Las voces que ayer (Dewey) y hoy defienden la pertinencia de la Sociología y, en particular de la Sociología de la Educación, coinciden en la actitud crítica y reflexiva que esta infunde en el alumnado de magisterio. Guerrero Serón (2007) llegó a plantear la formación del profesorado como destino natural de la Sociología de la Educación, un saber imprescindible que dota al alumnado "de los instrumentos teóricos y de análisis que le permitan comprender y actuar sobre el contexto social donde se están formando y donde van a desarrollar su trabajo" (p. 10).

El propósito principal de las asignaturas de Sociología es comprender la interrelación escuela-sociedad, prestando especial atención a las variables básicas de la desigualdad social: clase, género y etnia, como se demanda en la normativa que regula los planes de estudio de maestro. Desde este propósito, la "imaginación sociológica" (Mills, 1959) es considerada una cualidad esencial. A ella tenemos acceso todas las personas, permitiéndonos tomar conciencia de que nuestra manera de pensar y actuar indivi- dualmente está condicionada por la posición que ocupamos en la sociedad (Obiol i Francés et al., 2019 , p. 1086). En efecto, se trata - como plantean estos autores- de una competencia básica en la formación de futuras maestras y maestros, en la medida en que contribuye a formar docentes reflexivos y críticos.

En los Grados de Maestro, las asignaturas de Sociología suelen ubicarse en los primeros cursos, como parte de la formación básica, enmarcándose en un módulo de competencias denominado "Sociedad, familia y escuela". En los planes de estudios de la UCLM, este módulo se concreta en dos asignaturas de seis créditos cada una, denominadas "Sociología de la Educación" y "Educación y Sociedad", impartidas en primer y segundo curso respectivamente. Destacamos las siguientes competencias relacionadas con esta materia: 1) relacionar la educación con el medio; 2) analizar e incorporar de forma crítica las cuestiones más relevantes de la sociedad actual que afectan a la educación familiar y escolar, destacando el impacto social y educativo de los lenguajes audiovisuales y de las pantallas, los cambios en las relaciones de género e intergeneracionales, la multiculturalidad e interculturalidad, la discriminación e inclusión social y el desarrollo sostenible; 3) conocer la evolución histórica de la familia, los diferentes tipos de familias, de estilos de vida y educación en el contexto familiar.

Las competencias que se fijan para los títulos de Grado de Maestro emanan de diversas normativas. El Real Decreto de 2007, que regula la ordenación de las enseñanzas universitarias oficiales, establece que:

La formación en cualquier actividad profesional debe contribuir al conocimiento y desarrollo de los Derechos Humanos, los principios democráticos, de igualdad entre mujeres y hombres, de solidaridad, de protección medioambiental, de accesibilidad universal y de fomento de la cultura de la paz. (art. 3)

La Orden ECI/3857/2007 del 27 de diciembre, por la que se establecen los requisitos para la 
verificación de los títulos universitarios oficiales que habiliten para el ejercicio de la profesión de Maestro en Educación Primaria, plantea la necesidad de "regular espacios de aprendizaje respetuosos con los Derechos Humanos, colaborar con la comunidad educativa para fomentar la educación para una ciudadanía activa y fomentar la responsabilidad hacia un futuro sostenible" (art. 3). Para Educación Infantil, la Orden ECI/3854/2007 también incluye, entre otros aspectos, el "desarrollo de la competencia orientada a la reflexión en grupo, aceptación de normas y respeto a los demás" (art. 3).
El ApS, al conjugar en los estudiantes el aprendizaje académico con la prestación de un servicio a la comunidad orientado a su transformación y mejora, constituye una metodología ideal para desarrollar las competencias anteriores. Pero ¿en qué medida la participación en los proyectos ApS favorece el desarrollo de las competencias del Grado. La tabla 1, pone de manifiesto la intensa relación que existe entre las competencias de los títulos de Grado de Maestro y, más específicamente, de la materia de Sociología de la Educación, con la metodología ApS en Educación Primaria.

Tabla 1. Competencias de los títulos de Grado de Maestro relacionadas con el ApS y la materia de Sociología

\begin{tabular}{|c|c|c|}
\hline $\begin{array}{l}\text { Principios que deben inspirar los } \\
\text { títulos universitarios. } \\
\text { RD } 1393 / 2007 \text {, art. } 3.5\end{array}$ & $\begin{array}{c}\text { Competencias generales que los } \\
\text { estudiantes deben adquirir } \\
\text { (relacionadas con el ApS). } \\
\text { Orden ECI/3857/2007, Anexo, } \\
\text { Apartado 3 }\end{array}$ & $\begin{array}{c}\text { Competencias del módulo } \\
\text { Sociedad, familia y escuela } \\
\text { (relacionadas con la Sociología } \\
\text { y el proyecto ApS). } \\
\text { Orden ECI/3857/2007, Anexo, Apar- } \\
\text { tado } 5\end{array}$ \\
\hline $\begin{array}{l}\text { Respetar los derechos fundamen- } \\
\text { tales y de igualdad entre hombres } \\
\text { y mujeres. } \\
\text { - Promover los Derechos Humanos } \\
\text { y los principios de accesibilidad } \\
\text { universal. } \\
\text { - Contribuir a los valores propios de } \\
\text { una cultura de paz y de valores } \\
\text { democráticos. }\end{array}$ & $\begin{array}{l}\text { Diseñar y regular espacios de } \\
\text { aprendizaje en contextos de di- } \\
\text { versidad y que atiendan a la igual- } \\
\text { dad de género, a la equidad y al } \\
\text { respeto a los derechos humanos } \\
\text { que conforman los valores de la } \\
\text { formación ciudadana. } \\
\text { - Colaborar con los distintos sec- } \\
\text { tores de la comunidad educativa } \\
\text { y del entorno social. Asumir la di- } \\
\text { mensión educadora de la función } \\
\text { docente y fomentar la educación } \\
\text { democrática para una ciudadanía } \\
\text { activa. } \\
\text { Valorar la responsabilidad indivi- } \\
\text { dual y colectiva en la consecución } \\
\text { de un futuro sostenible. }\end{array}$ & $\begin{array}{l}\text { - Relacionar la educación con el medio } \\
\text { - Cooperar con las familias y la } \\
\text { comunidad. } \\
\text { - Analizar e incorporar de forma críti- } \\
\text { ca las cuestiones más relevantes de } \\
\text { la sociedad actual que afectan a la } \\
\text { educación familiar y escolar: impacto } \\
\text { social y educativo de los lenguajes } \\
\text { audiovisuales y de las pantallas; cam- } \\
\text { bios en las relaciones de género e } \\
\text { intergeneracionales; multiculturalidad } \\
\text { e interculturalidad; discriminación e } \\
\text { inclusión social y desarrollo sostenible }\end{array}$ \\
\hline
\end{tabular}

Fuente: Elaboración propia a partir de la ORDEN ECI/3857/2007, del 27 de diciembre y el Real Decreto 1393/2007, del 29 de octubre.

Nuestro desempeño formativo desde la Sociología persigue situar al alumnado en los procesos educativos y ante los retos que deberá enfrentar en su futuro profesional (Trottier \& Lessard, 2002, citados en Venegas, 2012, p. 407). Este propósito se pone a prueba, en particular, en la asignatura Educación y Sociedad, impartida en el segundo curso de las titulaciones estudiadas. En su desarrollo curricular, la materia de Sociología introduce a los estudiantes en los principios básicos de la investigación social, familiarizándolos con los principios metodológicos, enfoques, categorías y técnicas más usuales en la indagación educativa. En conexión con este 
aprendizaje exploratorio, se recorren cuestiones sociales de actualidad relacionadas con el ámbito educativo y familiar, se presentan ejemplos de estudios concretos, buscando mostrar a los estudiantes el equilibrio entre la investigación y su aplicación profesional. De ahí que los proyectos ApS desarrollados comprendiesen una gran diversidad de actuaciones, orientadas a dar respuesta a las demandas planteadas por los colegios colaboradores: apoyo a la lectoescritura en castellano e inglés, dinamización de recreos, patios inclusivos, grupos interactivos, promoción de la igualdad, apoyo escolar, educación saludable, dinamización de la biblioteca, cuentacuentos, etc.

De este modo, un frente de aprendizaje para los y las estudiantes que han participado en experiencias de ApS, ha sido el descubrimiento (o la toma de conciencia) del peso de las creencias, prejuicios o preconcepciones que, como docentes o educadores, construimos en torno al alumnado con el que trabajamos. Enfrentarse en la práctica con la meritocracia del pensamiento docente y sus implicaciones como predictores del rendimiento académico, es un aprendizaje necesario para desenmascarar la construcción social de estos juicios o representaciones que, como sabemos, el profesorado empieza a interiorizar en la formación inicial (Tarabini, 2015; San Román et al., 2015; López-Gamboa, 2019; Kaplan, 2012; Brozmanová et al., 2016). De ahí su potencial en la formación del profesorado universitario (Álvarez-Castillo et al., 2017).

Es precisamente en este contexto real ofrecido por el ApS donde se sitúa el significado de los conceptos, ideas y teorías que permiten avanzar en la formación del pensamiento práctico del estudiante, "donde ellos (y ellas) construyen recursos de comprensión y actuación como aprendices" (Pérez-Gómez, 2010, p. 48). Más adelante lo confirmaremos, con los resultados más relevantes de la exploración cualitativa realizada, tal y como es expresado por sus protagonistas: los propios estudiantes.

\section{Metodología}

El estudio se ha desarrollado desde un enfoque mixto, al combinar la recogida de datos cuantitativos (a través de cuestionarios online) y cualitativos (mediante las narraciones de experiencias en las memorias presentadas por los estudiantes para la evaluación de la asignatura). La orientación es, por tanto, principalmente descriptiva.

La muestra está configurada por el alumnado universitario de las Facultades de Educación de la UCLM, que cursó las asignaturas de Sociología de la Educación en primer curso y Educación y Sociedad en segundo, del Grado de Maestro en Educación Primaria, en los cursos académicos 2018/2019 y 2019/2020.

Los cuestionarios se dirigieron a estudiantes de primer curso, mientras que las memorias reflexivas se plantearon al alumnado de segundo, con más recorrido en la materia de Sociología.

En relación con el cuestionario, se invitó a participar a todos los estudiantes implicados en el proyecto ApS a través de la plataforma Moodle de las asignaturas (Campus Virtual UCLM), alcanzando un porcentaje de respuesta del $47 \%$ (117 estudiantes).

La muestra escogida para el análisis cualitativo de las memorias ha sido intencional, seleccionando aquellas centradas en los contenidos que mejor se ajustaban a los objetivos de la investigación. Se han analizado las memorias de cincuenta estudiantes. ${ }^{1}$

Tabla 2. Muestra del estudio. Estudiantes del Grado en Maestro en Educación Primaria e Infantil de la UCLM

\begin{tabular}{|l|r|}
\hline Cuestionario online & 117 \\
\hline Narraciones reflexivas & 50 \\
\hline Total & $\mathbf{1 6 7}$ \\
\hline
\end{tabular}

Fuente: Elaboración propia a partir de datos del estudio. 
En el diseño del cuestionario, se tomaron como referencia estudios previos (Capella et al., 2014; Campo, 2015; Folgueiras et al., 2013). Estaba compuesto por 21 preguntas, dirigidas a recoger información relativa a cuestiones organizativas, trabajo en grupo, implicación, relación con la asignatura y opinión sobre aspectos ligados a ella, junto a la percepción sobre sentimientos vividos y satisfacción con el proyecto ApS, utilizando una escala de valoración tipo Likert de 5 puntos (siendo 1 muy poco y 5 mucho).

En cuanto a la aportación cualitativa de las producciones escritas por el alumnado participante, el uso de las memorias o portafolios reflexivos, entre otras modalidades evaluativas, son técnicas habituales en investigaciones similares (Folgueiras, 2017; Loubet-Orozco, 2018). Se buscaba recabar percepciones y vivencias que complementasen el análisis cuantitativo y permitiesen profundizar en los aspectos de interés. Como veremos a continuación, en los testimonios seleccionados como apoyo a los resulta- dos del cuestionario, los estudiantes reflexionan sobre la experiencia personal vivida (individual y grupal), toman conciencia de las situaciones y contextos sociales observados e identifican los aprendizajes académicos (teórico-prácticos) movilizados en el marco de la asignatura Educación y Sociedad. Son, por tanto, tres ejes fundamentales que conjugan las percepciones de los estudiantes con el pensamiento teórico y con la práctica.

El análisis de los datos del cuestionario se realizó mediante el programa SPSS Statistics 24. Para el análisis cualitativo, tras el diseño de categorías, se utilizó el programa Atlas.ti 8.

\section{Resultados}

Una de las primeras cuestiones planteadas en este estudio fue en qué medida los y las estudiantes percibían la conexión entre el desarrollo del proyecto y los contenidos de la asignatura de Sociología de la Educación.

Figura 1. Valoración de la relación del ApS con la asignatura según el alumnado

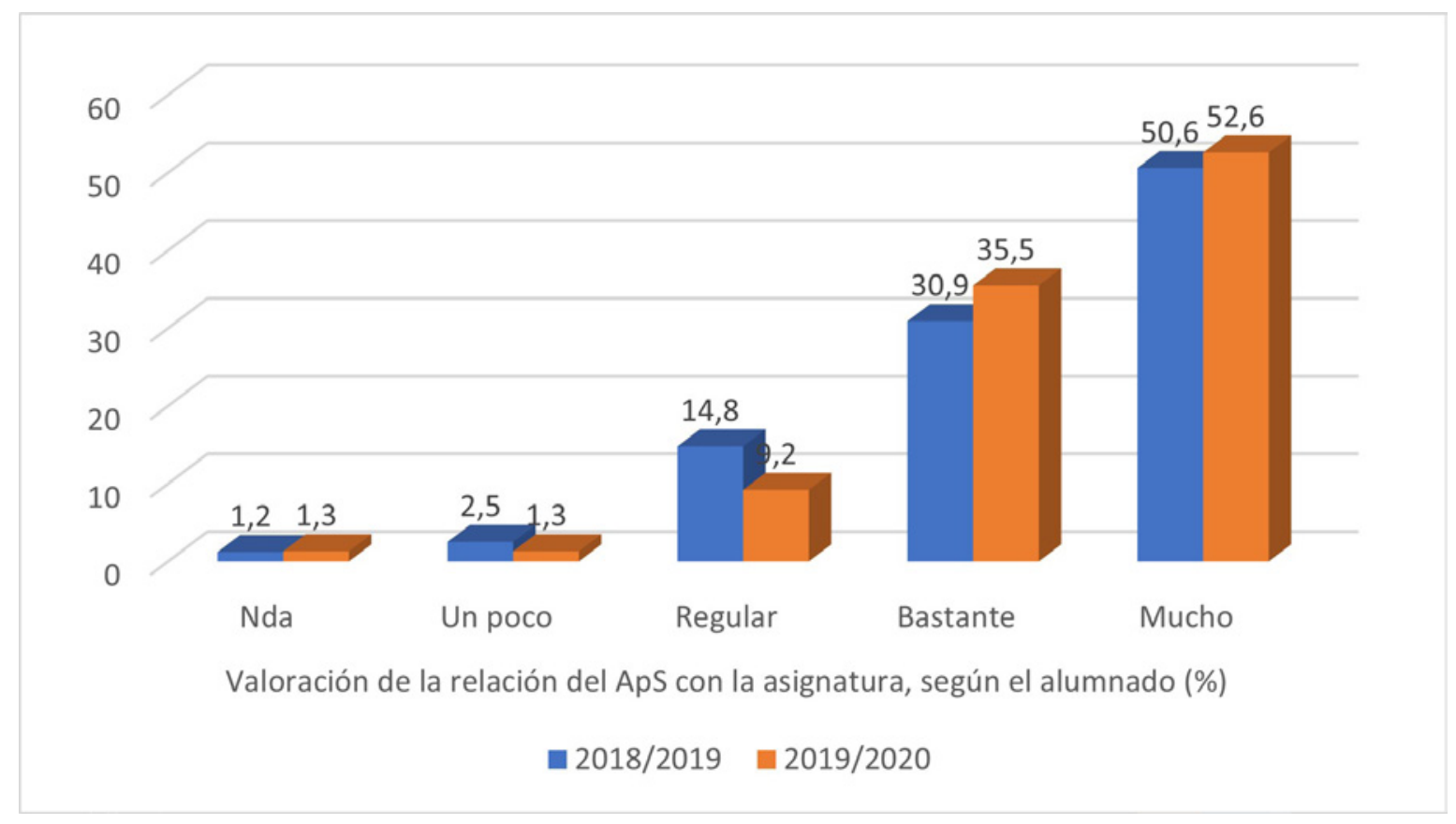

Fuente: Milla (2020, p. 18) 
La figura 1 nos muestra la elevada relación entre ambas percibidas por los estudiantes, situándose más del 50\% en la valoración más altas (5). La valoración media sobre este aspecto en el curso 2018/2019 es de 4,27 sobre 5 (DT: 0,895), incrementándose levemente en el curso 2019/2020 (media: 4,37; DT: 0,814).
Los estudiantes manifiestan que su experiencia ApS les ha ayudado a entender mejor los contenidos de la asignatura (media: 3,93; D.T.: $1,024) \mathrm{y}$, especialmente, a encontrar una mayor relación de la teoría con la práctica de la asignatura (media 4,14; D.T.: 0,989 ) y con la vida cotidiana (media 4,43; D.T.: 0,869).

\section{Figura 2. Relación del ApS con la teoría, con la vida cotidiana y con los contenidos. Curso 2019/2020}

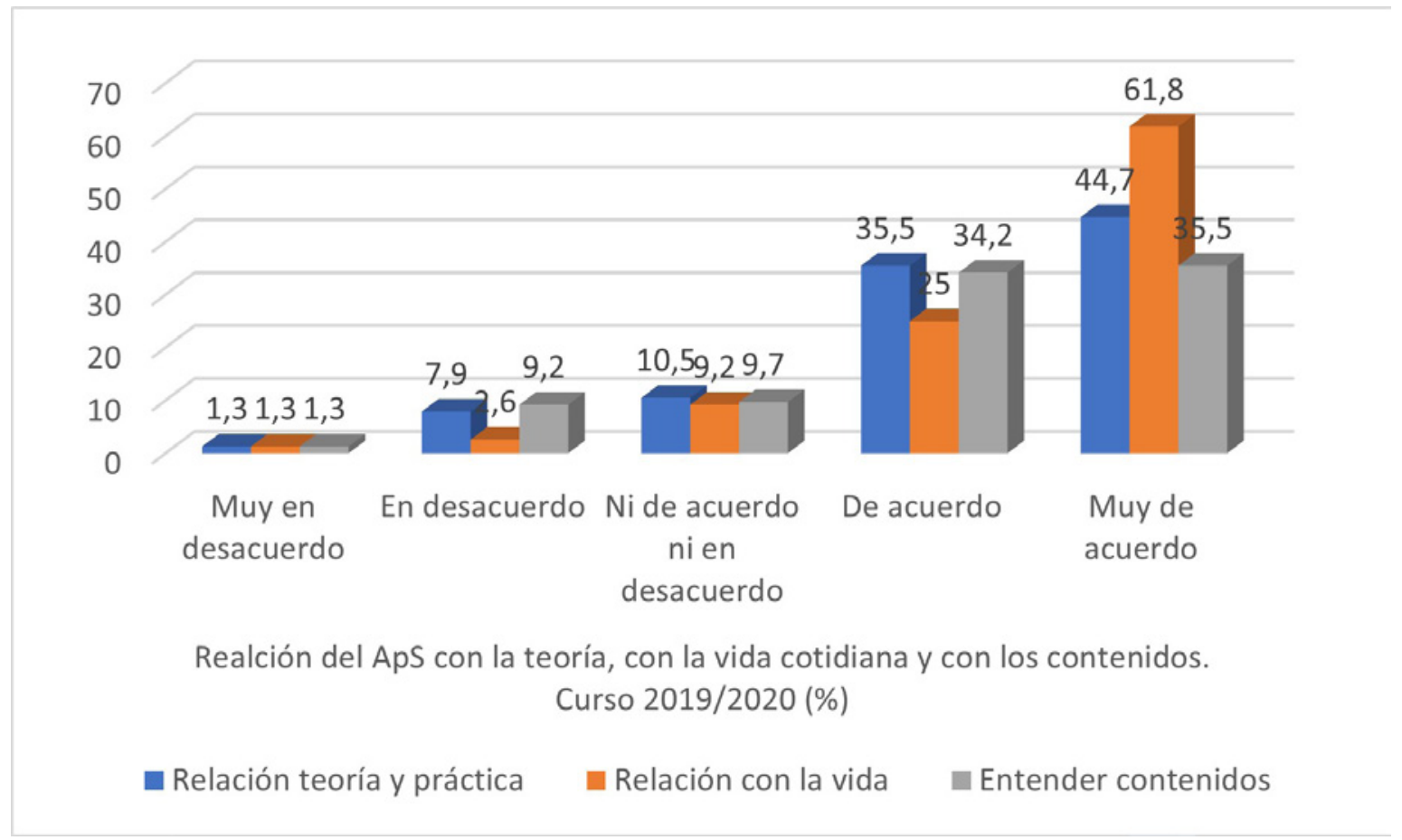

Fuente: Milla (2020, p. 18).

Del mismo modo, los resultados de la exploración cualitativa muestran la eficacia de la experiencia en la identificación y comprensión de los problemas sociológicos, a partir de la observación de situaciones reales en el contexto escolar. El encuentro con las desigualdades sociales, la diversidad cultural y la desigualdad de género, tiene un lugar destacado en las reflexiones de las estudiantes:

Hemos visto niños y familias con situaciones difíciles sociales y económicas, ya que hay un gran número de alumnado refugiado inmigrante. Esto me ha hecho ver la vida desde otra perspectiva, tenemos que ir a los retos para poder tratar las necesidades que se presentan y no acomodarnos, ya que todos y todas tienen derecho a ser educados. (M-4)

En el caso de la cultura gitana, la experiencia que he vivido en el ApS me ha sorprendido y tengo que reconocer que me ha servido para aclarar ciertos aspectos sobre su forma de vivir la vida, su educación y su cultura en general. La sociedad les pone reglas muy estrictas y como personas, debemos de ser capaces de priorizar el interior de nuestros iguales y dar oportunidad de conocer las vivencias de cada persona. (M-13) 
(...) haber trabajo con niños y niñas de etnia gitana, y ver que son como cualquier crío de su edad, con la misma imaginación, creatividad y capacidad de aprender. (M-18)

Observamos que el sexismo está muy presente en el aula, y es que las niñas no querían relacionarse con un niño que se les acercaba porque decían que era chico. Yo intenté mediar haciéndoles ver que no tenían por qué discriminarlo por el hecho de ser un chico, que todos eran iguales, independientemente del sexo. (M-22)

Observamos así, a partir de los testimonios recogidos, que las situaciones vivenciadas en la implementación de los proyectos de ApS han favorecido la práctica reflexiva como herramienta de trabajo docente en el aula. Cabe recordar que esta metodología se ha teorizado y difundido como modelo formativo de capacitación de los profesionales docentes (Domingo, 2013; LupiónCobos \& Gallego-García, 2017) y para el cambio educativo (Mayor \& Rodríguez, 2016).

La experiencia nos ha aportado conocimientos desde varias perspectivas para desarrollar nuestro pensamiento crítico, abstracto, reflexivo e innovador, para entender qué está ocurriendo dentro y fuera de la escuela. Nos ha servido para relacionar conceptos, aprender nuevas metodologías, taxonomías relativas a los procesos de aprendizaje y las habilidades cognitivas, la evaluación y las necesidades de cambio en el ámbito educativo... (M-9)

El patio es un espacio esencial en el contexto escolar y, especialmente, en la Educación Infantil. El tiempo de recreo es el momento en el que los niños y niñas disponen de más libertad para jugar, explorar, moverse y relacionarse con sus iguales. Esto lo hemos visto y lo hemos comprendido con la actividad de recreos activos del ApS. (M-27)

Otra muestra del valor del proyecto ApS en la formación del alumnado se muestran en las altas puntuaciones que arrojan las respuestas de los estudiantes, cuando son preguntados por la posibilidad de incluir esta metodología en otras asignaturas. Un $81,6 \%$ se manifiesta muy de acuerdo (media 4,75, D.T.: 0,635), ya que con esta experiencia han visto reforzada su vocación (73,7\% muy de acuerdo, media 4,58; D.T.: 0,868).

Gracias al desarrollo de la actividad ApS, los estudiantes perciben un desarrollo del propio conocimiento, conectando aprendizajes previos con nuevos contenidos (media 4,41; D.T.: 0,836 ), una mayor motivación hacia la asignatura $(76,3 \%$ de acuerdo o muy de acuerdo; media 4,04; D.T.: $0,916) \mathrm{y}$, en menor medida, un aumento de su atención (media 3,71; D.T.: 1,056).

Respecto al desarrollo de competencias vinculadas a la experiencia de ApS, las valoraciones son también altas, tanto las referidas a las competencias profesionales $(57,9 \%$ muy de acuerdo; media 4,37; D.T.: 0,877) como a las competencias transversales (53,9\% está muy de acuerdo, media 4,30 y D.T.: 0,924).

Casi el 54\% de los encuestados creen que no habrían aprendido más si el tiempo invertido en realizar ApS, se hubiese dedicado a dar clases en el aula.

Otros aspectos de gran relevancia son la valoración que realizan acerca de la contribución del ApS en la comprensión de su rol como futuros docentes (media 4,50; D.T.: 0,887) y la adquisición de conocimientos sobre cómo funciona un centro educativo (media 4,47; D.T.: 0,774).

En definitiva, se destaca la utilidad de la experiencia ApS en su formación como maestro/ maestra, otorgándole una valoración media de 4,71 sobre 5 (D.T.: 0,670 ) y que queda reflejada en estas palabras, expresadas por una estudiante:

(...) el papel del docente no se limita a impartir conocimientos a sus alumnas y alumnos, sino que va mucho más allá del ámbito educativo, ya que tiene que ejercer como guía y mediador en muchas ocasiones en situaciones conflictivas o complejas... no siempre en un contexto favorable. Es entonces cuando la escuela debe de actuar y proporcionarle al estudiante los medios que sean necesarios para facilitarle al máximo su situación y poner en práctica todas 
las técnicas y herramientas posibles para que la situación cambie a mejor. (M-4)

Dando un paso más, nos planteamos profundizar en las aportaciones del proyecto ApS a la adquisición de competencias profesionales concretas: las relativas al trabajo en equipo y al desarrollo de habilidades personales. Se observa que son aspectos muy bien valorados por la mayoría de los alumnos y que, además, muestran una correlación positiva con la satisfacción global con el proyecto ApS.

Cabe afirmar que parte del éxito en el desarrollo de estas actividades está relacionado con el buen funcionamiento del trabajo en grupo que destacan los alumnos (media 4,59, D.T.: $0,677)$ y que arroja una correlación significativa con la satisfacción expresada (bilateral al 0,$01 ; \mathrm{r}^{2}$ : $0,252)$. Las valoraciones volcadas en las memorias por las estudiantes protagonistas subrayan también la cooperación y el trabajo en equipo como una de las enseñanzas adquiridas:

Todos los días estuvimos trabajando de manera cooperativa en grupo. Eso provocó y facilitó que la propuesta que planteamos para el Aprendizaje y Servicio fuera más eficaz, dinámica, motivadora y productiva. (M-31)

Gracias al ApS ha sido una materia muy práctica y reflexiva, aprendiendo por nosotras mis- mas, desde nuestros errores, autoevaluarnos siendo críticas, además de aprender a trabajar en equipo y aumentar la creatividad. (M-11)

Como se viene afirmando, la evaluación muestra que la participación en estos proyectos favorece su formación en conocimientos necesarios para su futuro profesional. Tal y como destaca Uribe (2018), este es uno de los aspectos fundamentales que se derivan de la realización de actividades de este tipo. Concretamente, el ApS, beneficia la formación como docentes, relacionando su aprendizaje con la vida, desarrollando su propia competencia emocional (IbarrolaGarcía \& Artcuh, 2016; García \& Sánchez, 2017) y reforzando, en consecuencia, su vocación.

Parte de esos aprendizajes provienen del desarrollo de competencias vinculadas a sus habilidades personales. Preguntados los estudiantes por las percepciones emocionales en el desarrollo de su experiencia ApS, la mayoría manifiestan haberse sentido muy interesados, ilusionados, satisfechos, activos, entusiasmados, concentrados, despiertos, inspirados y fuertes.

En menor medida habían sentido nerviosismo y otorgan las puntuaciones medias más bajas a emociones "negativas", como irritabilidad, miedo, angustia, etc. La siguiente tabla muestra una ordenación de las valoraciones otorgadas a cada sentimiento.

Tabla 3. Valoración de los sentimientos en los participantes del ApS. Curso 2019/2020

\begin{tabular}{|c|c|c|}
\hline Ítem & Media (1-5) & D.T. \\
\hline Interesado & 4,78 & 0,479 \\
\hline Ilusionado & 4,7 & 0,589 \\
\hline Satisfecho & 4,57 & 0,806 \\
\hline Activo & 4,54 & 0,642 \\
\hline Entusiasmado & 4,47 & 0,856 \\
\hline Concentrado & 4,29 & 0,780 \\
\hline Despierto & 4,11 & 0,918 \\
\hline Decidido & 4,01 & 0,902 \\
\hline
\end{tabular}




\begin{tabular}{|c|c|c|}
\hline Ítem & Media (1-5) & D.T. \\
\hline Inspirado & 4 & 1,143 \\
\hline Fuerte & 3,93 & 0,971 \\
\hline Nervioso & 2,33 & 1,076 \\
\hline Afectado & 1,76 & 1,082 \\
\hline Agitado & 1,64 & 0,919 \\
\hline Asustado & 1,58 & 1,036 \\
\hline Angustiado & 1,46 & 0,807 \\
\hline Miedoso & 1,43 & 0,806 \\
\hline Avergonzado & 1,37 & 0,780 \\
\hline Culpable & 1,28 & 0,704 \\
\hline Irritable & 1,24 & 0,586 \\
\hline Agresivo & 1,12 & 0,431 \\
\hline
\end{tabular}

\section{Fuente: Elaboración propia a partir de datos del estudio.}

Cabe afirmar, por tanto, que esta experiencia resulta ser una fuente de sensaciones positivas, estimulantes y de desarrollo profesional y personal para los estudiantes del Grado en Maestro, nada más comenzar su andadura universitaria. Ese primer contacto con la realidad educativa en el comienzo de su vida universitaria supone para el alumnado una experiencia remarcable (Milla, 2020).

Todo ello lleva, como no podía ser de otro modo, a una elevada satisfacción general con el proyecto ApS. Un 60,5\% de los estudiantes en el curso 2028-19 otorgan la máxima puntuación a esta cuestión (media: 4,43; DT: 0,805), incrementándose hasta un 73,7\% en el curso 2019-20 (media 4,67; D.T.: 0,619).

En un análisis por género, no se han encontrado diferencias estadísticamente significativas en la satisfacción expresada (prueba de Kolmogorov-Smirnov: p: 439; tamaño del efecto: d Cohen: 0,18), si bien que son muchas las alumnas que hacen explícita esa satisfacción en sus discursos de "Educación y Sociedad" del Grado de Educación Infantil, donde todas las participantes son mujeres:
El APS me ha ayudado para conocerme a mí misma y saber qué cosas tengo que mejorar en mí a la hora de ser docente. (M-23)

Esta experiencia ha sido muy gratificante, no solamente hemos aprendido, sino que también hemos podido ayudar. (M-11)

(...) considero un enriquecimiento profesional esta experiencia y una gran satisfacción por ayudar (...). (M-4).

\section{Discusión y conclusiones}

Nuestros hallazgos de investigación han mostrado las posibilidades metodológicas del ApS en el ámbito de la formación inicial del profesorado, combinando aprendizaje de contenidos académicos con la prestación de un servicio a la comunidad. Pero el ApS es también una filosofía educativa que entronca con la dimensión transformadora de la educación que propugna toda la pedagogía crítica. En este sentido es donde hemos percibido el mayor calado de las aportaciones.

El análisis de las valoraciones de los y las estudiantes de magisterio revela la elevada satis- 
facción y la conexión de la experiencia formativa con las competencias curriculares y objetivos de aprendizaje de las asignaturas de Sociología. Observamos con ello la influencia positiva del ApS para reforzar y enriquecer el papel de la Sociología en la formación docente, un reto que perseguimos desde nuestra área de conocimiento y desde las Facultades de Educación.

En coincidencia con otros estudios que apuestan por extender el ApS en el ámbito universitario (Esparza et al., 2018), destacamos el impacto positivo de nuestra experiencia en los distintos colectivos implicados. Centrándonos en nuestros estudiantes, han aumentado su motivación, al contextualizar sus aprendizajes académicos y al haber podido utilizarlos para servir a la comunidad. Las clases de la Facultad se han hecho más dinámicas y participativas gracias a su implicación en el proyecto. Los colegios de infantil y primaria han podido cubrir algunas de sus necesidades, redundando en beneficio de los niños y niñas escolarizados. Por tanto, las Facultades de Educación han aumentado su impacto social en el entorno, contribuyendo al ejercicio de la responsabilidad social de la universidad.

La necesidad de promover sinergias entre todos los recursos educativos disponibles en la comunidad fue puesta de manifiesto en los informes internacionales sobre educación, como el de Coombs (1968), Faure (1973) o Delors (1996). En esta línea se han ido configurando diferentes propuestas educativas, como las Ciudades Educadoras, las Comunidades de Aprendizaje, los Planes Educativos de Entorno y las Redes Educativas Locales, el Proyecto Atlántida, etc. (Mayor-Paredes \& Rodríguez-Mar, 2015). El ApS viene a sumarse a esa lista, pero con la particularidad de permitir a los estudiantes universitarios ser verdaderos protagonistas.

Por último, cabe añadir la percepción de las profesoras del Área de Sociología que hemos liderado la implementación de los proyectos de ApS, coincidiendo en que la experiencia ha mejorado la difícil coordinación docente que existe en asignaturas compartidas (como Educación y Sociedad), sincronizando estilos y estrategias docentes que promueven el desarrollo de las competencias propuestas en el grado. En este sentido, los avances mostrados representan un avance significativo que habrá que investigar de manera sostenida en el futuro, preguntándonos si el ApS puede mejorar las estrategias didácticas, la motivación y evaluación del estudiantado universitario, estimulando la renovación y creatividad que necesita la enseñanza de la Sociología (Feito, 2020). Un desafío que contribuya a sentar las bases de una comunidad de aprendizaje con participación del profesorado y el alumnado.

\section{Nota}

1 Los fragmentos que se incluyen a lo largo del texto se identifican con un código (M-1 a M-50) correspondiente al número asignado a cada memoria reflexiva. Las autoras de estas memorias son estudiantes de $2^{\circ}$ curso del Grado de Maestro de Educación Infantil del Campus de Ciudad Real y responden a un perfil sociodemográfico relativamente homogéneo: mujeres jóvenes, entre 19 y 26 años, que viven en Ciudad Real o su entorno geográfico más próximo.

\section{Referencias bibliográficas}

Álvarez-Castillo, J.L., Martínez-Usarralde, M.J., González-González, H., \& BuenestadoFernández, M. (2017). El aprendizaje-servicio en la formación del profesorado de las universidades españolas. Revista Española de Pedagogía, 75(267), 199-217. http://doi.org/10.22550/REP75-2-2017-02

Brozmanová, A., Heinzová, Z., \& Chovancová, K. (2016). The Impact of Service-Learning on Students' Key Competences. The International Journal of Research on ServiceLearning and Community Engagement, 4(1), 367-276. https://bit.ly/3gDcFV1

Campo, L. (2015). Evaluar para mejorar los proyectos de aprendizaje servicio en la universidad. RIDAS, Revista Iberoamericana de Aprendizaje y Servicio, 1, 91-111. http://doi.org/10.1344/RIDAS2015.1.6

Capella, C., Gil, J., \& Martí, M. (2014). La metodología del Aprendizaje-Servicio en la Educación Física. Apunts. Educación Física y Deportes, 116(2), 33-43. 
https://doi.org/10.5672/apunts.2014-0983.es.

Coombs, P.H. (1968). La crisis mundial de la educación. Península.

Delors, J. (1996). La educación encierra un tesoro. Santillana.

Domingo, A. (2013). Práctica reflexiva para docentes. De la reflexión ocasional a la reflexión metodológica. Publicia.

Esparza, M., Morín, V., \& Rubio, L. (2018). La incorporación del aprendizaje-servicio en la universidad: La experiencia de la Universidad de Barcelona. RIDAS, Revista Iberoamericana de Aprendizaje Servicio, 6, 103-114. https://doi.org/10.1344/RIDAS2018.6.10

Faure, E. (1973). Aprender a ser. La educación del futuro. Alianza Editorial.

Feito, R. (2020). La difícil coordinación en la enseñanza de la Sociología. Revista Española de Sociología, 29(2), 401-409. https://doi.org/10.22325/fes/res.2020.23

Ferrán-Zubillaga, A., \& Guinot-Viciano, C. (2012). Aprendizaje-servicio: propuesta metodológica para trabajar competencias. Portularia, (12), 187-195.

http://doi.org/10.5218/prts.2012.0020

Folgueiras, P. (2017). Evaluación y actividades de aprendizaje en los proyectos de aprendizajeservicio. En L. Rubio y A. Escofet (Coords.), Aprendizaje-Servicio (ApS): Claves para su desarrollo en la Universidad (pp. 97-110). Octaedro.

Folgueiras, P., Luna, E., \& Puig, G. (2013). Service learning: Study of the degree of satisfaction of university students. Revista de Educación, (362), 159-185.

http://doi.org/10.4438/1988-592X-RE-2011-362-157

Furco, A. (2004). Impacto de los proyectos de aprendizaje-servicio. En Aprendizaje y servicio solidario en la Educación Superior y en los sistemas educativos latinoamericanos. Actas del $7 \mathrm{mo}$. Seminario Internacional "Aprendizaje y Servicio Solidario". Buenos Aires, 6 y 7 de octubre de 2004.

García-García M., \& Sánchez-Calleja, L. (2017). El aprendizaje servicio y el desarrollo de las competencias emocionales en la formación inicial del profesorado. Contextos Educativos. Revista de Educación, 20, 127-145. https://doi.org/10.18172/con.2991
Guerrero-Serón, A. (2007). La doble contribución de la sociología a la formación del profesorado, Revista Internacional de Sociología, 65(48), 203-220. https://doi.org/10.3989/ris.2007.i48.74

Gutiérrez, M., \& Moreno, P. (2018). El aprendizaje servicio como metodología para la formación integral de los estudiantes universitarios. Edetania. Estudios y propuestas socioeducativas, (53), 185-202. https://bit.ly/3b5NedG

Ibarrola-García, S., \& Artuch, R. (2016). La docencia en la universidad y el compromiso social y educativo. Contextos educativos: Revista de educación 19, 105-120. https://doi.org/10.18172/con.2763

Kaplan, C.V. (2012). Mirada social, exclusión simbólica y autoestigmación: Experiencias subjetivas de jóvenes de educación secundaria. En C.V. Kaplan, L. Krotsch y V. Orce, Con ojos de joven: Relaciones entre desigualdad, violencia y condición estudiantil (pp.15-78). Facultad de Filosofía y Letras de la Universidad de Buenos Aires.

López-Gamboa, G.E. (2019). Representaciones sociales de estudiantes de Magisterio acerca del éxito y el fracaso escolar: Una investigación en las escuelas normales del Estado de Yucatán. (Tesis doctoral). Universidad de Castilla-La Mancha. https://bit.ly/3hEX9ck

Loubet-Orozco L. (2018): Contribución de la sociología en la formación docente. Un ejercicio de intervención en México. Revista de Sociología de la Educación (RASE), 11(1), 5-20. https://doi.org/10.7203/RASE.11.1.10598

Lupión-Cobos, T., \& Gallego-García, M.M. (2017). Compartiendo la mirada: una experiencia en práctica flexiva para formación permanente. Revista Electrónica Interuniversitaria de Formación del Profesorado, 20(1), 127-144. http://doi.org/10.6018/reifop/20.1.244931

Mayor-Paredes, D., \& Rodríguez-Mar, D. (2015). Aprendizaje-Servicio: Construyendo espacios de intersección entre la escuela-comunidad-universidad. Profesorado. Revista de currículum y formación del profesorado, 19(1), 262-279. https://bit.ly/2EBGGY9

Mayor-Paredes, D., \& Rodríguez-Mar, D. (2016). Aprendizaje-servicio y práctica docente: una relación para el cambio educativo. Revista 
de Investigación Educativa, 34(2), 535-552. https://doi.org/10.6018/rie.34.2.231401

Milla-Martínez, L. (2020). El Aprendizaje-Servicio en la formación de futuros docentes: Una experiencia en el grado de Educación Primaria de la Facultad de Educación de Albacete. (Trabajo Fin de Master Universitario de Investigación e Innovación Educativa). Universidad de Castilla-La Mancha. https://bit.ly/32wcaqJ

Mills, C.W. [1959] (1986). La imaginación sociológica. Fondo de Cultura Económica.

Obiol i Francés, S., Beltrán-Llavador, J., Box-Varela, Z., Gabaldón-Estevan, D., Hernàndez-Dobon F., Martínez-Morales, I., \& Martínez-Morales, J.R. (2019). Enseñar Sociología a quienes no estudian Sociología, 1085-1095. V Congreso de Innovación Educativa y Docencia en Red. Universidad Pública de Valencia.

http://dx.doi.org/10.4995/INRED2019.2019.10476

Pérez-Gómez, A.I. (1993). La formación del docente como intelectual comprometido. La tarea de provocar la reconstrucción del conocimiento, Signos. Teoría y práctica de la educación, 8/9, 42-53. https://bit.ly/34HDtBc

Pérez-Gómez, A.I (2010). Aprender a educar. Nuevos desafíos para la formación de docentes. Revista Interuniversitaria de Formación del Profesorado, 68(24,2), 37-60. https://bit.ly/3lkcvFs

Perrenoud, Ph. (2002). La place de la sociologie dans la formation des enseignants: réflexions didactiques. Education et Sociétés, 1/9, 87- 99. https://doi.org/10.3917/es.009.0087
Rubio, L., \& Escofet, A. (Coords.) (2017). AprendizajeServicio (ApS): Claves para su desarrollo en la Universidad. Octaedro.

San Román, S., Vecina, C., Usategui, E., del Valle, A.I., \& Venegas, M. (2015). Representaciones sociales y orientación educativa del profesorado. Education Policy Analysis Archives/ Archivos Analíticos de Políticas Educativas, 23, 1-18. https://doi.org/10.14507/epaa.v23.2088

Tapia, M.N. (2008). Calidad académica y responsabilidad social: el aprendizaje servicio como puente entre dos culturas universitarias. En M. Martínez (Ed.), Aprendizaje servicio y responsabilidad social de las universidades. Octaedro-ICE.

Tapia, M.N. (2014). La aportación del aprendizaje-servicio en el mundo. Cuadernos de Pedagogía, 450, 54-56. https://bit.ly/2G57f8G

Tarabini, A. (2015). La meritocracia en la mente del profesorado: un análisis de los discursos docentes en relación al éxito, fracaso y abandono escolar. Revista de la Asociación de Sociología de la Educación, 8(3), 349-360. https://bit.ly/2Qz3BWp

Uribe, A. (2018). Percepción de los estudiantes de educación inicial frente al desarrollo de experiencias formativas en modalidad $\mathrm{A}+\mathrm{S}$. Revista Electrónica de Investigación Educativa, 20(4), 110-122. http://doi.org/10.24320/redie.2018.20.4.1826

Venegas, M. (2012). Sociología y formación del profesorado: aportaciones y balance en el nuevo paradigma universitario. Educatio Siglo XXI, 30(2), 403-422. https://bit.ly/2DbKdfi 


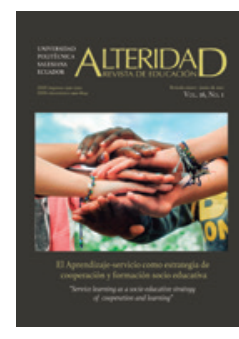

\title{
Metodología de aprendizaje-servicio en un proyecto integrado de costos y marketing
}

\author{
Service-learning methodology in an integrated cost and \\ marketing project
}

Dr. Francisco Ganga-Contreras es docente e investigador de la Universidad de Tarapacá (Chile) (franciscoganga@academicos.uta.cl) (https://orcid.org/0000-0001-9325-6459)

(D) Estela Rodríguez-Quezada es docente e investigadora de la Universidad de Bío-Bío (Chile) (erodrig@ubiobio.cl) (https://orcid.org/0000-0002-3259-0936)

(D) Nataly Guiñez-Cabrera es docente e investigadora de la Universidad de Bío-Bío (Chile) (nguinez@ubiobio.cl) (https://orcid.org/0000-0002-6109-8457)

Recibido: 2020-10-07 / Revisado: 2020-12-09 / Aceptado: 2020-12-14 / Publicado: 2021-01-01

\section{Resumen}

La formación de profesionales competentes, con visión y sello de compromiso con la sociedad, debe ir más allá de los procesos tradicionales de enseñanza, resultando entonces la innovación un factor clave. El aprendizaje-servicio (ApS) es una metodología que integra la enseñanza con el servicio comunitario de los estudiantes en un entorno real. Existen varios desafíos en la implementación de esta metodología activa, teniendo en cuenta las partes interesadas y las necesidades de la comunidad. En este sentido, este estudio busca describir la experiencia en cuanto al diseño, la implementación y la gestión de la metodología de aprendizaje-servicio en un proyecto integrado que contempla dos asignaturas, costos y marketing, en un programa de negocios en una universidad estatal del centro-sur de Chile. El trabajo se sustenta en la sistematización de experiencia, basada en tres fases de implementación dentro de la comunidad: (I) planificación, diseño y análisis, (2) entrega del servicio y, (3) evaluación, reflexión y monitoreo del aprendizajeservicio. Las etapas de diseño, implementación y gestión de un proyecto de estas características podrían servir de guía y orientaciones en futuras experiencias por parte de los profesores o las instituciones que se encuentren interesados en la innovación de los procesos de la enseñanza-aprendizaje.

Descriptores: Aprendizaje-servicio, costos, gestión educativa, gobernanza universitaria, implementación, marketing.

\section{Abstract}

The training of competent professionals, with a vision and stamp of commitment to society, must go beyond traditional teaching processes, with innovation being a key factor. Service-learning (S-L) is a methodology that integrates teaching with the community service of students in a real environment. There are several challenges in implementing this active methodology, taking into account the stakeholders and the needs of the community. In this sense, this study seeks to describe the experience regarding the design, implementation and management of the service-learning methodology in an integrated project that includes two subjects, costs and marketing, in a business program at a state university of the south-central Chile. The work is based on the systematization of experience, based on three phases of implementation within the community: (I) planning, design and analysis, (2) delivery of the service and, (3) evaluation, reflection and monitoring of service-learning. The stages of design, implementation and management of a project of these characteristics could serve as a guide and guidance in future experiences by teachers or institutions that are interested in the innovation of teaching-learning processes.

Keywords: Service-learning, costs, educational management, university governance, implementation, marketing.

Forma sugerida de citar: Ganga-Contreras, F., Rodríguez-Quezada, E., \& Guiñez-Cabrera, N. (2021). Metodología de aprendizaje-servicio en un proyecto integrado de costos y marketing. Alteridad, 16(1), 51-64. https://doi.org/10.17163/alt. v16n1.2021.04 


\section{Introducción}

Las organizaciones enfrentan un escenario caracterizado por profundas mutaciones sociales, políticas y económicas, fenómeno que se ha acrecentado dado el contexto de pandemia que está enfrentando el planeta, variables que generan inseguridades pues se ha incrementado la incertidumbre y obligado a la implantación de nuevos modelos (Ganga-Contreras, 2013; NiñoGonzález \& Linares-Herrera, 2020).

Es evidente que la generación, reproducción y transferencia de conocimientos, se mueve a velocidades impresionantes, en este mundo hipercomplejo y competitivo, vehiculizados por el profuso desarrollo de las tecnologías (GangaContreras et al., 2014; Ganga-Contreras et al., 2019a).

La realidad descrita, coloca el imperativo de ser cada vez más innovadores en la formación de los cuadros profesionales que necesita la comunidad donde se encuentra inserta la respectiva universidad con metodologías innovadoras y multifacéticas (Vidal-Raméntol \& FuertesCamacho, 2013; Sánchez-Marín et al., 2019) y aplicables a múltiples tipos de estudiantes (Puebla-Martínez et al., 2018) con propósitos educativos cada vez más amplios (Domínguez, 2018; Rubio, 2018).

El área de negocios no escapa a esta realidad y, por lo tanto, también se demandan profesionales que tengan una formación integral, con sensibilidad y empatía en el medio que se desenvuelven. En este contexto, nacen nuevas prácticas de hacer ciudadanía, formando a ciudadanos que sean participativos, responsables, y comprometidos con el bien común (Pérez-Galván \& OchoaCervantes, 2017).

Una metodología de enseñanza-aprendizaje que logra alcanzar este propósito es el aprendizaje-servicio (ApS), que intenta conectar de manera real al estudiante con la sociedad (Guiñez-Cabrera et al., 2020). Así, el ApS se ha logrado posicionar como una estrategia de educación profesional, que combina la formación académica y el servicio a la comunidad (GangaContreras et al., 2019b). Por lo tanto, formar ciudadanos críticos significa legitimar un proyecto educativo que se encuentre comprometido con la transformación social (Traver-Martí et al., 2019; Esteves-Fajardo et al., 2020). Como apunta Barrientos-Báez (2016), hoy se cuenta con unas herramientas que permiten que los procesos de aprendizaje sean mucho más personalizados y flexibles, como el mobile learning (AlisesCamacho, 2017) y el concepto de educomunicación (Rodríguez-García, 2017). En este caso concreto, la metodología ApS es un ejemplo del avance en estilos y herramientas de aprendizaje.

Existen varias definiciones de ApS, dependiendo del objetivo de estudio que se quiere lograr; puede entenderse como una experiencia educativa basada en cursos, donde los estudiantes son partícipes de actividades de un servicio organizado que satisfacen las necesidades identificadas de la comunidad (Orozco-Gómez et al., 2016).

La integración del servicio comunitario con el aprendizaje, enriquece los contenidos de los cursos y es evidente que los beneficios del ApS pueden tener un triple impacto positivo: estudiante, comunidad e institución (Al Barwani et al., 2013).

Las experiencias de ApS pueden ofrecer a los estudiantes de negocios una oportunidad para encontrar un sentido de responsabilidad personal, interactuar con la comunidad real, desarrollando mayores habilidades interpersonales, interculturales y sensibilidad ética (Simó-Algado et al., 2013; Carmona-Martínez et al., 2014) experimentando además los retos que regularmente demandan los proyectos reales, como la administración del tiempo, abordaje de las necesidades de los socios comunitarios y la colaboración con compañeros (Seider et al., 2011; Stefaniak, 2015). De este modo, Rodríguez-Izquierdo (2020) muestra que la metodología de enseñanza de ApS influye y mejora el compromiso académico de los estudiantes universitarios, mostrando actitudes más positivas hacia el estudio. 
Por otro lado, las instituciones se benefician del ApS - específicamente las escuelas de negocios- pueden generar contactos y contribuir a la comunidad, mejorando la imagen en el compromiso social, el vínculo con la comunidad y los logros por medio de los servicios comunitarios y la misión de educar a los estudiantes como personas socialmente responsables (Poon et al., 2011).

A su vez, la comunidad se puede beneficiar con esta pedagogía, pues las empresas tienen acceso a apoyos técnicos en materias específicas de administración.

Para este estudio en particular — se entenderá por ApS - aquella metodología pedagógica de enseñanza-aprendizaje basada en una o más asignaturas de un programa académico, que genera múltiples beneficios para todos los actores involucrados. Aunque existe un creciente interés en esta metodología, debido a sus grandes contribuciones, todavía no hay un marco de ejecución generalizado que pueda ser utilizado en cualquier contexto como en un proyecto integrado de dos asignaturas.

Considerando la falta de implementación de este tipo de proyectos en particular, este estudio tiene como propósito describir la experiencia del diseño, implementación y gestión de la metodología de ApS en un proyecto integrado de dos asignaturas (costos y marketing) en estudiantes de un programa de negocios en una universidad pública y estatal del centro-sur de Chile.

Para ello se recurre al modelo de ApS propuesto por Musa et al. (2017), el cual contempla tres fases: planificación, diseño y análisis del ApS; entrega del servicio de ApS; y; evaluación, reflexión y monitoreo del ApS.

Los resultados de este trabajo, podrían servir de guía para otras instituciones y profe- sores que quisieran implementar ApS y busquen mejorar sus procesos de enseñanza-aprendizaje a través de la innovación metodológica.

\section{Metodología de aprendizaje-servicio}

Dentro de los marcos de implementación, se encontró el trabajo de Pizarro et al. (2015) que muestran sus fases de implementación de la metodología de ApS, basándose en los postulados de Tapia (2007), donde la implementación de ApS fue en el curso de fundamento de costos realizado a partir de tres grandes fases: (1) búsqueda y clasificación de socios comunitarios, (2) implementación de la metodología y, (3) monitoreo y la evaluación. Así también, Petkus (2000), desarrolló un marco teórico-práctico para el ApS en el área de marketing, para guiar la planificación, la implementación y la evaluación de un curso de ApS en marketing por medio del modelo de ciclo de aprendizaje experimental de Kolb (1984).

Este proyecto integrado con ApS contempla dos asignaturas y se sustenta en el modelo de metodología de ApS propuesto por Musa et al. (2017), que se basa en tres fases de implementación: (1) planificación, diseño y análisis del ApS (implica identificar y analizar las necesidades y oportunidades para incorporarlas a los procesos y actividades de ApS), (2) entrega del servicio de ApS (enfocándose más en la implementación del proyecto integrado de ApS que tiene dos pasos, establecer la participación de la comunidad e institucionalizar el ApS dentro en la facultad, los estudiantes y la comunidad), (3) evaluación, reflexión y monitoreo del ApS (Ver Figura 1). 
Figura 1. Una metodología de implementación de ApS en un proyecto integrado

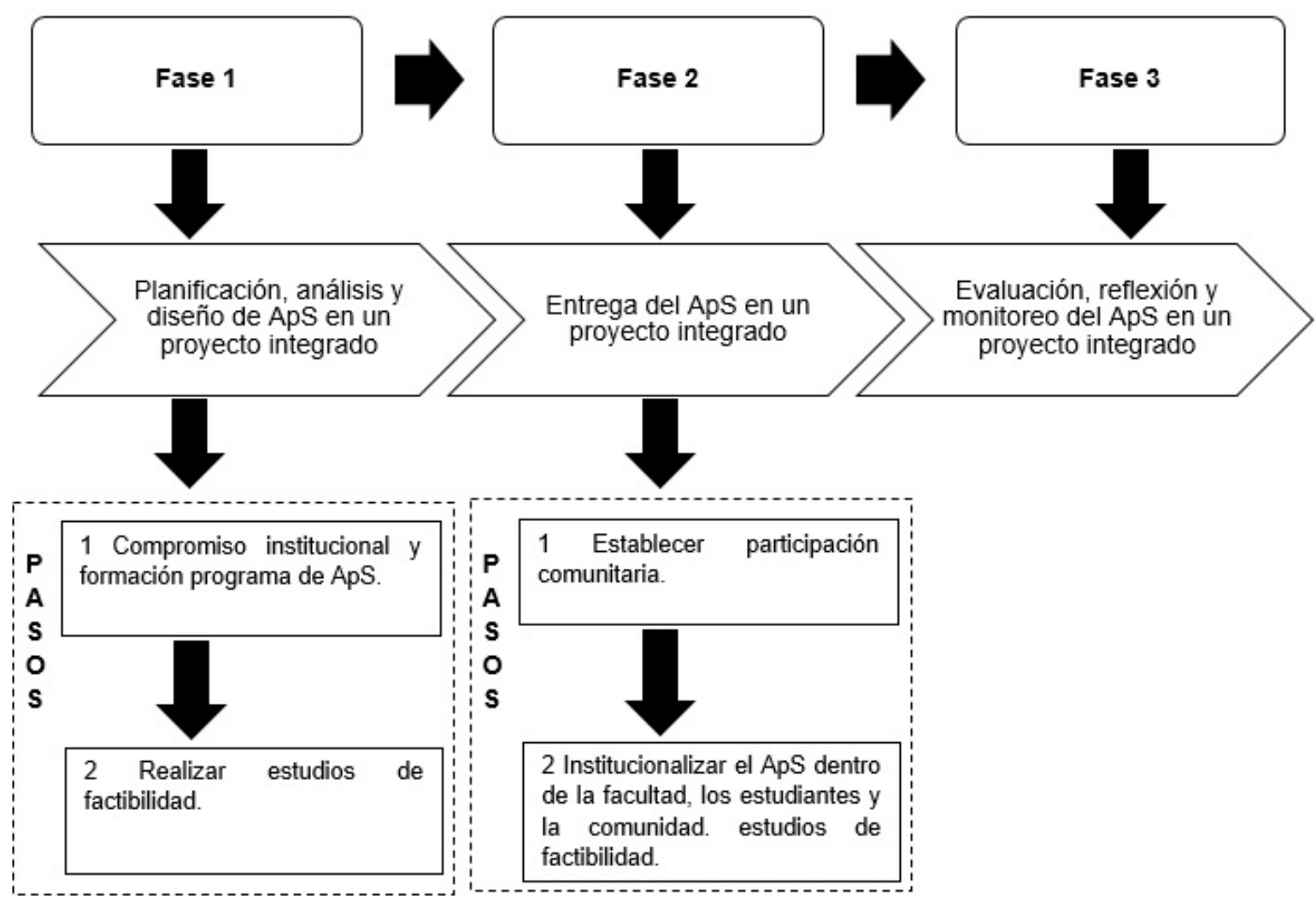

Fuente: Elaboración propia, basado en Musa et al. 2017.

\section{Propuesta}

\subsection{Fase 1: Planificación, análisis y diseño de ApS en un proyecto integrado}

Esta etapa, implica identificar y analizar las oportunidades y las necesidades para incorporarlas a los procesos y las actividades de ApS. Se distinguen dos pasos:

\subsubsection{Paso 1: Compromiso institucional y forma- ción programa de ApS}

El respaldo institucional es primordial para lograr buenos resultados en la implementación de la metodología de ApS (Guiñez-Cabrera et al., 2020). A su vez, es importante que los miembros de las instituciones comprendan que el ApS es un proceso efectivo para lograr objetivos académicos que son valorados por los estudiantes y la comunidad (Poon et al., 2011).

En el caso de la Universidad del Bío Bío (UBB), desde el 2008 posee un modelo educativo institucional, que centra la acción en el estudiante, preocupándose de su formación personal y profesional, buscando alcanzar un desarrollo integral como individuo, profesional y ciudadano, que le permite dar respuesta a las necesidades de su entorno. En este modelo, el proceso de enseñanzaaprendizaje, es fundamentalmente activo, donde la formación se orienta al logro de aprendizaje significativo. Un eje temático significativo es el compromiso, que corresponde a la responsabilidad profesional, personal y social, sobre la realidad económica y social; favoreciendo el desarrollo de la responsabilidad social por medio de la formación de profesionales que se encuen- 
tren comprometidos con su comunidad, con una mirada integradora de los problemas reales, velando por un desarrollo solidario. La formación y el reciclaje para un desarrollo profesional óptimo son piezas fundamentales para una organización (Barrientos-Báez et al., 2019; Ongallo-Chanción \& Gallego-Gil, 2020). Dentro de los componentes claves del aprendizaje, se considera el contexto experiencial, los conceptos procedimentales, teóricos y la puesta en práctica del conocimiento (Modelo Educativo UBB, 2017).

Por otro lado, Bringle y Hatcher (1996) sugieren que, durante la primera etapa de planificación, se necesita identificar la facultad interesada para desarrollar ApS e incluso formar un programa. El rol del programa de ApS de la facultad es hacer recomendaciones de los requisitos de ApS con respecto a los cursos, los estudiantes y la comunidad, siendo un vínculo entre la facultad y la comunidad (Musa et al., 2017).

La Facultad de Ciencias Empresariales (FACE) de la UBB, tiene un Plan de Mejoramiento denominado: "Desarrollo de competencias de los estudiantes de la Facultad de Ciencias Empresariales, a través de la metodología Aprendizaje Servicio y el uso de Tecnologías de la Información" (Programa Aprendizaje Servicio, 2017).

Como se sabe, las instituciones que se encuentran interesadas en el ApS, deben propiciar actividades de perfeccionamiento de los profesores, para desarrollar una comprensión común sobre el ApS y aumentar la confianza en la implementación de esta pedagogía (Bringle \& Hatcher, 1996). Sin el apoyo en la participación de los profesores, la incorporación del ApS en los planes de estudio no prosperará (Seifer \& Connors, 2007).

La UBB, posee un área de desarrollo pedagógico y tecnológico, y a su vez un programa permanente de pedagogía universitaria, a cargo de la unidad de gestión curricular y monitoreo donde proporciona capacitación a los profesores en variadas disciplinas, entre ellas se encuentra la metodología activa de ApS. Así también, el plan de mejoramiento de la FACE tiene como propósito fortalecer el aprendizaje y la gestión de los profesores basada en las experiencias reales (Programa Aprendizaje Servicio, 2017).

\subsubsection{Paso 2: Realizar estudios de factibilidad}

En el ApS, realizar un estudio de factibilidad es esencial antes de implementar el ApS en la comunidad (Musa et al., 2017). Hay cinco tipos de estudios de factibilidad que se deben llevar a cabo en la implementación del ApS; (1) Desarrollo del curso, (2) Proyectos de ApS, (3) Operativo, (4) Financiero, y (5) Técnico (Musa et al., 2017). Los estudios se describen a continuación.

\subsubsection{Desarrollo del curso}

El desarrollo de ApS dentro de la educación superior (ES) es principalmente un trabajo de los profesores (Bringle \& Hatcher, 1996). Los docentes necesitan estudiar cómo integrar el ApS dentro del plan de estudios en función de los requisitos y la dirección de las carreras. La preparación del curso es un proceso crucial en la implementación de ApS, revisando la remodelación del contenido del curso y los objetivos de aprendizaje donde los objetivos de ApS deben tener en cuenta los requisitos de los estudiantes y la comunidad (Musa et al., 2017).

El proyecto tiene que reflejar los contenidos del programa de estudios, las necesidades de la comunidad y la reflexión sobre las actividades de ApS (Gallgher et al., 1999). También, debe lograrse un acuerdo explícito y mutuo sobre los objetivos del ApS entre la facultad y la comunidad. La facultad también necesita estudiar los requisitos, las instrucciones, las actividades, los recursos de aprendizaje y las evaluaciones de los cursos, en este caso costos y marketing (Musa et al., 2017).

En primer lugar, las personas involucradas en el proyecto integrado, incorporaron las competencias del perfil genérico de la universidad como: disposición al aprendizaje y capacidad emprendedora (Mayer-Granados et al., 2019), 
liderazgo, trabajo colaborativo, capacidad para comunicarse y responsabilidad social; competencias que son fomentadas a través de la implementación de la metodología ApS. Y es que, según Barrientos-Báez et al. (2019), el nuevo modelo de enseñanzas aporta una manera diferente de entender la universidad y sus relaciones con la sociedad. La autonomía es la principal característica que las universidades tienen para responder con flexibilidad y rapidez a las cambiantes necesidades.

Luego, se revisaron las competencias del perfil de egreso, para garantizar que la implementación de esta metodología activa, tuviera concordancia con la formación del estudiante.

Después, se rediseñaron los respectivos cursos (costos y marketing), revisando los programas de las asignaturas para garantizar que el esquema del curso cumpliera con los contenidos abordados mediante ApS y las necesidades de los socios comunitarios. Adicionalmente, se analizó la metodología de ambas asignaturas, los contenidos actitudinales, conceptuales y procedimentales, y los criterios de evaluación; haciéndolos coherentes con las necesidades de los socios comunitarios. Los cursos fueron adecuados y relevantes para la comunidad, porque los objetivos de ApS enfatizan cómo los estudiantes de este programa de negocios, pueden proponer soluciones de costos y marketing para generar más oportunidades a las empresas de la zona, basándose en las necesidades reales de la sociedad donde están insertas.

También se consideró la respectiva carga académica (horas de trabajo) de los estudiantes; esta decisión permitió el alineamiento entre lo que especifica cada programa de las asignaturas (costos y marketing), con respecto a la carga semanal, que corresponde a cinco horas presenciales y cinco horas de trabajo autónomo semanales. Con respecto a la cantidad de tiempo en terreno, esta variable dependía de los requerimientos de los socios comunitarios, pero era requisito tener al menos una reunión presencial por semana, la cual dependía de la disponibili- dad del socio comunitario y el nivel de avance de los equipos de trabajo, siendo consideradas como parte del trabajo autónomo.

El proyecto integrado fue calificado con una nota en la escala de 1 a 7 y tenía una ponderación del 30\% de la calificación final en ambas asignaturas de costos y marketing. Una vez que se tuvo certeza de la efectividad de la implementación de la metodología, se continuó con la siguiente etapa.

\subsubsection{Proyectos de ApS}

Hay dos tipos de proyectos de ApS: servicios directos e indirectos (Gallgher et al., 1999). Este proyecto integrado fue un servicio directo que brindó apoyo a los socios comunitarios de manera presencial, satisfaciendo una necesidad determinada. Para lograrlo, los estudiantes debían comprender las necesidades que viven las empresas en la zona.

Esta implementación de ApS tenía la intención de mostrar a los estudiantes la relevancia del rol de los profesionales de negocios; se buscaba que ellos se convirtieran en verdaderos consultores para las empresas y otorgaran todos sus conocimientos de costos y marketing para mejorar los negocios asesorados.

Las asignaturas se diseñaron de tal manera que los estudiantes tendrían la oportunidad de lograr resultados como: comunicación efectiva, organización laboral, trabajo en equipo, identificación y solución de problemas, entre otros (Kearney, 2004).

La implementación de ApS en un curso de principios de marketing es probablemente el más desafiante, porque es muy probable que sea la primera exposición de los estudiantes a los conceptos y habilidades que se requieren en la comercialización; sin embargo, también es una excelente oportunidad para que estos alumnos principiantes experimenten la aplicación en el mundo real, transformándose en verdaderos consultores, evaluando los esfuerzos comerciales existentes e implementando planes estratégico 
donde se integran las diversas funciones de la mezcla de marketing (Petkus, 2000).

En lo referente a la asignatura de costos, los estudiantes podían realizar análisis de la documentación financiera identificando, clasificando, y calculando costos para los diferentes productos ofrecidos por las empresas; permitiendo poner en práctica conceptos teóricos relativos a la materia y vivenciar una experiencia real, además de complementar esto con el uso de las tecnologías de información y comunicación, al construir herramientas tecnológicas como las sugeridas por Pontes et al. (2020) que permitieron automatizar cada uno de los cálculos y crear diferentes escenarios de conveniencia para el servicio otorgado a los socios comunitarios.

\subsubsection{Operativo}

Se puede realizar un estudio de factibilidad operativa desde tres puntos de vista diferentes; facultad/ universidad, estudiante y comunidad (Musa et al., 2017). El estudio de viabilidad operativa debía considerar el compromiso institucional (Bringle \& Hatcher, 1996) y recursos. En este sentido, el plan de mejoramiento de la FACE, entregó apoyo a las profesoras en los cambios curriculares de ambas asignaturas y la orientación para la implementación de la metodología de ApS. Cuando se realizó la planificación, el equipo de las asignaturas, determinó el número de estudiantes por grupos, para poder lograr una correcta operatividad de la metodología de ApS; a su vez, desde la perspectiva de la comunidad, el estudio de factibilidad operativa identificó y determinó a los socios comunitarios más apropiados para la implementación de este proyecto integrado.

\subsubsection{Financiera}

El apoyo financiero requiere el compromiso de la institución (Seifer \& Connors, 2007). Un requisito financiero normalmente está determinado por el tamaño de las clases y la naturaleza del proyecto (Musa et al., 2017).
Gestionar catorce proyectos dentro de la comunidad fue un desafío y requiere una enorme cantidad de tiempo, trabajo y también recursos para lograr el objetivo final del ApS. La propuesta de presupuesto de ApS fue preparada en términos del diseño, planificación y costos involucrados, la cual se envió a la unidad responsable.

Después de presentar la propuesta de presupuesto de ApS, se recibió el respectivo soporte financiero de parte de la universidad, la Facultad de Ciencias Empresariales y el Departamento de Gestión Empresarial. La cantidad recibida por los patrocinadores se utilizó para el trabajo de campo, impresión de materiales, lanzamiento del proyecto integrado, trabajos administrativos $y$ relacionados; todo lo cual posibilitó la adecuada operacionalización de la metodología.

Tal como lo sugiere Musa et al. (2017), el plan de presupuesto se llevó a cabo garantizando que el proyecto integrado de ApS se pudiera implementar de manera efectiva y eficiente dentro de la comunidad.

El estudio de factibilidad financiera consideró los costos involucrados en la logística, donde se utilizaron las dependencias de la entidad educativa, específicamente el centro de extensión de la UBB, que se encuentra ubicado físicamente en un lugar céntrico y estratégico de la ciudad del centro-sur de Chile. El lanzamiento del proyecto y las presentaciones se realizaron en estas dependencias, para la facilidad y la comodidad, tanto de los empresarios (socios comunitarios) como de los estudiantes.

Dentro del trabajo administrativo, ambas profesoras de cada asignatura contaban con un ayudante respectivamente, para poder llevar a cabo de mejor manera el trabajo administrativo.

\subsubsection{Técnico}

El estudio de factibilidad técnica se relaciona con la cantidad de estudiantes que se pueden admitir para un buen desarrollo del proyecto de ApS (Musa et al., 2017), en este caso el proyecto integrado, contempló un total de 64 estudian- 
tes, resultando 14 equipos que trabajaron con el mismo número de empresas de la zona.

Dentro de la factibilidad técnica en el proyecto integrado, también se tuvo que identificar los requerimientos de tecnología y comunicación que demandaban los estudiantes, los socios comunitarios y los profesores. La UBB, realiza el préstamo de computadores portátiles a los estudiantes y profesores. El servicio de internet, los proyectores, la electricidad y el software utilizado para el análisis de datos se encontraban disponibles en la institución de educación.

\subsection{Fase 2: Entrega del ApS en un proyecto integrado}

Después de que todos los componentes en la fase 1 fueron considerados, la fase 2 se concentra en la implementación del proyecto integrado de ApS en las asignaturas, para ello se vale de dos pasos:

\subsubsection{Paso 1: Establecer participación comunitaria}

Crear una asociación entre la casa de estudios superiores y la comunidad es un proceso crucial para una participación comunitaria exitosa (Musa et al., 2017).

La participación comunitaria se describe como la colaboración entre la universidad y sus comunidades, para lograr el intercambio de recursos y conocimientos que sea mutuamente beneficioso en un contexto de asociación y reciprocidad (Driscoll, 2009).

Se necesita una asociación comunitaria bien planificada para garantizar que no solo estén dispuestas a participar, sino que también puedan colaborar eficazmente la comunidad y la respectiva entidad educativa. Durante el compromiso, tanto la comunidad como la universidad deben comprender y acordar mutuamente los beneficios de ApS para cada una de las partes (Musa et al., 2017).

Como la implicación preliminar y efectiva con los socios comunitarios es un proceso crucial, el equipo de ApS diseñó e implementó los siguientes pasos de participación de la comunidad y la institución de educación superior. En la primera reunión y lanzamiento del proyecto integrado de costos y marketing con ApS, se destacaron algunas preguntas, como: ¿qué es ApS?, ¿cómo el programa ApS beneficia a ambas partes?, ¿cuáles son los proyectos de costos y marketing que se podrían elaborar para la comunidad?, y ¿cuáles son las preferencias de proyecto que se relacionan con las necesidades?

En esta etapa, se utilizó un enfoque que lograra identificar las necesidades de los socios comunitarios. Como el ApS es una situación en la que todos ganan, los requisitos del contenido de los cursos, los conocimientos y las habilidades del estudiante se combinaron con la lista de proyectos de ApS propuestos por la comunidad. Ambos alcanzaron un acuerdo explícito y expectativas en términos de factibilidad de ejecutar por parte de los estudiantes a la comunidad.

\subsubsection{Paso 2: Institucionalizar el ApS dentro de la facultad, los estudiantes y la comunidad}

Después de identificar los requisitos de los cursos para trabajar con ApS, la macrounidad académica debe cultivar el ApS como parte de la cultura estudiantil (Musa et al., 2017). En esta línea de trabajo, la FACE, se adjudicó en el año 2014 un convenio de desempeño cuya finalidad es la ejecución y el desarrollo del Plan de Mejoramiento, financiado por el Banco Mundial a través del Ministerio de Educación de la República de Chile (Programa Aprendizaje Servicio, 2017). Dentro de sus propósitos se encuentra el perfeccionamiento de las competencias de los profesionales para la formación de los programas académicos de la Facultad con la metodología de ApS.

Otro objetivo fundamental apuntaba a mejorar la administración y el uso del equipamiento de TIC y de la infraestructura, para apoyar la gestión y el aprendizaje de los profesores a través de experiencias reales y con los contenidos de las respectivas asignaturas, implementando la metodología de ApS e instrumentos de eva- 
luación (Programa Aprendizaje Servicio, 2017). Es importante reseñar que las TIC ejercen una influencia cada vez mayor en los jóvenes ofreciendo la posibilidad de comunicarse interactivamente, de experimentar, de resolver problemas, de manejar todo tipo de datos y de simular situaciones reales (Barrientos-Báez, 2016).

La materialización de estas metodologías en las asignaturas fue a través de la incorporación de un proyecto integrado, que consistió en que los estudiantes debían asesorar a empresas pertenecientes a la Región de Nuble (Chile) en una necesidad concreta, conforme al perfil de egreso del estudiante de negocios, convirtiendo a los educandos en verdaderos consultores empresariales.

La evaluación de la actividad fue de manera sistemática y con todos los actores involucrados. Se esperaba que la incorporación de esta nueva metodología generara los siguientes resultados: mejoramiento del rendimiento académico en los estudiantes, aportes significativos en el desarrollo de habilidades sociales como trabajo colaborativo, comunicación efectiva oral y escrita (García-Roca, 2019), la búsqueda permanente de aprendizaje y establecimiento de redes de colaboración entre la universidad y las empresas del sector.

Para lograr este objetivo, se conformaron equipos de trabajo entre cinco y seis participantes con una población total de 64 estudiantes, resultando un total de 14 grupos de trabajo (dos secciones y ambas asignaturas).

La conformación de los equipos se realizó el primer día de clases utilizando para ello el cuestionario estilos de enseñanza-aprendizaje de VARK $^{1}$ y la metodología de aprendizaje basada en equipos (Team Based Learning), por lo cual se resguardó que la selección no fuese por afinidad y que los equipos de trabajo conformados fueran mixtos con distintos estilos de aprendizaje.

Los grupos de trabajo debieron definir un nombre para su equipo, y permanecieron permanente conformados durante todo el semestre y para todas las actividades que se desarrollaron en ambas asignaturas.
La asesoría del proyecto integrado de costos y marketing con ApS se desarrolló durante todo un semestre, los estudiantes tuvieron que contactar a una empresa con la cual decidirían trabajar en el proyecto y se planificó una reunión de trabajo mensual, entre los estudiantes, los empresarios y las profesoras en las dependencias de la universidad.

En la primera reunión de trabajo, se explicaron los objetivos del proyecto a los empresarios, definiendo los compromisos de ambas partes, tanto, de los estudiantes como de los empresarios para el exitoso desarrollo del proyecto integrado, y posteriormente cada equipo trabajó en conjunto para definir el problema a solucionar por parte de los estudiantes al interior de la empresa, también desarrollaron la planificación de las actividades (Carta Gantt) y la firma de acta de compromiso.

Por su parte los empresarios se comprometieron a facilitar toda la información que los estudiantes requirieran para el desarrollo del proyecto integrado, ejemplo: asistir mensualmente a las reuniones de trabajo programadas en la universidad y evaluar el desempeño de los grupos de trabajo; a su vez, los estudiantes y profesoras se comprometían a entregar un informe de asesoría que diera solución al problema planteado por el empresario en su empresa.

En cada reunión de trabajo los estudiantes presentaron un avance, de los aspectos que debía contemplar cada informe, de acuerdo con la planificación inicial, el que se entregaba en un informe escrito y luego se presentaba oralmente ante la comisión. La retroalimentación era inmediata en cada reunión de trabajo y posteriormente se calificaba tanto el informe escrito como la presentación.

\subsection{Fase 3: Evaluación, reflexión y monitoreo del ApS en un pro- yecto integrado}

Bringle y Hatcher (1996) —indican que los profesores y los estudiantes - pueden ser eva- 
luados utilizando el resultado del curso, como la satisfacción y el resultado del aprendizaje del estudiante, mientras que los socios comunitarios pueden evaluar el impacto de las actividades de ApS en sus necesidades satisfechas por los estudiantes en el proyecto integrado. El pensamiento de orden superior en cada etapa, es importante para enriquecer la experiencia de aprendizaje y potenciar la responsabilidad cívica y fortalecer a la comunidad (Seifer \& Connors, 2007).

Luego de las visitas a los socios comunitarios y el trabajo generado, los estudiantes regresaron a la Universidad para completar sus tareas y reflexionar en términos de las unidades de aprendizaje, desarrollo individual, habilidades blandas de comunicación y habilidades técnicas. Además, revisaban su bitácora de guía por cada visita, completaban un formulario de reflexión y un libro de registro. En la reflexión se obtuvo información de la experiencia vivida, el conocimiento y grado de comprensión de los cursos. las habilidades adquiridas y el impacto en la comunidad del proyecto integrado con ApS.

Se realizaron un total de cuatro presentaciones con entrega de informes escritos con los avances. Los aspectos evaluados pueden ser observados en la figura 2.

Figura 2. Aspectos evaluados en la aplicación de Aps

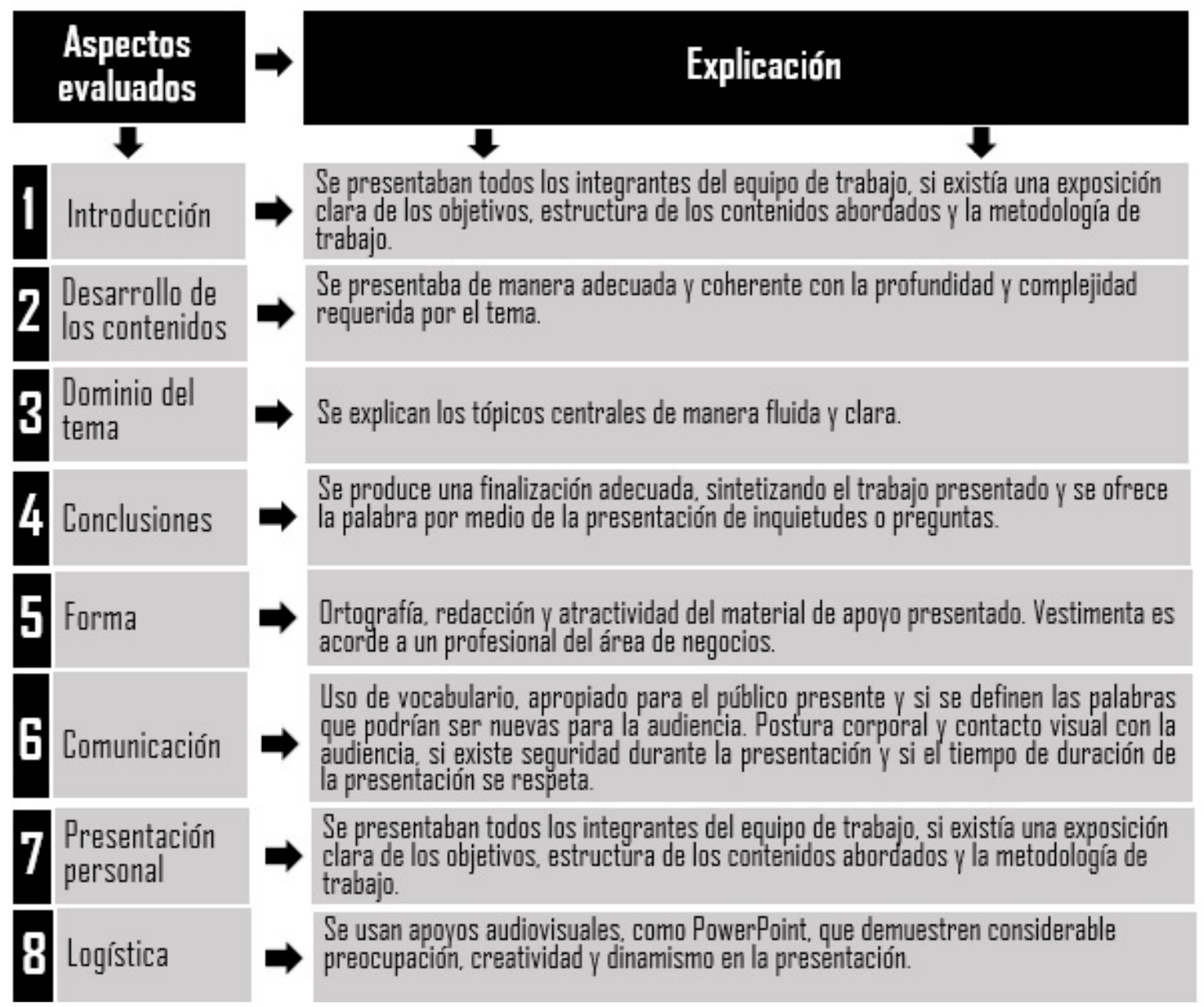

Fuente: Elaboración propia, basado en implementación de ApS. 
Para evaluar el impacto de esta metodología de ApS se utilizaron técnicas de investigación cualitativa-cuantitativa. El instrumento usado fue una encuesta de autoeficacia aplicada a los estudiantes al final del proyecto integrado.

Para hacer una reflexión, en términos de impacto comunitario y las relaciones universidad-comunidad (Musa et al., 2017), a los empresarios se les aplicó una encuesta de satisfacción al cierre del proyecto que constaba de once preguntas de las cuales seis eran cerradas y cinco preguntas abiertas que buscaban obtener su opinión respecto a la experiencia vivida con el proyecto, calificando la experiencia vivida de trabajar en este proyecto y evaluando las habilidades observadas en los estudiantes.

\section{Conclusiones}

Está claro que la metodología de ApS en un programa de negocios, mediante un proyecto integrado, tiene múltiples beneficios para todos los actores involucrados. Los estudiantes, al poder aplicar de manera práctica los contenidos entregados teóricamente en el aula, enriquecen su aprendizaje al adquirir experiencias desde el mundo real. Los socios comunitarios pueden abordar necesidades no satisfechas y las instituciones pueden generar acciones concretas de vinculación con el medio.

Sin embargo, además de conocer los beneficios de esta metodología innovadora, se debe considerar que dentro de la implementación de este proceso existen muchas aristas que son relevantes conocer y considerar para una buena ejecución de esta metodología de ApS.

Este estudio describió un proceso completo y detallado sobre el diseño, la implementación y la gestión de una metodología de ApS que contempló dos asignaturas, (costos y marketing) de la carrera de Ingeniería Comercial de la FACE de la UBB.

En este trabajo se presentaron pormenorizadamente cada una de las fases aplicadas durante el proceso con sus respectivas sub-etapas, todas las cuales son fundamentales para poder lograr un buen diseño, implementación y gestión de la metodología ApS en un proyecto integrado. Ninguno de los pasos es más importante que otros, por lo mismo, se estima que todos son vitales de llevarlos a cabo para poder lograr el objetivo deseado de tener una contribución a la enseñanza-aprendizaje significativa por medio de esta pedagogía innovadora.

Al realizar comparaciones con otros estudios se encuentra, por ejemplo, que Pizarro et al. (2015) indican que la implementación de ApS se basa en tres fases (búsqueda y clasificación de socios comunitarios, implementación de la metodología, y monitoreo-evaluación); del mismo modo, Petkus (2000) desarrolló un marco teórico-práctico para guiar un curso en marketing con ApS. Al analizarlos en detalles, se pueden encontrar varias diferencias con los modelos indicados anteriormente:

Se aplica esta metodología en una sola asignatura (en este estudio son dos).

El trabajo de Pizarro et al. (2015) indica tres fases, donde la primera corresponde a la búsqueda de los socios comunitarios, luego viene la fase de implementación de la metodología donde se vincula al socio comunitario con los estudiantes, y se entrega el producto de asesoría y finalmente viene el monitoreo y evaluación. La diferencia con la propuesta presentada se encuentra en las fases y especificación de cada una de ellas, donde este artículo va una etapa anterior que corresponde al compromiso institucional y los estudios de factibilidad.

Por su parte, el trabajo de Petkus, tiene como objetivo proporcionar un marco para la diseño e implementación de cursos de ApS en marketing, pero principalmente basándose en el programa de la asignatura en sí, no incorporando otras variables más bien operativas que son indispensables en el proceso de una buena implementación.

En vista de los antecedentes, se puede destacar que el gran aporte de este estudio, está en detallar cada fase, que comienza con una fase de 
factibilidad, dado que la mayoría de los modelos que se plantean para incorporar esta metodología de ApS comienzan desde la etapa de buscar socios comunitarios o de verificar si la metodología se ajusta con el programa de la asignatura. Este estudio hace hincapié en que esas fases son importantes, pero también, es necesario llevar a cabo estudios previos de factibilidad para conocer si será posible lograr los objetivos de una o varias asignaturas que incorporen esta metodología innovadora.

Se espera que los hallazgos de este estudio sean útiles para avanzar en nuestra comprensión de cómo diseñar, implementar y gestionar proyectos integrados con ApS, otorgando de este modo valor a todos los actores involucrados y al alcance de los objetivos de enseñanza-aprendizaje.

Si bien este estudio proporciona gran utilidad al describir la experiencia de una metodología innovadora en un proyecto integrado, también presenta una serie de limitaciones. Una de ellas apunta al diseño, la implementación y la gestión de la metodología de ApS en dos asignaturas concretas del área de negocios y en un solo contexto que es el chileno.

Por otro lado, la implementación de esta metodología se llevó a cabo en una institución de educación superior que cuenta con el apoyo a este tipo de metodologías, y que incluso tiene un programa institucional de ApS. Por lo tanto, en otro tipo de institución las fases para llevar a cabo este tipo de metodología podrían ser distintas o muy difíciles de operacionalizar.

Investigaciones futuras podrían realizarse en asignaturas de otras áreas, en otros contextos de Latinoamérica y en otro tipo de instituciones, para verificar si las fases identificadas en este estudio se cumplen o tienen diferencias significativas.

\section{Nota}

1. Visual, Aural, Read/Write, Kinesthetic por sus siglas en inglés.

\section{Referencias bibliográficas}

Al-Barwani, T., Al-Mekhlafi, A., \& Nagaratnam, R.P. (2013). Service-Learning Might be the Key: Learning from the challenges and implementation strategies in EFL Teacher Education in Oman. International Journal of Instruction, 6(2), 109-128. http://bit.ly/barwanietal

Alises-Camacho, M.E. (2017). Potencial pedagógico del Mobile Learning en el aula de música en secundaria. Revista de Comunicación de la SEECI, 43, 29-51. http://dx.doi.org/10.15198/seeci.2017.43.29-51

Barrientos-Báez, A. (2016). GDS Amadeus. Propuesta de innovación didáctica. En TIC actualizadas para una nueva docencia universitaria. McGraw Hill.

Barrientos-Báez, A., Barquero-Cabrero, M., \& Rodríguez-Terceño, J. (2019). La educación emocional como contenido transversal para una nueva política educativa: el caso del grado de turismo. Revista Utopía y Praxis Latinoamericana, 24(4), 147-165. https://bit. ly/3gMTolG

Bringle, R.G., \& Hatcher, J.A. (1996). Implementing service learning in higher education. Journal of Higher Education, 67(2), 221-239. https:// doi.org/10.1080/00221546.1996.11780257

Carmona-Martínez, M., Conesa-Pérez, M. del C., \& Ros-Clemente, M.I. (2014). Valoración del Aprendizaje basado en Problemas por los alumnos: diferencias por sexo. Historia $y$ Comunicación Social, 19, 725-734.

https://doi.org/10.5209/rev_HICS.2014.v19.44997

Domínguez, A. (2018). Fomento de la lectura y la escritura en lenguas indígenas de México: algunas consideraciones. Investigaciones Sobre Lectura, 10, 55-94. https://bit.ly/387X6ST

Driscoll, A. (2009). Carnegie's new community engagement classification: Affirming higher education's role in community. New Directions for Higher Education, 5-12. https:// doi.org/10.1002/he.353

Esteves-Fajardo, Z., Chenet-Zuta, M.E., PibaquePonce, M.S., \& Chávez-Rocha, M.L. (2020). Estilos de aprendizaje para la superdotación en el talento humano de estudiantes universitarios. Revista de Ciencias Sociales, XXVI(2), 225-235. https://bit.ly/34ffqbN 
Ganga-Contreras, F. (2013). Gerencia latinoamericana en las actuales plataformas organizacionales: Una mirada preliminar y sinóptica. Revista Venezolana de Gerencia, 18(64), 711722. https://bit.ly/Ganga-Contreras

Ganga-Contreras, F., Piñones, M. \& Valderrama, C. (2014). Innovaciones teóricas en administración: una sinóptica mirada diacrónica. Prisma Social, 12, 688-707.

https://bit.ly/Ganga-Contrerasetal

Ganga-Contreras, F., Rodríguez-Ponce, E., PedrajaRejas, L., \& Alarcón, N. (2019a). Percepciones de los funcionarios públicos sobre la relación entre Universidades Públicas y Privadas con el Estado De Chile. Interciencia, 44(9), 521 528. https://bit.ly/Ganga-Contrerasetal2

Ganga-Contreras, F., Guiñez-Cabrera, N., OlguínGutiérrez, C., \& Ceballos-Garrido, P. (2019b). Percepción estudiantil de la metodología "aprendizaje-servicio" en la asignatura de marketing. Opción, 35(90), 475-505. http://bit.ly/gangacontrerasetal

García-Roca, A. (2019). Los fanfictions como escritura en colaboración: modelos de lectores beta. El profesional de la información, 28(4). https://doi.org/10.3145/epi.2019.jul.04

Guiñez-Cabrera, N., Ganga-Contreras, F., OlguínGutiérrez, C., \& Ceballos-Garrido, P. (2020). Metodología de Aprendizaje Servicio: Experiencia de implementación desde la perspectiva de marketing. Revista Academia y Negocios, 6(1), 1-10.

http://bit.ly/guinezcabreraetal

Kearney, K.R. (2004). 'Students' Self-Assessment of Learning through Service-Learning'. American Journal of Pharmaceutical Education, 68(1), 1-13. http://bit.ly/kearneykr

Kolb, D.A. (1984). Experiential learning: Experience as the source of learning and development. Prentice Hall. http://bit.ly/kolb1984

Mayer-Granados, E.L., Charles-Coll, J.A., \& De la Garza-Ramos, M.A. (2019). El fomento emprendedor desde la universidad mexicana. Revista Venezolana de Gerencia, 24(85), 49-67. https://bit.ly/380eb0U

Modelo Educativo de la Universidad del Bío Bío. https://bit.ly/ModeloEducativoUBB

Musa, N., Ibrahim, D.H.A., Abdullah, J., Saee, S., Ramli, F., Mat, A.R., \& Khiri, M.J.A. (2017). A methodology for implementation of service learning in higher education institution: A case study from faculty of computer science and information technology, UNIMAS. Journal of Telecommunication, Electronic and Computer Engineering, 9(2-10), 101-109. http://bit.ly/musaetal

Niño-González, J.I., \& Linares-Herrera, M.P. (2020). Investigar: Acción impostergable. Bibliotecas. Anales de Investigación, 16(1), 5-6. https://bit.ly/384PUqJ

Orozco-Gómez, M., Sánchez-Fuentes, S., CuestaGómez, J.L., Cifuentes-García, A., \& MartínAlmaraz, R.A. (2016). Participación en comunidades de aprendizaje, como elemento clave para la formación inicial en el ámbito de la educación inclusiva e intercultural. Revista de Ciencias de la Comunicación e Información, 21(1), 35-44. http://doi.org/10.35742/rcci.2016.21(1).35-44

Ongallo-Chanción, C., \& Gallego-Gil, D. (2020). El 'emofeedback': la inteligencia emocional y el feedback en los procesos de acompañamiento. Revista de Ciencias de la Comunicación e Información, 25(2), 1-22. https://doi.org/10.35742/rcci.2020.25(2).1-22

Pérez-Galván, L.M., \& Ochoa-Cervantes, A. de la C. (2017). El aprendizaje-servicio (APS) como estrategia para educar en ciudadanía. Alteridad, 12(2). https://doi.org/10.17163/alt.v12n2.2017.04

Petkus, E. (2000). A Theoretical and Practical Framework for Service-Learning in Marketing: Kolb's Experiential Learning Cycle. Journal of Marketing Education, 22(1), 64-70. https://doi.org/10.1177/0273475300221008

Pizarro-Torres, V., Hasbun-Held, B., \& GonzálezCifuentes, T. (2015). Innovación en docencia: metodología de "aprendizaje y servicio" en contabilidad de costos. CAPIC REVIEW, 13, 89-99. https://doi.org/10.35928/cr.vol13.2015.47

Poon, P., Chan, T.S., \&Zhou,L.(2011). Implementation of Service-Learning in Business Education: Issues and Challenges. Journal of Teaching in International Business, 22(3), 185-192. https://doi.org/10.1080/08975930.2011.653746

Pontes, N., Dorado-Santana, \& Baptista-Calunga, A. (2020). A gestão documental em instituições escolares: directrizes para o desenho de um 
sistema de gestão electrónica de documentos escolares. Bibliotecas. Anales de Investigación, 16(1), 23-45. https://bit.ly/3nmtZln

Programa Aprendizaje Servicio de la Facultad de Ciencias Empresariales, Universidad del Bío Bío. https://bit.ly/ApSFACE

Puebla-Martínez, B., Rodas-Alfaya, L., \& Guede-Cid, R. (2018). Principales factores que intervienen en el diseño de los planes de aprendizaje en materia digital para mayores de 65 años. Revista Opción, Especial(18), 1929-1956. https://bit.ly/3a9nQFk

Rodríguez-Izquierdo, R.M. (2020). Aprendizaje Servicio y compromiso académico en Educación Superior. Revista de Psicodidáctica, 25(1), 45-51.

https://doi.org/10.1016/j.psicod.2019.09.001

Rodríguez-García, Y.M. (2017). Reconceptualización de la educación en la era digital: Educomunicación, redes de aprendizaje y cerebro factores claves en los actuales escenarios de construcción de conocimiento. Revista de Comunicación de la SEECI, 42, 85-118. https://doi.org/10.15198/seeci.2017.42.85-118

Rubio, A. (2018). Técnicas de aprendizaje de conocimiento científico a partir de textos. Investigaciones sobre Lectura, 10, 1-29. https://bit.ly/38mH7AL

Sánchez-Marín, F.J., Parra-Meroño, M.C., \& PeñaAcuña, B. (2019). Experiencias de trabajo cooperativo en la educación superior. Percepciones sobre su contribución al desarrollo de la competencia social. Vivat Academia, Revista de Comunicación, 147, 87-108. http://doi.org/10.15178/va.2019.147.87-108.

Seider, S.C., Gillmor, S.C., \& Rabinowicz, S.A. (2011). The Impact of Community Service Learning
Upon the Worldviews of Business Majors Versus Non-Business Majors at an American University. Journal of Business Ethics, 98, 485-503. https://doi.org/10.1007/s10551-010-0589-8

Seifer, S.D., \& Connors, K. (2007). Faculty Toolkit for Service-Learning in Higher Education. National Service Learning Clearinghouse. http://bit.ly/seiferandconnors

Simó-Algado, S., Ginesta-Portet, X., \& de San Eugenio-Vela, J. (2014). Aprendizaje Servicio Universitario: Creando empleo a partir de la emprendeduría social. Historia y Comunicación Social, 18, 627-638. https://doi.org/10.5209/rev_HICS.2013.v18.44265

Stefaniak, J.E. (2015). The implementation of servicelearning in graduate instructional design coursework. Journal of Computing in Higher Education, 27, 2-9. https://doi.org/10.1007/s12528-015-9092-7

Tapia, M.N. (2007). El aprendizaje-servicio en las organizaciones de la sociedad civil. En Programa Nacional Educación Solidaria. Aprendizaje y Servicio Solidario en las organizaciones de la sociedad civil. Programa Nacional Educación Solidaria. https://bit.ly/ApSenlasorgs

Traver-Martí, J.A., Moliner-García, O., \& SalesCiges, A. (2019). Negociando el currículum: Aprendizaje-servicio en la escuela incluida. Alteridad, 14(2), 195-206. https://doi. org/10.17163/alt.v14n2.2019.04

Vidal-Raméntol, S., \& Fuertes-Camacho, M.T. (2013). La dinámica de grupos para el trabajo cooperativo facilita la comunicación. Revista de Comunicación VIVAT Academia, 123, 1-12. https://doi.org/10.15178/va.2013.123.1-12 


\section{इALTERIDAD Aprendizaje-servicio en escuelas argentinas de Bachillerato Internacional \\ Service Learning enactment in International Baccalaureate Schools in Argentina}

(D) Dra. Liliana Mayer es investigadora adjunta del CONICET con sede en la Universidad Nacional de Misiones (Argentina) (Izmayer@gmail.com) (https://orcid.org/0000-0002-7364-4048)

(D) Lic. Wanda Perozzo-Ramírez es doctoranda en la Universidad Nacional de La Plata (Argentina) (wperozzo79@hotmail.com) (https://orcid.org/0000-0003-2763-5113)

Recibido: 2020-07-26 / Revisado: 2020-12-09 / Aceptado: 2020-12-11 / Publicado: 2021-01-01

\section{Resumen}

El artículo analiza los modos en que se realizan proyectos de aprendizaje-servicio (ApS) en el marco del Programa Diploma (PD) del Bachillerato Internacional (IB) en el área metropolitana de Buenos Aires, Argentina. A través de un estudio cualitativo, que combina entrevistas en profundidad a agentes institucionales, análisis documental y observaciones de clase en escuelas estatales y privadas, se indaga en los diversos sentidos de las actividades que estudiantes, docentes y directivos realizan para el componente Creatividad, Acción y Servicio (CAS) del PD. Los resultados del trabajo muestran conclusiones disímiles, cuando se trata de escuelas privadas asociadas a públicos de sectores medios y medios-altos, el ApS aparece orientado a la acción o servicio social, destinado a mermar déficits de un tercero. Por el contrario, cuando se trata de escuelas estatales, donde los estudiantes tienen perfiles socioeconómicos más cercanos a los beneficiarios de las escuelas privadas, logran trascender dicha orientación para lograr bienes comunitarios, tangibles o intangibles. Este perfil desventajado es motivo en algunas instituciones estatales para cancelar proyectos de ApS que trasciendan acciones solidarias puntuales y materiales. Del artículo se deduce la importancia de los agentes institucionales en la promoción de estos proyectos: si bien se trata de espacios donde los jóvenes son los protagonistas, el encuadre, habilitación o restricción para su realización dependerá de los adultos, de sus conocimientos, predisposición y valoración respecto del ApS como pedagogía y práctica.

Descriptores: Aprendizaje-servicio, desigualdades, internacionalización, cosmopolitismo, gestión educativa, Bachillerato Internacional.

\section{Abstract}

The article analyzes the ways in which servicelearning (SL) projects in schools in the metropolitan area of Buenos Aires, Argentina delivering the Diploma Program (PD) of the International Baccalaureate (IB). Through a qualitative study, which combines in-depth interviews with institutional agents, documentary analysis and classroom observations in state and private schools affiliated to the Program, the different senses of the activities that students, teachers and authorities carry out for the CAS component of the DP are investigated. The results of the study show dissimilar conclusions. When it comes to private schools associated with middle and upper-middle sectors, the SL projects appear oriented towards social action or service, aimed at reducing the deficits of a third party. On the contrary, when it comes to state schools, where students have socioeconomic profiles that are closer to the beneficiaries of those of the private schools, they manage to transcend this orientation to achieve tangible or intangible community assets. This disadvantaged profile is a reason for some state institutions to cancel SA projects that transcend specific and material solidarity actions. The article deduces the importance of institutional agents in the promotion of these projects: although these are spaces, where young people are the protagonists, the framing, empowerment or restriction for their realization will depend on adults, their knowledge, predisposition and valuation regarding $\mathrm{SL}$ as pedagogy and practice.

Keywords: Service Learning (SL), educational inequalities, cosmopolitism, internationalization, school management, International Baccalaureate.

Forma sugerida de citar: Mayer, L., \& Perozzo-Ramírez, W. (2021). Aprendizaje-servicio en escuelas argentinas de Bachillerato Internacional. Alteridad, 16(1), 65-75. https://doi.org/10.17163/alt.v16n1.2021.05 


\section{Introducción}

Los estudios de los procesos educativos en la Argentina coinciden en la fragmentación (Tiramonti, 2004) como rasgo del campo educativo en el país, relacionados con los subsistemas que integran las escuelas estatales y privadas. Estos estudios (Braslavsky, 1985), plantean la segmentación educativa referida a procesos de desinstitucionalización (Dubet \& Martuccelli, 1999) y pérdida de eficacia simbólica de las instituciones (Mayer, 2009), resultado de los impactos de la globalización en el sistema educativo, y de transformaciones en las legislaciones educativas locales que descentralizaban a las instituciones, agentes y destinatarios. Tal fragmentación nos lleva a reconocer el espacio social y educativo como ámbitos carentes de referencia a una totalidad. Cada fragmento se trasluce como frontera de referencia, un agregado institucional con referencias normativas y culturales comunes.

En este contexto de pérdida de eficacia simbólica de ciertos patrones, advertimos la proliferación de proyectos educativos vinculados al mundo global (Mayer, 2020), que responden a la incidencia de discursos globales de la educación, el giro hacia una educación pro-mercado, y a reconfiguraciones de la política educativa nacional y local. Según Beech y Barrenechea (2011), la Argentina se configura como un cisne negro en cuanto a la implementación de programas ligados a la internacionalización, debido a su tradición educativa, y por resistencia a la pregnancia de tales ideas por parte de los actores intervinientes — sindicatos- - . De esto que, parte de las instituciones que adhieren a esas narrativas, pertenezcan al ámbito privado, cuenten con mayor autonomía, donde intervienen otros actores institucionales (Larrondo \& Mayer, 2018; Mayer, 2020). Así, hubo espacios que no pudieron adaptarse, mientras otros abrieron intersticios por donde se instalaron discursos y prácticas foráneas. Según Ball y Youdell (2008), el caso argentino correspondería al de privatización exógena del sistema educativo, aludiendo a compo- nentes específicos que adoptaron lógicas tendientes a la privatización, aún sin fines de lucro. ${ }^{1}$ Estas líneas delimitan el contexto y particularidades en las que programas y agencias internacionales se insertan en Argentina (Beech, 2011).

Este es el caso de la Organización del Bachillerato Internacional (OBI) que ofrece varios programas a las escuelas en el mundo, siendo el Programa Diploma (PD) el más popular. Este constituye una malla para los últimos dos años de la escuela secundaria que, una vez aprobado, tiene reconocimiento universal, permitiendo el ingreso automático a una diversidad de universidades en el mundo. Para ofrecer el PD, las escuelas atraviesan arduos procesos de auditoría interna y aplicación. Esto rige, en particular, para las escuelas privadas que deciden aplicar. Para las escuelas estatales, que en nuestro continente adhieren con distintas modalidades (Beech et al., 2019; Resnik, 2015, 2016; Bunnell, 2008; Doherty et al., 2012), lo hacen por convenios marco que realizan las autoridades educativas jurisdiccionales y la OBI. Para ambos casos, estos acuerdos garantizan que su malla curricular contemple el dictado de siete asignaturas, teniendo como obligatorias Lengua y Matemática, Teoría del Conocimiento, la elaboración de una monografía final luego de un trabajo de investigación de dos años y, el desarrollo del componente CAS en el que los estudiantes realizan determinadas actividades certificadas que otorgan los créditos suficientes para completar el PD.

El componente CAS se engloba dentro del ApS, entendido como proyectos pedagógicos de servicio integrados al currículo, en los que los estudiantes aplican, verifican y profundizan los aprendizajes escolares aportando a la solución de un problema comunitario. El ApS como práctica pedagógica, aplica conceptos disciplinarios a espacios y problemas concretos, ofreciendo a las comunidades locales niveles de desarrollo comunitario (Furco, 2002; Castillo et al., 2007; Tapia, 2017, 2018).

Argentina cuenta con 61 escuelas que ofrecen el PD, diez de las cuales son estatales. 
Las escuelas de gestión privada, en su mayoría se encuentran en el Ârea Metropolitana de Buenos Aires (AMBA) y corresponden, más allá de sus heterogeneidades, a instituciones de elite (Bourdieu, 1984, 1986; Kahn-Raman, 2010). Las escuelas de gestión estatal, a excepción de una en la provincia de Buenos Aires, se ubican en la Ciudad de Buenos Aires (CABA), accediendo al programa luego de un convenio firmado entre autoridades del Ministerio de Educación de la Ciudad, que permite a las escuelas integrarse al mundo del IB, por sus siglas en inglés, sin pagar los aranceles que exige la OBI.

En el caso de las escuelas de gestión estatal de CABA, el Ministerio asume los costos - de instituciones y estudiantes - lo cual abre debates respecto del uso de los recursos en materia educativa y de la equidad en su distribución. Que se trate de esta jurisdicción no es casual, ya que es gobernada hace más de quince años por la alianza PRO-Cambiemos, con una mirada educativa más proclive al cosmopolitismo y al mercado que el resto de las jurisdicciones. El hecho de que solo diez escuelas hayan decidido participar del programa, da cuenta de disidencias que los proyectos institucionales muchas veces suponen del cisne negro mencionado. Señalamos estos procesos como específicos de la realidad educativa argentina que difiere de los modos en que se ha implementado el IB en otros países de la región, con promoción y crecimiento a partir del sector estatal, como es el caso de Perú, Ecuador y, con articulaciones público-privadas en Costa Rica (Beech et al., 2019). Respecto de la implementación del PD del IB, destacamos que se trata de un programa opcional para los estudiantes. En algunas instituciones — -según su ámbito de gestión- esto implica la creación de cursos paralelos para los alumnos que se inscriben. En otras, todos los alumnos tienen el mismo currículo y, luego, algunos rinden exámenes y demás requerimientos del Programa. La mayoría de las instituciones educativas intentan su universalización a través de varias estrategias, pero, por costos, ausencia de motivación, entre otros, muchas veces tal pretensión se dificulta.

\section{Metodología}

Este artículo se inscribe en una investigación más amplia que analiza los motivos por los que ciertas instituciones educativas deciden formar parte del PD y las diferencias en su aplicación. A partir de estos objetivos generales, hemos trazado los específicos, relacionados al tipo de ciudadanía que las escuelas IB vehiculizan, la contribución a la desigualdad y fragmentación educativa que estas instituciones generan, los modos en que se hacen presentes los discursos y agencias globales de educación en Argentina y, su influencia en la política educativa local. Para ello se entrevistaron a autoridades - coordinadores del IB y del área CAS - y docentes de varias escuelas IB, de ambos subsistemas — estatal y privado- .

Para el análisis propuesto nos valdremos del trabajo de campo en curso, iniciado en 2017, en el que se realizaron entrevistas en profundi$\mathrm{dad}^{2}$ a agentes educativos de escuelas de ambos ámbitos de gestión integradas al IB a través de la implementación del PD. Las entrevistas son complementadas por observaciones de clases, trabajo de archivo en las instituciones y análisis de documentos programáticos y de páginas web de diez instituciones seleccionadas, ubicadas en el AMBA.

Nuestra perspectiva comprende que las escuelas no son organizaciones reproductoras de discursos, sino agentes y agencias dotadas de sentido y objetivos. En este sentido, tomamos la noción de micropolítica (Ball, 2002), para dar cuenta de las mismas como espacios de lucha de poder, donde los actores pugnan por el control, y donde se cristalizan distintos objetivos e intereses que están ideológica y valorativamente orientados $y$, las formas concretas y singulares en que se desarrollan estas micropolíticas, construyen la macropolítica. Los agentes e instituciones no son reductibles a simples reproductores de programas - a modo de paquetes - sino que intervienen en su delimitación y construcción, de manera consciente o no: en las escuelas hay negociación, casualidad y acciones ad hoc. Si sostenemos que las políticas y programas en general y - los educativos en par- 
ticular - están mediadas por discursos y agencias internacionales (Beech, 2009) y, pese a la centralidad estatal existen otras organizaciones, con o sin lucro, que intervienen en la delimitación de las políticas y programas educativos, tanto en su desarrollo como en su implementación, podemos afirmar siguiendo a Ball et al. (2012) que, las políticas y programas educativos son constantemente reinterpretadas y transformadas por los diferentes actores participantes del proceso, en contextos diversos en lo que refiere a su materialidad, historia y relaciones de poder, donde juega un rol preponderante la creatividad de las escuelas y sus actores para interpretar, traducir y poner en práctica esas políticas y programas (Beech et al., 2019).

Afirmamos, que la escuela supone un trabajo sobre el otro, y que, de los proyectos institucionales, márgenes de libertad y negociación mencionados se construye un oficio de alumno determinado, ya que los maestros con sus particulares expectativas, métodos, modos de gestión de la clase, concepción del aprendizaje, del orden, del trabajo, de la cooperación, van dando lugar al ejercicio de este oficio en la dinámica de cada institución escolar (Ball et al., 2012).

\section{Resultados}

\subsection{Escuelas privadas: la ayuda al "otro" y el desarrollo de capaci- dades personales}

Como mencionamos, el IB tiene ciertas particularidades en su inserción en Argentina, a través de su implementación mayoritaria en escuelas privadas para públicos de elite. Una exdocente y coordinadora del IB, que actualmente se desempeña como consultora de la organización, dice de su experiencia:

El programa ayuda (a los estudiantes) a vincularse con la comunidad a través del CAS, para mí es una de los componentes centrales por cómo los saca [los extrae] de su contexto, como los vincula con otra cosa, como les hace ver la realidad otra que muchas veces no la ven. De un lado ni del otro, como eso que me decían de la escuela estatal como la escuela privada. Para los dos colegios es un beneficio, porque los dos (tipos de) colegios están saliendo de sus respectivas burbujas y vinculándose con otro colegio o con la comunidad, con la necesidad del otro.

Esta percepción se replica en casi la totalidad de los docentes y directivos implicados. Son varios los fragmentos donde resaltan la importancia de abrir los horizontes de los estudiantes en las escuelas de elite. Las entrevistas que así lo refieren, se anclan en la " $s$ " del componente CAS y en los modos en que, a partir de diversas acciones pedagógica y solidariamente orientadas, pueden desnaturalizarse privilegios considerados universales por los estudiantes, a quienes identifican como posibles líderes del país -y del mundo- (Mayer, 2020). Es debido, tanto a su posición privilegiada como a su proyección profesional, que autoridades y docentes ven positivamente el desarrollo de estos proyectos y competencias relacionadas al ApS, a la par que supone la inculcación de compromiso ético que se espera perdure más allá de la trayectoria educativa. El componente CAS, articula las actividades de ApS integrando el desarrollo de proyectos y prácticas pedagógicas en las cuales los estudiantes aplican sus aprendizajes en problemáticas comunitarias situadas. El objetivo del ApS se orienta hacia la articulación de proyectos pedagógicos implementados en el PD relacionados con la vinculación de los estudiantes en el ámbito comunitario.

En cuanto a la dimensión referida a la ayuda al otro, destacamos que muchas escuelas venían desarrollando experiencias antes de sumarse al IB y, a partir de su pertenencia, se intensifican y formalizan. Según una coordinadora del área ApS:

Yo siento que nosotros ya teníamos la tradición del viaje a frontera que se transformó cuando vimos lo que teníamos que hacer 
en CAS. Servicio, la $\mathrm{S}$ de CAS, es lo que va a articular, además le tuvimos que agregar otros elementos al viaje por ser un programa de dos años. El plan solidario creció de una manera preciosa, antes los chicos preparaban el viaje, ahora además del viaje y para ganarse el derecho a viajar, los chicos tienen que hacer módulos: uno se llama instituciones en el que una vez por semana tienen que ir a una institución de la zona a dar su tiempo, dar apoyo escolar, ir al hogar Juanito, y es muy valioso esa vuelta que le dimos. Yo me acuerdo que le dije al rector, '[el viaje a] Frontera es precioso, pero acá parece que viven en el termo del barrio, los pones en un micro, hacen mil kilómetros a visitar la pobreza'.

Un coordinador de otra institución que tenía un programa previo, afirma:

Lo que pasa es que CAS es más grande: normalmente se la interpreta como servicio a la comunidad y no, es más que eso, busca desarrollar la creatividad, la acción, el uso del cuerpo y la vocación de servicio. En el colegio se trabajaba en el servicio a la comunidad y lo que hizo CAS fue ponerle un marco. Ahora está en un ciclo de mayor preponderancia en el marco del aprendizaje servicio y hay una gran vocación del colegio que haya aprendizaje en el servicio en proyectos que propone la escuela, promovidos desde los docentes. Ahora que se hace la mudanza de la escuela se hizo un proyecto de vinculación con la comunidad del barrio con gente dedicada a eso, a conocer las inmediaciones del campus, las necesidades de la comunidad.

En el ApS hay un pasaje de aprendizajes solidarios de carácter vertical hacia construcciones de solidaridades horizontales (Tapia, 2017), relacionadas con pedagogías orientadas a la formación ciudadana. En ambos casos, sus autoridades refieren a modificaciones en sus niveles de compromiso con las "causas" que acompañan, que tratan de incorporar transversalmente en su cotidianeidad, así como en la sistematización que imprimen a sus proyectos. Siguiendo la propuesta del ApS, los proyectos articulan contenidos curriculares específicos de las edades teóricas y de escolarización de los estudiantes. Esto es relevante porque posibilita mejoras en el rendimiento de los estudiantes involucrados, así como se espera incremente su sentido de pertenencia institucional (Tapia, 2018). Más allá de las diferencias de cada caso, observamos que la realización de los proyectos de ApS, pasan a conformar parte de la identidad institucional $-\mathrm{y}$ de la biografía personal- de quienes lo realizan: "el programa de [la escuela de] frontera existe. Los chicos saben que están involucrados en él y esperan la etapa del año para viajar".

Esto, como señalan otros estudios (Billig, 2013), fomenta institucionalmente un modo de desnaturalizar los privilegios en los estudiantes al tiempo que un compromiso ético por tenerlos. Los viajes solidarios tienen un lugar central, un eje transversal del currículo que ocupa diferentes momentos según el calendario escolar. Los estudiantes se movilizan durante los meses previos con diversas acciones relacionadas a preparar el viaje: conseguir financiamiento y recursos necesarios para las mejoras en la escuela apadrinada, planificar las actividades, entre otras. Los viajes solidarios son una peculiaridad del caso argentino frente a otras experiencias (Mayer, 2019). En relación a instituciones del IB en países desarrollados, estas acciones se concretan en viajes internacionales, que suponen estancias individuales y de verano. $\mathrm{Al}$ igual que con el resto de los proyectos de ApS, los viajes son proyectos institucionales: mientras en otros países los estudiantes deben sumar créditos con acciones que ellos deciden realizar, y que exceden los convenios e iniciativas de las escuelas (Billig, 2013; Billig \& Good, 2013), en Argentina, se trata de iniciativas al interior del país canalizadas institucionalmente. Esta diferencia es central, en tanto involucra a la comunidad educativa - docentes, autoridades, padres y estudiantes - en proyectos elegidos intencionalmente, con objetivos institucionales y pedagógicos que la escuela esboza, y no solo como un deber cívico que se pregona institucionalmente, pero desentendiéndose de su práctica 
y ejecución. Esto marca una diferencia nacional, observada en todas las escuelas frente a otras latitudes: la solidaridad se concibe como un aspecto institucional y no como acciones individuales, aunque aspiran a fomentar prácticas que perduren y puedan replicarse por fuera del ámbito escolar. Un importante diferencial tiene que ver con que los viajes solidarios no se encuadran dentro de los viajes educativos, ya que se realizan en el marco de reforzar vinculaciones institucionales con procesos de internacionalización y movilidad estudiantil en el marco del programa PD.

Vemos relevante reflexionar aquí sobre las concepciones frente a lo global y lo local, como enfoque que orienta los objetivos de los programas IB, y cómo tales principios son resignificados en la implementación del ApS en las instituciones abordadas. En este sentido, es generalizada la concepción de la globalización como procesos que desde el ámbito educativo configuran formas de ciudadanía que desbordan la identidad nacional como instituyente en la formación de sentidos individuales y colectivos. El sentido de lo global en las escuelas IB, implica el reconocimiento de la diversidad, nuevas formas de convivencia, valores como la tolerancia y la vocación como modos de construcción de sujeto perteneciente a una comunidad local, en diálogo con lo regional y lo internacional.

El componente global de los programas IB constituye un núcleo de representaciones en las cuales el ámbito educativo se reconfigura en el marco de la globalización como tendencia que hegemoniza atravesamientos institucionales. Tales representaciones en torno al potencial de la internacionalización educativa, buscan transformar realidades promoviendo habilidades y competencias que configuren prácticas ciudadanas globales sustentadas en la solidaridad, el respeto de las diferencias, la coexistencia como modo de convivencia o la reflexividad como posibilidad de resolución de los conflictos.

En contraposición con las instituciones que detentan historia en el desarrollo de proyectos solidarios, encontramos otras que no:
Investigadora: ¿Ustedes tenían algo antes de CAS?

Coordinadora: No, la verdad que no. Sigue siendo algo que cuesta mucho

I: Pero, por ejemplo, yo mientras esperaba vi algo de un programa ambiental. ¿Eso no lo consideran como CAS?

C: No, eso no.

I: ¿Por qué?

C: Eso fue o es una iniciativa de un profesor de biología que decidió hacer acciones relacionadas con la costa del Rio [de la Plata] que está acá cerca de la escuela. Pero es algo particular y parte de su materia

Por lo anterior, remarcamos que no todas las instituciones cuentan con acervos solidarios previos a su inclusión en el PD. Esa carencia de historia en la materia constituye una dificultad para delinear acciones en la actualidad, junto con otros desajustes en la implementación a nivel general del IB. Destacamos esto porque el ApS aparece acá delimitado, en lugar de concebirse como elemento constitutivo de la escuela —algo que las instituciones anteriores tienen- aún con las diferentes etapas y compromisos disímiles que en su devenir institucional han atravesado.

\subsection{El ApS en escuelas estatales: Invisibilización y falencias como fortalezas}

Anteriormente analizamos los modos en que el aprendizaje escolar se asienta en escuelas privadas para públicos de elite. Sin embargo, esta red trasnacional incluye instituciones del subsistema de gestión estatal, en menor medida para el caso argentino. Distintas investigaciones (Braslavsky, 1985; Gamallo, 2015; Mayer, 2012; Narodowsky \& Andrada, 2001) muestran cómo los sectores medios y medios altos migraron de las escuelas estatales hacia el sector privado, movimiento que se profundizó en décadas recientes. En 
relación a los públicos aventajados, aunque permanecen en algunas escuelas estatales específicas, su matrícula está concentrada mayoritariamente en escuelas privadas. No obstante, los porcentajes de la matrícula del sector privado muestran que el paso a ese subsistema no es exclusivo de las elites, ya que el porcentaje alcanza al 30\% de la matrícula nacional (Feldfeber et al., 2018), pero en centros urbanos como en la Ciudad de Buenos Aires alcanza un 50\% (Larrondo \& Mayer, 2018). Estudios como el de Gamallo (2015) señalan que, en menor medida, los sectores deciles más perjudicados de la sociedad, acompañaron esa migración al sector privado de educación. Esto plantea una diferencia con las escuelas analizadas a las que asisten públicos privilegiados, con los que albergan las escuelas estatales, ya que estas instituciones no pueden asumir el rol de desnaturalizar los privilegios de pequeñas porciones de la sociedad. Tal es así que, para una rectora entrevistada, se complica el proceso del ApS:

Acá es muy difícil, hacen algunas cosas, algunas colectas y rifas, pero la realidad es que acá los chicos están más cerca de ser los receptores de esas acciones que de ser los que las generan.

Ante esta misma situación y perfiles socioeconómicos, autoridades de otra de las escuelas estatales adaptaron el componente CAS, ya que las situaciones son otras:

Antes yo trabajé en dos escuelas privadas que tenían el IB y coordinaba también el área de aprendizaje-servicio. ahí es más fácil en todo sentido: el IB estaba más asentado, era más conocido. Acá no es igual: son muy pocos los estudiantes que lo rinden. Si bien todos participan del taller, el compromiso y la exigencia no son las mismas. Lo otro que lo simplificaba era que era fácil identificar un tercero para quien obrar. Acá no podés hacer eso.

Luego, continúa:

Nosotros acá tenemos a chicos en situaciones muy complejas. No les podés pedir esfuerzos económicos. Lo que hicimos fue conjugar los saberes específicos de los chicos, como estudiantes de una escuela técnica, con el trabajo comunitario. Entonces desarrollamos una herramienta para medir el $\mathrm{PH}$ del lago de Palermo y de arroyos cercanos. Como somos una escuela estatal es fácil conseguir donaciones del equipamiento necesario, algo que como escuela privada no conseguiríamos. Es un proyecto para mejorar la calidad de vida de la comunidad.

A diferencia de las experiencias del sector privado, aquí existe un espacio áulico específico donde desarrollar el proyecto, que corresponde a la asignatura Taller. Allí trabajan de manera conjunta la coordinadora del área CAS, aportando sus saberes referidos al ApS y profesores del área específica para desarrollar el proyecto. Estos últimos son egresados de esta institución, con lo que estos proyectos están mediados por su filiación institucional, abonando al sentido de pertenencia y comunidad educativa. Mientras los profesores a cargo aportan los saberes específicos, la responsable de CAS aporta los conocimientos del área y las gestiones con empresas y donaciones, que repercuten en vinculaciones y trayectorias laborales de los alumnos.

\section{Discusión}

En párrafos anteriores hemos dado cuenta de los proyectos de las escuelas comprendidos dentro del área CAS del IB. Con esto no queremos decir que no existan experiencias de ApS más allá del $\mathrm{PD}$, sino que estas escuelas lo incorporan a partir de él. En relación con las escuelas de gestión privada, identificamos dos cuestiones de manera regular: primero, el desarrollo de proyectos referidos a un otro al que ayudar y, luego, la existencia de experiencias previas. Siguiendo la definición de ApS esgrimida, afirmamos que tales acciones se enmarcan en la idea de realización de servicios comunitarios, en donde, aunque existía intencionalidad solidaria no había conexión con los contenidos pedagógicos, es decir, no tienen 
base en el currículo, como afirmaron las autoridades entrevistadas. A su vez, la lógica del servicio comunitario supone menor compromiso de los estudiantes - y de la institución-y menor impacto de las acciones, al no estar pedagógicamente orientadas, ni estructuradas en el tiempo (Spring et al., 2008).

La integración al currículo del ApS supone niveles más altos de compromiso institucional, pues involucra el despliegue de estrategias y recursos - humanos, materiales y simbólicos- para realizar el proyecto. Este compromiso institucional es clave para que las narrativas y repertorios instalen su desarrollo, evitando que su implementación derive en posiciones voluntaristas de los docentes.

En torno a la inclusión del ApS en estas escuelas a través del IB, surge una limitación. Como indicamos al comienzo, al no ser obligatorio los estudiantes deciden sumarse al PD opcionalmente. Esto puede llevar a distintos niveles de compromiso, ya que para unos es obligatorio realizarlo y acreditarlo, y para otros no, según las exigencias institucionales. Aquí las instituciones tienen la posibilidad de incorporarlo más allá del IB.

En relación con ambos ámbitos de gestión, lo que emerge de las entrevistas es una asociación entre ApS y servicio comunitario, donde aparece como central la idea de ayudar a un otro, vulnerable en términos socio-económicos. Tal es así, que como vimos en el caso de una escuela privada, se invisibilizaron acciones comunitarias por el medioambiente o, dicho de otra forma, los saberes previos de las autoridades de esa institución impidieron que ese tipo de actividades se vislumbren como experiencias de ApS, pese a la existencia de manuales y bibliografía del área que incentiva estos proyectos.

Observamos también, en las escuelas estatales las posibilidades de desarrollo de experiencias acordes se limitan en función de la categoría socioeconómica a la que pertenecen los estudiantes, sin explorar otras opciones. Igualmente, pareciera que el desarrollo de las actividades ana- lizadas corresponde a una lógica de descarte: al no poder — según las autoridades institucionales- realizar actividades solidarias tradicionales, se exploran otras.

En ambos ámbitos de gestión, prima una ética ciudadana responsable y activa, donde los estudiantes-ciudadanos deben comprometerse con su entorno. Para las escuelas privadas tal compromiso es tanto privilegiados sociales, mientras que en la experiencia estatal que logra motorizar proyectos, parte del colectivo que encuentra una utilidad social a sus conocimientos. En este sentido, observamos narrativas que tensionan las desigualdades en las instituciones que implementan los programas IB. Respecto a las prácticas pedagógicas de ApS, observamos que siguen reforzando miradas escalares de las identidades sean locales, nacionales o internacionales. Aunque esta concepción de la globalización no se restringe al ámbito educativo en el cual se emplazan estos programas, si legitima valoraciones fragmentarias sobre la internacionalización como un abanico de oportunidades que ofrece el mundo IB, vinculado con el cosmopolitisimo como ideal.

La construcción de ciudadanía global comprende complejidades sobre las identidades, en tanto referencian al multiculturalismo y las diversidades como valores éticos del mundo global. Las relaciones entre lo global y lo local, aunque fragmentarias, refuerzan representaciones de la justicia, la paz, la tolerancia y convivencia haciendo del servicio, el compromiso y la reflexividad individual herramientas para el desarrollo de habilidades y competencias de ciudadanías globales. Estos componentes sustentan la lógica del CAS y del ApS como proyecto pedagógico posibilitando a los estudiantes generar solidaridades en ámbitos comunitarios. En ambos casos, el reconocimiento de los jóvenes como protagonistas y responsables es un factor aglutinante de estas prácticas.

Sobre esto proponemos consideraciones en torno a dos extremos - y los matices posibles-: por un lado, empoderan a los estudiantes en el reconocimiento de derechos vulnerados y 
que son ellos quienes deben buscar soluciones, muchas veces realizando reclamos al Estado, en cualquiera de sus niveles. En el otro extremo, estos formatos de participación no institucional pueden debilitar las acciones estatales, que se realizan por otros medios, en alianza con sectores intermedios - ONG - contribuyendo a debilitamientos mayores de las instituciones estatales. A su vez, marcan desigualdades entre escuelas que pueden movilizar y motorizar recursos y aquellas que no alcanzan a hacerlo. Esto tiende a desplegar formas de acción colectiva despolitizadas donde se restringe el espacio de la política e intervienen otros actores y lógicas. Así, advertimos en las desigualdades en la aplicación de los programas IB en los diversos ámbitos de gestión, tensiones que refuerzan resistencias de la institucionalidad del sistema educativo a la adaptación hacia lógicas globalizantes de los programas pedagógicos, sobre todo en las escuelas estatales, pues suponen procesos de elitización hacia adentro que lleva a estas escuelas a implementar lógicas de flexibilización de los componentes del programa IB, lo que no ocurre en las escuelas privadas estudiadas.

\section{Conclusiones}

En el artículo analizamos los modos de implementación de proyectos de ApS en escuelas privadas y estatales adheridas al PD del IB. Las implementaciones del ApS en estas escuelas se enmarcan en las normativas educativas nacionales vigentes que destacan la educación solidaria como dispositivo pedagógico para su vinculación con las problemáticas locales, fortaleciendo procesos de formación ciudadana.

En el caso de las escuelas privadas que realizan los proyectos - y contaban con acervo en su historia institucional respecto de proyectos comunitarios - pueden entenderse dentro de una lógica en la que se pretende formar individuos conscientes de sus privilegios para abrirlos al mundo y sacarlos de su zona de confort. Detrás de estas prácticas, emerge una lógica de buenos ciudada- nos, comprometidos con su sociedad, a modo de devolución por su posición social. Estas narrativas parecen estar acordes con otras que promueven procesos participativos no partidarios, en los que no se puede esperar que los representantes políticos - por diversos motivos - actúen y decidan movilizarse. Estas ayudas son seleccionadas e individualizadas, aún cuando se trate de un colectivo: se determina una institución, organización o grupo destinatario que se pueda asistir, sin pretensión de alterar el statu quo.

Aunque esto tiene aristas positivas, una desventaja mostrada por las autoridades es la de presentar repertorios despolitizados: los proyectos solidarios instituyen experiencias de ayuda al otro ofrecida en relación a falencias y sus destinarios no suelen ser problematizados como sujetos vulnerados en derechos esenciales, conllevando al reforzamiento de las posiciones originales (Cookson et al., 2010; Tiramonti \& Ziegler, 2008): según los segmentos analizados, las solidaridades se conciben como prácticas que amplían los universos estudiantiles, sin intencionalidad de buscar transformaciones integrales. Se plantean acciones para paliar posiciones desaventajadas, como colaborar con escuelas de frontera rurales, sin modificar situaciones esenciales. Cabe acá la pregunta respecto del rol de las escuelas en buscar soluciones estructurales.

Observamos en estas escuelas la aplicación de dispositivos de voluntariado y el desarrollo de la solidaridad privada que intenta ayudar con narrativas altruistas (Mayer, 2013), a un otro muchas veces remoto. Señalamos proyectos vinculados con prácticas devenidas de la Responsabilidad Social Empresarial; procesos de voluntariado y comunitarios. Estos procesos se vinculan con narrativas que las autoridades definen como adecuadas para sus escuelas, más centradas en los beneficios que pueden obtener los estudiantes que en sus impactos sobre las comunidades. También, como mencionamos, proyectos institucionales que podrían incorporarse al paraguas del ApS aparecen invisibilizados para las autoridades en tanto tal. 
En el caso de las escuelas estatales analizadas, vemos dos componentes a destacar: de un lado, autoridades que entienden al ApS en clave de ayuda, que al considerar que los estudiantes son quienes podrían precisarla, no encuentran motivaciones en realizar proyectos en esta área. Esta ausencia supone dificultades de seguimientos por parte de las autoridades del IB, que acreditan el funcionamiento del CAS. De otro lado, en la segunda escuela estatal estudiada, la aparente dificultad — la categoría socioeconómica de su población- se presentó como un desafío para pensar alternativas de proyectos concebidos de manera integral: como parte de una comunidad que entiende la necesidad del desarrollo sustentable y desarrolla una lógica más horizontal, donde las narrativas del ApS se amplifican, frente a miradas angostas de los casos del sector privado estudiados. Aquí son las propias dificultades las que llevan a las instituciones a reconocer problemas comunes a la sociedad movilizando a los estudiantes en su carácter de ciudadanos y futuros profesionales con protagonismo eficaz y técnico.

\section{Notas}

1 Otro caso señalado por los autores (Ball \& Youdell, 2008), refiere a la privatización exógena de la educación, correspondiente a una privatización de la educación, generando cuasi-mercados y teniendo en al caso chileno como principal expresión.

2. En todos los casos entrevistados, sus repertorios fueron abordados comprensivamente, teniendo en cuenta los contextos específicos dentro de los que se desarrollan. Desde nuestra perspectiva, todo actor social al narrar una situación determinada, la produce. Coincidimos con Saltalamacchia (1992) cuando señala que el individuo es "un lugar de "anudamiento" de un conjunto determinado de relaciones sociales" (p. 38). La entrevista debe ser entendida como el marco de una elaboración teórica conjunta en la que no surgirán acuerdos totales o aprovechamientos semejantes; pero sí interpretaciones que no existían antes de la relación (Saltalamacchia, 1992).

\section{Referencias bibliográficas}

Ball, S. (1989). La micropolítica de la escuela: hacia una teoría de la organización escolar. Paidós.

Ball, S., Maguire, M., \& Braun, A. (2012). How schools do policy. Policy enactments in secondary schools. Routledge.
Ball, S., \& Youdell, D. (2008). Hidden Privatization in public Education. University of London.

Beech, J. (2011). Global Panaceas, Local Realities: International Agencies and the Future of Education. Peter Lang.

Beech, J., \& Barrenechea, I. (2011). Pro-market educational governance: is Argentina a black swan? Critical Studies in Education, 52(3), 279-293. https://doi.org/10.1080/17508487.2011.604077

Beech, J., Guevara, J., \& Del Monte, P. (2019). Diploma Programme Implementation in Public Schools in Latin America: The cases of Buenos Aires, Costa Rica, and Peru. International Baccaulareate Organization. https://bit.ly/3lWXWIp

Bourdieu, P. (1984). Distinction: A social critique of the judgement of taste. Trans. R. Nice. Routledge \& Kegan Paul.

Bourdieu, P. (1986). The forms of capital. In Handbook of theory and research for the sociology of education, ed. J. Richardson, 241-58. Greenwood.

Billig, S. (2013). Impact of Participation in CAS on Students' Civic mindedness and engagement. RMC Research Corporation. https://bit.ly/2FhXljH

Billig, S., \& Good, B. (2012). International Baccalaurete IDiploma Programa. Evaluation Report. Study of North and South Students Civic Mindedness. Phase II. RMC Research Corporation. https://bit.ly/3jYfvWx

Braslavsky, C. (1985). La discriminación educativa en Argentina. Miño y Dávila.

Bunnell, T. (2008). The global growth of the International Baccalaureate diploma programme over the first 40 years: A critical assessment. Comparative Education, 44(4), 409-24. https://bit.ly/2R91TeW

Castillo, J., Erales, D., \& Sánchez, V. (2007). Manual de Aprendizaje-Servicio. Ministerio de Educación. https://bit.ly/3k1yKhQ

Cookson, P., \& Hodges Persell, C. (2010). Preparing for power: Twenty Five years later". In A. Howard, \& R. Gaztambide Fernández (Comps.), Educating elites. Class Privilege and educational advantage. Rowman and Littlefield Education.

Doherty, C., Luke, A., Shield, P., \& Hincksman, C. (2012). Choosing your niche: The social ecology of the International Baccalaureate 
Diploma in Australia, International Studies in Sociology of Education, 22(4), 311-332. https://bit.ly/3m5LYfp

Dubet, F., \& Martuccelli, D. (1999). ¿En qué sociedad vivimos? Losada.

Feldfeber, M., Puiggros, A., Robertson, S., \& Duhalde, M. (2018). La privatización educativa en Argentina. Documentos de Trabajo. Instituto de Investigaciones Pedagógicas "Marina Vilte". Secretaría de Educación CTERA. https://bit.ly/3m0kGqR

Furco, A. (2002). Is Service-Learning Really Better than Community Service? A Study of High School Service. In A. Furco, \& S.H. Billig (Eds.), Advances in Service-Learning Research: Vol. 1. Service-Learning: The Essence of Pedagogy. Information Age Publishing.

Gamallo, G. (2015). La "publificación" de las escuelas privadas en Argentina. Revista SAAP: Sociedad Argentina de Análisis Político, 9(1), 43-74. https://bit.ly/2GIrp8M

Kahn-Rahman, S. (2010). Getting in: How elite schools play the college game. In A. Howard, \& R. Gaztambide Fernández (Comps.), Educating elites. Class Privilege and educational advantage. Rowman and Littlefield Education.

Larrondo, M., \& Mayer, L. (2018). Ciudadanías juveniles y educación. Las otras desigualdades. Grupo Editor Universitario.

Mayer, L. (2009). Hijos de la democracia. ¿Cómo viven y piensan los jóvenes? Paidós.

Mayer, L. (2012). La conflictividad escolar cotidiana. Estrategias para su minimización. (Tesis de Doctorado). Universidad de Buenos Aires, no publicada.

Mayer, L. (2019). Viajar para aprender y aprender viajando. Estrategias educativas de sectores aventajados de Argentina. Universidad Politécnica Salesiana, Universitas, 30, 41-62. https://bit.ly/35mcHOX

Mayer, L. (2020). Grandes Proyectos para pequeños públicos. El caso de las escuelas internaciona- les en Argentina. En L. Mayer, M. Lerchundi, \& M.I. Domínguez, (comps) Infancias, juventudes y desigualdades: Experiencias, procesos, espacios. CLACSO.

Narodowski, M., \& Andrada, M. (2001). The privatization of education in Argentina, Journal of Education Policy, 16(6) 585-595.

https://bit.ly/35h8Dzr

Resnik, J. (2015). The incorporation of the International Baccalaureate in Magnet schools in the United States: Survival strategies of low performing schools. Educational Practice and Theory, 37(2), 79-106. https://bit.ly/33b6Klm

Resnik, J. (2016). The development of the International Baccalaureate in Spanish speaking countries: A global comparative approach. Globalisation, Societies and Education, 14(2), 298-325. https://bit.ly/2R5CbrJ

Saltalamacchia, H. (1992). La historia de vida: Reflexiones a partir de una experiencia de investigación. Ediciones SIJUP.

Spring, K., Grimm, R., \& Dietz, N. (2008). Community Service and Service-Learning in America's Schools, 2008. Office of Research and Policy Development, Community Service and Service-Learning. https://bit.ly/2FjoDpC

Tapia, M. (2017). Aprendizaje-servicio, un movimiento pedagógico mundial. En L. Rubio, \& A. Escofet (Coord.), Aprendizaje-servicio (ApS): Claves para su desarrollo en la Universidad. Octaedro-ICE.

Tapia, M. (2018). Guía para desarrollar proyectos de aprendizaje-servicio solidario. CLAYSS. https://bit.ly/3md8rHI

Tiramonti, G. (2004). La trama de la desigualdad educativa. Mutaciones recientes en la escuela media. Manantial.

Tiramonti, G., \& Ziegler, S. (2008). La educación de las elites. Aspiraciones, estrategias y oportunidades. Paidós. 



\section{ALTERIDAD}

p-ISSN: 1390-325x / e-ISSN: 1390-8642

Vol. 16, No. 1/ enero-junio 2021

\section{Sección Miscelánea}

(Miscellaneous Section)

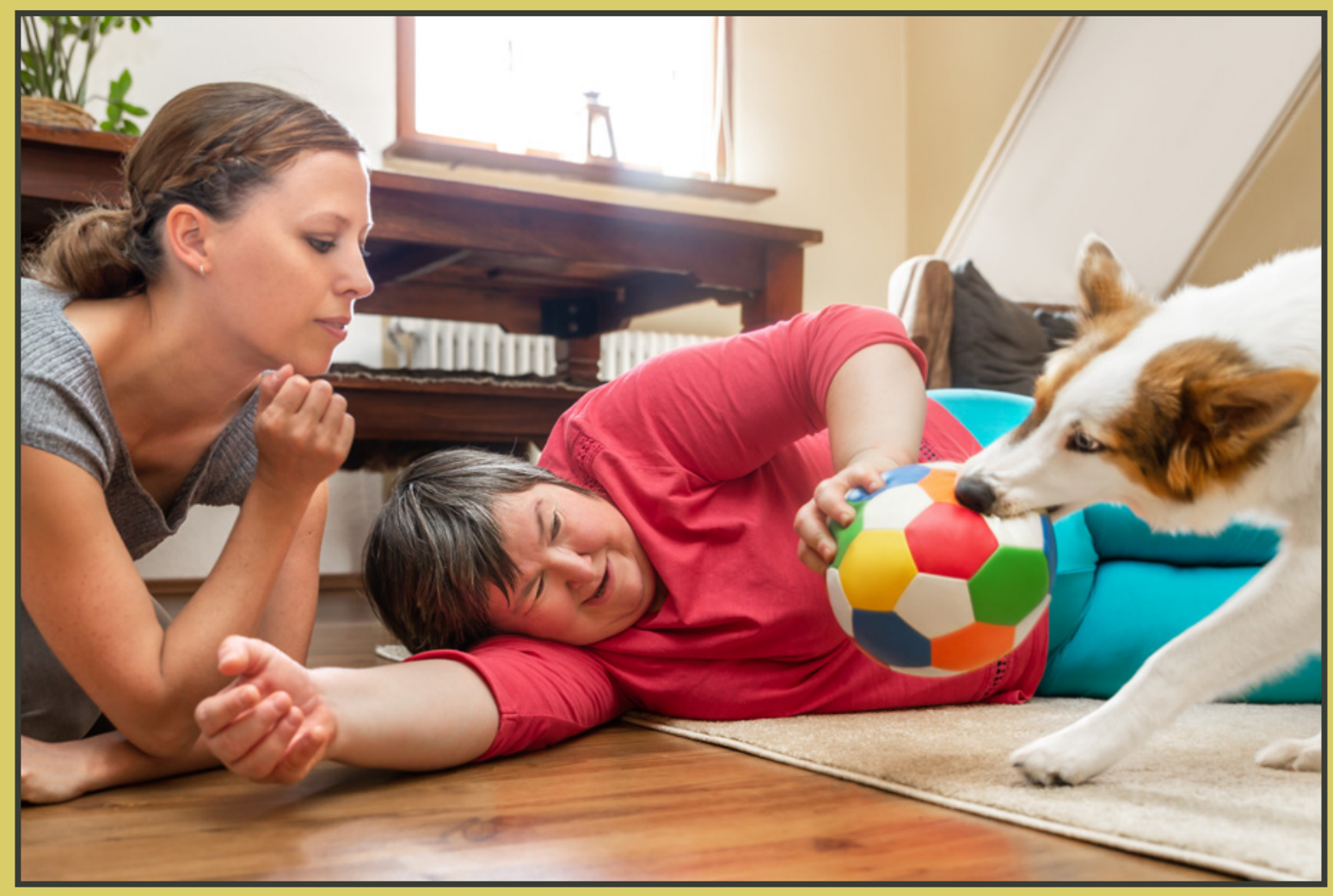

Fuente: https:/ / www.shutterstock.com/es/image-photo/mentally-disabled-woman-laying-on-floor-1113194162 


\section{=ALTERIDAD Investigación y aprendizaje: Retos en Latinoamérica hacia el 2030}

\section{Research and learning: Challenges in Latin \\ America towards 2030}

D Dr. Julio Juvenal Aldana-Zavala es docente e investigador de la Universidad Nacional Experimental Francisco de Miranda y Red de Investigación Koinonia (Venezuela) (julioaldanazavala@gmail.com) (https://orcid.org/0000-0002-7934-9103).

(D) Dr. Patricio Alfredo Vallejo-Valdivieso es docente e investigador de la Universidad Técnica de Manabí (Ecuador) (patricio_2871@yahoo.es) (https://orcid.org/0000-0003-3248-7864).

(D) Dr. Josía Isea-Argüelles es docente e investigador de la Universidad Nacional Experimental Francisco de Miranda y Red de Investigación Koinonia (Venezuela) (josiaisea@gmail.com) (https://orcid.org/0000-0001-8921-6446)

Recibido: 2020-01-31 / Revisado: 2020-10-21 / Aceptado: 2020-11-26 / Publicado: 2021-01-01

\section{Resumen}

La educación ha tenido un giro epistémico en su accionar pedagógico, transcendiendo del modelo tradicional enfocado en el docente, hacia uno focalizado en el estudiante. En paralelo, la investigación se ha fomentado hacia nuevas vertientes metódicas, siendo un factor clave en el aprendizaje. Hoy día es esencial la fusión del aprendizaje e investigación con la función de generar conocimientos desde nuevos ángulos educativos. Además, la UNESCO y otros entes enfocados a la educación, han propuesto la conformación de un modelo educativo para aprender a lo largo de la vida. Es así que la presente investigación presenta los alcances en investigación y aprendizaje en Latinoamérica, para tal fin se planteó como objetivo central: Analizar la investigación y aprendizaje como retos en Latinoamérica hacia el 2030, en este sentido se empleó una metodología descriptiva documental con un diseño bibliográfico, teniéndose como muestra poblacional, la revisión de 52 artículos de revistas indizadas en Scopus, Web of Science, Scielo, Redalyc, Latindex Catálogo 2.0. Esto con la finalidad de sistematizar propuestas de investigadores, identificándose factores pertinentes hacia la consecución de una educación transversal como medio para el logro de los ODS. Entre las conclusiones se tiene la necesidad de formar en una epistemología posibilitadora de una ecología de saberes en procura de contar con instituciones educativas, sostenibles y productivas como eje medular de la sociedad global.

Descriptores: Investigación pedagógica, organización, aprendizaje activo, educación alternativa, política educacional, estrategias educativas.

\section{Abstract}

Education has had an epistemic turn in its pedagogical action, going from the traditional model focused on the teacher, to one focused on the student; at the same time, research has been encouraged towards new methodical aspects, being a key factor in learning. Today, it is essential to merge learning and research with the function of generating knowledge from new educational angles. UNESCO and other entities focused on education have proposed the creation of an educational model for lifelong learning. Thus, this research presents the scope of research and learning in Latin America, for this purpose it was proposed as a central objective:To analyze research and learning as challenges in Latin America towards 2030, in this sense a descriptive methodology was used with a bibliographic design, taking as a population sample, the review of 52 articles from journals indexed in Scopus, Web of Science, Scielo, Redalyc, Latindex Catalog 2.0. This with the purpose of systematizing researchers' proposals, identifying pertinent factors towards the achievement of a transversal education as a means for the achievement of the SDG. Among the conclusions is the need to form an epistemology that makes possible an ecology of knowledge in order to have educational, sustainable and productive institutions as the core of the global society.

Keywords: Educational research, organization, activity learning, alternative education, educational policy, educational strategies.

Forma sugerida de citar: Aldana-Zavala, J., Vallejo-Valdivieso P., \& Isea-Argüelles, J. (2021). Investigación y aprendizaje: Retos en Latinoamérica hacia el 2030. Alteridad, 16(1), 78-91. https://doi.org/10.17163/alt.v16n1.2021.06 


\section{Introducción}

La educación global transita entre la sociedad de la información y transcender a la del conocimiento; ambos involucran lo tecnológico e informático, varía en cuanto se plantea que el estudiante debe transformar la información recibida (sociedad del conocimiento), tal como lo propone la UNESCO (2005). El aprendizaje desde lo abordado, involucra fomentar en el estudiante un proceso integral de interconexión con las múltiples realidades en donde se desenvuelve, siendo necesario un reconocerse a sí mismo y al otro como sujetos cognoscentes e inteligibles emocionales para construir desde la intersubjetividad un ambiente de respeto mutuo, valoración de las capacidades y trabajo cooperativo para la construcción del conocimiento en razón de conformar escenarios educativos donde la ética sea transversal en el razonamiento de comprender a la persona como un ente transcendental para la construcción de una mejor sociedad. A partir de lo planteado, la investigación tiene por objetivo central, analizar la investigación y aprendizaje como retos en Latinoamérica hacia el 2030.

\section{Método}

La metodología empleada es de tipo descriptivadocumental con un diseño bibliográfico, lo que permitió escrutar 52 artículos de revistas indizadas en Scopus, Web of Science, Scielo, Redalyc y Latindex Catálogo 2.0 con el fin de conocer la tendencia, retos, debilidades y fortalezas de la educación latinoamericana en función de la investigación y aprendizaje hacia el 2030; aplicándose la técnica de análisis de contenido para extraer las ideas más relevantes planteadas por los investigadores y así, construir un cuerpo teórico como aporte a la generación de conocimientos en actualización del estado de la cuestión, contribuyendo a generar investigaciones posteriores desde una óptica experimental o cualitativa.

\section{Resultados y discusión}

Se presentan cuatro áreas de análisis en conformidad de brindar respuesta al objetivo central, entre las cuales se encuentran: Educación y objetivos de desarrollo sostenible; La planificación centrada en la investigación; Docente investigador; Hacia un abordaje epistemológico educativo 2030.

\subsection{Educación y objetivos de desa- rrollo sostenible}

La educación al ser catalogada en factor transversal juega un papel primordial en la efectividad de lograr los objetivos de desarrollo sostenible, no puede percibirse como un ente aislado o dicotómico. Es necesario transcender hacia un modelo integrador donde los actores educativos tengan la oportunidad de construir conocimientos holísticos e interrelacionados con el mundo global y las múltiples necesidades a superar para lograr una sociedad de paz con base en el progreso productivo. Al respecto Murillo y Duk (2017), destacan el apremio del tiempo para cumplir con los ODS, requiriéndose estructurar urgentemente planes estratégicos en los entes educativos y de investigación, concatenados para optimizar recursos en la consecución de una educación centrada en la investigación para aprender a lo largo de la vida. Mientras que Cosme-Casulo (2018), complementa al señalar a la universidad como institución vital para tal fin, debido a su rol de formador de formadores e investigadores, profundizando la vinculación con las comunidades en razón de intercambiar saberes para la transformación mutua.

Ambos autores concuerdan en la necesidad de una educación basada en cambios de paradigmas desde la formación universitaria y las modalidades de investigar, viéndose involucrados los centros de investigación como factor gerencial para la proyección de investigaciones pertinentes al devenir 2030, incluyendo a las organizaciones públicas y privadas, en un trabajo mancomunado para el aporte de resultados sig- 
nificativos al logro de la supresión de la pobreza, concordando los autores en una correlación directa entre los objetivos de desarrollo sostenible 4 y 16.

La educación al no contar con el debido financiamiento entra en conflicto sobre el rol social que juega, es imprescindible preguntar si: ¿Es un bien común? o ¿un factor para el desarrollo económico? ¿indicador para el crecimiento social? y, ¿qué es realmente la educación y qué papel persigue de cara al 2030? Locatelli (2018), colabora en descubrir las respuestas al plantear la necesidad de "desarrollar sistemas más sostenibles” (p. 194). En una sociedad donde la deserción escolar es una amenaza para las clases sociales de mayor vulnerabilidad, se hace necesario generar una estructura escolar sostenible, lo cual implica flexibilizar los currículos para la integración e inserción laboral de los estudiantes, posibilitando complementarse entre lo económico y académico. En este sentido, Agosto et al. (2018), indican la necesidad de políticas de atención de los jóvenes, cooperando en su crecimiento integral, mediante la generación de una visión de futuro basada en proyectos de vida, para lo cual la educación no debe basarse en el mero modelo de inclusión, sino, complementarse con una epistemología compleja de abordaje de la realidad social como eje medular para configurar un racionamiento reflexivo del actuar para el bien de la sociedad.

El sistema educativo debe transitar al ritmo que lo hacen las sociedades, la dinámica social es cambiante y cada día surgen expectativas sobre todo en la población joven sobre lo que será su futuro socioeconómico, en un mundo donde lo tecnológico abre brechas entre quienes tienen o no acceso a la misma; es impensable que la escuela y la universidad del futuro próximo debe ser igual hasta lo que ahora conocemos y manejamos. Entonces, ¿cómo debe ser la educación de cara al 2030?; necesariamente integrativa de todos los factores que conforman la sociedad, conformando planes estratégicos de crecimiento integral en el cual se plantee el hacia dónde se pretende ir y cómo se va a lograr, al ser la educación el eje medular. Vera-del Carpio (2015), amplía diciendo que es necesario la unión de lo público con lo privado para ejecutar acciones concretas desde la educación al logro de una sociedad sostenible, con base en la formación preventiva de la salud, ecología y ambiente, aristas necesarias para contar con una sociedad saludable en todos sus ámbitos, optimizándose recursos para ser invertidos en educacióninvestigación, además de propiciar una cultura ciudadana de respeto para la convivencia entre el ser humano y factores bióticos-abióticos.

Azorín-Abellán (2017), indica el reto global de propiciar una educación para todos, eficaces e inclusivas, donde se exige desde los organismos multilaterales articular la inclusión, calidad, eficacia y equidad, como indicadores que permitan transversalizar la educación en pro de contribuir al logro de los objetivos de desarrollo sostenible, lo cual implica redescubrir el rol social de la educación como factor neurálgico en consideración de generar la sinergia de los diversos actores sociales con la finalidad de consolidar una actuación que permita el logro efectivo de los cuatros indicadores mencionados como elemento central para contar con una sociedad basada en la alteridad educativa.

\subsection{La planificación centrada en la investigación}

Una educación transversal e integrativa de procesos que permita concatenar acciones en pro de trabajar en la consecución de los 17 objetivos de desarrollo sostenible como acción concreta para la transformación social de los pueblos en favor de erradicar la pobreza, debe estar apuntalada en la mejora permanente de los estilos de cómo se promueve el aprendizaje en los ambientes educativos y contar con la investigación como eje fundamental para tal fin. De ese modo, el currículo debe estar concebido desde una intencionalidad investigativa donde los actores educativos trabajen cooperativamente para el logro 
de metas propuestas, es así que los docentes deben planificar desde una visión centrada en la investigación-acción como eje alternativo para superar el modelo dicotómico de educar e investigar, propio del enfoque disciplinar (Pérez-Van Leenden, 2019).

La planificación centrada en la investigación como modelo pedagógico invita a considerar el aporte y potencialidades de todos los actores involucrados en el proceso de aprendizaje, esto implica involucrar a la comunidad educativa en su contexto social, así cada uno puede brindar aportes significativos en la construcción de currículos donde se aprenda a pensar, construir, resolver problemas de interés social e innovar; trabajando en el enfoque por proyectos, así como otros donde el estudiante tome un rol protagónico en aras de articular acciones que favorezcan el conocimiento para la vida, considerándose esto como un criterio de calidad educativa, es necesario contar con programas estratégicos enfocados a guiar la educación de cara al 2030, esto un obstáculo para el logro de una educación inclusiva tal como lo señala (Meléndez-Rojas, 2017), presupuestando una educación creativa e innovadora a largo plazo, formando para ser eficientes en tecnología en armonía con el medio ambiente.

Uno de los aportes de la planificación centrada en la investigación es que permite concebir la educación desde la centralidad del estudiante y no desde el docente, con lo cual se pueden incluir diversos enfoques pedagógicos basados en la cosmovisión del aprendizaje dinámico, flexible y reflexivo, apoyado en las tecnologías de información y comunicación, contextualizado a las múltiples necesidades sociales (Peche-Cruz \& Giraldo-Supo, 2019). Ante esta postura pedagógica, Molina-Naranjo et al. (2018), destacan la necesidad de formar a los futuros docentes desde un currículo transversal en lo "epistemológico, axiológico, investigación, formación, competencias para la integración de las TIC y competencias profesionales generales" (p. 162); lo cual debe converger en el enfoque centrado en el estudiante, propiciándose progresivamente un cambio en la praxis del profesional educativo, posibilitándose la comprensión, para asumir nuevas posturas pedagógicas donde se transcienda el statu quo, favoreciéndose esta acción, desde la formación-evaluación continua como parte del proceso educativo (Huapaya-Capcha, 2019).

En virtud de lo abordado, es ingenuo pensar que, con el solo cambio de planes en lo documental sin contar con la debida sensibilización y formación a los actores educativos, estos optarán por asumir asertivamente los cambios paradigmáticos propuestos. De ahí un reto intrínseco en el logro de construir una planificación centrada en la investigación como estrategia transversal para el logro de una educación hacia el 2030. Otro reto es fundamentar la investigación como un proceso atractivo para los estudiantes, sin que esto implique la pérdida del carácter científico de la misma, ante lo cual, Loli-Ponce (2015), indica que los estudiantes manifiestan no tener el tiempo necesario para hacer investigaciones, aunque están conscientes de la importancia que reviste la misma para el aprendizaje y para el conocimiento, por cuanto el currículo disciplinar fragmentado, al percibir la investigación como un producto final del estudiante, no se contextualiza a lo largo del entramado curricular como un ente integrado a la formación.

Esto indica que el enfoque de planificación centrado en la investigación debe ser asumido desde una reconstrucción del currículo, por cuanto no podría trabajarse con una visión tradicional y emergente a la vez en la educación, se necesita de una transposición educativa para conformar una educación de calidad en la praxis y no en una mera retórica de los actores sociales. En este sentido, Calvo (2013), comenta que la formación docente debe estar planificada en función de la participación de los diversos factores sociales, lo cual implica una obligatoria concatenación entre la educación y las diversas instituciones públicas y privadas, planteándose un programa para todos en favor de una educación inclusiva. 
El involucramiento de los actores sociales para que sea efectivo, a juicio de Carrillo-Flores (2016), pasa por develar lo oculto de la educación, es decir, las ideologías que han estado implícitas en la misma como un modo de sincerar el trabajo hacia la transcendencia de la inclusión como un ente utópico, dado que la autora destaca que los principios y las intenciones educativas no son neutrales desde una perspectiva política. Es necesario realizar un paréntesis para señalar que cuando se plantea la educación inclusiva en el actual documento, se hace pensando en la posibilidad que todos los actores sociales tengan acceso a la educación distanciándose del término inclusiva como algo exclusivo de las personas con discapacidad- por cuanto existen discapacidades sociales que excluyen muchas veces, tal como promueve CornejoEspejo (2019), al concebir la inclusión como un reconocimiento ético de la realización humana, subrayando la importancia de la deconstrucción de los paradigmas que promueven la exclusión, es necesario retomar la esencia fundamental de la educación como un derecho al cual deben tener acceso todas las personas.

La planificación centrada en la investigación cuando se asume como un hecho complejo e inclusivo donde los actores educativos tienen la posibilidad de ser protagonistas y no espectadores; pronostica un cambio paradigmático donde la ciencia sin perder su rigurosidad se hace accesible. El aprendizaje contribuye a formar ciudadanos críticos-reflexivos, teniendo en consideración el término "bioresistencia" de Aya-Velandia (2018), quien explica que "es una manera de asumir los conocimientos científicos y aplicarlos en la cotidianidad" (p. 205). Se redescubre el rol de la persona como un ser integral donde los diversos factores exógenos influyen para la conformidad de un sujeto cognoscente al servicio de la sociedad.

Un sujeto cognoscente implica una relación con otros sujetos cognoscentes, siendo necesario transcender el paradigma basado en el sujeto cognoscente y un objeto cognoscible que ha estado permeando la investigación educativa tradicionalmente, posición apoyada por Cúnico et al. (2018). Estos autores cuestionan "el paradigma epistemológico dominante, alentando y fomentando nuevas formas de investigación en psicología" (p. 213); plantean desde la piscología, ciencia coadyuvante de los procesos pedagógicos, pero que además en una visión multi e interdisciplinar hacia donde se orienta la educación 2030, debe estar presente la investigación desde lo complejo.

No debe percibirse la investigación como un mero acto procedimental, debe existir una conciencia epistemológica por parte del investigador o investigadores en la que sea imprescindible abordar el conocimiento desde la filosofía como eje transversal en la educación. Esto contribuye a comprender los diversos enfoques investigativos y curriculares, generándose mejor comprensión del fenómeno educativo, ante lo cual es necesario fomentar la competencia epistemológica como arista transversal para imaginar la realidad educativa-investigativa desde una óptica compleja de la sociedad, involucrando la inclusión metodológica de nuevas posturas para la realización de la investigación (Aldana-Zavala, 2019).

Esta competencia se extrapola al investigador educativo desde el contexto inicial al universitario, esto contribuye a fomentar un abordaje epistémico-metodológico coherente y lógico del accionar investigativo en ambientes de aprendizaje. Así mismo, Borrero (2019) contribuye en complementar lo expuesto al indicar que los docentes tienen la disponibilidad de conocer nuevos modos de hacer investigación, pero presentar debilidades para la realización de investigaciones desde los diversos métodos, para lo cual requieren formación permanente, así como el apoyo de la gerencia educativa; además, es necesario que las instituciones educativas tengan planes de operatividad educativa concatenados a los de desarrollo socio político local y nacional.

Tal formación debe permear los estudios de posgrado donde los docentes e investigadores proyectan mejorar su profesionalización, terreno fértil para el abordaje de nuevos modos de for- 
mar e investigar como referencia en este ámbito se tiene en consideración a Proestakis-Maturana y Terrazas-Núñez (2017). Estos autores destacan el compromiso de abrir espacios de reflexión y discusión entre investigadores, estudiantes y docentes, para romper la estructura disciplinar; se destaca la necesidad desde los estudios doctorales, transcender en la construcción de investigaciones con perspectivas emergentes, involucra la visión de quién dirige el programa, así como de los asesores, integrantes de una reconstrucción epistémica del currículo. En complemento, DíazBazo (2017), comenta la importancia que tiene la investigación-acción en la implementación de algunas áreas temáticas en comparación con otras, lo que deja claro que estamos transitando en una sociedad pluripolar epistemológica y metódica, en donde es necesaria la integración y complementación, para lograr acuerdos en mejora de la educación, quizás lo transdisciplinario o complejo sea una opción; lo importante de destacar es el rol del docente como investigador.

\subsection{Docente investigador}

El docente investigador deja de lado la formación continua con la finalidad de acumular conocimientos y transmitirlos, para transcender a la construcción de los mismos. Esto implica un giro de $180^{\circ}$, por cuanto la constante indagación investigativa lo erige como una persona autodidacta en capacidad de aprender haciendo y posibilitando reflexionar en el día a día para motivarse a superarse a sí mismo en procura de ser mejor persona y, por ende, investigador. Muñoz-Martínez y Garay-Garay (2015), advierten que "la investigación educativa es una formación continua” ( $\mathrm{p}$. 398), por lo tanto, en un mundo dinámico se hace necesario un docente investigador con la finalidad de adoptar soluciones a los múltiples retos sociales a los cuales se enfrentan, esto implica modelar en los estudiantes el rol de investigador como elemento de aprendizaje para la vida.

Lo expuesto invita a reflexionar de modo constante en que es importante aprender y cómo aprenderlo, por cuanto existe una tendencia de eliminar de los pensum de estudios, todo aquello que no se perciba como utilitario para el crecimiento económico-tecnológico de la sociedad, ante lo cual surge una corriente discriminatoria del pensamiento humano, contribuyendo indirectamente en la aparición de sociedades de masas. Escámez-Sánchez et al. (2017) complementan reflexionando sobre la urgencia de educar para la conformación de una sociedad sostenible - en ese sentido- lo económico es vital para el crecimiento humano y educativo, pero no debe verse como el fin, sino, como un medio.

La importancia de compaginar en la formación de valores humanos, sociales y profesionales para formar para la vida con conciencia de la coexistencia humana con otras especies en el planeta tierra; así Rodríguez-Fiallos et al. (2019), proponen la investigación como una vía para la autorrealización y autonomía de la persona, necesidad que el docente investigador tenga una formación que le permita reconocer el valor de la persona en consonancia de aplicar estrategias pedagógicas flexibles y dinámicas, de acuerdo con el contexto social. Rivas-Tovar (2011) propone nueve competencias para la producción científica investigativa como eje transversal de la educación.

Transitar hacia una visión compleja del accionar investigativo es una tarea del día a día al cual se enfrentan los investigadores educativos, esto involucrar y deconstruir para construir nuevos estadios de hacer investigación. FernándezHernández y Cárdenas-Berrio (2015), amplían al señalar que la "poca visión dialéctica de algunos estudiantes ante el proceso de investigación, la carencia de métodos y herramientas más allá de los asociados a la investigación cuantitativa" ( $p$. 45); constituyéndose lo referido en un indicador de la necesidad de contar con docentes investigadores que cuestionen su realidad investigativa, atrofien lo cotidiano y en una emergente dialéctica redescubran el accionar investigativo como un medio para el crecimiento integral, fomentando esta aptitud en sus estudiantes para constituir equipos de investigación para la construcción 
permanente del conocimiento. Buendía-Arias et al. (2018) consideran pertinente superar la dicotomía entre investigación y práctica pedagógica, lo cual contribuirá en una educación para la reflexión, indagación y crecimiento autónomo de las personas.

El docente investigador se encuentra en la era educativa de enseñar a investigar, proceso que permite incorporar subprocesos como la lectura, indagación, análisis, reflexión, discriminación de información y aplicación de técnicas para el procesamiento de información, argumentación y uso de tecnología, entre otros, que contribuyen en formar significativamente para el aprendizaje a lo largo de la vida. Por otro lado, García et al. (2018), plantea que, con un buen docente investigador, tiende a mejorar las competencias investigativas en los estudiantes, mejorándose además su capacidad intelectual, siendo fundamental para tal fin, hablar y escribir bien la producción científica, por cuanto la sociedad global, confronta problemas para la lectura y apreciación crítica de la realidad social, el currículo educativo debe asumir este reto como parte de su cotidianidad pedagógica.

Destacándose la importancia que deben brindar las instituciones educativas a la investigación, sobre todo al papel fundamental del docente investigador, por cuanto lo contrario implica una subestimación de la investigación que va en quebranto de la calidad educativa y del aprendizaje, tal como lo advierte Pérez (2017). Así mismo, García-Gutiérrez y AznarDíaz (2019), confirman la visión de profundizar en la lectura, escritura y competencias investigativas como esencia formativa del futuro docente, reflexionándose así, sobre el papel que juega la universidad en la formación de los futuros educadores, quienes deben estar en consonancia con ejercer profesionalmente para brindar respuestas a las múltiples realidades sociales, para lo cual deben formarse en competencias investigativas para accionar asertivamente en tal fin.

Esto implica que las universidades en Latinoamérica deben redescubrir la investiga- ción como un eslabón para elevar la calidad educativa; Murillo y Martínez-Garrido (2019) concuerdan que la investigación tiende a manejarse desde la polarización de lo cuantitativocualitativo. A partir de lo descrito se involucra que en Latinoamérica aún falta por profundizar en la generación de investigaciones desde nuevos enfoques metodológicos, de allí que invitan a sistematizar experiencias pedagógicas e investigativas con la finalidad de concebir nuevos estilos de investigación pertinentes en la conformación de una educación de calidad. La actividad investigativa puede tener en cuenta métodos clásicos de lo cualitativo, pero poco abordados como punto de partida, siempre y cuando estos resulten pertinentes al accionar pedagógico del docente investigador. A juicio de HuchimAguilar y Reyes-Chávez (2013), la investigación biográfica-narrativa puede coadyuvar con lo descrito, requiriéndose formar en competencias comunicativas para ser efectivos en la realización de este tipo de investigación.

Otro enfoque que debe ser revisado para conciliar un docente investigador pertinente a los retos 2030, es lo referido al liderazgo educativo. Villa-Sánchez (2019), explica la importancia que tiene el liderazgo educativo como promotor de cambios significativos en la institución educativa, así como en los modelos de cómo se trabaja pedagógicamente, por cuanto un líder transformador encausa a aprender nuevas tendencias metodológicas en favor de promover cambios pedagógicos. El compromiso de la gerencia educativa en el accionar de políticas institucionales, ejerce una motivación en el liderazgo docente para conformar un trabajo cooperativo, dinámico y flexible, en razón de construir un aprendizaje pertinente desde el rol del docente investigador como líder transformador, situación planteada por Morgado et al. (2019), al concebir el rol del directivo desde una visión transformacional como necesaria para lograr cambios en la institución.

Trabajar desde la concepción de un liderazgo con base en la inteligencia emocional contribuye a permear al logro de metas en la 
institución educativa. Maya et al. (2019), sostienen que una praxis profesional centrada en lo humano, aporta sinergia al trabajo cooperativo. Izquierdo-Rus et al. (2019), destacan que, en el trabajo cooperativo, los estudiantes tienden a tener dos problemáticas: la primera que no les agrade el trabajo a realizar, y la segunda con quién lo van a realizar. La investigación educativa es un trabajo cooperativo desde la perspectiva epistemológica sujeto-sujeto, invita al docente a reflexionar sobre su liderazgo en el accionar pedagógico, el cual debe ser motivador y conciliador, en procura de equilibrar las emocionalidades de los estudiantes en favor de investigar para aprender a lo largo de la vida. García-Garnica y Martínez-Garrido (2019), apoyan la necesidad de contar con liderazgo escolar asertivo para la consecución de objetivos institucionales, como factor previo para establecer un efectivo aprendizaje cooperativo.

La investigación vista desde lo planteado, debe apoyarse en nuevas formas de experimentar la clase por parte de los estudiantes, donde estos tengan la posibilidad de tener mayor protagonismo y en donde se vean involucrados procesos investigativos. Esta visión no escapa al docente quien debe manejar nuevos estilos didácticos para contribuir en la transcendencia del modelo tradicional a enfoques que se encuentran en concordancia con una educación al 2030, insistiéndose en la formación permanente e integral del docente para asumir asertivamente tales retos. Del Arco-Bravo et al. (2019), consideran para tal fin, la intensificación del enfoque centrado en el estudiante, por cuanto este permite incentivar la motivación, especialmente entre los de mayor edad.

\subsection{Hacia un abordaje epistemoló- gico educativo 2030}

Como se ha abordado en líneas anteriores, es necesario el fomento de una competencia epistemológica en los investigadores docentes con la finalidad de cuestionar la realidad desde una perspectiva filosófica de la realidad, de cara al 2030. La educación latinoamericana se encuentra frente al reto de transcender la racionalidad cartesiana en asunción de asumir una postura epistémica que le permita identificarse para el trabajo pertinente y contextualizado a su realidad social. Pero, ¿cuál es esa epistemología? Podría indicarse que se mueve en dos mares: uno desde la visión compleja eurocéntrica emergida del conocimiento promovido desde la física cuántica versus al de la física clásica; un segundo, relacionado con una mirada desde lo decolonial, pero es acaso posible seguir en una lucha dicotómica o es viable la fusión para construir una visión inclusiva desde el saber científico.

Collado-Ruano (2017a), destaca la simbología de una sociedad en construcción, adherida desde diversos ángulos epistémicos, siendo Latinoamérica una fusión intercultural y, por ende, mestiza en lo epistemológico — es posible experimentar metódicas pedagógicas para afianzar una identidad científica en lo diverso y complejo- favoreciendo un ecosistema de saberes entre las culturas que habitan un territorio.

Es una eterna construcción hacia lo intercultural lo que permitirá compaginar un accionar epistemológico donde se valore la investigación educativa como centro para conformar conocimientos conducentes a una educación inclusiva 2030. La lucha de poderes entre las personas y colectivos, institucionalizados en las instituciones educativas que se aferran a un saber-poder como primogénito y superior en detrimento de otras opciones epistémicas y metódicas es un reto cultural a transcender para lograr el equilibrio de la sostenibilidad de los saberes. En complemento, Collado-Ruano (2017b), propone que "hacer frente a los desafíos de los ODS requiere crear una ecología de saberes que reintegre los diferentes conocimientos y dimensiones humanas" (p. 246).

La ecología de saberes permite integrar conocimientos ancestrales, científicos, cotidianos o de la sabiduría popular, para confluir en un equilibrio del conocimiento pertinente a 
proporcionar la ruptura de las perspectivas polarizadas de la educación planificada en función de las ideologías dominantes del poder político. Es necesario confrontar la realidad desde el aporte de los diversos actores sociales en la construcción de políticas educativas en razón de convivir desde la educación como un fenómeno de convivencia colectiva (Collado-Ruano et al., 2018), constituyéndose competencias pedagógicas-investigativas en coalición de las ciencias ancestrales y ciencias científicas.

El buen vivir puede ser una opción sostenible del equilibrio humano por cuanto procura convivir en una postura media entre la riqueza y la pobreza, donde se puedan cultivar valores éticos como expresión de interrelación entre los seres vivos y no vivos del planeta (ColladoRuano, 2016), siendo necesaria la revisión del modelo económico y su relación con las leyes biofísicas de la naturaleza.

Fernández-Galindez (2019) y AlfaroMardones et al. (2015), cooperan con lo planteado al advertir sobre la importancia de velar por la transformación y la autorreflexión como medio de sanación emocional-espiritual, como punto de referencia para lograr cambios en la educación y en lo social, lo cual implica que si no se forma para asumir la integralidad como expresión pedagógica, las concepciones epistemológicas de diferente planteamiento a la educación tradicional, pueden verse truncadas en su efectividad, colocando en peligro la opción de lograr la sostenibilidad como ejercicio para el buen vivir de la sociedad global. Acosta (2016) destaca la construcción transdisciplinar de la universidad para formar desde la coexistencia entre lo científico y las dimensiones que engloban al ser humano. Es una visión para confluir en una ecología de saberes y convivencia en la construcción de una sostenibilidad en el quehacer diario de los actores educativos, donde la formación sea concebida en edificar ciudadanía planetaria, como espacio de convivencia basada en el auto-respeto, entre lo sociológico y natura- leza, tal como destacan Aldana-Zavala y ColinaYsea (2019).

Desde la integralidad de los conocimientos se podrá contribuir eficazmente en la consecución de una educación de calidad e inclusiva, en donde las diversas miradas epistemológicas pueden converger para construir una mejor sociedad. Henao-Villa et al. (2017), apoyan al señalar la importancia que brinda a los estudiantes el aprendizaje basado en proyectos, aunque este se encuentra distanciado del currículo del semestre, lo cual expone como evidencia que aunque se hagan esfuerzos por parte de los docentes por transcender lo mecanicista sin el debido respaldo curricular, será un esfuerzo atomizado que no conducirá a cambios masivos en la población estudiantil, siendo uno de los retos al 2030, la transformación curricular hacia un enfoque centrado en el estudiante, soportado desde la formación pedagógica en las universidades. López-Salazar (2019), colabora indicando la necesidad de estructurar políticas públicas que sean construidas desde las comunidades, diagnosticando sus necesidades, situación similar al de la educación donde surge el escenario de construir desde una episteme donde se involucren los actores educativos en consonancia de edificar currículos contextualizados a sus necesidades e intereses sin perder de vista lo global como escenario de coexistencia colectiva.

El transitar al 2030 es una invitación abierta para configurar nuevos modos de hacer educación. Maldonado (2019), advierte de la metamorfosis de las ciencias sociales, producto de tres razones: "Primera razón: el mundo cambió (p. 115). Segunda razón: aparecen nuevas formas de ver, de explicar, por tanto, nuevos métodos y nuevas técnicas (p. 117). Tercera razón: cambió el ecosistema de las ciencias y el conocimiento" (p. 118). Ignorar lo planteado puede conducir a dejar de lado múltiples posibilidades de hacer ciencia en favor de promover adecuadas acciones en la próxima década, los avances tecnológicos siguen cada día y no existe certeza del mundo en el 2030. Lo cierto es que será distinto al de hoy, 
la diferencia será marcada en cómo se asuma el protagonismo educativo y científico, ojalá sea una cosmovisión epistemológica humanista e integradora de los conocimientos, dejando de lado la dicotomía que propone la supremacía del saber-poder como núcleo estático de conformismo praxiológico de los actores educativos.

\section{Conclusiones}

La revisión bibliométrica realizada vislumbra un horizonte de cara al 2030, basado en una educación diferente a la tradicional, donde se acentúa la necesidad de generar sinergias de epistemologías, métodos, técnicas, en pro de articular una gestión educativa integral donde las diferencias se constituyan en fortalezas por medio de la interrelación intercultural de las personas, saberes, conocimientos, en un marco de respeto mutuo, aceptación de las diversas posturas ideológicas para confluir en un currículo integrador en el cual se trabaje por áreas contextualizadas a la pertinencia social de la glocalidad.

Construir un currículo integrador requiere el aporte protagónico de todos los actores sociales, con la finalidad de edificar en función de lo que se debe aprender (1), de lo que se quiere aprender (2) y lo necesario de aprender (3). Tres distinciones que se diferencian: 1 . Lo que se debe aprender funciona como lo elemental que todos deben aprender. 2. Lo que se quiere aprender es brindarle la oportunidad a los estudiantes de ser escuchados para que participen en la construcción del conocimiento, promoviéndose una sociedad democrática basada en la equidad, respeto, autodeterminación de la persona, como factores primordiales para configurar un ciudadano ético, participativo, crítico y reflexivo, en los diversos procesos socioeconómicos a los cuales se enfrenta día a día. 3. Lo que se quiere aprender es lo que demanda la sociedad, el mundo globalizado para su progreso sostenible, así un estudiante que se encuentre en el medio rural podrá emprender acciones en función de aprender a trabajar con los recursos disponibles en su contexto.

Así el currículo educativo procurará trabajar en la conjunción de conocimientos científicos, saberes ancestrales y prácticas tecnológicas como un conjunto necesario para promover el buen vivir de la ciudadanía, evitándose la exclusión en toda su extensión humana y social. De ese modo, el currículo proyecta un ciudadano con visión global sostenible, por lo que es necesario que las instituciones educativas se redescubran para tal fin, por cuanto el modo de gerenciar en la educación debe girar con base en la fundación de una epistemología muti, inter, transdisciplinaria, compleja, sistémica y holística, necesitándose para tal fin formar a los docentes activos en todos los niveles del sistema educativo, futuros profesionales de la docencia, por lo cual las universidades están llamadas a aportar hoy en el cambio del mañana.

Lo planteado no se puede lograr si no hay una recta participación de los actores políticos, empresariales, sociales, culturales y deportivos, de la nación, por cuanto se necesita del aporte de todos para construir políticas educativas donde cada uno perciba su aporte, generándose identificación con un currículo educativo de cara al 2030, aunado a la inversión económica necesaria para la educación y su sostenimiento como servicio de calidad a la sociedad. Es necesario promover la gratuidad de la educación, pero no la regalía de la misma —es decir- los actores sociales deben comprender el gran valor de la educación, alejándose de posturas populistas que perciben la educación como un conjunto de votos y no de ciudadanía pensante, crítica y reflexiva.

Latinoamérica si realmente quiere crecer, progresar, y dejar de ser el continente de la esperanza para ser el protagonista global, debe confluir en una educación verdaderamente crítica, productiva y sostenible, esto implica amplificar en el currículo la perspectiva del emprendimiento, derogándose la postura del asalariado. No representa significancia similar asistir a la escuela con el convencimiento de formarte para ser asalariado 
algún día que el de producir e innovar para transformar la sociedad. Es allí donde la visión hacia la investigación podría ir girando a estilos donde se promueva la invención sostenible para la productividad de la glocalidad, es promover una economía diversificada no dependiente exclusivamente del patrón Estado, siendo necesario promover la ética como factor transversal para contribuir en la constitución de personas éticas, humanistas y cooperativas, en la construcción de alianzas para el sostenimiento ecológico del ecosistema social donde se desenvuelven.

\section{Referencias bibliográficas}

Acosta, J. (2016). Interdisciplinariedad y transdisciplinariedad: perspectivas para la concepción de la universidad por venir. [Interdisciplinarity and transdisciplinarity: perspectives for the conception of the university to come]. Alteridad, 11(2), 148-156. https://doi.org/10.17163/alt.v11n2.2016.01

Agosto, G., Fontela, M., Brandy, L., \& Langsam, M. (2018). La Agenda 2030 como herramienta de desarrollo para los jóvenes en Argentina. [The 2030 Agenda as a development tool for young people in Argentina]. Ciência \& Saúde Coletiva, 23(9), 2797-2802.

https://dx.doi.org/10.1590/1413-81232018239.13472018

Aldana-Zavala, J.J. (2019). La competencia epistemológica en el investigador social universitario venezolano. [Epistemological competence in the Venezuelan university social researcher]. Praxis, 15(1), 103-115. https://bit.ly/390Omwc

Aldana-Zavala, J., \& Colina-Ysea, F. (2019). Marketing verde en la conformación de una ciudadanía planetaria en el ámbito educativo latinoamericano. [Green marketing in the formation of a planetary citizenship in the Latin American educational field] Revista San Gregorio, 0(31), 150-161. https://bit.ly/392bmLo

Alfaro-Mardones, J., Fernández-Hernández, C., \& González-García, M. (2015). La transdisciplinariedad una herramienta para apuntar al Buen Vivir. [Transdisciplinarity a tool to target Good Living]. Polis (Santiago), 14(40), 23-42. https://dx.doi.org/10.4067/S0718-65682015000100002
Aya-Velandia, L. (2018). Cerebro-complejidad y bioresistencia. [Brain-Complexity and Bioresistance]. Revista de Investigación Psicológica, (19), 195-206. https://n9.cl/dd073

Azorín-Abellán, C. (2017). Una mirada desde los organismos internacionales a la educación para todos. [A look from international organizations to education for all]. Opción, 33(83), 203-228. https://bit.ly/3b6T90u

Borrero, R. (2019). Formación investigativa de los docentes en las instituciones públicas de Educación Secundaria: Un abordaje desde la gerencia. [Investigative Training of teachers in Public Secondary Education Institutions: An Approach from Management]. Revista Arbitrada Interdisciplinaria Koinonía, 4(8), 544-570. http://dx.doi.org/10.35381/r.k.v4i8.298

Buendía-Arias, X.P., Zambrano-Castillo, L.C., \& Insuasty, E.A. (2018). El desarrollo de competencias investigativas de los docentes en formación en el contexto de la práctica pedagógica. [The development of investigative skills of teachers in training in the context of pedagogical practice]. Folios, (47), 179-195. https://doi.org/10.17227/folios.47-7405

Calvo, G. (2013). La formación de docentes para la inclusión educativa. [Teacher training for educational inclusion]. Páginas de Educación, 6(1), 19-35. https://bit.ly/2x6fxIG

Carrillo-Flores, I. (2016). Balance de los Objetivos de Desarrollo del Milenio y su impacto en el derecho a la educación. [Taking stock of the Millennium Development Goals and their impact on the right to education]. Educación, 25(49), 103-119. https://dx.doi.org/10.18800/educacion.201602.006

Collado-Ruano, J. (2016). La huella socioecológica de la globalización. [The socio-ecological footprint of globalization]. Sociedad y Ambiente, (11), 92-121. https://n9.cl/gtyz3

Collado-Ruano, J. (2017a). Interculturalidad y descolonialidad: Retos y desafíos epistemológicos. [Interculturality and decoloniality: Epistemological challenges and challenges]. Revista nuestrAmérica, 5(9), 38-57. https://bit.ly/2Ui3lMT 
Collado-Ruano, J. (2017b). Educación y desarrollo sostenible: la creatividad de la naturaleza para innovar en la formación humana. [Education and sustainable development: the creativity of nature to innovate in human formation]. Educación y Educadores, 20(2), 229-248. https://bit.ly/2xNbPUW

Collado-Ruano, J., Madroñero-Morillo, M., \& ÁlvarezGonzález, F. (2018). Educación transdisciplinar: formando en competencias para el buen vivir. [Transdisciplinary education: training in skills for good living]. Ensaio: Avaliação e Políticas Públicas em Educação, 26(100), 619-644. https://dx.doi.org/10.1590/s0104-40362018002601487

Cornejo-Espejo, J. (2019). Nuevos excluidos en el sistema educacional chileno: problemas y desafíos. [New excluded in the Chilean educational system: problems and challenges] Páginas de Educación, 12(1), 28-48. https://dx.doi.org/10.22235/pe.v12i1.1766

Cosme-Casulo, J. (2018). Los Objetivos de Desarrollo Sostenible y la academia. [The Sustainable Development Goals and the academy]. MEDISAN, 22(8), 838-848. https://n9.cl/0ovgo

Cúnico, S., Pizzinato, A., Strey, M., \& Manso, A. (2018). Desafíos y posibilidades de la investigación cualitativa en Psicología: problematizaciones necesarias. Challenges and possibilities of qualitative research in Psychology: necessary problematizations]. Psicología, Conocimiento y Sociedad, 8(1), 194-217. https://dx.doi.org/10.26864/pcs.v8.n1.9

Del Arco-Bravo, I., Flores-Alarcia, O, \& Silva, P. (2019). El desarrollo del modelo flipped classroom en la universidad: impacto de su implementación desde la voz del estudiantado. [The development of the flipped classroom model in the university: impact of its implementation from the voice of the student body]. Revista de Investigación Educativa, 37(2), 451-469. http://dx.doi. org/10.6018/rie.37.2.327831

Díaz-Bazo, C. del P. (2017). La investigación-acción en la educación básica en Iberoamérica. Una revisión de la literatura. [Action research in basic education in Latin America. A review of the literature]. Magis, Revista Internacional de
Investigación en Educación, 10(20), 159-182. https://doi.org/10.11144/Javeriana.m10-20.iaeb

Escámez-Sánchez, J., Peris-Cancio, J., \& EscámezMarsilla, J. (2017). Educación de los estudiantes universitarios y gestión de la sostenibilidad. [University student education and sustainability management]. Perfiles educativos, 39(156), 174-190. https://n9.cl/o6y4

Fernández-Galindez, O. (2019). La transcomplejidad, una visión epistemológica del siglo XXI. [Transcomplexity, an epistemological vision of the 21st century]. Revista Conocimiento Libre y Licenciamiento CLIC, 19(10), 101116. https://bit.ly/2UcFjTL

Fernández-Hernández, S., \& Cárdenas-Berrio, M. (2015). Formación de competencias investigativas en Ciencias de la Información desde la Universidad de La Habana. [Training of investigative skills in Information Sciences from the University of Havana]. Revista Cubana de Información en Ciencias de la Salud, 26(1), 34-47. https://bit.ly/2WlwSIr

García, N., Paca, N., Arista, S., Valdez, B., \& Gómez, I. (2018). Investigación formativa en el desarrollo de habilidades comunicativas e investigativas. [Formative research in the development of communication and research skills]. Revista de Investigaciones Altoandinas, 20(1), 125-136. https://dx.doi.org/10.18271/ria.2018.336

García-Garnica, M., \& Martínez-Garrido, C. (2019). Dirección escolar y liderazgo en el ámbito iberoamericano. [School Management and Leadership in the Ibero-American Area]. Profesorado, Revista de Currículum y Formación del Profesorado, 23(2), 1-11. https://dx.doi.org/10.30827/profesorado.v23i2.9690

García-Gutiérrez, Z., \& Aznar-Díaz, I. (2019). The Development of Research Competencies, an Alternative to Train Childhood Educators as Teacher-Researchers. [El desarrollo de competencias de investigación, una alternativa para capacitar a educadores de la infancia como docentes-investigadores] Revista Electrónica Educare, 23(1), 1-22. https://doi.org/10.15359/ree.23-1.15

Henao-Villa, C., García-Arango, D., Aguirre-Mesa, E., González-García, A., Bracho-Aconcha, R., Solórzano-Movilla, J., \& Arboleda-López, 
A. (2017). Multidisciplinariedad, interdisciplinariedad y transdisciplinariedad en la formación para la investigación en ingeniería. [Multidisciplinarity, interdisciplinarity and transdisciplinarity in training for engineering research]. Revista Lasallista de Investigación, 14(1), 179-197. https://dx.doi.org/10.22507/rli.v14n1a16

Huapaya-Capcha, Y. (2019). Gestión por procesos hacia la calidad educativa en el Perú. [Process management towards educational quality in Peru]. Revista Arbitrada Interdisciplinaria Koinonía, 4(8), 243-261. http://dx.doi.org/10.35381/r.k.v4i8.277

Huchim-Aguilar, D., \& Reyes-Chávez, R. (2013). La investigación biográfico-narrativa, una alternativa para el estudio de los docentes. [Biographical-narrative research, an alternative for the study of teachers]. Revista Actualidades Investigativas en Educación, 13(3), 1-27. https://doi.org/10.15517/aie. v13i3.12026

Izquierdo-Rus, T., Asensio-Martínez, E., EscarbajalFrutos, A., \& Rodríguez-Moreno, J. (2019). El aprendizaje cooperativo en la formación de maestros de Educación Primaria. [Cooperative learning in the training of primary education teachers]. Revista de Investigación Educativa, 37(2), 543-559. http://dx.doi.org/10.6018/rie.37.2.369731

Locatelli, R. (2018). La educación como bien público y común. Reformular la gobernanza de la educación en un contexto cambiante. [Education as a public and common good. Reformulating the governance of education in a changing context]. Perfiles educativos, 40(162), 178-196. https://bit.ly/3ab5qAY

Loli-Ponce, R., Sandoval-Vegas, M., Ramírez-Miranda, E., Quiroz-Vásquez, M., Navarro-Casquero, R., \& Rivas-Díaz, L. (2015). La enseñanza aprendizaje de la investigación: representación social desde la perspectiva estudiantil. [Teaching learning research: social representation from the student perspective]. Anales de la Facultad de Medicina, 76(1), 47-56. https://n9.cl/x1dzh

López-Salazar, R. (2019). Bienestar y desarrollo: evolución de dos conceptos asociados al bien vivir. [Well-being and development: evolu- tion of two concepts associated with living well]. Revista Telos, URBE, Ciencias Sociales, 21(2), 288-312. https://doi.org/10.36390/ telos 212.03

Maldonado, C. (2019). Tres razones de la metamorfosis de las ciencias sociales en el siglo XXI. [Three reasons for the metamorphosis of the social sciences in the 21st century]. Cinta de Moebio. Revista de Epistemología de Ciencias Sociales, (64), 114-122. https://bit.ly/33r3vpu Maya, E., Aldana-Zavala, J., \& Isea-Argüelles, J. (2019). Liderazgo directivo y educación de calidad. [Management Leadership and Quality Education]. CIENCIAMATRIA, 5(9), 114129. https://doi.org/10.35381/cm.v5i9.102

Meléndez-Rojas, R. (2017). Prospectiva para la educación costarricense. Una oportunidad de transformar el sistema educativo para el siglo XXI. [Prospective for Costa Rican education. An opportunity to transform the educational system for the 21st century]. Actualidades Investigativas en Educación, 17(3), 720-744. https://dx.doi.org/10.15517/aie.v17i3.29072

Molina-Naranjo, J., Lavandero-García, J., \& Hernández-Rabell, L. (2018). El modelo educativo como fundamento del accionar universitario.: Experiencia de la Universidad Técnica de Manabí, Ecuador. [The educational model as the foundation of university action: Experience of the Technical University of Manabí, Ecuador]. Revista Cubana de Educación Superior, 37(2), 151-164. https://n9.cl/bvikz

Morgado, C., Aldana-Zavala, J., \& Isea-Argüelles, J. (2019). Gerencia transformacional desde el accionar docente directivo para el abordaje del contexto escolar. [Transformational management from the directive teaching action to approach the School Context]. CIENCIAMATRIA, 5(9), 48-72. https://doi.org/10.35381/cm.v5i9.99

Muñoz-Martínez, M., \& Garay-Garay, F. (2015). La investigación como forma de desarrollo profesional docente: Retos y perspectivas. [Research as a form of teacher professional development: Challenges and perspectives]. Estudios pedagógicos (Valdivia), 41(2), 389-399. https://dx.doi.org/10.4067/S0718-07052015000200023 
Murillo, F., \& Duk, C. (2017). El ODS 4 (y el 16) como meta para los próximos años. [SDG 4 (and 16) as a goal for the coming years]. Revista Latinoamericana de Educación Inclusiva, 11(2), 11-13. https://dx.doi.org/10.4067/S0718-73782017000200001

Murillo, F., \& Martínez-Garrido, C. (2019). Una mirada a la investigación educativa en América Latina a partir de sus artículos. [A Look at Educational Research in Latin America from its Articles]. REICE. Revista Iberoamericana sobre Calidad, Eficacia $y$ Cambio en Educación, 17(2). http://dx.doi.org/10.15366/reice2019.17.2.001

Peche-Cruz, H., \& Giraldo-Supo, V. (2019). El Aprendizaje Flip Learning centrado en el estudiante como generador de calidad educativa. [Student-centered Flip Learning as a generator of educational quality]. Revista Arbitrada Interdisciplinaria Koinonía, 4(8), 427-450. http://dx.doi.org/10.35381/r.k.v4i8.293

Pérez, L. (2017). Desarrollo de capacidades investigativas en estudiantes de pregrado de la carrera de arquitectura de la Facultad de Arquitectura y Urbanismo de la Universidad Técnica de Oruro: Resultados del estudio de campo. [Development of investigative capacities in undergraduate students of the architecture degree of the Faculty of Architecture and Urbanism of the Technical University of Oruro: Results of the field study]. Revista Ciencia, Tecnología e Innovación, 14(15), 861-868. https://n9.cl/3zb6

Pérez-Van Leenden, M. (2019). La investigación acción en la práctica docente. Un análisis bibliométrico (2003-2017). [Action research in teaching practice. A bibliometric analysis (2003-2017)]. magis, Revista Internacional de
Investigación en Educación, 12(24), 177-192. https://doi.org/10.11144/Javeriana.m10-20.ncev

Proestakis-Maturana, A., \& Terrazas-Núñez, W. (2017). Formación en investigación y supervisión en programas de doctorados. [Research training and supervision in doctoral programs]. Magis, Revista Internacional de Investigación en Educación, 10(20), 85-104. https://doi.org/10.11144/Javeriana.m10-20.fisp

Rivas-Tovar, L. (2011). Las nueve competencias de un investigador. [The nine skills of an investigator]. Investigación Administrativa, 108(2), 34-54. https://bit.ly/3diaXYK

Rodríguez-Fiallos, J., Navarrete-Pita, Y., EstradaMolina, O., \& Vera-Viteri, L. (2019). Valoraciones acerca de la relación entre competencias profesionales y las investigativas. [Assessments about the relationship between professional and investigative skills]. Revista Cubana de Educación Superior, 38(1), 5-11. https://n9.cl/6l2jg

UNESCO (2005). Hacia las sociedades del conocimiento. https://bit.ly/39Ydll7

Vera-Del Carpio, R. (2015). Gestión prospectiva sobre las dimensiones de desarrollo sostenible hacia el 2030 en los líderes de la Región de Puno-Perú. [Prospective management on the dimensions of sustainable development towards 2030 in the leaders of the Puno Region-Peru] Comuni@cción, 6(1), 05-15. https://n9.cl/w718

Villa-Sánchez, A. (2019). Liderazgo: una clave para la innovación y el cambio educativo. [Leadership: a key to innovation and educational change]. Revista de Investigación Educativa, 37(2), 301-326. http://dx.doi.org/10.6018/rie.37.2.365461 


\title{
EATERDAD Intervención familia-aula para el desarrollo de habilidades grafomotrices
}

\author{
Family-classroom intervention for the development of \\ graphomotor skills
}

Dra. Yanet Amanda Maquera-Maquera es docente e investigadora de la Universidad Nacional del Altiplano (Perú) (ymaquera@unap.edu.pe) (https://orcid.org/0000-0002-2492-6428).

(D) Dr. Saúl Bermejo-Paredes es docente e investigador de la Universidad Nacional del Altiplano (Perú) (sbermejo@unap.edu.pe) (https://orcid.org/0000-0001-9885-7974).

(D) Erika Olivera-Condori es docente del Instituto Superior Pedagógico Público de Puno (Perú) (erika_olco@hotmail.com) (https://orcid.org/0000-0001-9315-6853).

Recibido: 2020-06-09 / Revisado: 2020-12-02 / Aceptado: 2020-12-08 / Publicado: 2021-01-01

\section{Resumen}

La complejidad de las acciones pedagógicas para el profesorado de educación inicial, no se reduce a dirigir y dar pautas desde un pedestal; es parte de la clase, requiere de mucho tacto y preparación. Cada vez, el esfuerzo es mayor para innovar y generar procesos de aprendizaje estimulantes y productivos; sin embargo, paralelamente las expectativas de los padres y la sociedad son muy altas. Situación que convoca a transformar las prácticas pedagógicas y responder a las necesidades sociales y de aprendizaje de los niños. Los objetivos del estudio son: a) Describir las creencias de los educadores y padres de familia respecto a la iniciación de la alfabetización temprana en niños de cinco años de edad; y b) Establecer en qué medida el modelo de involucramiento familiar a través de la realización de actividades de motricidad fina desde los hogares, favorece el aprendizaje de las habilidades grafomotrices. La metodología empleada corresponde al enfoque mixto, de alcance descriptivo-explicativo. Los resultados evidencian no solo el impacto del modelo de involucramiento familiar, sustentado en la incorporación e intercambio de experiencias y conocimientos entre docentes de aula y padres de familia, en el aprendizaje de la alfabetización temprana; más bien resaltan que tomar en cuenta las creencias de los docentes y padres de familia son decisivas para transformar y cambiar la trayectoria de lo cotidiano y usual en la cultura educativa.

Descriptores: Aprendizaje-servicio, aprendizaje cooperativo, creencias pedagógicas, enseñanza de la escritura, influencia familiar, psicomotricidad.

\section{Abstract}

The complexity of pedagogical actions for initial education teachers is not reduced to directing and giving guidelines from a pedestal; it is part of the class, it requires a lot of tact and preparation. Every time, the effort is greater to innovate and generate stimulating and productive learning processes, however; at the same time, the expectations of parents and society are very high. Situation that calls for transforming pedagogical practices and responding to the social and learning needs of children. The objectives of the study are: a) to describe the beliefs of educators and parents regarding the initiation of early literacy in children of 05 years of age; and b) establish to what extent the family involvement model through the performance of fine motor activities from home, favors the learning of graphomotor skills. The methodology used corresponds to the mixed approach, descriptive-explanatory in scope. The results show not only the impact of the family involvement model, based on the incorporation and exchange of experiences and knowledge between classroom teachers and parents, in the learning of early literacy; Rather, they highlight that taking into account the beliefs of teachers and parents are decisive to transform and change the trajectory of the everyday and usual in the educational culture.

Keywords: Service-learning, cooperative learning, pedagogical beliefs, teaching of writing, family influence, psychomotor skills.

Forma sugerida de citar: Maquera-Maquera, Y.A., Bermejo-Paredes, S., \& Olivera-Condori, E., (2021). Intervención familia-aula para el desarrollo de habilidades grafomotrices. Alteridad, 16(1), 92-104. https://doi.org/10.17163/alt.v16n1.2021.07 


\section{Introducción}

La grafomotricidad es un proceso comunicativoevolutivo que se encarga de los pre-aprendizajes de la comunicación de signos gráficos (Suárez, 2004); aplica una serie de habilidades psicomotoras en los niños para prepararlos en el aprendizaje de la escritura, y constituye, un buen elemento para la interiorización de imágenes parciales de las letras (Alfonso et al., 2012; Lurçat, 1988; Segura et al., 2017); es la psicomotricidad aplicada como paso previo al acto de escribir, consistente en actividades como el garabato, producción de trazos, dibujo libre, sobre cualquier superficie (Ramón, 2016; Reynoso, 2019; Sugrañes et al., 2007), que se emplean en la educación preescolar, con el propósito de iniciar fructíferamente la alfabetización temprana. La adquisición y el dominio de la lengua escrita es una tarea trascendental en el desarrollo madurativo de todo niño y el reto más significativo para todo sistema escolar (Gómez-Díaz et al., 2015), es uno de los aprendizajes más difíciles y complejos, vinculado al manejo y aprendizaje de otras habilidades — por lo mismo- exige cierta madurez o condiciones necesarias para enfrentarlo y evitar el miedo, fracaso y frustración (Fornaris, 2011).

La educación infantil es el período más crítico y de mayor relevancia capital para el bienestar futuro en el desarrollo de la persona; las experiencias y procesos de socialización vividos serán las bases de las habilidades para aprendizajes ulteriores, configurar su identidad, autoestima y conocer el mundo que lo rodea (Balongo \& Mérida, 2017; Pastor, 2018; UNESCO, 2014). Esto implica tener conocimientos profundos sobre la atención temprana de la infancia y sus propósitos; conocer cada individualidad; develar el talento de cada niño para actuar y crear alternativas de respuesta a sus necesidades y problemas complejos. La educación inicial en el Perú se concibe como el nivel que sienta las bases para la formación integral de los niños menores de seis años, articulada de manera pedagógica y curricular con la educación primaria (MINEDU,
2017); dedica buena parte del tiempo lectivo a dar sentido y significado al desarrollo de las competencias comunicativas, en todas sus manifestaciones. Uno de los objetivos principales de la educación inicial constituye, la alfabetización (Lara \& Pulido, 2020), la adquisición y dominio de la lengua escrita (Gutiérrez \& Díez, 2015), que se ha convertido en prerrequisito para la promoción escolar.

La adquisición preescolar de la representación escrita del lenguaje es una valiosa habilidad que mejora los resultados de la alfabetización temprana de los niños (Gerde et al., 2019; Hall et al., 2015); no obstante, requiere previamente del desarrollo de las habilidades grafomotoras globales (Cisternas et al., 2014), que asociado a esto están los "primeros garabatos, en los que el niño no está dibujando el objeto en sí, sino que está fijando en el papel los gestos con los que él mismo representa a dicho objeto" (Montealegre, 2006, p. 26). Estas representaciones gráficas como manifestación del desarrollo motor fino están vinculadas a la "capacidad de usar la mano y los dedos de manera precisa, de acuerdo con la exigencia de la actividad y se refiere a las destrezas necesarias para manipular un objeto" (Serrano \& Luque, 2019, p. 16). De este modo, la escritura a mano sirve para vincular el procesamiento visual con la experiencia motora, facilitando las habilidades de reconocimiento de letras posteriores (James, 2017). Por consiguiente, la práctica de la grafomotricidad a mano es más fructífera respecto a otras alternativas (Grabowski, 2010); en este sentido Benítez y Sánchez (2018), concluyen en efecto que "educar el gesto gráfico desde el movimiento motriz es una alternativa potente en Educación Infantil porque facilita la resolución del problema de aprendizaje del trazado y la escritura" (p. 195).

La educación inicial a diferencia de otras modalidades y niveles de educación básica, no enseña contenidos temáticos, ni trata a los niños como estudiantes en situación escolar. No obstante, las posibilidades de un aprendizaje eficiente de la escritura frecuentemente, son limitadas 
en los entornos preescolares (Gerde et al., 2019); persisten las prácticas pedagógicas rutinarias que siguen un itinerario mecánico, preestablecido, poco propicio para enriquecer la actuación y configuración del andamiaje de la expresión y comunicación lingüística, que debe fundamentarse en el conocimiento metalingüístico (Arnaíz \& Bolarín, 2016), como capacidad para reconocer la naturaleza, formas y funciones del lenguaje escrito. Crear alternativas de respuesta a necesidades y problemas complejos de los niños preescolares, exigen a los docentes cada vez, mayor adaptabilidad e innovación en el empleo de diversas estrategias comunicativas en cada episodio interactivo, variando de forma cualitativa y cuantitativa (Gonzáles, 2015). Por lo contrario, el fracaso en la alfabetización temprana de los niños preescolares, se mantiene invariablemente, y cuando esto ocurre, se pierde el objetivo del aprendizaje de la escritura como una "herramienta de vida de cada ser humano y pasa a convertirse en un problema de aprendizaje" (Suárez, 2004, p. 6), que obstruye y retarda el proceso de aprendizaje del lenguaje escrito y la comunicación, en general.

La adquisición de la representación escrita del lenguaje por los niños ha sido vista como un aprendizaje que sólo corresponde al sistema escolar (Ferreiro, 2006); sin embargo, en la etapa preescolar los niños, reciben una mayor injerencia de sus entornos y contextos inmediatos, compuesta de diversos factores y en coparticipación de diversos agentes educativos, quienes deben crear estímulos adecuados en las condiciones favorables para potenciar el desarrollo (Gutiérrez et al., 2018). El aprendizaje temprano de la alfabetización traspasa los muros escolares, se da en diversos contextos, tanto formales como informales de aprendizaje (Parodi, 2010). Ante esta circunstancia, se plantea concebir escuelas infantiles no solo pensado para los niños, exclusivamente, sino centradas en familias, construyendo relaciones complementarias a partir del respeto, confianza y encuentro mutuos entre la familia y escuela (Ferrer \& Riera, 2015; Keyser,
2006). Bajo este modelo de involucramiento, se reconoce que los docentes establecen relaciones más fluidas y dinámicas con los padres de los niños, para que cooperen con la concreción de actividades específicas asignadas en la escuela, por cuanto son quienes conocen mejor las particularidades de cada niño y pueden influir enormemente en el desarrollo y bienestar de sus hijos y poder convertirse en un eje para asegurar la calidad de la educación preescolar (Mir et al., 2009; Pastor, 2018).

Así, la decadencia de las prácticas pedagógicas tradicionales de alfabetización temprana, abre paso hacia formas más democráticas y respetuosas de enseñanza, con intervención conjunta de educadores, comunidad educativa y la familia de los niños para promover capacidades comunicativas funcionales en todas sus manifestaciones, como base de un desarrollo integral (Díaz, 2019; Palos et al., 2017; Ramos, 2011). En esta perspectiva, el estudio tiene por objetivos: a) Describir las creencias de los educadores y padres de familia respecto a la iniciación de la alfabetización temprana en niños de cinco años de edad; y b) Establecer en qué medida el modelo de involucramiento familiar a través de la realización de actividades de motricidad fina favorece el aprendizaje de habilidades en niños preescolares de cinco años de edad.

Se trata de construir propuestas de aprendizaje sustentadas en acciones auténticas-participativas y experiencias del ámbito escolar y familiar, para atender articuladamente, las necesidades de aprendizaje de los niños y satisfacer las expectativas de la comunidad, y juntos contribuir a la transformación de nuestros contextos escolares, culturales y sociales. El estudio se inscribe en la perspectiva de la pedagogía participativa, de aprendizaje en servicio, considerado como propuesta pedagógica, programa, estrategia (Deeley, 2016; Mendia, 2012; Puig et al., 2007), que combina de manera activa y participativa procesos de aprendizaje y servicio a la comunidad, aportando un escenario formativo que potencia las habilidades de comunicación, 
actitudes sociales y la motivación requerida para la concreción de las tareas y competencias previstas (Chiva-Bartoll et al., 2018; Gil et al., 2016; Huda et al., 2018).

\section{Metodología}

\subsection{Ubicación temporal-espacial}

Estudio realizado durante el segundo semestre del año escolar 2019, en la Institución Educativa Inicial (IEI) San Martín de Porres, ciudad de Puno. Corresponde al distrito, provincia y departamento de Puno-Perú.

\subsection{Muestra}

Constituida por el total de niños y padres de familia, sección única de cinco años, IEI San Martín: a) 18 niños (ocho varones y diez mujeres); b) 18 padres de familia (15 mujeres y tres varones); y c) tres docentes, todas mujeres (las docentes de las secciones de tres y cuatro años, sólo participaron durante las entrevistas en profundidad). Para la selección de la muestra primaron dos criterios: la predisposición y cooperación de la maestra de aula, permitiendo que uno del equipo investigador asuma en aula el desarrollo de las sesiones experimentales en su lugar; $y$, el consentimiento e involucramiento real de los padres de familia en la propuesta pedagógica. Además, es necesario señalar que los padres de familia de esta sección de niños, constituían el grupo mejor organizado y destacado al interior de la institución educativa.

\subsection{Enfoque y alcance}

Por la naturaleza y propósitos explicitados es un estudio de caso, con enfoque mixto: cualitativocuantitativo y de alcance descriptivo-explicativo, ejecutado a través de 12 sesiones de aprendizaje tanto en aula como en los hogares de los niños, con una periodicidad de dos horas semanales ininterrumpidamente, durante el segundo semestre del año escolar 2019.

\begin{tabular}{|c|c|c|c|}
\hline $\begin{array}{l}\text { GRAFOMO- } \\
\text { TRICIDAD } \\
\text { (dimensiones) }\end{array}$ & $\begin{array}{l}\text { EJECUCIÓN DE } \\
\text { HABILIDADES }\end{array}$ & CRITERIOS DE EVALUACIÓN & $\begin{array}{l}\text { ESCALA DE } \\
\text { VALORACIÓN }\end{array}$ \\
\hline $\begin{array}{l}\text { Manipulativo- } \\
\text { vivencial }\end{array}$ & $\begin{array}{l}\text { Trazos sincré- } \\
\text { tico tensos y } \\
\text { distendidos }\end{array}$ & $\begin{array}{l}\text { Utilizando crayones de colores ejecuta garabatos, líneas } \\
\text { con angulaciones y ondulantes de manera continua. }\end{array}$ & \multirow{3}{*}{$\begin{array}{l}\text { Según escala de } \\
\text { evaluación de nive- } \\
\text { les de aprendizaje } \\
\text { establecida por el } \\
\text { Ministerio de Edu- } \\
\text { cación del Perú: } \\
\text { inicio C (00-10 pun- } \\
\text { tos), proceso B (11- } \\
15 \text { puntos) y logro A } \\
\text { (16-20 puntos). }\end{array}$} \\
\hline $\begin{array}{l}\text { Interiorización } \\
\text { simbólica }\end{array}$ & $\begin{array}{l}\text { Trazos linea- } \\
\text { les tensos y } \\
\text { distendidos }\end{array}$ & $\begin{array}{l}\text { El niño representa o sustituye objetos reales en objetos } \\
\text { internos al unir líneas de acuerdo con una imagen, tra- } \\
\text { za líneas del mismo tamaño y dirección, une dos pun- } \\
\text { tos a través de una línea, dibuja un objeto, otorgando } \\
\text { significados. }\end{array}$ & \\
\hline $\begin{array}{l}\text { Representación } \\
\text { perceptiva }\end{array}$ & $\begin{array}{l}\text { Trazos ico- } \\
\text { nográficos y } \\
\text { opacidades }\end{array}$ & $\begin{array}{l}\text { Representación de figuras abiertas-cerradas, formas } \\
\text { gráficas pre-esquemáticas y dibujo libre, distinguiendo } \\
\text { forma y fondo. }\end{array}$ & \\
\hline
\end{tabular}

Para describir las creencias de docentes y padres respecto a la iniciación de la alfabetización temprana en los niños preescolares, se empleó la técnica de la entrevista en profundidad previo al tratamiento experimental, considerando como categorías de análisis: a) Percepciones sobre vinculación escuela-familia (combinación de interacciones comunicativas, experiencias y conocimientos entre padres y maestros para concretar las tareas escolares y competencias de aprendizaje previstas para los niños); b) Creencias sobre alfabetización temprana y; el aprendizaje de habilidades grafomotrices durante el tratamiento cuasi-experimental en grupo único, con pre y posprueba, fueron determinados según resultados obtenidos mediante la téc- 
nica de la observación y la ficha de evaluaciónvaloración de los aprendizajes.

La ficha de evaluación-valoración, como instrumento de investigación empleada para medir el nivel de los aprendizajes en grafomotricidad, presentó básicamente la siguiente estructura:

\subsection{Procedimientos en la ejecución del modelo de intervención}

- Autorización formal y consentimiento de la dirección de institución, docente de aula y padres de familia, para ejecutar la propuesta de investigación educativa.

- Inclusión y aprobación de la propuesta bajo mecanismos de participación y consenso, durante las reuniones de trabajo compartidos entre docente de aula y padres de familia. El equipo investigador, ha delegado a un representante para proponer $y$ consensuar los propósitos, procedimientos y acciones del trabajo conjunto a implementarse, tanto al interior de aula, como en los hogares de los niños.

- La ejecución de las 12 actividades de aprendizaje en aula, bajo el modelo de intervención, estuvo a cargo de un miembro del equipo investigador. La maestra de aula y los otros investigadores asumían la observación de la clase con la finalidad de realizar un balance en el avance de la propuesta y proceder a los reajustes, si así se requerían.

- Las actividades o tareas desarrolladas por los niños en los hogares, fueron ejecutadas siguiendo un plan de procedimientos sencillos, previamente consensuados y aprobados en las reuniones de sección de cinco años, según dimensiones de la variable dependiente y los logros de aprendizaje previstos respecto a habilidades grafomotoras. Estas actividades, estaban articuladas a la secuencia metodológica desarrollada en aula, denominándose con- vencionalmente: extensión de la sesión de aprendizaje, bajo la dirección de los padres o familiares. Ante la expectativa generada y solicitud permanente de los padres, en muchas ocasiones, los miembros del equipo investigador asistieron a la ejecución de actividades en el hogar a fin de asesorar y monitorear la intervención.

- El equipo investigador sometía a evaluación semanal la marcha del experimento en todos sus componentes. Cualquier propuesta de replanteamiento, implicaba consensuar entre todos los participantes del estudio, en particular con la maestra de aula.

- La entrevista en profundidad fue realizada antes y después de las reuniones de padres y docentes, así como en los momentos de ingreso, espacios de espera y salida de los niños de la institución educativa, prioritariamente.

\subsection{Variables/categorías de análisis}

La variable independiente estuvo representada por el modelo de intervención familia-aula, tipificándose como una estrategia de aprendizajeservicio, a partir de la cual se diseñaron y ejecutaron 12 sesiones de aprendizaje, centradas en la concreción de actividades de psicomotricidad fina, considerando las dimensiones viso-motor, manual y viso-manual. La grafomotricidad como variable dependiente, tuvo por dimensiones de estudio a los niveles: manipulativo-vivencial (trazos sincréticos tensos y distendidos); interiorización simbólica (trazos lineales tensos y distendidos); y representación perceptiva (trazos iconográficos y realización de opacidades), que fueron medidos por la escala de aprendizaje establecida por el Ministerio de Educación del Perú: inicio C (00-10), proceso B (11-15) y logro A (16-20).

Por otra parte, las creencias descritas por los padres de familia y docentes, respecto a la alfabetización temprana en niños de cinco años, constituyen la categoría de análisis abordada 
desde la perspectiva cualitativa. Para este efecto, los datos recogidos fueron codificados del siguiente modo: $\mathrm{D}=$ docente y $\mathrm{F}=$ padre de familia, agregándosele un número entre paréntesis para diferenciar cada miembro de la población. Ejemplo: $\mathrm{D}(1)$ identifica a la primera docente. En el caso de los padres de familia la numeración llega hasta 18.

\subsection{Análisis de datos}

Los datos cuantitativos se analizaron mediante el software SPSS, determinándose la t calculada y el p-valor específico, en relación con el nivel de significación correspondiente, conforme se ofrece en la sección de resultados. Para los datos cualitativos se recurrió al análisis de contenido y el procedimiento de interpretación consistió básicamente en considerar la frase como unidad de análisis, para asegurar la fiabilidad de la comprensión e interpretación de los conceptos o significados. La hipótesis estadística planteada fue:

$$
\begin{aligned}
& \mathrm{Ho}: \mu_{2}=\mu_{1} \\
& \mathrm{H} a: \mu_{2}>\mu_{1}
\end{aligned}
$$

\section{Resultados}

El estudio ofrece resultados de valor pedagógico y social a través de datos y reflexiones cualitativos (creencias sobre iniciación en alfabetización temprana) y cuantitativos (aprendizaje de habilidades grafomotrices a través del modelo de intervención pedagógica familia-escuela), que guardan una estrecha relación entre sí: coincidiendo con los resultados de otros estudios, las creencias o subjetividades constituyen un espacio de construcción de significados y sentidos que dirigen las acciones y modos de ser de los individuos (Izaguirre \& Alba, 2016); las creencias o subjetividades que elaboran los docentes orientan su trabajo, influyen y modifican sus prácticas pedagógicas, son fundamentales en la toma de decisiones curriculares y concreción de los objetivos de aprendizaje, integran nuevos aprendizajes en situaciones prácticas y finalmen- te, las subjetividades guían las acciones y toma de decisiones en los docentes (Cuadra et al., 2015; Gómez et al., 2014; Hernández-Álvarez, 2010).

\subsection{Creencias de padres de fami- lia y docentes sobre iniciación en alfabetización temprana de niños de cinco años de edad}

Las docentes de educación inicial, consideran que la articulación familia-escuela, es un asunto de corresponsabilidad, para garantizar y contribuir a una adecuada formación integral y educación de calidad de los niños preescolares; sin embargo — - según sus creencias pedagógicasiniciar a los niños de cinco años en habilidades para la escritura no es lo usual; sin embargo, se muestran con apertura hacia nuevas situaciones y propuestas de enseñanza-aprendizaje.

Tanto los padres y nosotros como docentes tenemos la obligación de integrarnos, estar más cerca de nuestros niños, ambos somos los responsables de su educación. (D-1)

La educación de los niños no es responsabilidad exclusiva de la maestra, sino sobre todo también de los padres. (D-3)

Definitivamente, en esta institución y en toda la educación inicial producto de nuestras reuniones pedagógicas, hemos ya aclarado que educación inicial no se dedica a la enseñanza de la lectoescritura, vayamos a ver qué sucede con la propuesta, estoy inquietada, parece distinta. (D-2)

Por su parte, los padres de familia admiten que es necesario mantener vínculos de comunicación permanente con la maestra de aula y la institución educativa, para conocer de cerca los progresos y dificultades de aprendizaje en los niños; y tienen expectativas de ver a sus niños que hayan adquirido las competencias básicas en lectoescritura, al culminar la educación inicial a los cinco años de edad. 
Tenemos que estar siempre comunicados. Nos interesa que nuestros niños sepan más, mejor si la maestra se esfuerza por enseñarles a leer y escribir. (F-8)

Muy de acuerdo la comunicación, sino cómo nos enteraríamos de lo que aprenden los niños, ahora sería una gran cosa que nuestros niños empiecen y terminen la promoción sabiendo escribir algo. (F-13)

Los padres estamos por nuestros niños, siempre estaremos identificados con la institución y dispuestos a participar en todo. (F-1)

Es más juego y poco aprendizaje de conocimientos, yo aplaudiría si los niños terminaran escribiendo. (F-18)

Sí, claro sin comunicarnos con la maestra, no estaríamos enterados con lo que pasa en la institución, es muy importante. (F-5)

Algunas percepciones de los padres de familia, señalan a la institución educativa como una organización independiente y arbitraria a sus intereses, además, atribuyen a los educadores el papel de la enseñanza y trabajo con los niños; no obstante, se muestran colaborativos con la organización de padres y la maestra de aula.

La institución nunca consulta con los padres, sólo nosotros nos dedicamos a cumplir lo que ellos mandan, pero ahí estamos, cualquier asunto lo asumimos, no nos negamos. (F-4)

Si de enseñar se trata, eso corresponde a las docentes, nosotras podíamos tal vez apoyar con algo. (F-6)
Las creencias pedagógicas de las educadoras respecto al vínculo docente-padre de familia, privilegian el sentido de mayor apertura y permeabilidad entre ambas partes, sustentada en relaciones respetuosas recíprocas, fundamentalmente. Además, enfatizan que los padres deben ser parte de los procesos de retroalimentación en casa, situación que implica un trabajo cooperativo entre padres y docentes, a favor de los aprendizajes de los niños.

Deben entender que nosotras y ellos los padres, modelamos a los niños, tenemos que ser flexibles y guardar respeto entre nosotros. (D-1)

Ellos, los padres deben reforzar aquello que hacemos con los niños en el aula, porque a nosotras los niños, no nos ven exactamente como docentes. (D-2)

\subsection{Modelo de involucramien- to para el desarrollo de la grafomotricidad}

El modelo de intervención pedagógica interactivo familia-aula, diseñado en la perspectiva metodológica de la estrategia aprendizaje-servicio, centrado en la ejecución de actividades psicomotoras finas - a través de un tratamiento cuasi-experimental - ha permitido incrementar los niveles de aprendizaje en las habilidades grafomotoras manipulativo-vivencial, interiorización simbólica y representación perceptiva de los niños de cinco años de edad. Y como tal, según estos resultados se acepta la hipótesis alterna rechazándose la nula, conforme es evidenciable en la siguiente tabla acompañado por el p-valor y la regla de decisión correspondiente. 
Tabla 1. Resultados prueba de muestras independientes niveles de grafomotricidad en niños de cinco años

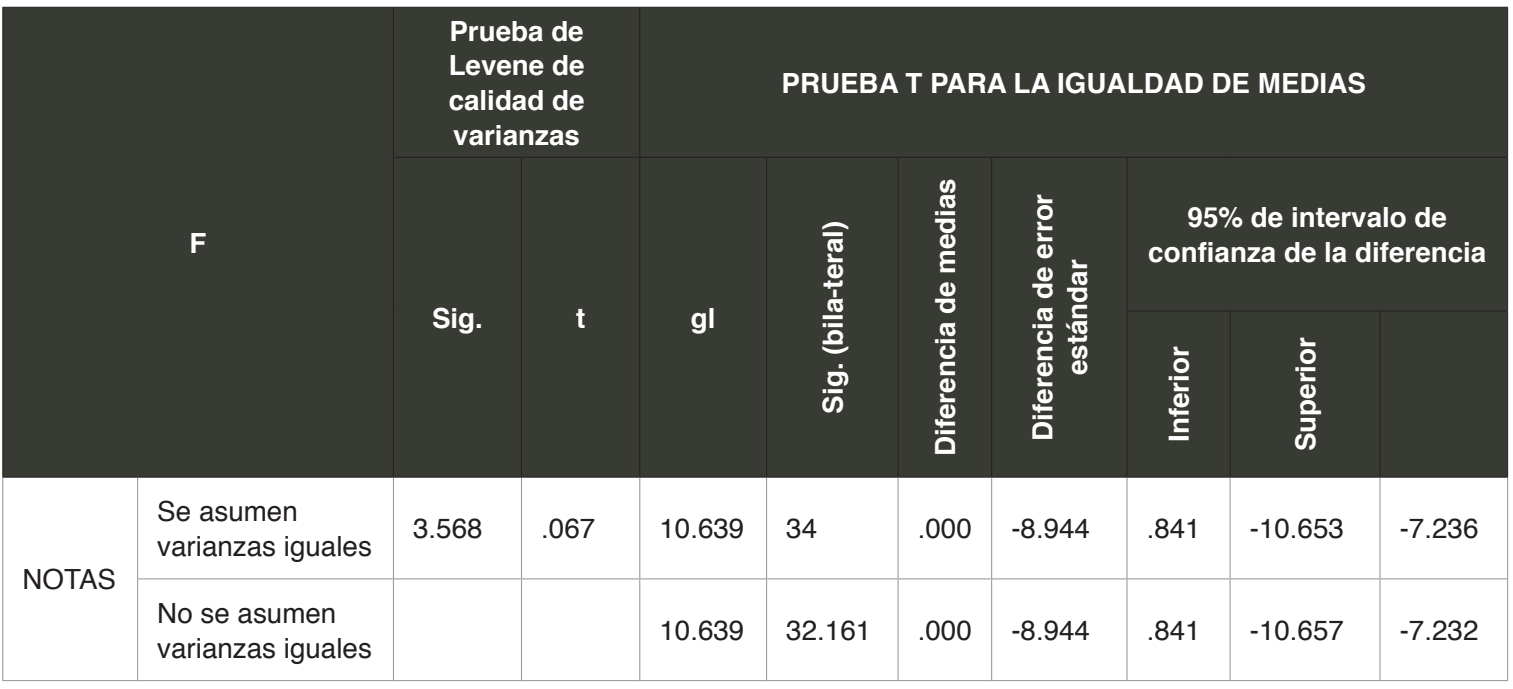

Fuente: Elaboración por autores, según datos primitivos analizados en SPSS

\section{Determinación de p-Valor}

$P$ Valor $=\frac{\text { Sig }}{2}$

\section{Regla de decisión}

Como $P$ Valor $<\alpha$ entonces se rechaza $H o$ y se acepta $\mathrm{Ha}$

Como $0<0.05$ entonces se rechaza $H o$ y se acepta $\mathrm{Ha}$

Los resultados del estudio son concordantes con otros trabajos similares de investigación que, confirmaron la eficacia de programas de intervención psicomotriz, visuomotor en el desarrollo de la grafomotricidad (Gonzáles, 2015; Layes et al., 2019); sin embargo, atribuir una certeza total a los mismos es discutible, requieren intervenciones de mayor rigurosidad científica. El diseño de investigación cuasi-experimental sin grupo control, es una limitante de validez interna que impide atribuir el grado en que ciertamente la manipulación de la variable independiente, es responsable de los cambios registrados en los aprendizajes de habilidades grafomotoras.

Lo que sí queda claro después del trabajo aplicativo, aun cuando no formaron parte de los propósitos del estudio, son las bondades del modelo de intervención pedagógica familiaaula como estrategia de aprendizaje-servicio (Mendía, 2016; Tapia, 2010): los niños trabajan colaborando interactivamente con sus padres y profesores para maximizar sus propios aprendizajes; se generan situaciones en las cuales se esperan que ocurran formas particulares de interacción para generar el logro de un aprendizaje (Collazos \& Mendoza, 2009); implica para los docentes renovar los procesos pedagógicos habituales, establecer relaciones más cercanas, dialógicas y afectivas con los niños, padres de familia y la comunidad en general, para concretar las aspiraciones relacionadas con la calidad de los aprendizajes y la educación; se renuevan los roles convencionales de docentes y estudiantes mediante transacciones colaborativas-interactivas y consensuadas, orientadas al logro de metas establecidas (Revelo-Sánchez et al., 2018).

\section{Discusión y conclusiones}

La familia y la escuela constituyen los espacios más privilegiados para construir y fructificar el desarrollo integral de los niños, ninguna de ellas 
por sí sola, de manera aislada y diferenciada puede acompañar, satisfacer y potenciar las capacidades de aprendizaje y los talentos de los niños, con calidad y pertinencia; se requiere, de la cooperación permanente y oportuna entre ambas partes, definitivamente. No obstante, en nuestro contexto las estrategias para fomentar los vínculos entre familia-escuela y comunidad son aún frágiles, limitadas y tradicionales que conllevan a plantear y redefinir el rol de la educación en general (Bermejo et al., 2020; Razeto, 2018); de tal modo, que la escuela no sea una esperanza de bienestar, sino el lugar de disfrute permanente, desde la cual se vive la vida (Bermejo \& Maquera, 2019); persiste la tendencia a valorar los procesos de alfabetización temprana, el aprendizaje de la lectoescritura en general, como prácticas relacionadas solo con la escuela (Vance et al., 2007), regularmente.

De acuerdo con los resultados obtenidos, el modelo de involucramiento familiar, escuelahogar, es una estrategia de aprendizaje-enseñanza factible y aceptable (Goldman et al., 2019), para acompañar y seguir los procesos de aprendizaje de las habilidades grafomotrices en niños de cinco años de edad, reconoce la colaboración activa de los padres en el apoyo a los niños, con la ejecución de tareas específicas asignadas por los docentes (Pastor, 2018); se constituye en un espacio privilegiado de participación y aprendizaje, metodología indispensable en los procesos formativos familiares (Mendoza \& Zúñiga, 2017); por tanto, ostenta un valor pedagógico y social.

Su implementación y ejecución depende previamente, de las actitudes y creencias positivas tanto de los padres de familia como de los docentes. Comprender las creencias de los maestros y padres respecto a cómo contribuir en la construcción de los aprendizajes y conocimientos en los niños, es crucial; por cuanto informan a sus prácticas de valiosas habilidades para apoyar los aprendizajes reales (Gerde et al., 2019); actúan como filtros del conocimiento adquirido que permite a las personas entender el mundo y desenvolverse en él de una determinada manera (Díaz, 2013); de lo contrario -como refieren Patiño y Rojas (2009) — una pedagogía que niegue la subjetividad no es pedagogía, porque negaría al sujeto como constructor de representaciones significativas culturales, sociales e individuales.

Las estrategias de vinculación familiaaula, sustentadas en la ejecución de actividades de psicomotricidad fina, según los resultados de aprendizaje obtenidos por la mayoría de niños comprendidos en el tratamiento experimental, permiten el incremento o desarrollo de las habilidades de grafomotricidad. Los niños pueden maximizar su propio aprendizaje, interactuando a través de actividades colaborativas junto a sus padres y docentes; los padres de familia participan activamente y asumen co-responsabilidad en los procesos formativos de los niños en la escuela; y los docentes adoptan nuevos roles, establecen relaciones más dialógicas y afectivas con los niños y sus padres, implicándolos en las aspiraciones de concretar las metas educativas. En efecto, diferentes estudios realizados, confirman que el desarrollo de las habilidades grafomotoras en los niños, están basados en la adquisición de la motricidad fina (Gonzáles, 2015), que existe una estrecha relación entre motricidad fina y escritura (Lica et al., 2010); proponiéndose por consiguiente, la ejercitación fina y gruesa para el aprendizaje del grafismo (Segura et al., 2017), que incluso paulatinamente, será útil para aumentar la identificación y el reconocimiento de las letras (Gil et al., 2012; Zemloc et al., 2018). No obstante, se debe tener en cuenta las limitaciones de rigor científico-metodológico del estudio, explicitadas en la sección de los resultados.

El modelo experimentado resultó estimulante y desafiante para el aprendizaje de las habilidades grafomotrices, parte por establecer conexiones de confianza y comunicación más fluidas entre la realidad escolar y la cotidianidad de la vida de los niños. Logra que el niño realice por cuenta propia, acciones válidas y correctas de ejecución gráfica en el espacio que debe representar, manteniendo control postural adecuado, dominio del brazo y la manera cómo debe sostener el lápiz. 
Es más, el procedimiento implicado contribuye a materializar ideas que sugieren actividad y responsabilidad en los niños para configurar su estilo de vida (Ortiz, 2012). El niño al desarrollar el sentido del movimiento y la representación de manera autónoma y reflexiva, no se expone a la clásica frase de: qué se puede y qué no se puede. Deja la imitación como procedimiento favorito en la educación preescolar, y se predispone por iniciativa propia y estímulo social desarrollar competencias propias y diversificadas que lo identificarán como persona única y distinta.

La importancia de estos hallazgos, no solamente radica en el diseño de contextos de aprendizaje estimulantes y desafiantes para los niños y haber generado entre docentes y padres, oportunidades y espacios para participar, intercambiar y compartir experiencias y conocimientos durante el acompañamiento en los procesos formativos de los niños; sino en la comprobación de la existencia de un potencial humano (Guerrero, 2000), capaz de cambiar la trayectoria de lo cotidiano y usual. Por otra parte - se pone en evidencia que- las creencias, conocimientos, experiencias y la capacidad de adaptación hacia cambios inesperados tanto de padres y educadores respecto a la formación del niño, es la mayor fortaleza, el mejor aporte y esfuerzo en común para cambiar la cultura educativa. Es posible concretar realidades alternativas de práctica pedagógica, diseñando y participando en contextos de aprendizaje compartidos entre la escuela y la cotidianidad de la vida de los niños. Lo que los padres y la sociedad esperan de los docentes y la escuela, pueden encontrarlos en ellos mismos, al experimentar, enriquecer y producir nuevos estilos y valores de ser padres y contribuir a la formación humana, trascendiendo espacios y límites.

\section{Referencias bibliográficas}

Alfonso, S., Deaño, M., Almeida, L., Conde, Á., \& García-Señorán, M. (2012). Facilitación del conocimiento alfabético en preescolar a través del entrenamiento en codificación, gra- fomotricidad y lectura. Psicothema, 24(4), 573-580. https://bit.ly/31Rjhth

Arnaíz, P., \& Bolarín, M.J. (2016). Introducción a la psicomotricidad. Editorial Síntesis S. A.

Balongo, E., \& Mérida, R. (2017). Proyectos de trabajo: una metodología inclusiva en Educación Infantil. Revista Electrónica de Investigación Educativa, 19(2), 125-142.https://bit.ly/36LJs8L

Benítez, M., \& Sánchez, C. (2018). Procesos educativos en educación infantil mediante el grafismo y la escritura. Enseñanza \& Teaching. Revista Interuniversitaria de Didáctica, 36(2), 195-214. https://bit.ly/3qyK8pO

Bermejo, S., Maquera, Y.A., \& Bermejo., L.Y. (2020). Procesos de educación intercultural y autosegregación indígena en los aimaras de Puno-Perú. Revista Historia de la Educación Latinoamericana, 23(34). https://bit.ly/39OVFLA

Bermejo-Paredes, S., \& Maquera-Maquera, Y. (2019). Interpretación de la escuela rural andina en comunidades aimaras de Puno-Perú. Revista Electrónica Educare, 23(2), 1-15. https://bit.ly/37HBtsv

Cisternas, Y., Ceccato, R., Gil, D., \& Marí, M.I. (2014). Funciones neuropsicológicas en las habilidades de inicio a la lectoescritura. Revista INFAD de Psicología, 1 (1), 115-122. https://bit.ly/37zAfiS

Chiva-Bartoll, O., \& Gil-Gómez, J. (2018). Aprendizajeservicio universitario. Modelos de intervención e investigación en la formación inicial docente. Octaedro.

Collazos, C., \& Mendoza, J. (2009). Cómo aprovechar el "aprendizaje colaborativo" en el aula. Educación y Educadores, 9(2), 61-76. https://bit.ly/33Pxn0b

Cuadra, D., Jorquera, R., \& Pérez, M. (2015). Las teorías subjetivas del profesor acerca de su salud laboral: implicancias en la promoción de la salud preventiva en el trabajo docente. Revista Ciencia y Trabajo, 17(52), 1-6. https://bit.ly/2VGty90

Deeley, S. (2016). El aprendizaje-servicio en educación superior. Teoría práctica y perspectiva crítica. Narcea.

Díaz, C. (2013). Estudio de caso sobre las creencias de estudiantes de pedagogía en inglés respecto 
a la autoeficacia percibida y la enseñanza del idioma. Núcleo, 25(30), 41-67.

https://bit.ly/3kKoawX

Díaz, G.M. (2019). Tratamiento pedagógico de las alteraciones en la lectura y la escritura. Monografía de Licenciatura. Universidad Nacional de Educación Enrique Guzmán y Valle. Lima. https://bit.ly/3gVsK9g

Ferreiro, E. (2006). La escritura antes de la letra. CPUe, Revista de Investigación Educativa, (3), 1-52. https://bit.ly/2XZdfWC

Ferrer, M., \& Riera, M. (2015). Relaciones y encuentros con las familias en educación infantil. RELAdEI Revista Latinoamericana de Educación Infantil, 4(2), 27-42. https://bit.ly/3gTPd6V

Fornaris, M. (2011). Factores necesarios para la adquisición de la lectoescritura. Cuadernos de Educación y Desarrollo, (30), 3. https://bit.ly/3fRKCR5

Gerde, H.K., Wright, T.S., \& Bingham, G.E. (2019). Creencias de los maestros de preescolar e instrucción para la escritura. Revista Educación Docente de la Primera Infancia, 40(4), 326-351.

Gil, J., Moliner, O., Chiva, O., \& López, R. (2016). Una experiencia de aprendizaje-servicio en futuros docentes: Desarrollo de la competencia social y ciudadana. Revista Complutense de Educación, 27(1), 53-73. https://bit.ly/2VFg3GM

Gil, S.A., Deaño, M.D., Almeida, L.S., Rodríguez, A.C., \& García, M. (2012). Facilitación del conocimiento alfabético en preescolar a través del entrenamiento en codificación, grafomotricidad y lectura. Psicotema, 24(4), 573-580. https://bit.ly/31Rjhth

Goldman, S.E., Sanderson, K.A., \& Lloyd, B.P (2019). Efectos de la comunicación entre la escuela y el hogar con refuerzo implementado por los padres en el comportamiento fuera de la tarea para estudiantes con TEA. Discapacidades Intelectuales y del Desarrollo 57(2), 95-111. https://bit.ly/33Nf7EW

Gómez-Díaz, R., García-Rodríguez, A., \& CordónGarcía, J.A. (2015). APPrender a leer y escribir: aplicaciones para el aprendizaje de la lectoescritura. Education in the Knowledge Society, 16(4), 118-137.

https://doi.org/10.14201/eks2015164118137
Gómez, V., Muñoz, C., Silva, I., González, M.P., Guerra, P., \& Valenzuela, J. (2014). Creencias y oportunidades de aprendizaje en la práctica educativa en contextos de pobreza. Perfiles Educativos, 36(144), 173-188. https://bit.ly/39MFMFm

Gonzáles, J. (2015). Las competencias de comunicación en el inicio de la lectoescritura. Revista Brasileira de Estudios Pedagógicos, 96(243), 416-438. https://bit.ly/3mLZgxP

González, M.E. (2015). La escritura en primer año de la escuela primaria y la psicomotricidad. Revista Psicomotricidad, Movimiento y Emoción, (1), 1-14. https://bit.ly/2PMxZwj

Grabowski, J. (2010). Speaking, writing and memory span in children: Ouput modality affects cognitive performance. International Journal of Psychology, 45(1), 28-39. https://doi.org/10.1080/00207590902914051

Guerrero, L. (2000). Educación inicial: a la búsqueda del tesoro escondido. ¿Cómo enfocar la misión de la educación inicial hacia la emergencia y el florecimiento del inmenso potencial humano? Revista Iberoamericana de Educación, 22, 75-92. https://bit.ly/31OCwnl

Gutiérrez, D., Socorro, A., \& Ruiz, M. (2018). Impacto de la educación inicial y preescolar en el neurodesarrollo infantil. IE Revista de investigación educativa de la REDIECH, 9(17), 33-51. https://bit.ly/2Yf3AeP

Gutiérrez, R., \& Díez, A. (2015). Aprendizaje de la escritura y habilidades de conciencia fonológica en las primeras edades. Bordón. Revista de Pedagogía, 67(4), 43-59.

https://bit.ly/3gcTQJI

Hall, A.H., Simpson, A., Guo, Y., \& Wang, S. (2015). Examinando los efectos de la instrucción de escritura preescolar en las habilidades emergentes de alfabetización: una revisión sistemática de la literatura. Alfabetización, Investigación e Instrucción, 54(2), 115-134. https://bit.ly/3kEUUaV

Hernández-Álvarez, J.L., Velázquez-Buendía, R., Martínez, M. E., \& Díaz del Cueto, M. (2010). Creencias y perspectivas docentes sobre objetivos curriculares y factores determinantes de actividad física. Revista Internacional de Medicina y Ciencias de la Actividad Física y el Deporte, 10(38), 336-355. 
https://bit.ly/2VI08Yj

Huda, M., Shukri, K., Hisyam, N., \& Mohd, B. (2018). Transmitir la responsabilidad cívica basada en el liderazgo: conocimientos del aprendizaje mediante servicio. Revista Internacional de Ética y Sistemas, 34(1), 20-31. https://bit.ly/3qsEnKl

Izaguirre, R., \& Alba, D. (2016). Reflexiones sobre el papel de la subjetividad en el proceso docente-educativo. MULTIMED, 20(2), 437448. https://bit.ly/3osXUrY

James, Kh. (2017). La importancia de la experiencia de escritura a mano en el desarrollo del cerebro alfabetizado. Direcciones Actuales en Ciencias Psicológicas, 26(6), 502-508.

Keyser, J. (2006). De padres a socios: Construyendo un programa de primera infancia centrado en la familia. NAEYC y Redleaf Press.

Lara, P.A., \& Pulido, O. (2020). Escritura como práctica de sí y escuela rural. Praxis \& Saber, 11(25), 21-45. https://bit.ly/33NqRat

Layes, S., Chouchani, M.S., Mecheri, S., Lalonde, R., \& Rebaï, M. (2019). Eficacia de una intervención basada en visuomotor para niños con discapacidades de lectura y ortografía: un estudio piloto. Revista Británica de Educación Especial, 46(3), 317-339.

Lica, M.M., Ruiz, D.L., \& González, A.P. (2010). Relación entre ejecuciones deficientes de motricidad fina con dificultades de escritura: Análisis de un caso. Revista de Educación y Desarrollo, (13), 17-23. https://bit.ly/2PQ01qG

Lurçat, L. (1988). Pintar, dibujar, escribir, pensar. El grafismo en el preescolar. Cincel-Kapelusz.

Mendía, R. (2016). El aprendizaje-servicio una metodología para la innovación educativa. Convives, 16, 20-26. https://bit.ly/2VKNrMe

Mendoza, E., \& Zúñiga, M. (2017). Factores intra y extra escolares asociados al rezago educativo en comunidades vulnerables. Alteridad. Revista de Educación, 12(1), 79-91. https://bit.ly/3qqIt5s

MINEDU (2017). Programa Curricular de Educación Inicial. https://bit.ly/33VCNaX

Mir, M., Batle, M., \& Hernández M. (2009). Contextos de colaboración familia-escuela durante la primera infancia. Revista Electrónica de Investigación e Innovación Educativa y

Socioeducativa, 1(1), 45-58.

https://goo.gl/dGD1Kb

Montealegre, R. (2006). Desarrollo de la lectoescritura: adquisición y dominio. Acta Colombiana de Psicología, 9(1), 25-40. https://bit.ly/30TvCy5

Ortiz, M.E. (2012). Currículo y competencia. ¿Qué sujeto infantil están produciendo? Alteridad. Revista de Educación, 7(1), 50-57. https://doi.org/10.17163/alt.v7n1.2012.04

Palos, M.Ú., Avalos, M.L., Flores, F., \& Montes, R. (2017). Creencias de madres y docentes sobre el aprendizaje de la lectoescritura en Educación Preescolar. Revista Actualidades Investigativas en Educación, 17(3), 168-189. https://bit.ly/3lLBIrv

Parodi, G. (2010). Saber leer. Instituto Cervantes Aguilar.

Pastor, R. (2018). Construyendo escuela juntos. Estrategias de vinculación entre la familia y la escuela. Educación y Futuro. Revista de investigación aplicada y experiencias educativas, (39), 89-116. https://bit.ly/3anBYc1

Patiño, L., \& Rojas, H.M. (2009). Subjetividad y subjetivación de las prácticas pedagógicas en la universidad. Educación y Educadores, 12(1), 93-105. https://bit.ly/2IgDx1O

Puig, J.M., Batlle, R., Bosch, C., \& Palos, J. (2007). Aprendizaje servicio. Educar para la ciudadanía. Editorial Octaedro.

Ramón, M. (2016). El papel de la grafomotricidad como paso previo a la escritura. (Tesis maestría). Departamento de Educación. Universidad Jaume I. Castellón-España. https://bit. ly/33WTcMn

Ramos, M. (2011). El problema de comprensión y producción de textos en el Perú. Revista Digital de Investigación en Docencia Universitaria, 5(1), 30-53. https://doi.org/10.19083/ridu.5.5

Razeto, A. (2018). Estrategias para promover la participación de familias en la educación de niños en escuelas chilenas. Educação e Pesquisa, 44, 1-20. https://bit.ly/2LfNEoZ

Revelo-Sánchez, O., Collazos-Ordoñez, C.A., \& Jiménez-Toledo, J.A. (2018). El trabajo colaborativo como estrategia didáctica para la enseñanza/aprendizaje de la programación: Una revisión sistemática de literatu- 
ra. Tecnológicas, 21(41), 115-134. https://bit. ly/3lKUrTZ

Reynoso, M. (2019). XI Congreso Internacional de Investigación y Práctica Profesional en Psicología. XXVI Jornadas de Investigación. $\mathrm{XV}$ Encuentro de Investigadores en Psicología del MERCOSUR. I Encuentro de Investigación de Terapia Ocupacional. I Encuentro de Musicoterapia. Facultad de Psicología-Universidad de Buenos Aires, Buenos Aires. https://bit.ly/33T7uNX

Segura, M., Sabaté, M., \& Caballé, C. (2017). La psicomotricidad, un recurso para la mejora del grafismo en educación infantil. Aportaciones de la psicomotricidad al grafismo. Revista Iberoamericana de Psicomotricidad y Técnicas Corporales, (42), 5-19. https://bit.ly/30S07En

Serrano, P., \& Luque, C. (2019). Motricidad fina en niños y niñas. Desarrollo, problemas, estrategias de mejora y evaluación. Narcea, S.A.

Suárez, B. (2004). El desafío de la escritura: en busca de la grafomotricidad. Revista Iberoamericana de Psicomotricidad y Técnicas Corporales, (16), 5-16.
Sugrañes, E., Àngel, À.M., Neus, M. Antón, M., Colomé, J., Martí, M.T., Martín, R.M., Pinell, M., Rodríguez, N., Yuste, M., \& Yuste, R. (2007). La educación psicomotriz (3-8 años). Cuerpo, movimiento, percepción, afectividad: $U$ propuesta teórico práctica. Graó.

Tapia, M.N. (2010). La propuesta pedagógica del 'Aprendizaje-Servicio': Una perspectiva latinoamericana. Tzhoecoen, Revista Científica, $5,23-43$.

UNESCO (2014). El Informe de seguimiento de la EPT en el mundo. Enseñanza y aprendizaje: lograr la calidad para todos. UNESCO. https://bit.ly/31QbxrK

Vance, C., Smith, P.H., \& Murillo, L.A. (2007). Prácticas de lectoescritura en padres de familia. Influencias en el desarrollo de la lectoescritura de sus hijos. Revista Latinoamericana de Lectura, 28(3), 6-15. https://bit.ly/3kH7zKq

Zemloc, D., Vinci-Booher, S., \& James, Kh. (2018). La producción de símbolos visuales-motores facilita el reconocimiento de letras en niños pequeños. Leyendo y Escribiendo, 31(6), 1255-1271. 


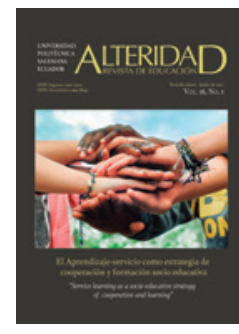

\title{
La improcedencia de estandarizar el trabajo docente: Un análisis desde Chile
}

\author{
The inadmissibility of standardizing the teaching work: An \\ analysis from Chile
}

Cristian Oyarzún-Maldonado es doctorando e investigador de la Universidad de Chile (Chile) (cristian.oyarzunm@usach.cl)

(https://orcid.org/0000-0003-481 1-8633)

(D) Rodolfo Soto-González es doctorando e investigador de la Universidad de Barcelona (España) (rodolfo.soto@usach.cl) (https://orcid.org/0000-0003-3061-6036)

Recibido: 2019-03-15 / Revisado: 2020-10-17 / Aceptado: 2020-12-02 / Publicado: 2021-01-01

\section{Resumen}

Cada vez, más países implementan políticas de rendición de cuentas y estandarización como solución a los problemas de equidad y calidad educativa. Este artículo examina la pertinencia de diseñar el trabajo docente con base en diferentes mecanismos de estandarización. Para ello, se utiliza la propuesta de Henry Mintzberg, una teoría de comportamiento organizacional que plantea mecanismos de coordinación referidos a distintas formas de organizar el trabajo según sus características y objetivos. Con este marco teórico se analiza el modelo escolar chileno, que sobresale por el uso de la estandarización para regular procesos y resultados. El análisis confirma la hegemonía de estos mecanismos de estandarización mediante distintos dispositivos evaluativos y prescriptivos de la política escolar, así como también permite afirmar su improcedencia por efecto de diversas externalidades negativas empíricamente sustentadas. A partir de este examen se discute la pertinencia de otros mecanismos de coordinación para el diseño de la política escolar, proponiéndose un modelo que prevalezca en formas regulatorias ligadas con el desarrollo de habilidades situadas, el trabajo colaborativo y la formación en valores socioeducativos.

Descriptores: Modelo escolar chileno, políticas escolares, trabajo docente, estandarización de procesos, estandarización de resultados, comportamiento organizacional.

\section{Abstract}

Every day, more countries implement reimbursement and standardization policies as a way to solve problems related to equity and quality education. This article examines the design appropriateness of teaching work, based on different standardization mechanisms. Thus, the Henry Mintzberg proposal is used, an organizational theory behavior that proposes coordination mechanisms regarding different ways of organizing work according to its characteristics and objectives. Using this theoretical framework, the Chilean school model is analyzed, which stands out using standardization to regulate processes and results. The analysis confirms the hegemony of these standardization mechanisms using different evaluative and prescriptive devices of the school policy, as well as allows to affirm their inadmissibility because of diverse empirically supported negative externalities. Emanating of mentioned above, the appropriateness of other coordination mechanisms for the design of school policy is discussed, proposing a model that prevails in regulatory forms linked to the development of situated skills, collaborative work and training in socioeducational values.

Keywords: Chilean school model, school policies, teaching work, standardization of processes, standardization of results, organizational behavior.

Forma sugerida de citar: Oyarzún-Maldonado, C., \& Soto-González, R. (2021). La improcedencia de estandarizar el trabajo docente: Un análisis desde Chile. Alteridad, 16(1), 105-116. https://doi.org/10.17163/alt.v16n1.2021.08 


\section{Introducción}

Ante el desafío de mejorar la calidad y equidad de los sistemas escolares contemporáneos, uno de los modelos de gobernanza de mayor auge en la actual agenda educativa global es el New Public Management (NPM) que, con distintas adaptaciones locales, ha sido implementado en diversos países de Asia, Europa, Latinoamérica y Norteamérica (Bezes et al., 2012; Hall et al., 2015; Holloway et al., 2017; Maroy \& Pons, 2019; Maroy et al., 2016; Normand et al., 2018). Dicho modelo se basa en la transferencia de teorías y técnicas de gestión desde la empresa privada a organizaciones tradicionalmente públicas (Ball \& Youdell, 2008) como, por ejemplo, las escuelas. Este marco se concretiza en un conjunto de medidas que pueden incluir provisión mediante cuasi-mercados, descentralización administrativa, convenios de desempeño, estandarización de prácticas y resultados, accountability con consecuencias de alto riesgo, pago por el logro de metas, entre otras (Anderson \& Cohen, 2015; Carvalho \& Normand, 2018; Gleeson \& Knights, 2015; Verger \& Normand, 2015).

Lejos de generar consensos y adhesión irrestricta, la aplicación del NPM en el campo educativo provoca intensos debates y cuestionamientos acerca de su capacidad para propender hacia el mejoramiento escolar (Maroy \& Pons, 2019; Normand et al., 2018). Así, la literatura internacional ha concentrado particular interés en aquellos dispositivos que estandarizan resultados y prácticas pedagógicas, así como en las externalidades negativas que conllevan para el trabajo docente. $\mathrm{Al}$ respecto, se ha sostenido que la utilización de pruebas estandarizadas de medición de aprendizajes a gran escala vinculadas a consecuencias provoca un reduccionismo curricular y una sobrevaloración de los resultados, convirtiéndose estos en el propósito unívoco de la enseñanza (Chan, 2010; Darling-Hammond, 2014; Luengo-Navas, \& Saura-Casanova, 2013). A su vez, se han reportado hallazgos acerca de la estandarización de las labores del profesorado, los cuales advierten de profundos cambios en la labor cotidiana que se traducen en fenómenos de performatividad (Ball et al., 2013), emasculación de saberes locales frente a las prescripciones de la política (Herr, 2015) y malestar psicológico por efecto de una intensificación del trabajo para lograr su adecuación a dichas prescripciones (Tsang \& Kwong, 2016; Viera \& Oliveira, 2013).

En este contexto general, el presente artículo expone un análisis teórico respecto de las dificultades que conlleva aplicar mecanismos de estandarización propios del NPM en el trabajo docente y su inadecuación metodológica para regular las prácticas pedagógicas. Con este propósito, se utiliza como marco analítico la teoría de Henry Mintzberg, una teoría de comportamiento organizacional que plantea mecanismos de coordinación referidos a seis formas de operacionalizar, verificar y articular las actividades de una organización, los cuales varían según la naturaleza y objetivos del trabajo (Mintzberg, 1980; 1984). A través de los mecanismos de coordinación, esta teoría aborda profusamente la estandarización por resultados y procesos, proporcionando argumentos respecto de su conexión a actividades laborales específicas. Por ende, estos planteamientos conceptuales permiten analizar la pertinencia o improcedencia de estas formas de coordinación aplicadas al trabajo docente.

Por su parte, el objeto de este análisis se concentrará en la política escolar de Chile, caso nacional calificado como extremo en cuanto a la adopción de políticas promercado y dispositivos basados en el NPM, y que sobresale por el uso de mecanismos de estandarización tanto a nivel de la gestión escolar como del trabajo docente (Assaél \& Cornejo, 2018; Falabella, 2015; Verger et al., 2016). Puntualmente, se releva la estandarización de resultados ejercida por medio del SIMCE, ${ }^{1}$ que no solo evalúa los niveles de aprendizaje alcanzados mediante pruebas estandarizadas de alcance nacional, sino que además constituye la principal fuente de datos utilizada para la elaboración de un ranking de desempeño ${ }^{2}$ asociado a castigos que se aplican sobre las escue- 
las (Assaél et al., 2018; Carrasco, 2013; Pino et al., 2016). Mientras que se identifica una intensa estandarización de las prácticas pedagógicas, observable en instrumentos oficiales que sistematizan "mejores prácticas", entre los que puede nombrarse el Manual de la Buena Enseñanza (MBE) que opera de modo prescriptivo al sustentar un Sistema Nacional de Evaluación Docente con consecuencias de alto riesgo (Ávalos, 2017; Cavieres \& Apple, 2016; Cornejo et al., 2015; Fardella, 2013; Sisto, 2012). La temática adquiere una relevancia adicional para el contexto latinoamericano debido a la creciente difusión de modelos de privatización educativa en la región (Verger et al., 2017) y, en particular, de modelos basados en la estandarización (Internacional de la Educación para América Latina, 2015).

Considerando todo lo anteriormente expuesto, este artículo se estructura en tres apartados principales. En el primer apartado se ofrece una descripción conceptual de los mecanismos de coordinación postulados en la teoría de Mintzberg. En segundo lugar, se analiza la correspondencia de la estandarización de procesos y de resultados con las formas de estandarización aplicadas en el contexto de la política escolar chilena, así como también se plantean cuestionamientos sobre la aplicación de este tipo de estandarizaciones en el trabajo docente. En el tercer apartado se proponen otros mecanismos de coordinación que, a partir del análisis, resultan más concernientes a la actividad pedagógica. Finalmente, en las conclusiones se expone una síntesis del análisis efectuado y sus implicancias para el diseño de la política.

\section{Los mecanismos de coordina- ción de Henry Mintzberg}

Todas las organizaciones requieren diseñar y realizar un cierto número de tareas específicas para alcanzar sus objetivos. Por ello, toda actividad productiva requiere de un proceso o una secuencia de acciones interdependientes que poseen un comienzo y un final, las cuales pueden ser regu- ladas mediante mecanismos de coordinación (Pucheu, 2013; Schmidt, 2006). Como se anticipó, los mecanismos de coordinación son diversas formas de sistematizar, verificar y articular el trabajo, que se utilizan para diseñar y garantizar el éxito de un proceso productivo. Ergo, se les considera elementos fundamentales en la estructura de una organización, en tanto operan como el aglutinante que la mantiene unida y comunicada. Siguiendo los postulados de la cibernética, también pueden ser entendidos en términos de formas de control, en la medida que - coordinación y control- se orientan a comprobar la calidad de las acciones ejecutadas (Mintzberg, 1992; 1993).

Henry Mintzberg (1980) propone seis mecanismos de coordinación:

El primero se denomina ajuste mutuo y consiste en obtener la coordinación del trabajo mediante la simple comunicación informal en interacciones horizontales. Este medio de coordinación es característico en organizaciones poco estructuradas, donde la gente trabaja en estrecha colaboración y con base en relaciones informales. Asimismo, suele emplearse en organizaciones de alta especialización, pues funciona ante circunstancias de extrema complejidad e incertidumbre que requieren elaborar respuestas innovadoras (Mintzberg, 1984).

El segundo es la supervisión directa, que consigue la coordinación endosando la responsabilidad a una persona sobre el trabajo de los demás, verticalizándose las relaciones laborales mediante instrucciones y observancia directa (Mintzberg, 1984).

El tercer mecanismo es la estandarización de procesos, referida a una forma de coordinación relacionada con un programa de trabajo que prescribe secuencias de procesos o prácticas, teniendo por consecuencia la reducción de la necesidad de una comunicación continuada y presencial. Esta coordinación es determinada $a$ priori, es decir, antes que se realicen las tareas laborales, pues los procesos de trabajo, tanto los inputs - habilidades y conocimientos- como 
los outputs - acciones-pueden confeccionarse en una normativa predeterminada o manual de procedimientos (Mintzberg, 1984).

El cuarto término es la estandarización de resultados, que tiene por finalidad normalizar los resultados mediante su prescripción, focalizándose únicamente en el rendimiento esperado (Mintzberg, 1984).

Como quinto mecanismo, se tiene la estandarización de habilidades, que constituye la forma de coordinación más apropiada en tareas complejas, las cuales no pueden emplear las dos formas anteriores de estandarización (Pucheu, 2013). Con más detalle, esta modalidad de estandarización trata sobre la especificación de las habilidades y conocimientos requeridos para la realización de un trabajo. En consecuencia, la estandarización de habilidades logra por vía indirecta y orgánica lo que las otras normalizaciones — procesos y resultados- intentan conseguir de forma exógena y prescriptiva (Mintzberg, 1984).

Finalmente, se encuentra la estandarización de criterios, que concibe la coordinación a partir de la transmisión de un sistema de creencias y significados compartido entre los integrantes de la organización, es decir, la construcción de una cultura organizacional (Mintzberg, 1984).

Si bien ninguna organización basa su funcionamiento en un único mecanismo de coordinación, sino que estos tienen ocurrencia simultánea, es habitual que los objetivos organizacionales y los parámetros de diseño del trabajo ejerzan un predominio a favor de unos mecanismos por sobre los demás. En este sentido, siguiendo la noción de predominancia, Mintzberg (1984) identifica una tipología de organización cuyo funcionamiento se basa preminentemente en la estandarización de procesos y de resultados, centrales en el contexto del presente análisis.

Efectivamente, existen organizaciones que se desenvuelven en diversos sectores productivos y de servicios, empero se caracterizan por realizar una labor operativa que es rutinaria y con procesos altamente estandarizados, esta es la denominada burocracia mecánica. En esta confi- guración, la tecnoestructura ${ }^{3}$ ejerce su influencia prescribiendo los procesos de trabajo mediante una descentralización limitada de carácter horizontal y generando una estructura orientada al orden y la repetición de procesos para alcanzar resultados también prescritos (Mintzberg, 1980). La burocracia mecánica es efectiva en condiciones donde la tarea y el entorno suelen ser estables y simples. Por el contrario, estos sistemas de control centralizados generan organizaciones que, al tratar con circunstancias variables, se vuelven lentas e ineficaces. Esto se hace patente en actividades donde se buscar proveer servicios personales o de transferencia de capacidades, pues estas actividades requieren respuestas particulares a las necesidades de cada usuario (Pucheu, 2013).

\section{La estandarización de proce- sos y resultados en el trabajo docente: El caso de Chile y sus cuestionamientos}

En un sistema escolar de amplitud nacional es posible que tengan cabida todos los mecanismos de coordinación postulados por Mintzberg. Sin embargo, en el caso chileno la adopción de dispositivos del NPM ha fortalecido la aplicación de consecuencias en forma de incentivos y amenazas de despido o cierre ante el no cumplimiento de las prácticas y los resultados estandarizados (Oyarzún et al., 2019). Por lo anterior, incluso si se presenta coexistencia de múltiples formas de coordinación, son los mecanismos de estandarización de procesos y resultados aquellos que consiguen mayor centralidad en el sistema escolar chileno. En este apartado se analizarán sintéticamente cómo estos dos mecanismos condicionan la labor docente, junto con los cuestionamientos que se desprenden a partir de tal examen.

Para comprender la manera en que la estandarización de procesos se presenta normativamente en el quehacer de los profesores desde la óptica de Mintzberg (1984), es necesario tomar nota que este autor sugiere para la organización 
de las escuelas la pertinencia de la estandarización de habilidades. Las configuraciones estructurales que resultan de la primacía de alguno de estos mecanismos de estandarización, ya sea de procesos, resultados o habilidades, difieren fundamentalmente en cuanto a la autonomía conferida al personal del núcleo de operaciones, es decir, los profesores que trabajan en las aulas. En términos simples, ante la estandarización de habilidades la autonomía de los docentes se alza, mientras que frente a la estandarización de procesos o de resultados decrece, manteniéndose el poder en las prescripciones externas de los instrumentos de la política.

En Chile, las disposiciones legales han asegurado que los docentes sean posicionados como ejecutores de planes, bases curriculares y marcos normativos ajenos a la escuela, elaborados sin su participación y, por tanto, reduciendo su autonomía (Cornejo et al., 2015; Fernández et al., 2016; Sisto, 2012). Los artefactos y dispositivos que formalizan el contenido de la práctica pedagógica de manera más directa comprenden las Bases Curriculares obligatorias, los textos escolares de distribución estatal, el MBE y diversos mecanismos de accountability con consecuencias de alto riesgo, aplicados tanto a nivel de los docentes como de la escuela (Assaél et al., 2018).

Como ejemplo de lo anterior, se tiene que a nivel individual el desempeño de los docentes está vinculado a un Sistema Nacional de Evaluación que deriva en consecuencias referidas a incentivos - bonificaciones individuales $\mathrm{y}$ acceso a instancias de perfeccionamiento- $y$ sanciones - posibilidades de despido luego de dos evaluaciones continuadas en nivel insuficiente, categoría de más bajo desempeño-(Bonifaz, 2011). Esta evaluación se basa en cuatro instrumentos que miden el ajuste a estándares o indicadores de desempeño contenidos en el MBE, que incluyen la irrestricta aplicación de las bases curriculares y de las prácticas pedagógicas preestablecidas (Taut \& Sun, 2014). A pesar de las modificaciones realizadas mediante la reciente Ley de Desarrollo Profesional Docente del 2016, varios autores sostienen que, en este ámbito, el sistema evaluativo conserva una modalidad gerencialista y basada, predominantemente, en una accountability individual de altas consecuencias (Assaél \& Cornejo, 2018; Ávalos, 2017; Ruffinelli, 2015). Por su parte, a nivel organizacional o de la escuela, el modelo de gestión escolar - fuertemente influenciado por el NPM- establece sistemas de contractualización vertical en que las escuelas suscriben convenios para el cumplimiento de estándares de gestión y resultados cuya inobservancia implica eventuales sanciones, lógica de funcionamiento que fue instalada con la promulgación de la Ley de Subvención Escolar Preferencial (SEP) del 2008 (Oyarzún et al., 2019). A partir de este hito, las escuelas son clasificadas según su desempeño — como se anticipó, el sistema de clasificación fue perfeccionando- de manera tal que un bajo rendimiento sostenido podría implicar el cierre de la organización escolar (Parcerisa \& Falabella, 2017).

Por sí misma, la existencia de estos artefactos y dispositivos no permite suponer que sean tratados como condicionantes de la estandarización. No obstante, en el caso chileno, dichos artefactos y dispositivos son aplicados mediante un accountability de altas consecuencias tanto a nivel organizacional como individual. Esto configura un sistema fuertemente prescriptivo que instituye la estandarización como principal mecanismo de coordinación y, por ende, como objetivo central del trabajo docente. Particular trascendencia adquiere la estandarización de resultados pues, principalmente, son los resultados obtenidos por los estudiantes en el SIMCE los que determinan, en mayor medida, las categorías de clasificación. Sumado a esto, tales resultados son publicados para ser revisados por las familias, agregando presión social y robusteciendo la centralidad de este tipo de mecanismo de coordinación. Las investigaciones y experiencias desarrolladas en Chile reportan que tales disposiciones confinan el trabajo docente hacia prácticas no esperadas como la pérdida de instancias de trabajo colaborativo (Assaél et al., 2012; Assaél et al., 2014) 
y el entrenamiento para las evaluaciones estandarizadas, llevando a la desvalorización de otras áreas de conocimiento (Pino et al., 2016; Reyes \& Akkari, 2017; Weinstein et al., 2016). De este modo, la desprofesionalización estriba en que se espera el acatamiento de estos instrumentos y evaluaciones externas en condiciones donde el tiempo lectivo es insuficiente $y$, además, se exige responsabilización de un alto volumen de trabajo administrativo, destinado únicamente a la producción de evidencias para rendir cuentas (Assaél et al., 2012; Braslavsky, 1999; Fardella, 2013; Rojas \& Leyton, 2014).

Entonces, ¿cuál sería el sentido de estandarizar los procesos y resultados de un trabajo? Según Mintzberg, las actividades ocupacionales se estandarizan para reducir su variabilidad, operar en condiciones calificadas como libres de incertidumbres y, de esta manera, garantizar su predicción; así como también para responder a un deseo arbitrario de orden, ejercer control sobre el comportamiento, concentrar el poder en la tecnoestructura y/o percibir al trabajador como una pieza intercambiable. Empero, en la pedagogía la variabilidad y la diversidad son la regla $y$, por ende, estructurar la práctica pedagógica a un estudiante "promedio" e inexistente no hace más que promover la exclusión y generar un servicio educativo que aborda inoportunamente las necesidades de los educandos (Meyer et al., 2014).

Es más, el propio Mintzberg $(1980 ; 1984)$ afirma que el trabajo profesional no puede ser controlado debido a su alta complejidad y multiplicidad de resultados posibles, siendo improcedente su estandarización por procesos o resultados. Así, la estandarización de procesos y resultados aplicada al trabajo profesional de los docentes tiene varios efectos perversos: a) la obediencia a las normas por parte de los profesionales se transforma en un fin en sí mismo; b) se vuelve inefectivo dado que el operario profesional pierde control sobre el trabajo complejo; c) reduce los procesos analíticos subyacentes al trabajo profesional; d) desequilibran la relación entre profesional-cliente (aquí profesor-estu- diante) al deshacer el contacto libre y personal; e) reduce la innovación; y f) aumenta la pasividad del profesional.

Finalmente, es pertinente examinar el papel de la supervisión directa en tanto mecanismo de coordinación que, en el contexto del sistema chileno, aparece subsumido a la supremacía de la estandarización por procesos y resultados. Si bien el discurso de la política actual atribuye a los directores e integrantes del equipo directivo un rol trascedente como "líderes pedagógicos", en su labor cotidiana tienen como principal preocupación asegurar que sus escuelas avancen en las categorías de desempeño mediante mejores resultados en el SIMCE y asegurar fuentes de financiamiento suficientes en función del sistema de subvención per cápita (Montecinos et al., 2015; Weinstein et al., 2016). En consecuencia, siguiendo la evidencia empírica sobre el caso chileno, algunas de las secuelas resultantes que implican decisiones directivas son: a) la aplicación de medidas de selección para mejorar la composición socioeconómica y cognitiva del estudiantado (Carrasco et al., 2017; Weinstein et al., 2016); b) implementación de medidas de discriminación y expulsión (Carrasco \& Fromm, $2016)$; c) que las escuelas de menor nivel socioeconómico concentren a estudiantes con discapacidad intelectual (Fundación Chile, 2013; Rosas \& Santa Cruz, 2013); y d) concentrar la enseñanza en las áreas evaluadas, apartándose de una concepción integral de la enseñanza (Assaél et al., 2018; Reyes \& Akkari, 2017).

\section{Discutiendo "los otros" meca- nismos de coordinación para el caso de Chile}

Como se señaló, Mintzberg asevera que la estandarización de procesos y resultados no son mecanismos adecuados para coordinar las prácticas pedagógicas (Mintzberg, 1984; Pucheu, 2013). Concretamente, este autor asumió que la estandarización de habilidades podía considerarse como un dispositivo que se adecuaba 
de mejor manera a la complejidad inherente de la situación educativa. Organizacionalmente, el resultado de priorizar este mecanismo conlleva la emergencia de burocracias profesionales, caracterizadas por un conjunto de profesionales que disponen de autonomía, pero que no necesariamente colaboran entre sí.

Siguiendo a Mintzberg (1984), los problemas comunes que surgen en la burocracia profesional incluyen: a) dificultad en la coordinación de los profesionales; b) rencillas a raíz de intentar comprender contingencias fuera de las categorías de conocimiento que comparten; c) dificultad para abordar profesionales carentes de ética, dado que las habilidades, por normalizadas que estén, requieren un juicio considerable; d) dificultad para abordar profesionales incompetentes que no quieren actualizar sus conocimientos; e) desatención de las necesidades de la organización, pues no se perciben como parte de un equipo; f) no adecuarse a las necesidades de los usuarios para dar lugar, únicamente, a lo que saben o quieren hacer los profesionales; g) incapacidad para innovar.

En esta línea, Braslavsky (1999) cita a Mintzberg, postulando que la teoría del último permite comprender, desde una mirada histórica, el estado de profesionalización que existía antes de la actual desprofesionalización del magisterio. Esta autora propone que, más que buscar profesionalizar o volver a la situación anterior, es necesario re-profesionalizar o reinventar la profesión docente para el siglo XXI. Este proceso debería considerar, principalmente, habilidades que permitan tanto un mejor desempeño en las problemáticas y situaciones coyunturales como una mayor participación en la reinvención de la escuela y los sistemas educativos.

Siguiendo con la mismalógica, Carbonneau y Hétu (2005) refieren que cada maestro debe enfrentar situaciones inéditas y, para las cuales, deberá elaborar una respuesta singular, pues ante los problemas educativos no existen soluciones universales. Es así como se requieren competencias para analizar críticamente las prácticas, tomando en cuenta múltiples modelos de acción (Carbonneau \& Hétu, 2005), cuerpos teóricos y normas (Altet, 2005) y, por supuesto, las necesidades y particularidades de los estudiantes en su contexto (Coll, 2016). Por ello, los marcos normativos que prescriben la práctica docente de manera genérica en Chile, por ejemplo, el MBE, pueden ser útiles como uno más entre diversos modelos o enfoques pedagógicos.

Entonces, la formación profesional depende de un análisis reflexivo efectuado con pares docentes y centrado en las prácticas pedagógicas cotidianas, cuyo resultado producirá saberes con base en la acción (Altet, 2005). Por tanto, la colaboración es esencial para impulsar procesos de innovación y mejora educativa desde una reflexión compartida (Butler \& Schnellert, 2012). Desde el modelo de Mintzberg, es posible asimilar el mecanismo denominado ajuste mutuo con la dinámica del trabajo colaborativo. Efectivamente, este teórico postula que precisamente este mecanismo permite una mejor adaptación a situaciones complejas y particulares y, además, favorece la innovación.

En este escenario, las comunidades de aprendizaje resultantes del fortalecimiento del ajuste mutuo pueden favorecer la discusión de aspectos técnicos, pero también de valores y propósitos, siendo esencial una diversidad de voces (Philpott, 2018). En consecuencia, los espacios reflexivos y colaborativos pueden incluir a docentes y, además, a otros actores educativos e integrantes de la comunidad educativa, dando paso a acuerdos comunes bajo un razonamiento democrático. Es así como también resultaría necesario la estandarización de criterios, formulada por Mintzberg, que aporta al desarrollo de culturas organizacionales, pero desde una lógica inductiva, es decir, a partir del diálogo constructivo entre los distintos actores sociales que conforman una comunidad. El desarrollo conjunto de ambos mecanismos señalados — ajuste mutuo y estandarización de criterios-podría inducir a la generación de habilidades profesionales, pero ya no a partir de la lógica del estándar emana- 
do de una matriz centralizada, sino desde una perspectiva situada y focalizada que responda a la diversidad y condición siempre cambiante y contextual de la enseñanza.

Sin perjuicio de lo anterior, la aplicación y desarrollo de formas de trabajo más afines a la pedagogía también depende de condiciones estructurales. En este sentido, se identifican tres aspectos críticos para la ocurrencia de un trabajo colaborativo, innovador y basado en conocimientos situados. Como primer punto, las prácticas de gestión promovidas desde la política que pretenden instalar dinámicas colaborativas y reflexivas a nivel de la escuela son aun incipientes, ${ }^{4}$ en función de lo cual podrían carecer de una utilización genuina por parte de los actores educativos ante la presión que ejercen los dispositivos del NPM, asimismo la exigencia obligatoria vía decretos o normativas no asegura su aparición ni permanencia. Al respecto, se identifica la pertinencia de desactivar los mecanismos sancionatorios que otorgan carácter prescriptivo a muchas instancias impulsadas desde la política escolar. En segundo lugar, es necesaria la concesión de espacios temporales que favorezcan la realización de formas de trabajo colaborativo, como las comunidades de aprendizaje. Este aspecto parece aún insuficiente, pues, aun considerando los cambios introducidos con la Ley de Desarrollo Profesional Docente, el tiempo no lectivo para la preparación de clases alcanza sólo al 35\% en 2019 (OCDE, 2017). En tercer lugar, otro aspecto refiere a revertir la escasa confianza depositada en los educadores, sus capacidades y conocimientos locales (Carrasco, 2013; Sisto, 2012). En relación con esto, la evaluación individual refrendada en la Ley de Desarrollo Profesional Docente se visualiza como un dispositivo gerencialista (Ávalos, 2017; Ruffinelli, 2016) que externaliza la categorización de "buenos" y "malos" educadores mediante el juicio de evaluadores externos con base en un sistema uniforme de estándares. Esto no solo ejerce un impulso en contra del trabajo colaborativo, sino que también evidencia desconfianza en las capacidades y el juicio profesional de los maestros.

\section{Consideraciones finales}

Los planteamientos revisados previamente permiten comprender que las aportaciones teóricas de Mintzberg se distancian de la estructuración normativa del sistema escolar chileno, en particular respecto de las prácticas pedagógicas y de la gestión escolar. Con más detalle, el discurso actual con evidente acervo tecnocrático y estandarizador que demanda la aplicación de dispositivos y tecnologías del NPM, asumidas "apriorísticamente" como efectivas (Verger \& Normand, 2015), genera una serie de efectos perversos o externalidades negativas. Es así como se posibilita que la adscripción a las prescripciones se constituya en un fin en sí mismo o que los procesos analíticos subyacentes al trabajo pedagógico se reduzcan de manera drástica, entre otras. En otras palabras, los procesos de estandarización de procesos y resultados son improcedentes ante la dinámica pedagógica y, paradojalmente, tienden a burocratizar el trabajo docente en vez de hacerlo más efectivo.

En conclusión, la hegemonía de mecanismos de estandarización por procesos y resultados que requieren condiciones de regularidad y simpleza es infructuosa y perjudicial, siendo necesarias otras formas de regular este tipo de trabajo. Por consiguiente, como corolario de este análisis y pensando en el diseño del trabajo docente, se propone considerar con mayor predominancia otros mecanismos de coordinación más afines a la labor pedagógica, entre los que se identifican: a) la estandarización de habilidades: competencias críticas y reflexivas que incluyan múltiples conocimientos teóricos y prácticos; b) el ajuste mutuo: facilitación de espacios de colaboración y comunidades de aprendizaje; y c) la estandarización de criterios: acuerdos valóricos generados inductivamente desde los centros escolares.

De este modo, la clasificación de mecanismos de coordinación plateada por Mintzberg hace varias décadas en el campo organizacional constituye un marco teórico atingente para comprender las diversas unidades y dinámicas 
que estructuran y regulan un sistema escolar. Puntualmente, a través de este ya clásico lente en el ámbito corporativo, es posible identificar múltiples problemáticas relacionadas con la forma de diseñar el trabajo docente en Chile. Inclusive, a lo largo de estas páginas hemos reflexionado, desde la perspectiva elegida, respecto de posibles líneas de transformación para la optimización del sistema escolar analizado.

\section{Notas}

1. Sistema Nacional de Medición de la Calidad Educativa: evaluación estandarizada del aprendizaje en las asignaturas de Lenguaje y Comunicación; Matemática; Ciencias Naturales; Historia, Geografía y Ciencias Sociales e Inglés. Las pruebas del SIMCE se aplican censalmente en $2^{\circ}, 4^{\circ}, 6^{\circ}, 8^{\circ}$ básico, y II medio, siguiendo un Plan de Evaluaciones (Fuente: https://bit. ly/36tDuJo).

2. La Ley 20.529 que crea el Sistema de Aseguramiento de la Calidad de la Educación (2011), fija cuatro categorías de desempeño: insuficiente, medio bajo, medio y alto. Además, en su artículo 31 tipifica las condiciones que podrían implicar la pérdida del Reconocimiento oficial para una escuela que permanece, a lo menos, cuatro años en categoría de desempeño insuficiente.

3. Grupo de tecnócratas encargados del diseño del trabajo.

4. Por ejemplo, las horas para trabajo colaborativo entre profesores de aula regular y profesionales del Programa de Integración escolar para la atención de estudiantes con necesidades educativas especiales (Fuente: https://bit.ly/391xiz0).

\section{Referencias bibliográficas}

Altet, M. (2005). La competencia del maestro profesional o la importancia de analizar las prácticas. En L. Paquay, M. Altet, E. Charlier, \& P. Perrenoud (Coords.), La formación profesional del maestro. Estrategias y competencias (pp. 33-54). Fondo de Cultura Económica.

Anderson, G., \& Cohen, M.I. (2015). Redesigning the identities of teachers and leaders: A framework for studying new professionalism and educator resistance. Education Policy Analysis Archives, 23(85). http://dx.doi.org/10.14507/epaa.v23.2086

Assaél, J., \& Cornejo, R. (2018). Work regulations and teacher subjectivity in a context of standardization and Accountability Policies in Chile. In R. Normand, M. Liu, L. Carvalho, D. Andrade, \& L. Levasseur (Eds.), Education Policies and the Restructuring of the Educational Profession, Global and Comparative Perspectives (pp. 245-257). Springer.

Assaél, J., Albornoz, N., \& Caro, M. (2018). Estandarización educativa en Chile: tensiones y consecuencias para el trabajo docente. Educação Unisinos, 22(1), 83-90.

Assaél, J., Acuña, M., Contreras, P., \& Corbalán, F. (2014). Transformaciones en la cultura escolar en el marco de la implementación de políticas de accountability en Chile. Un estudio etnográfico en dos escuelas clasificadas en recuperación. Estudios Pedagógicos, 40(2), 7-26.

http://dx.doi.org/10.4067/S0718-07052014000300001

Assaél, J., Contreras, P., Corbalán, F., Palma, E., Campos, J., Sisto, V., \& Redondo, J. (2012). Ley SEP en escuelas municipales emergentes: ¿cambios en la identidad docente? Revista de Pedagogía Crítica, 11, 219-228. http://dx.doi. org/10.25074/07195532.11.453

Ávalos, B. (2017). Teacher evaluation in Chile: Highlights and complexities in 13 of experience. Teachers and Teaching, 24(3), 297-311. https://doi.org/10.1080/13540602.2017.1388228

Ball, S., \& Youdell, D. (2008). La privatización encubierta en la educación pública. Instituto de Educación, Universidad de Londres.

Ball, S., Bailey, P., Mena, P., del Monte, P., Santori, D., Tseng, C., Young, H., \& Olmedo, A. (2013). A constituição da subjetividade docente no Brasil: um contexto global. Revista Educação em Questão, 46(32), 9-36.

https://doi.org/10.21680/1981-1802.2013v46n32ID5114

Bezes, P., Demazière, D., Le Bianic, T., Paradeise, C., Normand, R., Benamouzig, D. Pierru, F., \& Evetts, J. (2012). New public management and professionals in the public sector. What new patterns beyond opposition? Sociologie du travail, 54, 1-52. http://dx.doi.org/10.1016/j.soctra.2012.07.001

Braslavsky, C. (1999). Bases, orientaciones y criterios para el diseño de programas de formación de profesores. Revista Iberoamericana de Educación, 19, 13-50. https://doi.org/10.35362/rie1901054

Bonifaz, R. (2011). Capítulo 1: Origen de la evaluación docente y su conexión con las políticas públicas en educación. En J. Manzi, J., R. 
González, \& Y. Sun (Eds.), La evaluación docente en Chile (pp. 13-32). MIDE UC.

Butler, D.L., \& Schnellert, L. (2012). Collaborative inquiry in teacher professional development. Teaching and Teacher, 28(8), 1206-1220. https://doi.org/10.1016/j.tate.2012.07.009

Carbonneau, M., \& Hétu, J. (2005). La formación práctica de los maestros y el nacimiento de una inteligencia profesional. En L. Paquay, M. Altet, E. Charlier, \& P. Perrenoud (Coords.), La formación profesional del maestro. Estrategias y competencias (107-138). Fondo de Cultura Económica.

Carrasco, A. (2013). Mecanismos performativos de la institucionalidad educativa en Chile: Pasos hacia un nuevo sujeto cultural. Observatorio cultural, 15, 4-10. https://bit.ly/2JIKlpy

Carrasco, A., \& Fromm, G. (2016). How local market pressures shape leadership practices: evidence from Chile. Journal of Educational Administration and History, 48(4), 290-308. https://doi.org/10.1080/00220620.2016.1210584

Carrasco, A., Gutiérrez, G., \& Flores, C. (2017). Failed regulations and school composition: selective admission practices in Chilean primary schools. Journal of Education Policy, 32(5), 642-672. https://doi.org/10.1080/02680939.2 017.1312549

Carvalho, M.L., \& Normand, R. (2018). Introduction. In R. Normand, M. Liu, L. Carvalho, D. Andrade, \& L. Levasseur (Eds.), Education Policies and the Restructuring of the Educational Profession, Global and Comparative Perspectives (pp. 1-12). Springer.

Cavieres, E., \& Apple, M. (2016). La ley docente y la clase media: Controlando el desarrollo de los profesores chilenos. Cadernos CEDES, 36(100), 265-280. https://dx.doi.org/10.1590/cc0101-32622016171391

Chan, W. (2010). A Review of Education Reform-New Senior Secondary (NSS) Education in Hong Kong. International Education Studies, 3(4), 26-35. https://doi.org/10.5539/ies.v3n4p26

Coll, C. (2016). La personalización del aprendizaje escolar. El qué, el por qué y el cómo de un reto insoslayable. En J. Vilalta (Dir.), Reptes de l'educació a Catalunya. Anuari d'Educació 2015 (pp. 43-104). Fundació Jaume Bofill.
Cornejo, R., Albornoz, N., Castañeda, L., Palacios, D. Etcheberrigaray, G., Fernández, R., Gómez, S., Hidalgo, F., \& Lagos, J.I. (2015). Las prescripciones del trabajo docente en el nuevo marco regulatorio de políticas educativas en Chile. Psicoperspectivas, 14(2), 72-83. http://dx.doi.org/10.5027/PSICOPERSPECTIVASVOL14-ISSUE2-FULLTEXT-580

Darling-Hammond, L. (2014). Standards, assessments and educational policy: pursuit of genuine accountability. Educational Testing Service.

Falabella, A. (2015). El mercado escolar en Chile y el surgimiento de la Nueva Gestión Pública: el tejido de la política entre la dictadura neoliberal y los gobiernos de la centroizquierda (1979 a 2009). Educaçao \& Sociedade, 36(132), 699-722. http://dx.doi.org/10.1590/ES0101-73302015152420

Fardella, C. (2013). Resistencias cotidianas en torno a la institucionalización del modelo neoliberal en las políticas educacionales: El caso de la docencia en Chile. Psicoperspectivas, 12(2), 83-92. http://dx.doi.org/10.5027/psicoperspectivas-Vol12Issue2-fulltext-294

Fernández, R., Albornoz, N., Cornejo, R., \& Etcheberrigaray, G. (2016). Los discursos sobre autonomía del trabajo docente en el nuevo marco regulatorio educativo chileno. Currículo sem Fronteiras, 16(2), 283-302. https://bit.ly/33CcO7u

Fundación Chile (2013). Análisis de la implementación de los programas de integración escolar (PIE) en establecimientos que han incorporado estudiantes con necesidades educativas especiales transitorias (NEET). https://bit.ly/33CcV2U

Gleeson, D., \& Knights, D. (2015). Challenging dualism: Public professionalism in 'troubled' times. Sociology, 2(40), 277-295. https://doi.org/10.1177\%2F0038038506062033

Hall, D., Grimaldi, E., Gunter, H., Møller, J., Serpieri, R., \& Skedsmo, G. (2015). Educational reform and modernisation in Europe: The role of national contexts in mediating the new public management. European Educational Research Journal, 14(6), 487-507. https://doi.org/10.1177/1474904115615357

Herr, K. (2015). Cultivating disruptive subjectivities: Interrupting the new professionalism. 
Education Policy Analysis Archives, 23(86). http://dx.doi.org/10.14507/epaa.v23.2097

Holloway, J., Sørensen, T.B., \& Verger, A. (2017). Global perspectives on high-stakes teacher accountability policies: An introduction. Education Policy Analysis Archives, 25(85). http://dx.doi.org/10.14507/epaa.25.3325

Internacional de la Educación para América Latina (2015). La estandarización de la evaluación. Las pruebas nacionales e internacionales ¿medición o evaluación? Utdannings Forbundet/ Internacional de la Educación para América Latina.

Ley $\mathrm{N}^{\circ}$ 20.529. Sistema Nacional de Aseguramiento de la Calidad de la Educación Parvularia, Básica y Media y su Fiscalización. Diario Oficial de la República de Chile, Santiago, Chile, 27 de agosto de 2011.

Maroy, C., \& Pons, X. (2019). Accountability Policies in Education. A Comparative and Multilevel Analysis in France and Quebec. Springer.

Maroy, C., Pons, X., \& Dupuy, C. (2016). Vernacular globalisations: neo-statist accountability policies in France and Quebec education. Journal of Education Policy, 32(1), 100-122. https://doi.org/10.1080/02680939.2016.1239841

Meyer, A., Rose, D.H., \& Gordon, D. (2014). Universal Design for Learning: Theory and Practice. CAST.

Mintzberg, H. (1980). Structure in 5's: A synthesis of the research on organization design. Management Science, 26(3), 322-341. https://doi.org/10.1287/mnsc.26.3.322

Mintzberg, H. (1984). La estructuración de las organizaciones. Ariel Economía.

Mintzberg, H. (1992). El poder en la organización. Ariel Economía.

Mintzberg, H. (1993). El proceso estratégico. Conceptos, contextos y casos. Prentice-Hall Hispanoamericana.

Montecinos, C., Ahumada, L., Galdames, S., Campos, F., \& Leiva, M.V. (2015). Targets, threats and (dis)trust: The managerial troika for public school principals in Chile. Education Policy Analysis Archives, 23(87). http://dx.doi.org/10.14507/epaa.v23.2083

Luengo-Navas, J., \& Saura-Casanova, G. (2013). La performatividad en la educación. La construcción del nuevo docente y el nuevo gestor performativo. REICE-Revista Iberoamericana sobre Calidad, Eficacia y Cambio en Educación, 11(3), 139-153. https://bit.ly/2I1 epvQ

Normand, R., Liu, M., Carvalho, L.M., Andrade, D., \& LeVasseur, L. (2018). Education Policies and the Restructuring of the Educational Profession. Global and Comparative Perspectives. Springer.

Organización para la Cooperación y el Desarrollo Económicos (OCDE) (2017). Evaluaciones de políticas nacionales de educación. Educación en Chile. OCDE, Fundación SM.

Oyarzún, C., Soto, R., \& Moreno, K. (2019). Tensiones del trabajo docente en un contexto gerencialista: una revisión de literatura sobre el caso chileno. Educação (UFSM), 44(1).

http://dx.doi.org/10.5902/19846444434888

Parcerisa, L., \& Falabella, A. (2017). La consolidación del Estado evaluador a través de políticas de rendición de cuentas: Trayectoria, producción $\mathrm{y}$ tensiones en el sistema educativo chileno. Education Policy Analysis Archives, 25(89). http://dx.doi.org/10.14507/epaa.25.3177

Philpott, C. (2018). Teacher agency and professional learning communities: what can learning rounds in Scotland teach us? In M. Peters, B. Cowie, \& I. Menter (Eds.), A companion to research in teacher education (pp. 269-282). Springer.

Pino, M., Oyarzún, G., \& Salinas, I. (2016). Crítica a la estandarización para la rendición de cuentas: narrativas de resistencia para transformar el sistema de evaluación en Chile. Cadernos Cedes, 36(100), 337-354. https://doi.org/10.1590/cc0101-32622016171362

Pucheu, A. (2013). Lo que cambia son las personas. RIL Editores.

Reyes, I., \& Akkari, A. (2017). La privatización de la educación en Chile: análisis de los discursos del profesorado y de la dirección de los centros sobre la calidad de la educación y la rendición de cuentas. RASE, Revista de Sociología de la Educación, 10(3), 363-380. http://dx.doi.org/10.7203/RASE.10.3.9891

Rojas, M.T., \& Leyton, D. (2014). La nueva subjetividad docente: Construcción de subjetividades docentes en los inicios de la implementación de la Subvención Escolar Preferencial en 
Chile. Estudios pedagógicos, 40 (número especial), 205-221.

http://dx.doi.org/10.4067/S0718-07052014000200012

Rosas, R., \& Santa Cruz, C. (2013). Dime en qué colegio estudiaste y te diré qué CI tienes. Radiografía al desigual acceso al capital cognitivo en Chile. Ediciones UC.

Ruffinelli, A. (2016). Ley de desarrollo profesional docente en Chile: de la precarización sistemática a los logros, avances y desafíos pendientes para la profesionalización. Estudios Pedagógicos, 42(4), 261-279. https://dx.doi. org/10.4067/S0718-07052016000500015

Schmidt, T. (2006). A review of structure in fives: Designing effective organizations. https://bit.ly/3onM4j7

Sisto, V. (2012). Identidades desafiadas: individualización, managerialismo y trabajo docente en el Chile actual. PSYKHE, 21(2), 35-46. http://dx.doi.org/10.7764/psykhe.21.2.542

Taut, S., \& Sun, Y. (2014). The Development and Implementation of a National, Standardsbased, Multi-method Teacher Performance Assessment System in Chile. Education Policy Analysis Archives, 22(71). http://dx.doi.org/10.14507/epaa.v22n71.2014

Tsang, K.K., \& Kwong, T.L. (2016). Teachers' emotions in the context of education reform: labor process theory and social constructionism. British Journal of Sociology of Education, 38(6), 841-855.

https://doi.org/10.1080/01425692.2016.1182007
Verger, A., \& Normand, R. (2015). Nueva gestión pública y educación: Elementos teóricos y conceptuales para el estudio de un modelo de reforma educativa global. Educaçao \& Sociedade, 36(132), 599-622. http://dx.doi.org/10.1590/ES0101-73302015152799

Verger, A., Zancajo, A., \& Fontdevila, C. (2016). La economía política de la privatización educativa: políticas, tendencias y trayectorias desde una perspectiva. Revista Colombiana de Educación, (70), 47-78. https://doi.org/10.17227/01203916.70rce47.78

Verger, A., Moschetti, M., \& Fontdevila, C. (2017). La privatización educativa en América Latina: Una cartografía de políticas, tendencias y trayectorias. Education International. https://doi.org/10.13140/RG.2.2.16049.58724

Vieira, L., \& Oliveira, T. (2013). As condições do trabalho docente na Educação Infantil no Brasil: alguns resultados de pesquisa (20022012). Revista Educação em Questão, 46(32), 131-154. https://doi.org/10.21680/1981-1802.2013v46n32ID5125 Weinstein, J., Marfán, J., Horn, A., \& Muñoz, G. (2016). Chile: School leadership challenged by double accountability towards schools. In J. Easley II, \& P. Tulowitzki (Eds.), Educational Accountability. International perspectives on challenges and possibilities (pp. 54-72). Routledge. 


\section{EALTERIDAD Formación inclusiva del profesorado de primaria en tres regiones chilenas \\ Inclusive training of elementary teachers in three chilean regions}

Mauricio Andrés Valdés-Pino doctorando de la USAL (España) (mauriciovaldes@usal.es) (https://orcid.org/0000-0002-2311-9392)

(D) Dra. María Isabel Calvo-Álvarez es docente e investigadora de la USAL (España) (isabelc@usal.es) (https://orcid.org/0000-0001-9071-2711)

(D) Dr. Fernando Martínez-Abad es docente e investigador de la USAL (España) (fma@usal.es) (https://orcid.org/0000-0002-1783-8198)

Recibido: 2020-08-10 / Revisado: 2020-12-02 / Aceptado: 2020-12-08 / Publicado: 2021-01-01

\section{Resumen}

La formación inicial del docente de Educación General Básica (EGB) en Chile ha sido un tema que viene en discusión hace muchos años, sin embargo, no se ha ajustado a los requerimientos de las últimas legislaciones implementadas para abordar una educación inclusiva (Ley de inclusión, Decreto N83 y actualizaciones del Decreto $N^{\circ}$ 170), así como tampoco se ha ajustado a las necesidades y requerimientos de quienes están al frente en cada aula junto a sus estudiantes. Este artículo pretende analizar e identificar las necesidades formativas en inclusión de los docentes egresados entre 2008 y 20 I 8. Se aplicó un cuestionario elaborado ad hoc, con un diseño descriptivo $(n=|| 8)$ al profesorado. Los resultados señalan las necesidades formativas teóricas y metodológicas, con una predominancia en los aspectos metodológicos que permitan a los docentes trabajar con diversos diseños estratégicos que promuevan el auto-aprendizaje o trabajo colaborativo, implementar adaptaciones curriculares requeridas por el Decreto 83, generar planes educativos individuales, que permitan centrar el aprendizaje en la persona, conocer la importancia de los espacios virtuales para promover la educación inclusiva y resaltar la importancia de los recursos humanos (psicopedagoga, psicólogo, educadora diferencial u otros), para facilitar el trabajo con estudiantes con Necesidades Educativas Especiales (NEE). Por lo tanto, esta investigación permitirá que las instituciones formadoras adecúen su formación a estas necesidades y generen proyectos de formación inicial y continua los docentes en Chile.

Descriptores: Enseñanza y formación, formación de docente, educación especial, formación de docentes de primaria, perfeccionamiento, formación básica.

\section{Abstract}

The initial training of elementary teacher in Chile has been a topic that has been under discussion for many years, however, it has not been adjusted to the requirements of the latest legislation implemented to address an inclusive education (inclusion law Decree No. 83 and updates to Decree No. 170), as well as not being adjusted to the needs and requirements of those who are at the forefront in each classroom with their students. This article aims to analyze and identify the training needs for inclusion of graduate teachers between 2008 and 2018. A questionnaire prepared ad hoc, with a descriptive design $(n=1 \mid 8)$ was applied to teachers. The results indicate the theoretical and methodological training needs, with a predominance in the methodological aspects that allow teachers to work with various strategic designs that promote self-learning or collaborative work, implement curricular adaptations required by decree 83 , generate individual educational plans, that allow to focus learning on the person, know the importance of virtual spaces to promote inclusive education and highlight the importance of human resources (psycho-pedagogue, psychologist, differential educator or others), to facilitate work with students with SENTherefore, this research will allow training institutions to adapt their training to these needs and generate initial and ongoing training projects for teachers in Chile.

Keywords: Education and training, teacher training, special education, primary teacher training, advanced training, basic training.

Forma sugerida de citar: Valdés-Pino, M., Calvo-Álvarez, M.I., \& Martínez-Abad, F. (2021). Formación inclusiva del profesorado de primaria en tres regiones chilenas. Alteridad, 16(1), 117-129. https://doi.org/10.17163/alt.v16n1.2021.09 


\section{Introducción}

El objetivo de este artículo es conocer las necesidades de formación en inclusión de los docentes egresados de EGB en el contexto de la ley de inclusión en Chile. Además, pretende analizar las diferencias en las siguientes variables: género, tipo de necesidades con las que trabajan, formación recibida, ciudad de desempeño laboral y edad; para ello se ha creado un cuestionario online.

En los últimos años, Chile ha procurado una formación inicial que apunte a un desarrollo integral de los estudiantes, mediante una serie de disposiciones e iniciativas legales, como los estándares de la formación inicial, la prueba INICIA y la ley de Carrera Docente.

Se evaluará la formación inicial con base en las respuestas de los docentes del cuestionario que fue creado con dos dimensiones: teórica y metodológica.

El estándar base en formación de la calidad docente en Chile surge del CPEIP (Centro de Perfeccionamiento Experimentación e Investigaciones Pedagógicas), que establece orientaciones mínimas para todas las universidades chilenas y/o CFP (Centros de Formación Profesional). Estos principios se establecen para hacer frente a la ley de calidad y equidad de la educación, que data del año 2011.

La prueba INICIA (2008), según Ruffinelli (2013) y San Martín (2014) evalúa tres competencias: conocimientos pedagógicos, conocimientos de la disciplina y didácticos y reflexión pedagógica, con el objeto de analizar si la formación inicial, de ahí su nombre, tienen efectos en el desempeño de los estudiantes en algunas mediciones, como por ejemplo en el SIMCE (Sistema de Medición de la Calidad de la Educación).

Martinic et al. (2014) en su estudio recoge la baja coherencia entre la formación inicial de los docentes de EGB y la práctica de su desarrollo profesional. La Organización para la Cooperación y Desarrollo Económico-OCDE (2013), señala que la efectividad del profesor es una de las variables importante para un fenóme- no que es multicausal, pues logra determinar que existe un efecto consistente, pero moderado del efecto profesor y el desempeño de los estudiantes. Por su parte, Arnaiz (2005) agrega que:

Lo verdaderamente importante es que los profesores cambien los pensamientos y actitudes en nuevos planteamientos de solidaridad, de tolerancia y en nuevas prácticas educativas que traigan consigo una nueva forma de enfrentarse a la pluralidad y a la multiculturalidad del alumnado. (p. 17)

Ante lo anterior, Lee y Shute (2010) y Martínez (2016) demuestran que el efecto moderado del profesor en las pruebas censales, como el SIMCE tiene mayor significancia en matemáticas y menos consistente en lenguaje.

Ainscow (1991), Echeita (2013), Florian (2010), Infante (2010) y López et al. (2014) señalan que existen aspectos a desarrollar en la formación inicial o permanente de los docentes, tales como: la necesidad de trabajar conceptos como integración e inclusión, identificar y valorar las características del modelo inclusivo y modelos de atención a la diversidad en principios, características y focos de atención.

En los aspectos metodológicos y con el fin de responder a las necesidades de los estudiantes y/o aula diversa e inclusiva, se debería iniciar por reconocer e identificar los diferentes estilos de aprendizaje (Carbonero et al., 2010; Bahamón et al., 2012) o diferencias individuales (Pegalajar \& Colmenero, 2017; Vadillo, 2014), el potencial de aprendizaje (Moreno \& López de Maturana, 2015; Tébar, 2010), la participación para la inclusión (Calvo et al., 2016), y el aprendizaje colaborativo e interdisciplinar (Durán \& Climent, 2017; García-Valcárcel et al., 2014; Jiménez, 2014; Marín et al., 2014; Muñoz et al., 2014; Vargas et al., 2017).

En definitiva, si evidenciamos que la formación inicial o continua de los docentes es una dificultad y puede terminar convirtiéndose en una barrera para una educación que atienda a la inclusión, es pertinente - al menos- que se 
analicen las barreras que se presentan en educación e impiden dar una respuesta real y precisa a los estudiantes con NEE (Necesidades Educativas Especiales), ya sea desde el aspecto metodológico como teórico.

Garantizar calidad en educación implica - por ende- otorgar apoyos necesarios para eliminar cualquier tipo de discriminación y el abordaje de la diversidad. Esto a su vez, requiere distinguir las barreras o accesos según su tipo y condición (Echeita, 2013).

La Ley de inclusión $\left(\mathrm{N}^{\circ} 20.845\right)$ entiende por barreras o apoyos a todos los soportes entregados a los estudiantes de parte de un educador que, por alguna razón, presenten una NEE, y que en algunos casos impiden alcanzar los objetivos de aprendizaje. Por lo tanto, la formación inicial es fundamental para mejorar las herramientas de los docentes y así enfrentar dichas barreras en el logro de una genuina inclusión.

Cisternas y Lobos (2019) identifican en su investigación las situaciones que obstaculizan la atención a la diversidad:

Todos los docentes noveles sostienen que se insertaron en espacios escolares donde las culturas, normativas y definiciones institucionales les imponen barreras para las prácticas que quisieran desarrollar. Destacan tres obstáculos: a) se promueve la competencia entre estudiantes y su clasificación y ordenamiento según rendimiento, b) existe presión por lograr cobertura curricular, aunque el costo sea la falta de profundización y c) la tendencia a estandarizar las estrategias de enseñanza y/o de evaluación. (p. 46)

Arnaiz (2005), Granada et al. (2013), Meckes y Hurtado (2014) y Ruffinelli (2013) sostienen que la formación para la atención de la diversidad es fundamental, ya que el $92 \%$ de estudiantes de Pedagogía manifiestan que los profesores de educación regular no tienen la formación necesaria para atender a los estudiantes con NEE.

$\mathrm{Al}$ analizar las mallas curriculares de algunas universidades o CFP de profesores de EGB en Chile, se observa que existe un mínimo de materias centradas en la atención a la diversidad, inclusión y/o NEE. Sotomayor et al. (2011) realizaron una investigación exploratoria sobre la formación inicial de docentes de EGB en Chile, aunque adscrita a la disciplina de lenguaje y comunicación, y entre sus hallazgos se advierte la importancia del conocimiento de contenidos en dificultades de aprendizaje o NEE.

Carter (2015) recomienda el "keep pace with the curriculum" (p. 24), pues señala que algunos factores de la formación de la educación inicial de alta calidad están dados por recibir o no formación en NEE y discapacidades.

Del mismo modo, es necesario revisar los programas de formación continua o permanente del profesorado. Conde y Martín (2016) señalan que el docente tiene dos momentos fundamentales en su vida laboral: la primera centrada en la enseñanza, esta se produce cuando el profesor es novel o principiante; y la segunda del profesor experto que concentra su tarea en el aprendizaje. En ambas, presentan la necesidad de formación.

En relación con otros indicadores de calidad en la formación inicial docente, Ruffinelli (2013) señala que el sistema de ingreso a la carrera profesional, PSU (Prueba de Selección Universitaria) ya sea a una universidad o CFP no genera diferencias significativas en sus resultados si el docente ha tenido o no formación continua o permanente. Sin embargo, se observa un mayor efecto del profesor en los resultados en función del nivel socioeconómico del estudiante, es decir, a mayor nivel de precariedad de los estudiantes mayor es el efecto profesor.

Entonces, al saber que uno de los factores determinantes para la buena calidad educativa es la formación inicial y permanente para los docentes, es necesario preguntarse ¿Qué se debe realizar para potenciarla? ¿Cómo hacer para que el profesor adquiera las herramientas adecuadas para que todos sus estudiantes logren alcanzar los niveles que requieren los planes y programas del Ministerio de Educación? 


\section{Método}

Esta investigación pretende analizar e identificar si la formación de los docentes de la carrera de EGB de instituciones públicas o privadas de tres regiones de Chile en (Valparaíso, Santiago y Concepción) recibida en los últimos diez años en Chile en aspectos teóricos y metodológicos permite dar respuesta a las disposiciones legales emanadas del Ministerio de Educación.

\subsection{Diseño}

Se utilizó un diseño descriptivo no experimental transversal, con una recogida de información a través de cuestionarios, con los que se busca identificar cuáles son las necesidades teóricas y metodológicas de los docentes en Chile para enfrentar las disposiciones legales del Ministerio de Educación en el aula en el contexto de la Ley de Inclusión. Este método exploratorio se utiliza para "familiarizarse con fenómenos relativamente desconocidos" (Sampieri et al., 2010, p. 79), para luego contrastarla con una situación real y así tratar de mejorar la misma.

\subsection{Participantes}

La población de estudio estuvo conformada por docentes en desarrollo de su profesión egresados en los últimos diez años (2008-2018), obteniéndose una muestra final de 118 profesores. La selección se realizó mediante un muestreo no probabilístico de tipo casual o incidental; pues se extrajeron directamente una muestra por accesibilidad o disponibilidad para participar en la muestra (Latorre et al., 2003).

De la muestra obtenida, el $77.2 \%$ fueron mujeres y el $22.8 \%$ resultaron hombres, el $41.6 \%$ residían en Santiago (región Metropolitana y capital del país), el $28.7 \%$ en Valparaíso y el 29.7\% en Concepción (región del Biobío). Un 56.8\% eran profesores menores de 34 años, entre $35 \mathrm{y}$ 50 años eran el $30.5 \%$ y el $12.7 \%$ resultaron profesores mayores de 50 años. El $69.5 \%$ poseía solo estudios universitarios y el $30.5 \%$ poseía estudios de posgrado. Finalmente, el $60.2 \%$ trabajaba con estudiantes que poseían únicamente NEE de tipo transitorias, un $5.1 \%$ trabajaba con estudiantes que poseían únicamente NEE de carácter permanente y un $34.7 \%$ trabajaba con estudiantes que poseían NEE transitorias y permanentes.

\subsection{Instrumento}

Para el estudio se utilizó como instrumento una escala tipo Likert de elaboración propia, con el fin de identificar las necesidades de los docentes de educación general básica en su formación inicial en lo que respecta a elementos teóricos y metodológicos en el contexto de la ley de inclusión. Las respuestas oscilan entre 1 y 4, siendo 1 que "no posee conocimientos" y 4 que "posee mayores conocimientos" en la dimensión teórica y en la dimensión metodológica, también oscilan entre 1 y 4, siendo 1 "poco conocimiento" y 4 "mucho conocimiento".

Para el diseño de los ítems se utilizaron los siguientes criterios: Pertinencia, pues cada ítem pretendía evaluar el nivel de conocimiento de aspectos teóricos y metodológicos de los docentes; Claridad, pues cada ítem se presentó con un lenguaje cercano para los encuestados; Precisión, ya que se analizó que cada ítem evaluará el constructo en cuestión.

El instrumento quedó compuesto por 33 ítems en dos dimensiones: La primera relacionada con los conocimientos teóricos y la segunda conocimientos metodológicos de los docentes en el contexto de la educación inclusiva. Una vez construida la escala, se sometió a validación de contenido por parte de siete expertos del área de formación universitaria de la carrera de pedagogía general básica de universidades públicas o privadas. Una vez realizada la validación teórica, el instrumento se desarrolló en dos variables, una de nueve ítems, correspondiente a la dimensión teórica y otra de 24 ítems correspondiente a la dimensión metodológica. El nivel de acuerdo interjueces, calculado a partir del coeficiente de 
V de Aiken, se situó en 0.84 para la dimensión teórica y de 0.90 para la dimensión metodológica, valores aceptables que superan el umbral 0.75 establecido (Charter, 2003; Penfield \& Giacobbi, 2004). Para la validación de la dimensionalidad de la escala se aplicó un AFE (Análisis Factorial Exploratorio). Los índices del test de esfericidad de Bartlett e índice KMO (Kaiser-Meyer-Olkin) alcanzaron niveles adecuados, indicando la pertinencia de la realización del AFE. Dados estos resultados se ejecutó una extracción de factores mediante componentes principales, aplicando el criterio de Kaiser. La estructura factorial de los resultados coincidió exactamente con la estructura teórica del instrumento (todos los ítems aportaron cargas factoriales superiores a $0.4 \mathrm{en} \mathrm{la}$ dimensión teórica correspondiente), alcanzando una varianza extraída del $55.9 \%$ en la primera dimensión y de $64.8 \%$ en la segunda dimensión. Debemos tener en cuenta que en las Ciencias Sociales valores de varianza extraída superiores al 50\% son considerados como buenos (Delgado, 2014), lo que nos permite concluir que existe un alto nivel de correlación entre ítems y dimensiones. Por ende, fue posible extraer dos dimensiones principales: Teórica y metodológica.

La versión final del cuestionario se desarrolló en una plataforma online, para facilitar su aplicación. Esta se hizo utilizando el formulario de Google Drive, al que se le incorporaron datos sociodemográficos. El consentimiento informado y las preguntas de las dos dimensiones señaladas, puede ser revisada en: https://bit.ly/3oPOkQr

\subsection{Variables}

Esta investigación consideró cinco variables de carácter sociodemográficos para el análisis del instrumento: Género, nivel educacional, residencia (región), edad y NEE con las que trabaja.

\subsection{Procedimiento}

Se procedió a aplicarlo, proceso que se extendió entre los meses de agosto y septiembre de 2018.
Para procesar los resultados obtenidos y hacer el análisis estadístico se utilizó el software SPSS versión 25 , llevándose a cabo un análisis descriptivo donde se analizó la distribución de frecuencias para las dos dimensiones del cuestionario. Igualmente, se analizó la distribución de frecuencias para cada una de las dimensiones, así como diferentes contrastes de hipótesis para las comparaciones por grupos sociodemográficos (dos o más grupos independientes). Dado cada caso, se aplicó el contraste paramétrico (Prueba de $t$ y ANOVA) o no paramétrico (U de MannWhitney y $\mathrm{H}$ de Kruskal-Wallis) en función del cumplimiento de los supuestos previos de normalidad y homocedasticidad.

\section{Resultados}

\subsection{Conocimientos de los docen- tes de educación general básica en aspectos teóricos y metodológicos}

Se observa en la tabla 1 que la mayor parte de los docentes del estudio, dan cuenta de poseer altos conocimientos de los aspectos teóricos referidos a las disposiciones legales en el contexto de la ley de inclusión chilena.

La media obtenida en la dimensión teórica fue de 2.9 puntos sobre un máximo de 4 , con una desviación estándar de 0.67 puntos, lo que permite afirmar que los docentes alcanzan altos conocimientos en la dimensión teórica, con una dispersión moderada y en lo que respecta la dimensión metodológica los datos muestran que existe menor conocimiento de los profesores de los que requieren para enfrentar las disposiciones legales. La media obtenida de los docentes es de 2.73 puntos y una desviación estándar de 0.74 puntos, lo que permite observar que el conocimiento de los aspectos metodológicos es sensiblemente menor que el de la dimensión teórica, con una mayor dispersión. 
Tabla 1. Estadísticos de la dimensión teórica y metodológica

\begin{tabular}{lllllllll}
\multicolumn{1}{c}{ Dimensión } & $\mathbf{N}$ & Media & $\mathbf{P}_{\mathbf{2 5}}$ & $\mathbf{M d n}$. & $\mathbf{P}_{\mathbf{7 5}}$ & $\mathbf{S x}$ & As. & Curt. \\
\hline Teórico & 118 & 2.94 & 2.44 & 3.00 & 3.47 & 0.68 & -0.343 & -0.525 \\
\hline Metodológico & 118 & 2,73 & 2.25 & 2.75 & 3.37 & 0.74 & -0.279 & -0.635 \\
\hline
\end{tabular}

\section{Elaboración propia.}

Se aprecia que gran parte de los docentes manifestó estar centrado en un alto conocimiento de la dimensión teórica en lo que respecta a educación inclusiva. No obstante, la mayor debilidad se aprecia en el primer ítem con 33.9\% de profesores que afirmaron no conocer algunos autores en la temática de inclusión.

Por otra parte, sus mayores conocimientos teóricos están dados en las preguntas 2,3 y 9 con $28.8 \%$, 36.4\% y $62.7 \%$, como se puede apreciar en la tabla 2. Al respecto, sorprende que los docentes en ejercicio en su gran mayoría declaren distinguir claramente la diferencia entre integración e inclusión, conceptos que han coexistido mucho tiempo en la educación chilena (Casassus, 2002; López et al., 2014; Soto, 2004).

En la dimensión metodológica se observa en la tabla 2 que las preguntas que presentan las principales dificultades son el ítem 15 con un $72.1 \%$ de la muestra que señala "poco conocimiento" o más cercano a "poco" y que se relaciona con aspectos referidos a espacios virtuales que favorezcan la educación inclusiva. También se destaca la pregunta 3 , en la que un $38.2 \%$ de la muestra declararon que poseen "poco conocimiento" o más cercano a él para trabajar con diferentes estilos de aprendizaje; el ítem 5, donde el 38.2\%, reconocieron identificar los niveles de complejidad de un contenido y adaptarlos para atender el potencial de aprendizaje en una educación inclusiva; el ítem 8 , donde el $45.8 \%$ da cuenta de estar más cerca de tener "poco conocimiento" para diseñar una clase que considere el auto-aprendizaje o el trabajo colaborativo para atender la educación inclusiva en su aula; y el ítem 14, donde el $51.7 \%$ de la muestra señaló que está más cercano a "poco conocimiento" de lo que es una adaptación curricular o realizar un plan educativo individual que le permita atender a los estudiantes con NEE.

En esta dimensión, se analiza por separado una sub-dimensión de aspectos metodológicos en el contexto de la ley de inclusión en Chile, asociada a aspectos evaluativos. En esta sub-dimensión aparecen tres preguntas con un porcentaje más asociado a tener "poco conocimiento" o cercanos a él en su formación universitaria en aspectos de evaluación asociada a la educación inclusiva.

En el ítem 21, el 53.4\% no tuvo una formación que le permita llevar un registro de logros de cada uno de sus estudiantes; en el ítem 22 un $39.9 \%$ de los docentes declararon no tener herramientas obtenidas en su formación para el manejo de diversas estrategias de evaluación para medir los aprendizajes esperados de sus estudiantes; y en el ítem 23, en la que el 39.4\% del profesorado señaló que no reconoce la metodología de retroalimentación como una forma de ajustar, proponer y acordar mejoras para el aprendizaje de sus estudiantes. 
Formación inclusiva del profesorado de primaria en tres regiones chilenas

Tabla 2. Análisis descriptivo por frecuencia de la dimensión teórica y metodológica

\begin{tabular}{|c|c|c|c|c|c|c|}
\hline Ítem & $1(\%)$ & $2(\%)$ & $3(\%)$ & $4(\%)$ & Media & Sx \\
\hline T1 & 33.9 & 27.1 & 27.1 & 11.9 & 2.16 & 1.03 \\
\hline T2 & 5.9 & 26.3 & 26.3 & 28.8 & 2.90 & 0.88 \\
\hline T3 & 5.9 & 24.6 & 33.1 & 36.4 & 3.00 & 0.92 \\
\hline T4 & 7.6 & 28.8 & 34.7 & 28.8 & 2.84 & 0.93 \\
\hline T5 & 10.2 & 18.6 & 37.3 & 33.9 & 2.94 & 0.96 \\
\hline T6 & 5.1 & 19.5 & 39.0 & 36.4 & 3.06 & 0.87 \\
\hline T7 & 11.9 & 16.1 & 39.0 & 33.1 & 2.93 & 0.98 \\
\hline T8 & 2.5 & 16.1 & 43.2 & 38.1 & 3.16 & 0.78 \\
\hline T9 & 2.5 & 11.0 & 23.7 & 62.7 & 3.46 & 0.79 \\
\hline M1 & 14.4 & 11.9 & 39.0 & 34.7 & 2.94 & 1.02 \\
\hline M2 & 4.2 & 25.4 & 37.3 & 33.1 & 2.99 & 0.87 \\
\hline M3 & 6.8 & 31.4 & 37.3 & 24.6 & 2.72 & 0.95 \\
\hline M4 & 9.3 & 24.6 & 38.1 & 28.0 & 2.84 & 0.93 \\
\hline M5 & 6.8 & 31.4 & 37.3 & 24.6 & 2.79 & 0.89 \\
\hline M6 & 5.1 & 20.3 & 40.7 & 33.9 & 3.03 & 0.86 \\
\hline M7 & 5.9 & 28.0 & 45.8 & 20.3 & 2.80 & 0.82 \\
\hline M8 & 11.9 & 33.9 & 31.4 & 22.9 & 2.65 & 0.96 \\
\hline M9 & 9.3 & 25.4 & 39.8 & 25.4 & 2.81 & 0.92 \\
\hline M10 & 15.3 & 34.7 & 30.5 & 19.5 & 2.54 & 0.97 \\
\hline M11 & 9.3 & 30.5 & 39.0 & 21.2 & 2.72 & 0.90 \\
\hline M12 & 11.0 & 26.3 & 41.5 & 21.2 & 2.72 & 0.92 \\
\hline M13 & 22.0 & 28.0 & 39.0 & 11.0 & 2.38 & 0.95 \\
\hline M14 & 17.8 & 33.9 & 29.7 & 18.6 & 2.49 & 0.99 \\
\hline M15 & 33.1 & 39.0 & 14.4 & 13.6 & 2.08 & 1.00 \\
\hline M16 & 9.3 & 28.0 & 43.2 & 19.5 & 2.72 & 0.88 \\
\hline M17 & 5.1 & 25.4 & 40.7 & 28.8 & 2.93 & 0.86 \\
\hline M18 & 8.5 & 22.0 & 41.5 & 28.0 & 2.88 & 0.91 \\
\hline M19 & 5.1 & 19.5 & 39.0 & 36.4 & 3.06 & 0.87 \\
\hline M20 & 12.7 & 22.9 & 28.8 & 35.6 & 2.87 & 1.04 \\
\hline ME21 & 11.9 & 41.5 & 33.1 & 13.6 & 2.48 & 0.87 \\
\hline ME22 & 9.3 & 31.4 & 39.8 & 19.5 & 2.69 & 0.89 \\
\hline ME23 & 8.5 & 31.4 & 33.1 & 27.1 & 2.78 & 0.94 \\
\hline ME24 & 11.9 & 25.4 & 40.7 & 22.0 & 2.72 & 0.93 \\
\hline
\end{tabular}

Elaboración propia. 


\subsection{Diferencias por grupos en función de variables sociodemográficas}

Analizando las diferencias de género en las dimensiones, mediante la prueba paramétrica $T$ Student para grupos independientes, se observó que, en la dimensión teórica, a pesar de la puntuación media de los hombres es ligeramente inferior a la de las mujeres, no existen diferencias significativas. No obstante, sí se observan diferencias significativas en función del género en la dimensión metodológica. En concreto, las mujeres alcanzan puntuaciones superiores a los hombres (tabla 3).

Tabla 3. T Student género en la dimensión teórica y metodológica

\begin{tabular}{|c|c|c|c|c|}
\hline \multirow{2}{*}{ Género } & \multicolumn{2}{|c|}{ Dimensión teórica } & \multicolumn{2}{|c|}{ Dimensión metodológica } \\
\hline & Media (Sx) & $t(p)$. & Media (Sx) & t (p.) \\
\hline Hombre & $2,44(0.65)$ & \multirow{2}{*}{$-1.15(.25)$} & $2,44(0.66)$ & \multirow{2}{*}{$-1.15(.015)$} \\
\hline Mujer & $2.59(0.62)$ & & $2.83(0.75)$ & \\
\hline
\end{tabular}

\section{Elaboración propia.}

Al comparar las puntuaciones en las dimensiones, en función del nivel educacional (universitario o magíster), aplicando la prueba paramétrica T Student para variables independientes, se observó que, aunque la diferencia de medias es ligeramente favorable a los profesores con grado de magíster, no existen diferencias significativas a nivel poblacional. En lo que respecta a la dimensión metodológica, se pudo apreciar que tampoco existen diferencias significativas, tal como se observa en la tabla 4.

Tabla 4. T Student nivel educacional en la dimensión teórica y metodológica

\begin{tabular}{|c|c|c|c|c|}
\hline \multirow{2}{*}{ Nivel educacional } & \multicolumn{2}{|c|}{ Dimensión teórica } & \multicolumn{2}{|c|}{ Dimensión metodológica } \\
\hline & Media (Sx) & $t$ (p.) & Media (Sx) & t (p.) \\
\hline Universitario & $2.48(0.64)$ & \multirow{2}{*}{$-1.89(.62)$} & $2.80(0.78)$ & \multirow{2}{*}{$1.48(.14)$} \\
\hline Magíster & $2.71(0.57)$ & & $2.58(0.65)$ & \\
\hline
\end{tabular}

\section{Elaboración propia.}

En cuanto a las diferencias en las dimensiones en función de la región, se aplica la prueba ANOVA de un factor para contrastarlas, se aprecia que no existen diferencias significativas en el conocimiento de la muestra en lo que respecta al lugar de residencia (Valparaíso, Santiago o Concepción) de los docentes de EGB para ambas dimensiones (Ver tabla 5).

Tabla 5. ANOVA Residencia de la dimensión teórica

\begin{tabular}{|c|c|c|c|c|}
\hline \multirow{2}{*}{ Ciudad } & \multicolumn{2}{|c|}{ Dimensión teórica } & \multicolumn{2}{|c|}{ Dimensión metodológica } \\
\hline & Media (Sx) & $F(p)$. & Media (Sx) & $F(p)$. \\
\hline Valparaíso & $2.70(0.57)$ & \multirow{3}{*}{$3.05(.51)$} & $2.85(0.71)$ & \multirow{3}{*}{$1.84(.16)$} \\
\hline Santiago & $2.38(0.63)$ & & $2.81(0.69)$ & \\
\hline Concepción & $2.63(0.64)$ & & $2.56(0.81)$ & \\
\hline
\end{tabular}

Elaboración propia. 
En relación con la edad, al aplicar la prueba ANOVA de un factor se pudo observar que existen diferencias significativas en el conocimiento de los participantes en la dimensión metodológica y no así en la dimensión teórica. En concreto al aplicar la prueba post-hoc (procedimiento de Scheffé) se aprecia que los dos primeros tramos, es decir los docentes entre 0-34 y entre 35-49 años poseen diferencias significativas en los conocimientos metodológicos en el contexto de la ley de inclusión en Chile, favorables a los profesores de 0-34 años. Al aplicar la misma ANOVA para una muestra de un factor, se pudo observar que no hay diferencia en los docentes, en lo que respecta al tipo de NEE con las que trabajan, tanto para la dimensión teórica como metodológica (ver tabla 6).

Tabla 6. ANOVA edad y NEE de los participantes en la dimensión teórica como metodológica

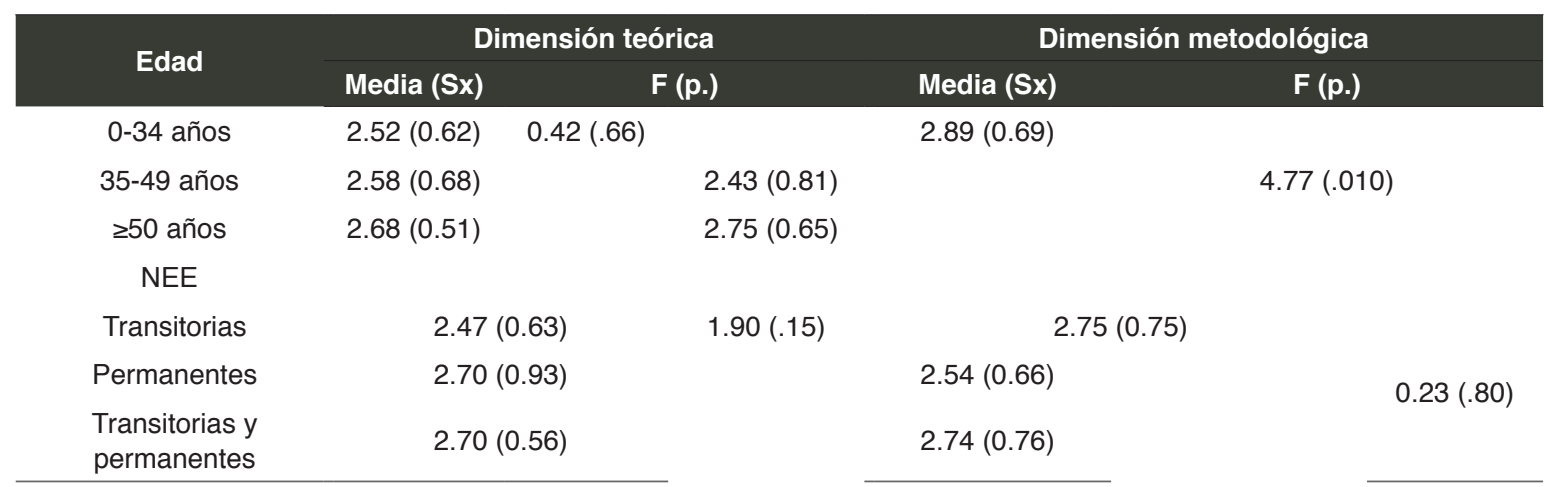

Elaboración propia.

\section{Discusión}

Es importante debatir sobre la diferencia alcanzada en la dimensión metodológica en función a la variable edad, donde se observan puntuaciones superiores en el grupo de docentes de 0-34 años, con respecto al profesorado de 35-49 años, se podría suponer que los docentes de menor edad tienen una actitud más positiva hacia la inclusión. A pesar de que los resultados entre el profesorado mayor de 50 años no son concluyentes, cabe destacar que el tamaño de muestra de este tramo era reducido, únicamente de 15 personas. Otras investigaciones (Forlin \& Chambers, 2011; González-Gil et al., 2016) han demostrado que los docentes con menos experiencia, principiantes tienen una actitud más positiva hacia los estudiantes con algún tipo de NEE.

En la dimensión metodológica, es posible observar que existen mayores debilidades en la formación inicial para trabajar con diversos diseños estratégicos de una clase que promuevan el auto-aprendizaje o trabajo colaborativo, tema que ha sido fundamental para la educación inclusiva (García-Valcárcel et al., 2014; Jiménez, 2014; Marín et al., 2014; Muñoz et al., 2014; Ortiz \& Gastelú, 2016; Vargas et al., 2017; Puighellivol et al., 2019).

Los docentes declaran no haber obtenido en su formación inicial y/o continua preparación en la promoción de redes de colaboración para trabajar hacia una educación inclusiva, aspecto estudiado y demostrado que tiene un alto impacto en la educación inclusiva (Puighellivol et al., 2019; Ainscow et al., 2004; García-Valcárcel et al., 2014; Madrazo et al., 2018; Nel et al., 2014; Vargas et al., 2017).

La falta de formación inicial o continua ha dificultado la capacidad para implementar adaptaciones curriculares requeridas por el Decreto 83 o generar planes educativos individuales, que permita centrar el aprendizaje en la 
persona como medida (habitual o extrema) para atender a estudiantes con NEE. González-Gil et al. (2019) coinciden que la principal barrera es la falta de formación, pues la que reciben es de carácter teórico y no se condice con la práctica de la enseñanza.

Es clave al discutir la importancia de la escuela inclusiva, lo importante de conocer espacios virtuales que la promuevan. Sotomayor et al. (2011) y principalmente (Puigdellivol et al. (2019) señalan que la digitalización en la educación viene a ser una oportunidad para la educación y en especial para los estudiantes con NEE, ya que "las herramientas digitales pueden ayudar al entorno educativo en distintos ámbitos, y específicamente a responder con garantías a la diversidad" (p. 667).

En fin, los docentes consideran que en su formación no aprendieron la importancia de los recursos humanos (psicopedagoga, psicólogo, educadora diferencial u otros), como agentes facilitadores en el trabajo con estudiantes con NEE. En este sentido, Torres-Santomé (2019) señalaba la importancia de trabajar siempre con apoyos de otros — profesores y especialistaspara una mejor intervención de cada realidad escolar. A lo que Puigdellivol et al. (2019) rescatan los beneficios de la mirada de un especialista, puesto que esta permite un diagnóstico más integral y las eventuales necesidades que podría presentar el estudiante en su posterior aprendizaje.

\section{Conclusiones}

Los datos del estudio ponen de manifiesto que los futuros docentes adquieren, a lo largo de la formación inicial una formación completa y actualizada que favorece incluir y desarrollar los cambios y propuestas a nivel legislativo; al menos en los aspectos teóricos. Sin embargo, desde el punto de vista metodológico hay que resaltar dos diferencias significativas que se aprecian en el análisis de los resultados; una de ellas es de género, que se producen en los conocimientos de los profesores de EGB, donde las mujeres poseen un dominio mayor de conocimientos metodológicos que los varones. $\mathrm{Al}$ respecto, otros estudios e investigaciones previas (Alonso et al., 2012; Chiner, 2011; Rebolledo et al., 2011) han señalado que las mujeres tienen una actitud más positiva hacia la inclusión, lo que implica que implementan mayores estrategias para que los estudiantes logren sus objetivos de aprendizajes.

En contraste a estos resultados, el trabajo de González-Gil et al. (2016) indica que no existen diferencias de género en las prácticas educativas, observando únicamente diferencias en las políticas inclusivas, que parecen integrar mejor los varones, pero los resultados permiten proponer una revisión de las mallas en la formación inicial para una adecuación a los requerimientos/demandas/necesidades de los docentes para responder a las necesidades del contexto escolar.

Otro punto conclusivo es la falta de articulación entre las instituciones formadoras y las exigencias de la práctica pedagógica, al menos desde el punto de vista metodológico; dado que las instituciones formadoras deben estar en constante mejora de su calidad para asegurar la formación profesional de sus estudiantes. En este sentido, los resultados obtenidos en este trabajo coinciden con los señalados por Carter (2015), que refieren a la necesidad de atender la individualidad de los estudiantes con NEE, tal como se señaló en la introducción, y que da cuenta del denominado "keep pace with the curriculum" (p. 24).

En definitiva, entre los aportes de este trabajo, es posible considerar la importancia de la formación inicial y continua de los estudios de los profesores, responsabilidad que deben asumir los organismos formadores y el Estado, como también las comunidades educativas al momento de generar sus programas de formación (Cisternas \& Lobos, 2019; Contreras \& Villalobos, 2010; Lozano, 2016).

\section{Limitaciones y prospectiva}

Este artículo presenta como una limitación la generalización, pues si bien el estudio está basa- 
do en las tres regiones más pobladas de Chile, es posible que existan experiencias de formación en regiones menos pobladas del país y que no fueron consideradas en la investigación. Tampoco es posible generalizar los resultados obtenidos en esta investigación a otros países latinoamericanos, dada la diversidad de formación docente en la región.

Por último, a nivel prospectivo este estudio permite abrir nuevas líneas de investigación asociadas a la práctica docente, la función de los profesores tutores y la importancia de la capacitación de los futuros maestros, como también prepararlos. Pudiéndose complementar con un estudio cualitativo que permita el contraste con la opinión de los docentes formadores, más allá de la percepción de aquellos que están en ejercicio y de la revisión de las mallas curriculares con el fin de mejorar la educación y alcanzar una educación inclusiva para todos.

\section{Referencias bibliográficas}

Ainscow, M. (1991). Effective schools for all: An alternative approach to special needs in education. Cambridge Journal of Education, 21(3), 293-308. https://doi.org/10.1080/0305764910210304

Ainscow, M., Booth, T., \& Dyson, A. (2004). Understanding and developing inclusive practices in schools: A collaborative action research network. International Journal of inclusive education, 8(2), 125-139. https://doi.org/10.1080/1360311032000158015

Alonso, R., Hernández, A., \& Hanamboure, R. (2012). Logros y desafíos para un currículo inclusivo. Pedagogía Universitaria, 17(3), 61-75.

Arnáiz, P. (2005). Atención a la diversidad. Programa curricular. Editorial Universidad Estatal a Distancia.

Bahamón-Muñetón, M.J., Vianchá-Pinzón, M.A., Alarcón-Alarcón, L.L., \& Bohórquez- Olaya, C.I. (2012). Estilos y estrategias de aprendizaje: Una revisión empírica y conceptual de los últimos diez años. Pensamiento psicológico, 10(1), 129-144. https://bit.ly/2RcCv85
Calvo, M.I., Verdugo, M.Á., \& Amor, A.M. (2016). La participación familiar es un requisito imprescindible para una escuela inclusiva. Revista Latinoamericana de Educación Inclusiva, 10(1), 99-113. https://bit.ly/35qBW2H

Carbonero, M.Á., Martín-Antón, L.J., Román, J.M., \& Reoyo, N. (2010). Efecto de un programa de entrenamiento al profesorado en la motivación, clima de aula y estrategias de aprendizaje de su alumnado. Revista Iberoamericana de Psicología y Salud, 1(2), 117-138. https://bit.ly/33jQJJW

Carter, A. (2015). Carter review of Initial Teacher Training (ITT) Inglaterra. https://bit.ly/2ZrUZWA

Casassus, J. (2002). Cambios paradigmáticos en educación. Revista Brasileira de Educação, 20, 48-59. https://bit.ly/3kcYGHL

Charter, R.A. (2003). A breakdown of reliability coefficients by test type and reliability method, and the clinical implications of low reliability. The Journal of General Psychology, 130(3), 290-304. https://doi.org/10.1080/00221300309601160 Chiner, E. (2011). Las percepciones y actitudes del profesorado hacia la inclusión del alumnado con necesidades educativas especiales como indicadores del uso de prácticas educativas inclusivas en el aula (Tesis Doctoral). Universidad de Alicante. https://bit.ly/3lZsJ61

Cisternas, L., \& Lobos, A. (2019). Profesores nóveles de enseñanza básica: Dilemas, estrategias y obstáculos para abordar los desafíos de una educación inclusiva. Revista Latinoamericana de Educación Inclusiva, 13(1), 37-53. http://dx.doi. org/10.4067/S0718-73782019000100037 Conde-Jiménez, J., \& Martín-Gutiérrez, Á. (2016). Potencialidades y necesidades de mejora en la formación de profesores noveles universitarios. Revista Electrónica de Investigación Educativa, 18(1), 140-152. https://bit.ly/3ifq2fD

Contreras, G., \& Villalobos, A. (2010). La formación de profesores en Chile: Una mirada a la profesionalización docente. Educación y Educadores, 13(3), 397-417. https://bit.ly/3ipAhOw 
Delgado, C. (2014). Viajando a Ítaca por mares cuantitativos. Amarú.

Durán, D., \& Climent, G. (2017). La formación del profesorado para la educación inclusiva: Un proceso de desarrollo profesional y de mejora de los centros para atender la diversidad. Revista Latinoamericana de Educación Inclusiva, 5(2), 153-170. https://bit.ly/33p4kQi

Echeita, G. (2013). Inclusión y exclusión educativa: De nuevo 'Voz y Quebranto'. REICE. Revista Electrónica Iberoamericana sobre Calidad, Eficacia y Cambio en Educación, 11(2), 99-122. https://bit.ly/2ZpHXbW

Florian, L. (2010). Special education in the era of inclusion: The end of special education or a new beginning? The Psychology of Education Review, 34(2), 22-29. https://bit.ly/2DUK0xq

Forlin, C., \& Chambers, D. (2011). Teacher preparation for inclusive education: Increasing knowledge but raising concerns. Asia-Pacific Journal of Teacher Education, 39(1), 17-32 https://doi.org/10.1080/1359866X.2010.540850

García-Valcárcel, A., Basilotta, V., \& López, C. (2014). Las TIC en el aprendizaje colaborativo en el aula de Primaria y Secundaria. Comunicar, 21(42), 65-74. https://bit.ly/32hXaxB

González-Gil, F., Martín-Pastor, E., Poy, R., \& Jenaro, C. (2016). Percepciones del profesorado sobre la inclusión: Estudio preliminar. Revista Electrónica Interuniversitaria de Formación del Profesorado, 19(3), 11-24. https://doi.org/10618/reifop.19.3.219321

González-Gil, F., Martín-Pastor, E., \& Poy, R. (2019). Educación inclusiva: Barreras y facilitadores para su desarrollo. Análisis de la percepción del profesorado. Revista Currículum y formación del profesorado, 23(1), 243-263. https://doi.org/10.30827/profesorado.v23i1.9153

Granada Azcárraga, M., Pomés Correa, M.P., \& Sanhueza Henríquez, S. (2013). Actitud de los profesores hacia la inclusión educativa. Papeles de Trabajo, 25, 51-59. https://bit.ly/3bOOIJw

Infante, M. (2010). Desafíos a la formación docente: Inclusión educativa. Estudios Pedagógicos (Valdivia), 36(1), 287-297. https://bit.ly/3ijmzN2
Jiménez, A. (2014). La didáctica multigrado y las aulas rurales: Perspectivas y datos para su análisis. Innovación educativa, 24, 119-131. https://doi.org/10.15304/ie.24.1994

Latorre, A., Rincón, D., \& Arnal, J. (2003). Bases metodológicas de la investigación educativa. Hurtado.

Lee, J., \& Shute, V. (2010). Personal and SocialContextual Factors in K-12 Academic Performance: An Integrative Perspective on Student Learning. Educational Psychologist, 45(3), 185-202.

https://doi.org/10.1080/00461520.2010.493471

López, V., Julio, C., Pérez, M., Morales, M., \& Rojas, C. (2014). Barreras culturales para la inclusión: Políticas y prácticas de integración en Chile. Revista de Educación, 363, 256-281. https://doi.org/10-4438/1988-592X-RE-2012-363-180

Lozano, A. (2016). Las trayectorias formativas de los formadores de docentes en México. Actualidades Investigativas en Educación, 16(1), 136-161. https://doi.org/10.15517/aie.v16i1.22671

Madrazo, A., Juarros, I., \& Loroño, M. (2018). Funcionamiento democrático y ABP: Factores determinantes para la inclusión y el rendimiento del alumnado. Revista Electrónica de Investigación Educativa, 20(2), 103-112.

Marín V., Negre, F., \& Pérez, A. (2014). Construction of the foundations of the PLE and PLN for collaborative learning. Comunicar: Revista Científica de Comunicación y Educación, 21(42), 35-43. https://doi.org/10.3916/C42-2014-03

Martínez, F. (2016). La evaluación de docentes de educación básica. INEE. https://bit.ly/2RfsuXF

Martinic, S., Moreno, R., Müller, M., Pimentel, F., \& Rittershaussen, S. (2014). Análisis comparativo del componente de práctica en el currículo de formación profesional de médicos y profesores en la Pontificia Universidad Católica de Chile. Estudios pedagógicos, 40(1), 179196. https://bit.ly/32hrJni

Meckes, L., \& Hurtado, C. (2014). Los nuevos profesores en Chile: ¿Quién los contrata, qué aprenden y cuán efectivos son? Notas de Educación, 16. https://bit.ly/3k5hXuv

Moreno, A., \& López de Maturana, L. (2015). Ambientes educativos escolares: Una inves- 
tigación sobre la propensión a aprender en jardines infantiles chilenos. Estudios pedagógicos (Valdivia), 41(Especial), 169-180. http://dx.doi.org/10.4067/S0718-07052015000300011.

Muñoz, J., Serrano, R., \& Marín, V. (2014). El aprendizaje colaborativo y su desarrollo a través de mapas mentales. Una innovación educativa en la formación inicial docente. Educatio Siglo XXI, 32(2), 193-212. https://bit.ly/3mempJ6

Nel, M., Engelbrecht, P., Nel, D., \& Tlale, D. (2014). South African teachers' views of collaboration within an inclusive education system. International Journal of Inclusive Education, 18(9), 903-917. https://doi.org/10.1080/13603116.2013.858779

OCDE (2013). The role of financial education in financial inclusion. OCDE. https://bit. ly/3hoFjcK

Pastor, C. G. (2003). Segregación, integración e inclusión. Bordón. Revista de pedagogía, 55(1), 9-26. https://bit.ly/35v7Wmf

Pegalajar, M. \& Colmenero, M. (2017). Actitudes y formación docente hacia la inclusión en educación secundaria obligatoria. Revista Electrónica de Investigación Educativa, 19(1), 84-97.

https://doi.org/10.24320/redie.2017.19.1.765

Penfield, R., \& Giacobbi, P. (2004). Applying a score conidence interval to Aiken's item contentrelevance index. Measurement in physical education and exercise science, 8(4), 213-225. https://doi.org/10.1207/s15327841mpee0804_3

Puigdellivol, I., Petreñas, B., \& Jordi, A. (2019. Estrategias de apoyo en la escuela inclusiva: Una visión interactiva y comunitaria. Graó.

Rebolledo, M., García, R., Piedra, J., \& Vega, L. (2011). Diagnóstico de la cultura de género en educación: Actitudes del profesorado hacia la igualdad. Revista de Educación, 355, 521-526. https://doi.org/10-4438/1988-592X-RE-2010-355-035
Ruffinelli, A. (2013). La calidad de la formación inicial docente en Chile: La perspectiva de los profesores principiantes. Calidad en la educación, (39), 117-154. https://doi.org/10.31619/caledu.n39.80

Sampieri, H., Collado, F., \& Lucio, B. (2010). Metodología de la investigación. (5. ed.). Mc Graw Hill.

San Martín, E. (2014). ¿Es la prueba INICIA una medida predictiva de efectividad docente? FONIDE. https://bit.ly/33cj4BC

Sotomayor, C., Parodi, G., Coloma, C., Ibáñez, R., \& Cavada, P. (2011). La formación inicial de docentes de Educación General Básica en Chile. ¿Qué se espera que aprendan los futuros profesores en el área de Lenguaje y Comunicación? Pensamiento Educativo, 48(1), 28-41.

http://dx.doi.org/10.7764/PEL.48.1.2011.3

Tébar, L. (2010). La evaluación de aprendizaje y competencias en el aula. Fides et Ratio-Revista de Difusión cultural y científica de la Universidad La Salle en Bolivia, 4(4), 86-98. https://bit.ly/35y3Fyi

Torres-Santomé, J. (2019). Formación del profesorado y educación como proyecto político e inclusivo. Educação \& Realidade, Porto Alegre, 44(3), e84911. http://dx.doi.org/10.1590/2175-623684911

Vadillo, R. (2014). Integración e inclusión educativa vs integración e inclusión excluyente. Revista Mexicana de Investigación Educativa, 19(63), 1285-1290. https://bit.ly/2FmDDTQ

Vargas, F., Sazatornil, J., \& Cisternas, C. (2017). Aprendizajes, inclusión y justicia social en entornos educativos multiculturales. Revista Electrónica de Investigación Educativa, 19(3), 10-23.

https://doi.org/10.24320/redie.2017.19.3.830 


\section{=ALTERIDAD Perspectiva de género en Educación Básica Superior y Bachillerato}

\section{Gender perspective in Superior Basic Education and High School}

D Ximena Patricia Vizuete-Salazar es docente e investigadora de la Pontificia Universidad Católica del Ecuador y de la Unidad Educativa Amelia Gallegos Díaz (Ecuador) (ximena.p.vizuete.s@pucesa.edu.ec) (https://orcid.org/0000-0003-2591-4215)

(D) Dr. Alexander Ramón Lárez-Lárez es docente e investigador de la Pontificia Universidad Católica del Ecuador, Universidad de Otavalo (Ecuador) (alarez@pucesa.edu.ec) (https://orcid.org/0000-0003-2763-5113)

Recibido: : 2020-08-21 / Revisado: 2020-11-20 / Aceptado: 2020-12-08 / Publicado: 2021-01-01

\section{Resumen}

Investigaciones sobre género han demostrado que el ambiente escolar es el espacio idóneo para eliminar estereotipos sobre desigualdad, discriminación y violencia. Esto se debe a que, es en este periodo, donde los adolescentes aprenden a relacionarse según sus concepciones culturales o siguiendo estereotipos aprendidos desde su hogar o en el entorno. Consecuentemente, el estudio tuvo como objetivo evaluar la influencia de la perspectiva de género en la interacción social del adolescente en ambientes escolares en los niveles de Educación General Básica Superior y Bachillerato en la Unidad Educativa Amelia Gallego Díaz. La investigación se fundamentó en un enfoque cuantitativo, diseño no experimental, corte transversal y alcance descriptivo. El instrumento utilizado para la recogida de datos ha sido una adaptación de la escala de actitudes hacia la igualdad de género dirigido al alumnado de García-Pérez et al. (20 I0), aplicado a una muestra de 263 estudiantes de la institución en estudio. Al hacer el análisis, los resultados en los indicadores de la perspectiva de género muestran una actitud adaptativa que incide directamente en un trato de igualdad y equidad en la interacción social de los estudiantes; es decir, en esta institución educativa los estudiantes se han ido adaptando a las situaciones que la actualidad les depara, sin embargo, aún queda un importante porcentaje que se mantiene firme a las enseñanzas que les han inculcado en su núcleo familiar.

Descriptores: Ambiente educacional, interacción social, perspectiva de género, educación, estereotipos de género, adaptación del estudiante.

\section{Abstract}

Research on gender has shown that the school environment is the ideal space to eliminate stereotypes about inequality, discrimination, and violence. This is because, during this period, adolescent learn to form relations with others based on their cultural conceptions or following stereotypes learned from home or environment. Consequently, the objective of this study was to evaluate the influence gender perspective on the social interaction of adolescents in school environments, in secondary and high school education at Amelia Gallego Díaz high school. This research was carried out with a quantitative approach, non-experimental design, cross-sectional, and descriptive scope. The method employed for data collection was scale adaptation of attitudes towards gender equality aimed at students from García-Pérez et al. (20 I0) was implemented. This was applied to a sample of 263 students from the institution under study. When analysing the data, the results on the indicators, from gender perspective portrayed an adaptive attitude that directly affects equality and impartial treatment in the social interaction of students; this means in this high school, students have been adapting to the situations that nowadays arise. However, there is still a significant percentage of students that remain firm to the disciplines they have instilled from their family nucleus.

Keywords: Educational environment, social interaction, gender perspective, education, gender stereotypes, student adjustment.

Forma sugerida de citar: Vizuete-Salazar, X., \& Lárez-Lárez, A. (2021). Perspectiva de género en Educación Básica Superior y Bachillerato. Alteridad, 16(1), 130-141. https://doi.org/10.17163/alt.v16n1.2021.10 


\section{Introducción}

En la reciente década se han abordado diferentes investigaciones sobre la perspectiva de género, desde diferentes ámbitos (Benavente \& Valdés, 2014, Trejo-Sirvent et al., 2015; Camarera \& Saavedra, 2018). En los mismos se destaca, la atención para mejorar la igualdad y la equidad; disminuir la desigualdad, discriminación y violencia entre hombres y mujeres. Así mismo, países de todo el mundo han incorporado en sus constituciones nacionales, regulaciones sobre la igualdad de género y destinado, parte de sus recursos, a la implementación de políticas que luchan con la desigualdad, la exclusión y discriminación que impulsan la participación femenina en diversos contextos de la sociedad (Organización de las Naciones Unidas, 2014). Aun cuando, se han conseguido grandes avances, continúan apareciendo desigualdades en las sociedades respecto a conductas sexistas, roles de género y reproducción de estereotipos. Al respecto, Duarte y García (2016) refieren que la diferencia entre sexos y la opresión de género se debe a que existen discrepancias biológicas e históricas que no se pueden cambiar, y que se afirman en ideologías o mitos.

Este planteamiento, tal como corrobora Chávez-Carapia (2017), aún no se ha logrado. Múltiples esfuerzos se han desarrollado a nivel internacional, a lo largo de los años. Destaca la IV Conferencia de Beijín (1995) como obligación y deber gubernamental de los suscribientes, establecer una plataforma para encaminar sus políticas en la que se respeten la igualdad de hombres y mujeres. Sin embargo, estudios realizados por organizaciones a favor de los derechos en el mundo, han alertado sobre estudiantes gays, bisexuales, transgéneros y lesbianas que han sido víctimas de agresiones en el entorno de su escuela, mayoritariamente por otros alumnos, directivos y docentes violentos (Organización de las Naciones Unidas para la Educación, la Ciencia y la Cultura, 2015). Lo que evidencia, un largo camino por recorrer.
La problemática persiste a nivel mundial, en Ecuador no es diferente. El género en la sociedad ecuatoriana ha tomado relevancia como una forma para lograr derechos de igualdad en sectores discriminados. La discriminación estigmatiza al ser humano pues lo diferencia, tanto en lo físico como en lo cultural, evidenciando la desigualdad y fijación de estereotipos. La Constitución de la República (2008) incorporó principios y derechos para enfrentar la inequidad, violencia de género y la discriminación. Elementos que también han sido mencionados en el Plan Nacional Toda una Vida (2017-2021) y en el documento emitido por la Defensoría del Pueblo, denominado "Política Institucional de Igualdad de Género 2016-2019”. Al respecto este último organismo menciona que, aun cuando se han dado avances en la materia, el Ecuador tiene una "cultura arraigadamente patriarcal y androcéntrica, reflejada en prácticas sociales e institucionales, que evidencian la ausencia de estrategias y acciones que promuevan la igualdad de género y la no discriminación" (p. 6).

En materia educativa, también es imperioso tratar de erradicar la discriminación a través de la tolerancia y la educación (Medina et al., 2015). Incorporar en la formación el enfoque hacia la perspectiva de género, según Solís (2016), permite transformar esquemas valorativos en los que se desarrollen destrezas y habilidades desde las diferencias sexuales y de género, como parte del proceso de aprendizaje. Para Castillo y Gamboa (2013), "la igualdad de género requiere de un proceso de aculturación en el cambio de las concepciones y prácticas que han sido socialmente aprendidas" (citado en Azorín, 2017, p. 46). Refieren que, el adolescente es un grupo clave de la sociedad, que debe ir formándose, con una perspectiva de género que ejerza una igualdad entre sexos desde los diversos contextos sociales.

Según el Fondo de las Naciones Unidas para la Infancia (UNICEF), la adolescencia es el espacio donde el joven aprende a relacionarse con sus pares, entre hombres y mujeres, según 
sus concepciones culturales o siguiendo estereotipos aprendidos desde su hogar o el entorno (UNICEF, 2015). Es una etapa para iniciar relaciones con otros y definir su identidad: experiencia y conocimiento. Lozano (2014), afirma que el adolescente en el proceso de precisar su personalidad, expandir sus relaciones entre iguales o constituirse parte de un grupo, sigue estereotipos de género de acuerdo con concepciones culturales sobre la que se constituye su formación, partiendo de elementos de su identidad asignados por la cultura. El adolescente aparte de luchar con sus aspectos físicos y emocionales de la edad, también tiene que enfrentarse a situaciones externas como la imposición de la cultura en cuanto al género, que se refleja en la forma de vestir, de expresarse y de relacionarse con sus pares; y seguir patrones de conducta impuestos por la sociedad.

Sustentado en estos planteamientos, la investigación reviste gran importancia en el campo social y especialmente educativo, porque permitió comprender y visibilizar las concepciones de género y estereotipos que están actuando en el lenguaje, comportamiento y otras manifestaciones. Por ello, se planteó como propósito, evaluar cómo la perspectiva de género influye en la interacción social del adolescente en ambientes escolarizados, en los niveles de Educación General Básica Superior y Bachillerato de la Unidad Educativa Amelia Gallegos Díaz, ubicada en Riobamba-Ecuador. A partir de la identificación de los comportamientos basados en estereotipos de género del adolescente, se procedió a determinar y analizar los factores que inciden, en esta perspectiva, para el desarrollo social dentro de espacios escolares y establecer los niveles de incidencia entre las dos dimensiones (perspectiva de género e interacción social).

\subsection{Concepciones de género}

El enfoque de género en la adolescencia, como temática de investigación, ha tomado relevancia. Rodríguez et al. (2017) afirman que el género representa un elemento propio e intrínseco de la personalidad, donde se conjugan creencias, estilo de vida, oportunidades y el comportamiento en la sociedad. Guzmán (2015) señala que existe un papel de supremacía y poder de los hombres sobre las mujeres que se basa en la forma dicotómica y estructural en que las personas construyen el mundo. Los términos sexo y género son diferentes. Según Liscano (2016) el sexo es la visión biológica que diferencia a hombres y mujeres, mientras que el género es la dimensión sociocultural de las conductas, maneras y expresiones de las personas. Guerra López (2016) menciona que el género va creando un perfil social de los individuos de acuerdo con su naturaleza o el sexo al que pertenecen. Estos planteamientos permiten afirmar que el sexo y el género están relacionados, pero cada uno cumple una función específica; mientras que el primero está determinado por una condición desde que el sujeto nace, el segundo se caracteriza por la influencia de la sociedad. Así, de manera universal, se encuentran concepciones de las actuaciones y papeles que hombres y mujeres tienen dentro de la sociedad. De acuerdo con Torres (2018), estas manifestaciones están condicionadas e identificadas por su naturaleza de ser y hacer en la esfera social; desde el nacimiento, la representación social y sexual masculina y femenina estará predeterminado, independientemente del hecho de que, como persona madura, no quiera cumplir con la tarea que se le ha encomendado.

De igual forma, Serret (2016) expresa que hombres y mujeres no son iguales, pues biológicamente, es así, sino también porque son definidos cada uno, como consecuencia de lo que aprenden en su entorno ideológico, familiar, económico y social. Entonces, los roles de género se basan en el sexo y son las normas sociales y de comportamiento, percibidas socialmente como apropiadas y generalizadas históricamente. Esta representación social de hombres y mujeres para Bruel et al. (2013), se fundamenta en el comportamiento propio de cada uno y la interacción entre individuos. Para Aguilar et al. (2013), la 
diferencia radica en la formación de ambos para ejercer su función en la sociedad: el hombre se considera independiente, autónomo y con poder, mientras que la mujer es educada para atender y cuidar a las personas; guardiana del hogar.

El comportamiento de los jóvenes en la adolescencia tiene particularidades al asumir un rol en la sociedad. Beltrán (2012) afirma que los hombres adolescentes, en muchos casos como una forma de demostrar su masculinidad, adquieren prácticas culturales tales como que el hombre tiene que defenderse, hacer deporte, usar determinado estilo de peinado, vestimenta, uso de lenguaje grotesco e insultante, etc. En esta etapa de desarrollo social del adolescente se adquieren actitudes y valores que ayudan a la formación de su identidad para el manejo de conflictos y la regulación de la agresión. Según Javaloy et al. (2016), es una forma de mantener la sociedad a través del intercambio de expresiones, palabras, gestos en los que las personas participan con un objetivo común. Para Uranga et al. (2016), se considera la relación con otros individuos, que es parte de la vida de los seres, en la cual surgen las creencias humanas y, a través de este vínculo, se moldean las actitudes y se crean valores. Desde una perspectiva similar, Suárez y Vélez (2016) exponen que es una forma de dar orden a los comportamientos para relacionarse con otras personas e influir en aquellos con quienes se interactúa desde una determinada perspectiva. Siguiendo a Meza y Páez (2016) es una influencia recíproca en la que tanto el individuo como las demás personas, interactúan, cambian o modifican el comportamiento.

Por lo tanto, el contexto educativo le dará la oportunidad de discernir, si la educación que ha recibido le ayudará a adaptarse al entorno social, o si, por el contrario, tendrá que hacer algunos cambios en el comportamiento y la conducta. Durante este período, que va desde la niñez hasta la adolescencia, las personas experimentan diferentes tendencias de relaciones que conducen a estilos como el agresivo, asertivo y el pasivo. Estas variaciones dependen del núcleo familiar y su composición. Para Ortiz et al. (2018) la convivencia permite el desarrollo de la empatía en la que intervienen el apego, la reciprocidad afectiva y la construcción de criterios morales sólidos.

Teniendo en cuenta que, la perspectiva de género se vuelca hacia las personas que muestran diversas circunstancias, se puede llegar a comprender que existe una biodiversidad social, donde existe una diferencia sexual y representaciones sociales construidas alrededor de ella. En este sentido, Solís (2016) expone que la:

Perspectiva de género es una visión crítica, explicativa y alternativa de lo que acontece en el orden de género, permitiendo analizar las profundas y complejas causas de dicha opresión y de los procesos históricos que la originan y la reproducen. (pp.101-102)

\section{Metodología}

\subsection{Diseño}

El enfoque de esta investigación se fundamenta en un paradigma cuantitativo; diseño descriptivo, de corte transversal. El método cuantitativo sirvió para recolectar la información, a partir de la cuantificación numérica y análisis estadístico (Cabezas et al., 2018). La descripción permitió evidenciar la realidad directamente e identificar los factores que incidieron en la perspectiva de género, en un ambiente educativo. La investigación fue de corte transversal pues se conoció la realidad en un espacio y tiempo determinado (Hernández et al., 2014).

\subsection{Población y muestra}

La población estuvo conformada por 764 estudiantes de la Unidad Educativa Amelia Gallegos Díaz, de los cuales $510(66,75 \%)$ pertenecieron al sexo femenino y $254(33,25 \%)$, al sexo masculino; distribuidos en paralelos, grados, edades y sexo. La muestra estuvo estructurada por 263 
alumnos de $8^{\circ}, 9^{\circ}$ y $10^{\circ}$ de Educación Básica Superior (entre 12 y 14 años de edad) y $1^{\circ}, 2^{\circ}$ y $3^{\circ}$ de Bachillerato. De acuerdo con el nivel educativo un $40,7 \%$ fueron estudiantes de Básica Superior y un 59,3\% de Bachillerato. Se aplicó un muestreo aleatorio estratificado proporcional, por cuanto la población no fue homogénea (Gamboa, 2017) y se seleccionaron elementos de cada subgrupo. Luego se aplicó un muestreo aleatorio simple por sexo, grados y paralelos y se utilizó la tabla de números aleatorios para seleccionar a cada uno de los participantes.

\subsection{Instrumento}

Un cuestionario fue empleado para la recogida de la información. El mismo se adaptó de la escala de actitudes hacia la igualdad de género, elaborado por García et al. (2010), compuesto por 41 preguntas cerradas, con cuatro opciones de respuesta (nunca, algunas veces, casi siempre y siempre). La confiabilidad fue calculada a través del coeficiente Alfa de Cronbach, y con el software estadístico SPSS versión 21. El resultado fue de 0,801 (confiable).

El instrumento fue organizado en función a los indicadores de las variables: perspectiva de género (estereotipos, discriminación, violencia y sexo) e interacción social (equidad e igualdad). Los ítems 1-9: estereotipos, aborda comportamientos generalizados de hombres y mujeres; ítems 10-16: discriminación, describe diversas situaciones en la que las personas desde su género se sienten excluidas; ítems 17-22: violencia, preguntas relacionadas con agresión, desorden, infidelidad; ítems 23-31: sexo, plantea situaciones en las concepciones de ser hombre y ser mujer; ítems 31-36: equidad, expone interrogan- tes sobre las oportunidades que tienen hombres y mujeres; ítems 37-42): igualdad, indica diversas situaciones en ambientes escolares.

\subsection{Procedimiento}

Inicialmente, se realizaron los trámites respectivos ante la autoridad del Distrito Educativo y de la institución para la debida autorización y se comunicaron los objetivos de la investigación. Previo a la aplicación del instrumento se gestionó la aceptación de los padres de familia y la disposición de los participantes. Se aplicó el instrumento, en el tercer parcial del año lectivo 2019-2020, en horario académico. Finalmente, se procedió a analizar estadísticamente los datos aportados por los involucrados.

\subsection{Análisis de datos}

Para analizar la información se utilizó la estadística descriptiva como promedios, porcentajes y la elaboración de tablas y la estadística inferencial como el análisis de correlación de Spearman's, en función a los valores obtenidos de las respuestas para cada uno de los indicadores, dimensiones y variables.

\section{Resultados}

En la tabla 1 se presentan los puntos de corte utilizados para determinar la actitud de los estudiantes hacia la igualdad de género (sexista, adaptativa o igualitaria) y, a su vez, evaluar la perspectiva de género en la interacción social de los adolescentes en ambientes escolares, niveles educativos de General Básica Superior y Bachillerato, en función de las variables de la investigación. 
Tabla 1. Resultados globales

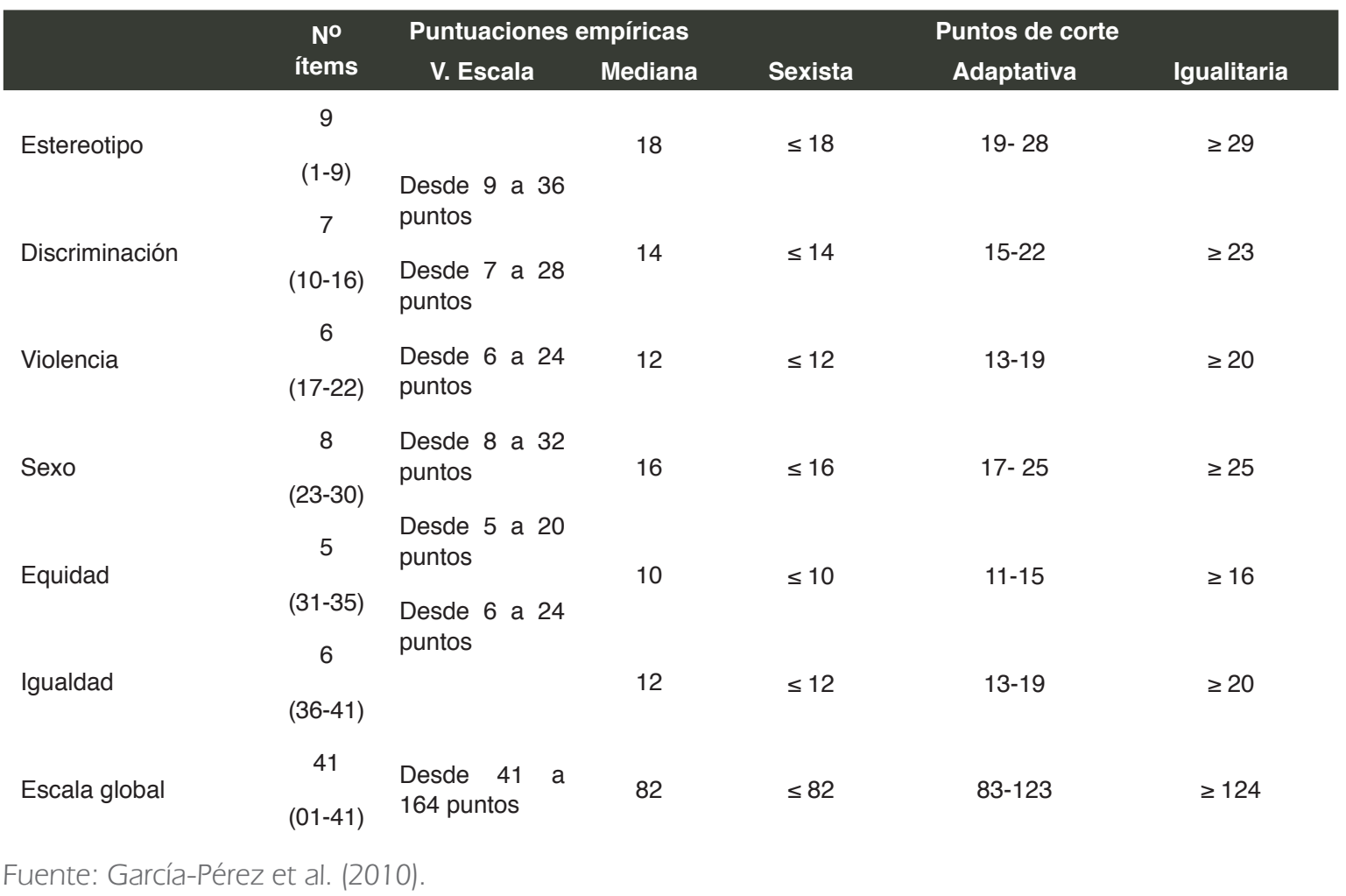

Según García-Pérez et al. (2010) la actitud sexista comprende analizar los puntos de vista competitivo entre hombres y mujeres, así como acciones inconscientes de conductas asociadas al género y modelos sociales donde predomina el hombre sobre la mujer. La actitud adaptativa comprende ejercer acciones fundamentadas en una perspectiva de comportamiento adecuado socialmente que, aun cuando evidencia diferencias y desigualdades, muestra incertidumbre en la valoración de algunos estereotipos. La actitud igualitaria asume la existencia de desigualdad y pondera positivamente las conductas de hombres y mujeres desde una visión con equidad.

En la tabla 3 se puede apreciar el comportamiento de los diferentes indicadores en relación con los puntos de cortes establecidos en la tabla 2. En correspondencia con el estereotipo se puede apreciar una actitud adaptiva en las hembras como los varones. Asimismo, ocurre con la discriminación, la violencia, el sexo, la equidad e igualdad, donde los valores promedios para ambos sexos, expresan una actitud adaptativa hacia la igualdad de género. La perspectiva de los participantes en el estudio basada en los puntos de corte de escala, demuestra que las hembras adoptan actitudes adaptativas $(86,2 \%)$, igualitario $(13,3 \%)$ y sexistas $(0,5 \%)$; mientras que los varones manifiestan actitudes adaptativas $(85,9 \%)$ e igualitario $(14,1 \%)$. Las opiniones de los estudiantes se acercan a niveles próximos hacia la actitud adaptativa (figura 1). 
Tabla 2. Resultados globales en función al sexo

\begin{tabular}{|c|c|c|c|c|}
\hline & \multicolumn{4}{|c|}{ Resultados de la actitud obtenida por los estudiantes en función al sexo } \\
\hline & \multicolumn{2}{|c|}{ Media } & \multicolumn{2}{|c|}{ D.T. } \\
\hline & H & v & H & v \\
\hline Global (42 ítems) & 110,57 & 110,17 & 10,658 & 11,022 \\
\hline Estereotipos & 27,96 & 26,47 & 4,108 & 4,525 \\
\hline Discriminación & 18,66 & 19,39 & 3,664 & 2,915 \\
\hline Violencia & 15,88 & 17,16 & 2,605 & 3,004 \\
\hline Sexo & 19,55 & 19,83 & 3,100 & 3,190 \\
\hline Equidad & 12,62 & 12,05 & 2,247 & 2,705 \\
\hline Igualdad & 15,91 & 15,28 & 2,535 & 3,434 \\
\hline
\end{tabular}

Fuente: Elaboración propia

Figura 1. Perspectiva de las actitudes de los estudiantes

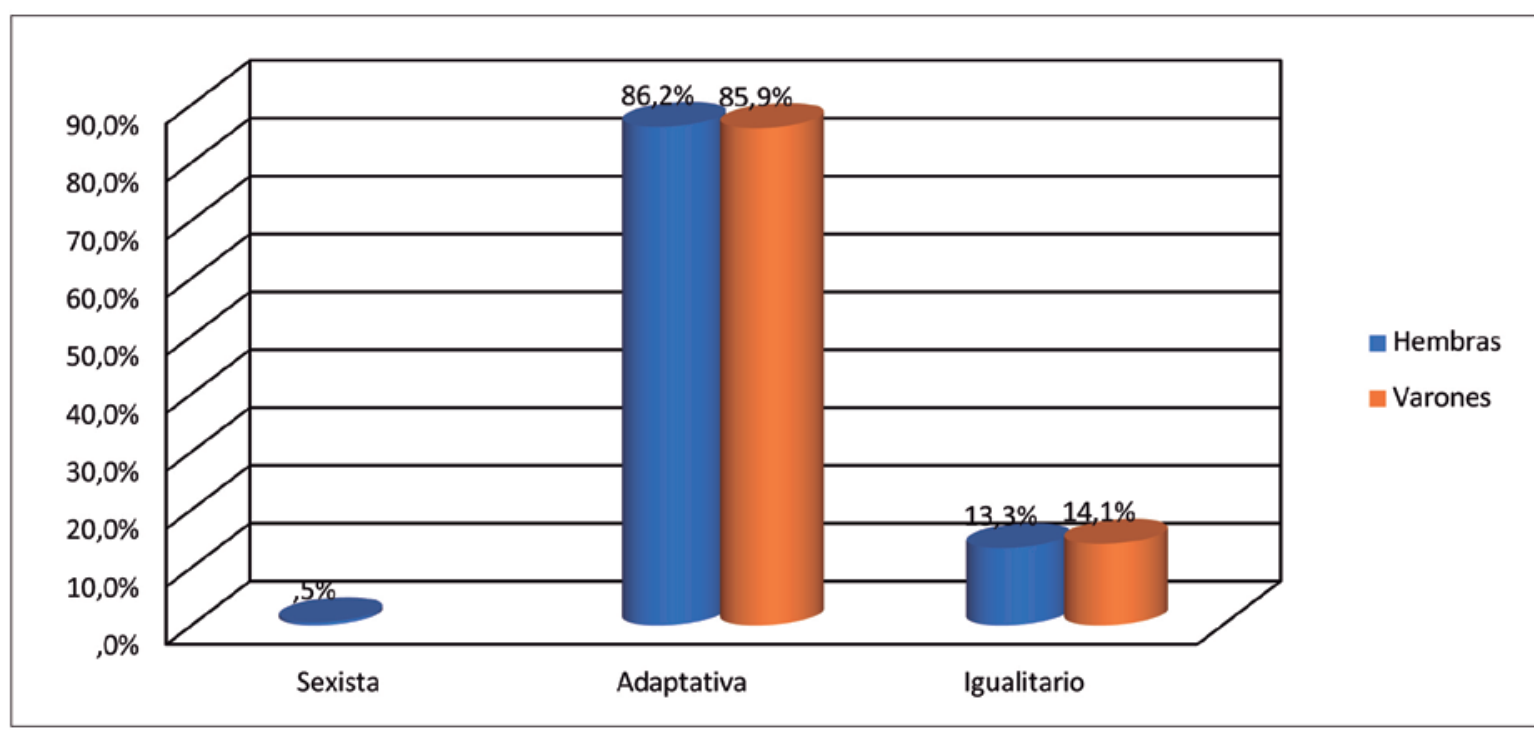

\section{Fuente: Elaboración propia.}

En la tabla 3 se pueden observar los resultados del análisis de correlación no paramétrica de Spearman's. Existe una correlación altamente significativa entre la perspectiva de género y la interacción social, a un nivel de significancia de 0,01 . Esto explica que ambas variables están altamente asociadas; por lo tanto, los resultados en los indicadores de la perspectiva de género muestran una actitud adaptativa que incide directamente en un trato de igualdad y equidad en la interacción social de los estudiantes. 
Tabla 3. Correlación no paramétrica de Spearman's

\begin{tabular}{|c|c|c|c|c|}
\hline & & & $\begin{array}{l}\text { Perspectiva de } \\
\text { género }\end{array}$ & $\begin{array}{c}\text { Interacción } \\
\text { social }\end{array}$ \\
\hline \multirow{6}{*}{ rho de Spearman's } & \multirow{3}{*}{ Perspectiva de género } & Coeficiente de Correlación & 1,000 &, $370^{* *}$ \\
\hline & & Sig. (2-tailed) & . & ,000 \\
\hline & & $\mathrm{N}$ & 259 & 259 \\
\hline & \multirow{3}{*}{ Interacción social } & Coeficiente de Correlación &, $370^{\star *}$ & 1,000 \\
\hline & & Sig. (2-tailed) & ,000 & . \\
\hline & & $\mathrm{N}$ & 259 & 259 \\
\hline
\end{tabular}

** La Correlación es significativa en el nivel 0.01 (2-tailed).

Fuente: Elaboración propia.

\section{Discusión}

La investigación conllevó a realizar un análisis estructural desde la diversidad de características que pueden ser generadas por una muestra representativa de alumnos. Se pudo constatar una diferencia marcada de la perspectiva de género con respecto al sexo. La información permitió construir un análisis de los indicadores de las variables:

Estereotipo: Los estudiantes mantienen una alta perspectiva con una tendencia a moderado, sobre los estereotipos acerca de las generalizaciones y creencias; lo cual es entendible porque en la etapa adolescente se adquiere paulatinamente un conocimiento más preciso de estos aspectos. Al respecto, Andrade-Zurita et al. (2017) afirman que estas prácticas sociales, estos modelos ejercitados, ideas creadas, discursos y representaciones culturales, son aceptados en la moral y ética por las comunidades y simultáneamente promovidos y reproducidos por las instituciones escolares.

Discriminación: Aquí se imponen los estereotipos; surge cuando las diferencias entre géneros se convierten en desigualdad. Sin embargo, en los resultados, los estudiantes aceptan tener amigos homosexuales, lo que se manifiesta con un grado de aceptación hacia la igualdad; pero se disocia en actividades que son consideradas para mujeres (tareas de cuidado), lo que permite infe- rir que existe una alta percepción en las establecidas al rol estereotipado para los varones $y$, moderada para el comportamiento que es adecuado para mujeres. A ese respecto, Andrade-Zurita et al. (2017), refieren que existen apreciaciones de los alumnos acerca de la conducta social representada por mujeres u hombres; y que estos relacionan la discriminación sociocultural a la perspectiva de género. Para Silva- Diverio (2016) los adolescentes, en su comportamiento, se interconectan y apoyan en actividades propias de su sexo. En el caso de las hembras, nuevamente, se evidencian actitudes relacionadas con labores de atención a las personas, la comprensión y los sentimientos; mientras que los varones destacan en la capacidad de obrar con fuerza física, medir la superioridad de uno con el otro y mostrar su aspecto varonil.

Violencia: La información mostró una actitud claramente sexista e influida socialmente por estereotipos que abundan en considerar, el sometimiento social del hombre sobre la mujer. Se acepta la vulnerabilidad de la mujer, creencia compartida por la misma muestra de hembras. De la Osa et al. (2013) reportaron que, los adolescentes, en un importante número, son tolerantes y no están de acuerdo con acciones violentas; sin embargo, persisten momentos en los cuales su comportamiento amerita respuestas agresivas basadas en el papel que cumplen como 
hombres. Por tanto, se debe evitar a como dé lugar la agresión a la mujer y hacer entender a los estudiantes, como lo afirman Jiménez y Estévez (2017) "la igualdad de género propicia el desarrollo en las sociedades (p. 254).

Sexo: Los adolescentes mantienen una perspectiva sexista ante la figura femenina $y$ masculina en la sociedad, persistiendo la postura de vulnerabilidad hacia la mujer por el hecho de serlo. Se observa que las posiciones sexistas y adaptativas están relacionadas al carácter social y estereotipado, que les dan a los indicadores involucrados en esta dimensión; son adquiridos en un proceso en los que se integran, la cultura, el entorno social, el grupo familiar y la escuela. Segato (2016) afirma que, con la edad, las diferencias signadas en el comportamiento entre varones y hembras cada vez es mayor y repercuten negativamente en sus interrelaciones; por lo que se debe educar a la población no solo con medidas explícitas, sino también a través de medidas indirectas que propicien valores y actitudes positivos en los comportamientos de discriminación, para hacerlos visibles y eliminarlos.

Equidad: La equidad se encuentra soslayada; se observa una sobrevaloración sexista ante este indicador. Sin embargo, los estudiantes son más sensibles acerca de que las hembras superan académicamente a los varones $y$, en el campo deportivo y social, consideran que hay igualdad en ambos sexos en la práctica de juegos. Al respecto, Ruiz-Ramírez y Ayala-Carrillo (2016) explican la importancia de concientizar sobre la equidad de género para transformar la forma de pensar, ante los roles que mujeres y hombres, cumplen en el desarrollo social y económico.

Igualdad: Los adolescentes han aceptado que existen otras formas de masculinidad $y$ feminidad y que pueden convivir en ambientes educativos en igualdad de condiciones, pero se observó una tendencia a asumir que no existe igualdad en ciertas actividades estereotipadas tanto de hombres y mujeres. En este sentido, Villegas (2018) demostró que existe una marcada desigualdad entre las estudiantes en relación con los varones que gozan de mayor consideración en el ámbito social. Al respecto, Vega et al. (2019) afirman que para lograr un desarrollo equilibrado y productivo se deben implementar acciones que propicien la igualdad entre varones y hembras, así como la formulación de un cuerpo de políticas que regulen y fomenten la participación equitativa con miras a promover una educación inclusiva y respetuosa del otro. Los adolescentes son más considerados cuando se habla de igualdad, eso ayuda a "reducir las brechas de género en cuanto a oportunidades y derechos" (UNESCO, 2015, p.14).

De acuerdo con los puntos de corte definidos, la muestra manifestó perspectivas adaptativas que inciden directamente en un trato de igualdad y equidad, en la interacción social de los estudiantes. El análisis de correlación evidenció un nivel alto de significancia entre las variables.

\section{Conclusiones}

La perspectiva de género que tienen los adolescentes actuales ha cambiado considerablemente en comparación con la de hace veinte años. Aun cuando en Ecuador continúan prevaleciendo actitudes arcaicas como el machismo y la homofobia, las tendencias han variado a favor de la igualdad de género y condiciones.

En referencia a los factores que inciden en la perspectiva de género del adolescente para el desarrollo social dentro de ambientes escolares en los niveles de Educación General Básica Superior y Bachillerato se infiere que los sociales, religiosos, ideológicos, políticos, históricos, económicos y culturales, prevalecen en los estereotipos, la discriminación, la violencia y el sexo.

Los participantes del estudio con respecto a la actitud adaptativa, mostraron que se han ido adecuando a las situaciones que les deviene el presente; la mayoría lo hace porque no tienen discrepancias en la igualdad de oportunidades. Sin embargo, aún queda un bajo porcentaje que se mantiene firme a las enseñanzas sexistas que le han inculcado desde su núcleo familiar. 
Se evidenció que los alumnos entienden que la mujer es parte fundamental y activa de la sociedad, no solo como madre, sino también como profesional, que ayuda a mejorar el aparato productivo del país; aun así, se mantienen tendencias a ubicarlas en la realización de tareas domésticas.

Los estereotipos sociales se encontraron relacionados con el hecho que los hombres son el sexo fuerte y lideran las actividades grupales, viéndose como muy natural que los padres concedan mayor libertad a los varones. También los resultados evidencian la tendencia a creer que ellos son más capaces para desempeñar tareas técnicas y mecánicas; responsables de mantener económicamente a la familia, y que el presidente del país debe ser un hombre. Las mujeres, son socialmente consideradas mejores estudiantes y más vulnerables físicamente que los hombres.

En general, parte de la actitud de los jóvenes a nuevas circunstancias se ven marcadas por la formación que reciben en los hogares; existe la condición de estigmatizar lo desconocido, pero esas barreras se han ido disminuyendo pues las nuevas tecnologías permiten apreciar y cotejar situaciones similares que se presentan en otros países. De igual forma, la mujer ha ganado terreno en todos los espacios sociales logrando ubicarse en el lugar de la igualdad, donde el sexo o el género no definen la capacidad individual de las personas.

El análisis realizado en esta investigación reafirma la necesidad de proponer acciones centradas en políticas de igualdad, reforzadas con actividades que sensibilicen sobre estos temas, desde el perfil adaptativo del alumno. Resulta necesario cambiar, modificar y suprimir actitudes y conductas sociales que tipifiquen el género relacionados con la esfera privada y tareas asistenciales. Por otra parte, se recomienda evitar la conformación de escenarios donde se permita la violencia de género, a partir de actividades formativas que busquen la convivencia social y la paz.

Es imprescindible que, desde el hogar, los padres y familiares en general aborden temas que se relacionen con el género como condición social, pero desde un sentido reflexivo y de tolerancia; que evite la exclusión o discriminación de los jóvenes que no se identifiquen con su sexo. En las instituciones educativas se debe capacitar y actualizar a los profesores para que puedan aclarar las dudas que los estudiantes formulen y no exista una concepción o una información errada, que genere dudas y confusión. Se deben implementar estrategias dirigidas a desarrollar un proceso educativo desde la coeducación, basado en valores como la tolerancia, la aceptación a nuevas formas de expresar su género, la convivencia armónica, la diversidad, la inclusión, la pluralidad y la autonomía.

\section{Referencias bibliográficas}

Aguilar, Y., Valdez, J., González, N., \& González, S. (2013). Los roles de género de los hombres y las mujeres en el México Contemporáneo. Enseñanza e Investigación en Psicología, 18(2), 207-224. https://bit.ly/2KZwgRP

Andrade-Zurita, S., Rosero-Morales, E., LucasSolórzano, C., Armas-Arias, S., \& NúñezEspinoza, M. (2017). Violencia de género en ambientes escolares: Desigualdades entre los sexos. UTCIENCIA. Ciencia y tecnología al servicio del pueblo, 4(1), 24-36. https://bit.ly/2W1LRqo

Asamblea Constituyente de la República del Ecuador. Constitución de la República del Ecuador. Registro Oficial. No 449. Año II, del 20-102008.

Azorín-Abellán, C.M. (2017). Actitudes hacia la igualdad de género en una muestra de estudiantes de Murcia. Revista Complutense de Educación, 28(1), 45-60. http://dx.doi. org/10.5209/rev_RCED.2017.v28.n1.48715

Beltrán-Gálvez, M. (2012). La otra cara de la moneda: mujeres que practican violencia. Revista Punto Género, (2), 71-92. https://doi.org/10.5354/0719-0417.2012.28365

Benavente, M., \& Valdés, A. (2014). Políticas públicas para la igualdad de género: Un aporte a la autonomía de las mujeres. Comisión 
Económica para América Latina y el Caribe (CEPAL). https://bit.ly/3dlxX87

Bruel, T., Scarparo, H., Calvo, A., Sebastián, J., \& Blanco, A. (2013). Estudio psicosocial sobre las representaciones sociales de género. [A Psychosocial Study about the Social Representations of Gender] Diversitas: Perspectivas en Psicología, 9(2), 243-255. https://doi.org/10.15332/s1794-9998.2013.0002.01

Cabezas, E., Andrade, D., \& Torres, J. (2018). Introducción a la metodología de la investigación científica. ( $1^{\text {a }}$. Ed). Electrónica. Universidad de las Fuerzas Armadas ESPE. https://bit.ly/2xMXHeB

Camarera, M., \& Saavedra, M. (2018). La perspectiva de género en los programas de estudio de las licenciaturas contables administrativas. [The gender perspective in the curriculum of management accountants degrees]. Nóesis: Revista de Ciencias Sociales y Humanidades, 27(54). https://doi.org/10.20983/noesis.2018.2.3

Chávez-Carapia, J. (2017). Percepción de la igualdad de género en jóvenes universitarios. Grupo de investigación Centro de Estudios de la Mujer. 2015-2016. UNAM: Revista de Trabajo Social, 75-90. https://bit.ly/2SLtF2m

Defensoría del Pueblo-Ecuador (2016). Política Institucional de Igualdad de Género (20162019). https://bit.ly/2WWCUyX

Duarte, J., \& García, J. (2016). Igualdad, equidad de género y feminismo, una mirada histórica a la conquista de los derechos de las mujeres. [ Equity, Gender Equality and Feminism, a historical look at the conquest women's rights]. Revista CS, 2(18), 13-38. https://doi.org/10.18046/recs.i18.1960

De la Osa, Z., Andrés, S., \& Pascual, I. (2013). Creencias adolescentes sobre la violencia de género. Sexismo en las relaciones entre adolescentes. European Journal of Investigation in Health, Psychology and Education, 3(3), 265275. https://doi.org/10.30552/ejihpe.v3i3.51

Fondo de las Naciones Unidas para la Infancia (2015). Educación para Todos. Organización de las Naciones Unidas para la Educación, la Ciencia y la Cultura.

Gamboa, M. (2017). Estadística aplicada a la investigación educativa. Dilemas Contemporáneos: Educación, Política y Valores, V(2).
https://bit.ly/2xJBbU1

García-Pérez, R., Rebollo, M.A, Buzón, O., GonzálezPiñal, R., Barragán, R., \& Ruiz, E. (2010). Actitudes del alumnado hacia la igualdad de género. Revista de Investigación, 28(1), 217232. https://bit.ly/2zgDRZN

Guerra-López, R. (2016). Persona, sexo y género. Los significados de la categoría "género" y el sistema "sexo/género" según Karol Wojtyła. Revista de Filosofía Open Insight, 7(12), 139-164. https://bit.ly/2XsvkLL

Guzmán, F. (2015). Violencia de género en adolescentes: Análisis de las perspectivas y de las acciones educativas propuestas por la Junta de Andalucía. (Tesis de doctorado). Universidad de Sevilla. https://bit.ly/3fnU0gm

Hernández, R., Fernández, R., \& Baptista, P. (2014). Metodología de la investigación (6a. ed.). Mc Graw Hill.

Javaloy, F., Espelt, E., \& Rodríguez, Á. (2016). Comportamiento colectivo y movimientos sociales en la era global. En J. Morales, E. Gaviria, M. Moya, \& I. Cuadrado (Coords.), Psicología social, 641-691. Mc Graw Hill. https://bit.ly/2AavSOH

Liscano, D. (2016). Representaciones sociales sobre las personas LGBTI en la universidad: perspectivas del profesorado y alumnado. Revista Nacional e Internacional de Educación Inclusiva, 9(3), 231-249. https://bit.ly/2WduByn

Lozano, A.V. (2014). Teoría de Teorías sobre la Adolescencia. [Theory of Theories about Adolescence]. Última década, 22(40), 11-36. https://dx.doi.org/10.4067/S0718-22362014000100002

Medina, V., Coronilla, U., \& Bustos, E. (2015). La discriminación dentro del salón de clases. [Discrimination in the classromm]. RIDE Revista Iberoamericana para la Investigación $y$ el Desarrollo Educativo, 6(11), 855-867. https://doi.org/10.23913/ride.v6i11.134

Meza, J., \& Páez, R. (2016). Familia, escuela y desarrollo humano: Rutas de investigación educativa. ( $1^{\text {a }}$ ed). Kimpres S.A.S. https://bit.ly/36qnYfw

Organización de las Naciones Unidas (1995). La Declaración de Beijing: IV Conferencia Mundial sobre Mujeres. IV Conferencia 
Mundial sobre las mujeres. Beijing: N.N.U.U. https://bit.ly/3b91FMs

Organización de las Naciones Unidades Mujeres (2014). Declaración Política y documentos de Beijing +5. ONUM. https://bit.ly/2Wegxoz

Organización de las Naciones Unidas para la Educación la Ciencia y la Cultura (2015). Igualdad de género. Patrimonio y creatividad. https://bit.ly/3cYW8tu

Ortiz-Jiménez, J.G., Ramírez-Garzón, M.I., Moreno-F., M., \& Martínez-Morales, E. M. (2018). Las rutas de las emociones: Sujetos e instituciones en tránsito a la paz. Taller de Edición Rocca. https://bit.ly/2WAEqpg

Rodríguez, P., Matud, M., \& Álvarez, J. (2017). Género y calidad de vida en la adolescencia. Journal of Behavior, Health \& Social Issues, 9(2), 89-98. https://doi.org/10.1016/j.jbhsi.2017.11.001

Ruiz-Ramírez, R., \& Ayala-Carrillo, M. (2016). Violencia de género en instituciones de educación. Ra Ximhai, 21-32. https://doi.org/10.35197/rx.12.01.2016.01.rr

Secretaría Nacional de Planificación y Desarrollo. Consejo Nacional de Planificación (2017). Plan Nacional Toda una Vida 2017-2021. Quito. Ecuador. Resolución No. CNP-0032017 del 22-09-2017. https://bit.ly/3cYDBgV

Segato, R. (2016). La guerra contra las mujeres. Traficantes de sueños: Mapas. https://bit.ly/2LVoHMk

Serret, E. (2016). Hacia una redefinición de las identidades de género. GénEro ơs, Revista de investigación y divulgación sobre los estudios de género, 18(9), 71-97. https://bit.ly/3fr6Hai

Silva-Diverio, I. (2016). La adolescencia y su interrelación con el entorno. Instituto de la Juventud (INJUVE). https://bit.ly/2WXA6lm
Solís-Sabanero, A. (2016). La perspectiva de género en la educación. En J.A. Trujillo-Holguín y J.L. García-Leos (Coords.), Desarrollo profesional docente: reforma educativa, contenidos curriculares y procesos de evaluación, 97-107. https://bit.ly/2SLNXsx

Suárez, P., \& Vélez, M. (2016). El papel de la familia en el desarrollo social del niño: una mirada desde la afectividad, la comunicación familiar y estilos de educación parental. [The role of the family in social development of child: a look from affectivity, family communication and education] Psicoespacios, 12(20),173197. https://doi.org/10.25057/issn.2145-2776

Torres, L. (2018). Interiorización de los estereotipos de género en la sociedad argentina y el ideal de belleza en los mensajes publicitarios [Tesis de doctorado, Universidad Complutense de Madrid]. https://bit.ly/2SPgCgi

Trejo-Sirvent, M.L., Llaven-Coutiño, G., \& Pérez y Pérez, H.C. (2015). El enfoque de género en la Educación. Atenas, 4(32), 49-61. https://bit.ly/2Wb43xI

Vega, A., García, S., Candela, B., Santos, J., Díaz, M., \& Torrado, E. (2019). De la teoría a la práctica educativa en igualdad. [From theory to educational practice in equality]. Revista de la ULL, 31-50.

https://doi.org/10.25145/b.innovaull.2019.002

Villegas, V. (2018). Concepciones de género y convivencia escolar en los y las estudiantes de la Unidad Educativa CMDT. César Endara Peña Herrera. [Conceptions of gender and school coexistence in the students of the Educational Institution CMDT César Endara Peña Herrera]. Retos de la Ciencia, 2(2), 139154. https://bit.ly/2WGcUGZ 



\section{ALTERIDAD}

p-ISSN: 1390-325x / e-ISSN: 1390-8642

Vol. 16, No. 1/ enero-junio 2021

\section{Normas Editoriales (Publication guidelines)}

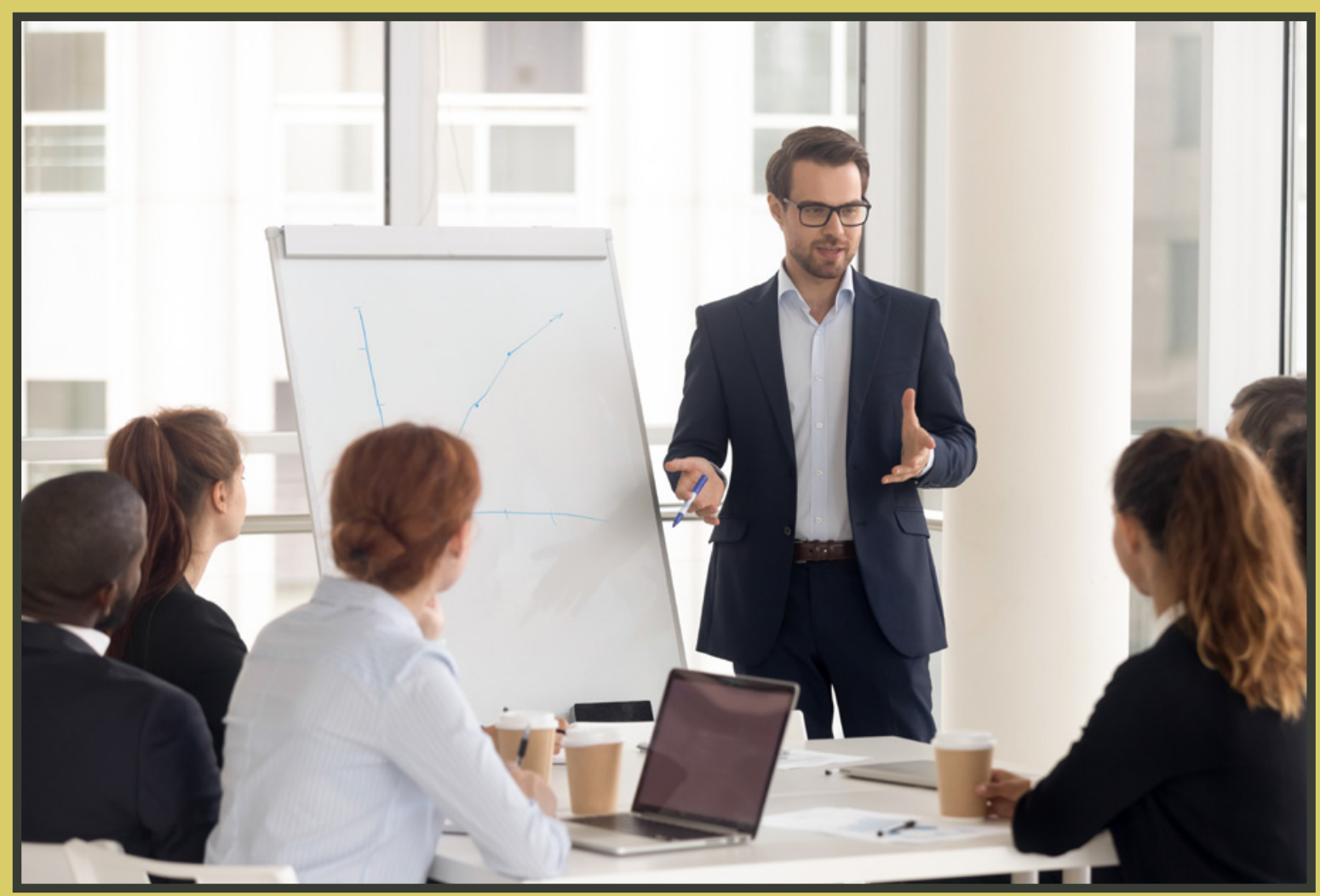

https:/ / www.shutterstock.com/es/image-photo/male-business-coach-speaker-suit-give-1361250578 


\title{
Normas de Publicación en «Alteridad»
}

\author{
http://alteridad.ups.edu.ec/ \\ p-ISSN:1390-325X / e-ISSN:1390-8642
}

\section{Información general}

«Alteridad» es una publicación científica bilingüe de la Universidad Politécnica Salesiana de Ecuador (UPS), editada desde enero de 2006 de forma ininterrumpida, con periodicidad fija semestral (enero-julio).

Es una revista científica arbitrada, que utiliza el sistema de evaluación externa por expertos (peer-review), bajo metodología de pares ciegos (doble-blind review), conforme a las normas de publicación de la American Psychological Association (APA). El cumplimiento de este sistema permite garantizar a los autores un proceso de revisión objetivo, imparcial y transparente, lo que facilita a la publicación su inclusión en bases de datos, repositorios e indexaciones internacionales de referencia.

«Alteridad» se encuentra indexada en el Emerging Sources Citation Index (ESCI) de Web of Science, en la Scientific Electronic Library Online (SciELO), en el Sistema de Información Científica REDALYC, en el directorio y catálogo selectivo del Sistema Regional de Información en Línea para Revistas Científicas de América Latina, el Caribe, España y Portugal (Latindex), en el Directory of Open Access Journals (DOAJ), en el European Reference Index for the Humanities and Social Sciences (ERIHPLUS), en la Red Iberoamericana de Innovación y Conocimiento Científico (REDIB), en el Portal Dialnet; está evaluada en la Matriz de Información para el Análisis de Revistas (MIAR), en la Clasificación Integrada de Revistas Científicas (CIRC), y en el sistema Qualis de revisión de revistas de CAPES. Además, se encuentra en repositorios, bibliotecas y catálogos especializados de todo el mundo.

La revista se edita en doble versión: electrónica (e-ISSN: 1390-8642) e impresa (ISSN: 1390-325X) en español e inglés; siendo identificado cada trabajo con un Digital Object Identifier System (DOI). Todos los artículos publicados en «Alteridad» tienen licencia Creative Commons Reconocimiento-No-Comercial-Compartir igual (RoMEO blue journal).

\section{Alcance y política}

\subsection{Temática}

«Alteridad» es una revista especializada en Educación y sus líneas transdisciplinares como Didáctica, Políticas Públicas, Gerencia de Centros Escolares, Educomunicación, TIC, Pedagogía Social, entre otras; y todas aquellas disciplinas conexas interdisciplinarmente con la línea temática central.

\subsection{Secciones}

La revista tiene periodicidad semestral (20 artículos por año), publicada en los meses de enero y julio y cuenta por número con dos secciones de cinco artículos cada una, la primera referida a un tema Monográfico preparado con antelación y con editores temáticos y la segunda, una sección de Misceláneas, compuesta por aportaciones variadas dentro de la temática de la publicación. 


\subsection{Aportaciones}

Todos los trabajos deben ser originales, no haber sido publicados en ningún medio ni estar en proceso de arbitraje o publicación. Se editan preferentemente resultados de investigación empírica, redactados en español, portugués o inglés, siendo también admisibles estudios y selectas revisiones de la literatura (state-of-the-art):

- Investigaciones: 5000 a 6500 palabras de texto, incluyendo título, resúmenes, descriptores, tablas y referencias. Se valorarán especialmente los resultados de la investigación, el rigor metodológico, la relevancia de la temática, la calidad de la discusión científica, la variedad, actualidad y riqueza de las referencias bibliográficas (preferiblemente de publicaciones indexadas en JCR y Scopus). Se esperan mínimo 35 referencias.

- Estudios y revisiones de la literatura: 6000 a 7000 palabras de texto, incluidas tablas y referencias. Se valorará especialmente el debate generado, la relevancia de la temática, la originalidad de las aportaciones y referencias justificadas, actuales y selectivas de alrededor de 70 obras (preferiblemente de publicaciones indexadas en JCR y Scopus).

\section{Proceso editorial}

\subsection{Envío de manuscritos}

Los manuscritos deben ser enviados única y exclusivamente a través del Open Journal System (OJS), en el cual todos los autores deben darse de alta previamente, si bien uno solo de ellos será el responsable de correspondencia. Ningún autor podrá enviar o tener en revisión dos manuscritos de forma simultánea, estimándose una carencia de cuatro números consecutivos ( 2 años). Un artículo podrá tener como máximo 3 autores, aunque si se justifica en función del tamaño del estudio, podrán ser hasta 5.

«Alteridad» acusa recepción de los trabajos enviados por los autores, informa por email y la plataforma del proceso de aceptación o rechazo; y en el caso de aceptación, del proceso de edición.

En el Portal oficial de la revista, en la sección Normativas, están las Normas para Autores, el formato de estructura de los artículos, la Portada y Carta de presentación, el chequeo previo al envío, los formularios de evaluación por parte de los revisores externos y una guía para el envío del artículo a través de OJS. Antes de su envío se recomienda encarecidamente que se compruebe el manuscrito con el Protocolo de chequeo previo. Deben remitirse simultáneamente dos documentos:

a. Portada y Carta de presentación (usar el modelo oficial), en la que aparecerán:

- Portada (Título, Resumen y Descriptores previstos en el Manuscrito).

- Nombre y apellidos completos de cada uno de los autores, organizados por orden de prelación; seguido por la categoría profesional, centro de trabajo, correo electrónico de cada autor y número de ORCID. Es obligatorio indicar si se posee el grado académico de doctor (incluir Dr./ Dra. antes del nombre).

- Se incluirá además una declaración (Cover letter) de que el manuscrito se trata de una aportación original, no enviada ni en proceso de evaluación en otra revista, confirmación de las autorías firmantes, aceptación (si procede) de cambios formales en el manuscrito conforme a 
las normas y cesión parcial de derechos a la editorial.

b. Manuscrito totalmente anonimizado, conforme a las normas referidas en el epígrafe 4.

\subsection{Proceso de revisión}

En un plazo máximo de 30 días, a partir de la recepción del documento, el autor de correspondencia recibirá una notificación, indicando preliminarmente si se estima o desestima para el arbitraje por los revisores científicos. En el caso de que el artículo presente deficiencias formales, no trate el tema educativo, o tenga un elevado porcentaje de similitud con otro(s) documento(s), el Consejo editorial desestimará el trabajo sin opción de vuelta. Por el contrario, si presenta carencias superficiales de forma, se devolverá al autor para su corrección antes de comenzar del proceso de evaluación. La fecha de recepción del artículo no computará hasta la recepción correcta del mismo.

Los artículos serán evaluados científicamente por una media de tres expertos en el tema. Los informes indicarán las siguientes recomendaciones: Aceptar el envío, Publicable con modificaciones, Reenviar para revisión, No publicable. A partir del análisis de los informes externos, se decidirá la aceptación o rechazo de los artículos para su publicación. En el caso de resultados discrepantes se remitirá a un nuevo dictamen, el cual será definitivo. El protocolo utilizado por los revisores es público (Investigaciones; Estudios y revisiones de la literatura).

En general, una vez vistas las revisiones científicas externas, los criterios que justifican la decisión sobre la aceptación/rechazo de los trabajos por parte del Consejo Editor son los siguientes:

- Actualidad y novedad.

- Relevancia y significación: Avance del conocimiento científico.

- Originalidad.
- Fiabilidad y validez científica: Calidad metodológica contrastada.

- Organización (coherencia lógica y presentación formal).

- Apoyos externos y financiación pública/ privada.

- Coautorías y grado de internacionalización de la propuesta y del equipo.

- Presentación: Buena redacción.

El plazo de evaluación científica de manuscritos, superados los trámites previos de estimación por el Consejo Editor, es de 100 días como máximo; los remitidos para Calls for papers, sus fechas de revisión científica se inician al cierre de los mismos. Los trabajos que sean evaluados positivamente y requieran modificaciones, deberán ser reenviados con los cambios, dentro de los siguientes 15 días.

\subsection{Edición y publicación del manuscrito}

El proceso de corrección de estilo y maquetación de los artículos aceptados es realizado por el Consejo Técnico de la Revista en coordinación con la Editorial Abya-Yala. «Alteridad» se reserva el derecho de hacer corrección de estilo y cambios editoriales que considere necesarios para mejorar el trabajo. A los autores de artículos se enviará una prueba de imprenta en formato PDF para su corrección únicamente de tipografía y ortografía en un máximo de tres días.

La Editorial Abya-Yala realizará, gratuitamente para los autores, la traducción profesional de la versión final del manuscrito al idioma inglés (o español, según la versión original), lo que garantizará su consulta y difusión internacional. Los artículos serán publicados en la plataforma de la revista en tiempo y forma. Todos los artículos, en sus dos versiones idiomáticas (español e inglés), son publicados en formato PDF, HTML, EPUB y XML-Jats. 


\subsection{Promoción y difusión del artículo publicado}

Los autores se comprometen a darle la máxima difusión a su artículo publicado en «Alteridad». En este sentido, se les exhorta a compartir y archivar su artículo publicado en las redes académicas (Academia.edu, ResearchGate, Mendeley, Kudos), sociales (Twitter, Facebook, LinkedIn, publicando en estos también el DOI), repositorios institucionales, web o blog personal, entre otras. Asimismo, se anima a los autores a compartir el artículo publicado a través de listas de correo electrónico, grupos de investigación y contactos personales.

«Alteridad» cuenta con sistemas de medición de métricas alternativas (PlumX) que permiten verificar el cumplimiento de este compromiso. Para la postulación de futuros artículos de autores de «Alteridad», se tendrá presente el impacto de los trabajos anteriores.

\section{Estructura de los manuscritos}

Los trabajos se presentarán en tipo de letra Arial 10, interlineado simple, justificado completo y sin tabuladores ni espacios en blanco entre párrafos. Solo se separarán con un espacio en blanco los grandes bloques (título, autores, resúmenes, descriptores, créditos y epígrafes). La página debe tener 2 centímetros en todos sus márgenes. Los trabajos deben presentarse en documento de Microsoft Word (.doc o .docx), siendo necesario que el archivo esté anonimizado en Propiedades de Archivo, de forma que no aparezca la identificación de autor/es.

\subsection{Portada}

Título (español) / Title (inglés): Conciso pero informativo, en castellano en primera línea y en inglés en segunda, conformado por el mayor número de términos significativos posibles. El título no solo es responsabilidad de los autores, pudiéndose proponer cambios por parte del Consejo Editorial. Se aceptan como máximo 80 caracteres con espacio.

Resumen (español) / Abstract (inglés): Se describirán de forma concisa y en este orden: Justificación del tema, objetivos, metodología empleada (enfoque y alcance), resultados más relevantes, discusión y principales conclusiones. Ha de estar escrito de manera impersonal "El presente trabajo analiza...". En el caso del Abstract no se admitirá el empleo de traductores automáticos por su pésima calidad. Tendrá como extensión entre 220/230 palabras.

Descriptores (español) / Keywords (inglés): Se deben exponer 6 descriptores por cada versión idiomática relacionados directamente con el tema del trabajo. Será valorado positivamente el uso de las palabras claves expuestas en el Thesaurus de la UNESCO (http://bit.ly/2kIgn8I) o del Vocabulario controlado del IRESIE (http://bit.ly/2mgg4m8).

\subsection{Estructura IMRDC}

Para aquellos trabajos que se traten de Investigaciones de carácter empírico, los manuscritos respetarán rigurosamente la estructura IMRDC, siendo opcionales los epígrafes de Apoyos y Notas. Los trabajos que se traten de Estudios y revisiones de la literatura podrán ser más flexibles en sus epígrafes, especialmente en Metodología, Resultados y Discusión. En todas las tipologías de trabajos son obligatorias las Referencias bibliográficas. 
1. Introducción y estado de la cuestión: Debe incluir los fundamentos teóricos y el propósito del estudio, utilizando citas bibliográficas, así como la revisión de la literatura más significativa del tema a nivel nacional e internacional. Se valorará positivamente el uso de referencias de alto impacto (JCR y Scopus).

2. Metodología: Debe ser redactado de forma que el lector pueda comprender con facilidad el desarrollo de la investigación. Deberá contener la explicación sobre el enfoque (cuantitativo, cualitativo o mixto) y el alcance (exploratorio, descriptivo, correlacional o explicativo). En su caso, describirá la muestra y la forma de muestreo, así como se hará referencia al tipo de análisis estadístico aplicado. Si se trata de una metodología original, es necesario exponer las razones que han conducido a su empleo y describir sus posibles limitaciones.

3. Resultados: Se procurará resaltar los resultados y las observaciones más relevantes de la investigación, describiéndose, sin hacer juicios de valor, el material y métodos empleados para el análisis. Los resultados se expondrán en figuras o/y tablas según las normas de la revista (Ver epígrafe 4.4). Aparecerán en una secuencia lógica en el texto, las tablas o figuras imprescindibles, evitando la redundancia de datos.

4. Discusión y conclusiones: Resumirá los hallazgos más importantes, relacionando las propias observaciones con estudios de interés, señalando aportaciones y limitaciones, sin redundar datos ya comentados en otros apartados. Asimismo, el apartado de discusión y conclusiones debe incluir las deducciones y líneas para futuras investigaciones.

\subsection{Apoyos y Notas}

Apoyos (opcionales): El Council Science Editors recomienda a los autor/es especificar la fuente de financiación de la investigación. Se considerarán prioritarios los trabajos con aval de proyectos competitivos nacionales e internacionales. En todo caso, para la valoración científica del manuscrito, este debe ir anonimizado con XXXX solo para su evaluación inicial, a fin de no identificar autores y equipos de investigación, que deben ser explicitados en la Carta de Presentación y posteriormente en el manuscrito final.

Las notas (opcionales) irán, solo en caso necesario, al final del artículo (antes de las referencias). Deben ser utilizadas para aclarar términos o hacer anotaciones marginales. Los números de notas se colocan en superíndice, tanto en el texto como en la nota final. No se permiten notas que recojan citas bibliográficas simples (sin comentarios), pues éstas deben ir en las referencias. En caso de contener alguna cita, su referencia deberá encontrarse también en la sección de Referencias bibliográficas.

\subsection{Referencias bibliográficas}

Las citas bibliográficas deben reseñarse en forma de referencias al texto. No debe incluirse bibliografía no citada en el texto. Su número ha de ser suficiente y necesario para contextualizar el marco teórico, la metodología usada y los resultados de investigación en un espacio de investigación internacional: Mínimo 35 para los manuscritos de investigaciones de carácter empírico, y alrededor de 70 para los estudios y revisiones de literatura.

Se presentarán alfabéticamente por el apellido primero del autor (agregando el segundo solo en caso de que el primero sea de uso muy común, y unido con guion). Las citas deberán extraerse de los documentos originales preferentemente revistas y en menor medida libros. Dada la trascendencia para los índices de citas y los cálculos de los factores de impacto, se valorarán positivamente el 
uso de referencias provenientes de publicaciones indexadas en JCR y/o Scopus y la correcta citación conforme a la Norma APA 6 (http://bit.ly/2meVQcs).

Es prescriptivo que todas las citas que cuenten con DOI (Digital Object Identifier System) estén reflejadas en las Referencias (pueden obtenerse en https://search.crossref.org/). Todas las revistas y libros que no tengan DOI deben aparecer con su link (en su versión on-line, en caso de que la tengan, acortada, mediante Bitly: https://bitly.com/), y de los sitios web además la fecha de consulta en el formato indicado.

Los artículos de revistas deben ser expuestos en idioma inglés, a excepción de aquellos que se encuentren en español e inglés, caso en el que se expondrá en ambos idiomas utilizando corchetes.

\section{Normas para las referencias}

\section{a) Publicaciones periódicas}

- Artículo de revista (un autor): Ochoa, A. (2019). The type of participation promoted in schools is a constraint factor for inclusive education. [El tipo de participación que promueve la escuela, una limitante para la inclusión]. Alteridad, 14(2), 184-194. https://doi.org/10.17163/alt. v14n2.2019.03

- Artículo de revista (hasta veinte autores): Guarderas, P., Larrea, M., Cuvi, J., Vega, C., Reyes, C., Bichara, T., Ramírez, G., Paula, Ch., Pesantez, L., Íñiguez, A., Ullauri, K., Aguirre, A., Almeida, M., \& Arteaga, E. (2018). Sexual harassment in Ecuadorian universities: Content validation for instrument development. [Acoso sexual en las universidades ecuatorianas: Validez de contenido de un instrumento de medición]. Alteridad, 13(2), 214-226. https://doi.org/10.17163/alt. v13n2.2018.05

- Artículo de revista (sin DOI): López, L., \& Ramírez-García, A. (2014). Medidas disciplinarias en los centros educativos: ¿Suficientes contra el acoso escolar? Perfiles Educativos, 36(145), 32-50. https://bit.ly/37Xd5mw

\section{b) Libros y capítulos de libro}

- Libros completos: Cuéllar, J.C., \& Moncada-Paredes, M.C. (2014). El peso de la deuda externa ecuatoriana. Abya-Yala.

- Capítulos de libro: Padilla-Verdugo, J. (2014). La Historia de la Educación desde los enfoques del conocimiento. In E. Loyola (Ed.), Ciencia, Tecnología y Sociedad (CTS). Miradas desde la Educación Superior en Ecuador (pp. 107-128). Abya-Yala. https://bit.ly/3etRnZH

\section{c) Medios electrónicos}

- Aunión, J. (2011, marzo 12). La pérdida de autoridad es un problema de toda la sociedad, no es específico del aula. El País. https://bit.ly/2NlM9Dp

\section{Normas para epígrafes, tablas y figuras}

Los epígrafes del cuerpo del artículo se numerarán en arábigo. Irán sin caja completa de mayúsculas, ni subrayados, ni negritas. La numeración ha de ser como máximo de tres niveles: 1. / 1.1. / 1.1.1. Al final de cada epígrafe numerado se establecerá un retorno de carro. 
Las tablas y figuras deben presentarse incorporadas en el texto en Microsoft Word ${ }^{\circledR}$ ubicadas en el sitio en el que los autores consideren que deben estar. Se emplearán únicamente cuando sean necesarias e idóneas, debiendo limitarse su uso por cuestiones de espacios (máximo 6 entre tablas y figuras). Ambas deben ser enumeradas en arábigo y tituladas con la descripción de su contenido. Si la fuente de la tabla o figura no fuera de elaboración propia, los autores deberán incorporar al pie de la tabla o la figura la fuente de la que se extrae [por ejemplo, Fuente: Romero-Rodríguez (2016, p. 32)].

Las tablas deben estar elaboradas en el propio documento de Microsoft Word ${ }^{\circledR}$, por lo que no se aceptarán tablas cortadas y pegadas de otros documentos que no puedan ser editados en el proceso de diagramación. Las figuras, además de ser incorporadas en el documento de Microsoft Word ${ }^{\circledR}$, deberán ser enviadas como material complementario al momento del envío en el OJS de "Alteridad», debiendo tener una calidad superior a 600 dpi, en archivos de tipo TIFF, JPEG o PNG.

\section{Tasas y APC}

«Alteridad» es una revista Open Access, incluida en el Directory of Open Access Journals (DOAJ) que oferta toda su producción de forma íntegra online en abierto para toda la comunidad científica. Asimismo, no establece ninguna tasa económica durante todo el proceso editorial para la publicación de los artículos, incluyendo la revisión científica, la maquetación y la traducción de los mismos. No existe ningún publication fee, ni Article Processing Charge (APC) vinculados con esta publicación, ni para autores ni para lectores. Asimismo, la revista tiene licencia Creative-Commons ReconocimientoNo-Comercial-Compartir igual (RoMEO blue journal), lo que permite libre acceso, descarga y archivo de los artículos publicados. Todos los gastos, insumos y financiamiento de «Alteridad» provienen de los aportes realizados por la Universidad Politécnica Salesiana.

\section{Responsabilidades éticas}

Cada autor/es presentará una declaración responsable de autoría y originalidad, así como sus responsabilidades éticas contraídas.

- Originalidad: Los trabajos deben ser originales y no deben estar siendo evaluados simultáneamente en otra publicación, siendo responsabilidad de los autores el cumplimiento de esta norma. Las opiniones expresadas en los artículos publicados son responsabilidad del autor/ es. «Alteridad», como socio internacional de CrossRef ${ }^{\circledR}$, emplea la herramienta antiplagio CrossCheck ${ }^{\circledR}$ y iThenticate ${ }^{\circledR}$ para garantizar la originalidad de los manuscritos.

- Autoría: En la lista de autores firmantes deben figurar únicamente aquellas personas que han contribuido intelectualmente al desarrollo del trabajo. Haber colaborado en la recolección de datos no es, por sí mismo, criterio suficiente de autoría. «Alteridad» declina cualquier responsabilidad sobre posibles conflictos derivados de la autoría de los trabajos que se publiquen.

- Transmisión de los derechos de autor: Se incluirá en la carta de presentación la cesión de derechos del trabajo para su publicación en «Alteridad». La Universidad Politécnica Salesiana (la editorial) conserva los derechos patrimoniales (copyright) de los artículos publicados; favorece y permite la reutilización de las mismas bajo la licencia de uso indicada en ut supra. 


\title{
Publication Guidelines of «Alteridad»
}

\author{
http://alteridad.ups.edu.ec/ \\ p-ISSN:1390-325X / e-ISSN:1390-86
}

\section{General information}

«Alteridad» is a bilingual scientific publication of the Salesian Polytechnic University of Ecuador (UPS), published since January 2006 uninterruptedly, on a semi-annual basis (January-July).

It is an arbitrated scientific journal, which uses the peer-review system under the double-blind review, in accordance with the publication standards of the American Psychological Association (APA). The compliance with this system ensures authors an objective, impartial and transparent review process, making it easier for authors to be included in reference international databases, repositories and indexes.

«Alteridad» is indexed in the Web of Science's Emerging Sources Citation Index (ESCI), at the Scientific Electronic Library Online (SciELO), in the REDALYC Scientific Information System, in the directory and selective catalog of the Regional Online Information System for Scientific Journals of Latin America, the Caribbean, Spain and Portugal (Latindex), in the Directory of Open Access Journals (DOAJ), in the European Reference Index for the Humanities and Social Sciences (ERIHPLUS), in the Ibero-American Network of Innovation and Scientific Knowledge (REDIB), on the Dialnet Portal; it is evaluated in the Information Matrix for Journal Analysis (MIAR), the Integrated Classification of Scientific Journals (CIRC), and the Qualis review system for CAPES journals. In addition, it is in repositories, libraries and specialized catalogs around the world.

The journal is published in two versions: electronic (e-ISSN: 1390-8642) and printed (ISSN: 1390-325X) in Spanish and English; each manuscript is identified with a Digital Object Identifier System (DOI). All articles published in «Alteridad» have the Creative Commons Attribution-NonCommercial-Share Equal license (RoMEO blue journal).

\section{Scope and policies}

\subsection{Topics}

«Alteridad» is a journal specialized in Education and its transdisciplinary lines such as Didactics, Public Policies, School Management, Edu-communication, ICT, Social Pedagogy, among others; and all those disciplines related to the main topic.

\subsection{Sections}

The journal has a semi-annual periodicity (20 articles per year), published in January and July and has two sections of five articles each by number; the first referring to a Monographic topic 
prepared in advance and with thematic topic and the second, a section of Miscellaneous, composed of varied contributions within the theme of the publication.

\subsection{Contributions}

All manuscripts must be original, and must not have been published in any other journal or must not be in the arbitration or publication process in another journal. Empirical research results are published in Spanish, Portuguese or English, and studies and state-of-the-art are also admissible:

- Researches: 5000 to 6500 text words, including title, abstracts, descriptors, tables and references. Particular assessment will be made of research results, methodological rigor, the relevance of the subject, the quality of scientific discussion, the variety, timeliness and richness of bibliographic references (preferably publications indexed in JCR and Scopus). At least 35 references are expected.

- Literature studies and reviews: 6000 to 7000 text words, including tables and references. The debate generated, the relevance of the subject, the originality, current and selective contributions and references of around 70 works (preferably from publications indexed in JCR and Scopus) will be particularly valued.

\section{Editorial process}

\subsection{Submission of manuscripts}

Manuscripts must be submitted only and exclusively through the Open Journal System (OJS), in which all authors must register in advance, although only one will be responsible for the correspondence. No author may submit or review two manuscripts simultaneously, estimating a time of four consecutive numbers ( 2 years). An article may have a maximum of 3 authors, although if justified depending on the size of the study, there may be up to 5 .

«Alteridad» informs the reception of the manuscript submitted by the authors; the information related to the acceptance or rejection of the manuscript is sent by email and the platform; and in the case of acceptance, the author is also informed of the editing process.

In the website of the journal, in the Guidelines section, are presented the Guidelines for the Authors, the format of the structure of the articles, the cover page and cover letter, the pre-submission list, the evaluation forms by the external reviewers and a guide for the submission of the article through OJS. Before the submission, it is strongly recommended that the manuscript be checked with the Pre-Check Protocol. Two documents should be sent simultaneously:

a) Cover page and cover letter (use the official model), on which will appear

- Cover page (Title, Abstract and key words provided in the Manuscript).

- Full name of each of the authors, organized in priority order; followed by the professional category, institution, email of each author and ORCID number. It is mandatory to indicate if the authors have a $\mathrm{PhD}$ academic degree (include Dr. before the name). 
- A Cover letter will also be included indicating that the manuscript is an original contribution, has not been sent or evaluated in another journal, with the signature of the authors, and acceptance (if applicable) of formal changes to the manuscript compliant with the rules and partial transfer of rights to the publisher.

b) Fully anonymized manuscript, in accordance with the rules referred to in section 4 .

\subsection{Revission process}

Upon having received the document and in a maximum period of 30 days, the correspondence author shall receive a notification, indicating whether the manuscript is estimated or dismissed for the arbitration process by the scientific reviewers. In the case that the article has formal problems, or does not address the educational subject, or has a high similarity percentage to another document(s), the editorial board shall dismiss the work without the option to return it. Conversely, if it has superficial problems, it will be returned to the author for the corrections before starting the evaluation process. The submission date of the article will be considered based on the final submission when the article is presented with the corrections.

The articles will be scientifically evaluated by an average of three experts of the topic. Reports will indicate the following recommendations: Accept the Submission, Publishable with Modifications, Sent the manuscript back for its Review, Not Publishable. The acceptance or rejection of the manuscript for its publication will be decided from the analysis of external reports. In the case of dissenting results, it shall be forwarded to a new opinion, which shall be final. The protocol used by reviewers is public (researches; studies and state-of-the-art).

In general, once the external scientific reviews are taken into view, the criteria justifying the decision on the acceptance/rejection of the manuscript by the Editorial board are:

- Current and novelty.

- Relevance and significance: Advancement of scientific knowledge.

- Originality.

- Reliability and scientific validity: Proven methodological quality.

- Organization (logical coherence and formal presentation).

- External support and public/private funding.

- Co-authoring and internationalization degree of the proposal and the team.

- Presentation: Good writing.

The timeline for the scientific evaluation of manuscripts, after the previous estimation procedures by the Editorial Board is a maximum of 100 days. In relation to the manuscripts sent for Calls for papers, their scientific review dates begin once the call finishes. Manuscripts that are positively evaluated and require modifications must be sent with the changes, within the next 15 days.

\subsection{Editing and publishing of the manuscript}

The edition and layout processes of the accepted articles is performed by the Technical Board of the journal in coordination with the Abya-Yala Editorial. «Alteridad» reserves the right to make 
style corrections and editorial changes if necessary to improve the manuscript. A proof of printing in PDF format will be sent to the authors for the correction of typography and spelling in a maximum of three days.

Abya-Yala Editorial will carry out, free of charge for the authors, the professional translation of the final version of the manuscript into the English language (or Spanish, according to the original version), which will guarantee the consultation and international dissemination of the manuscript. The articles will be published on the journal's platform in a timely manner. All articles, in their two language versions (Spanish and English), are published in PDF, HTML, EPUB and XML-Jats format.

\subsection{Promotion and dissemination of the published article}

The authors are committed to give maximum diffusion to their article published in «Alteridad». In this sense, they are encouraged to promote their published article on academic networks (Academia.edu, ResearchGate, Mendeley, Kudos), social (Twitter, Facebook, LinkedIn, also publishing the DOI), institutional repositories, web or blog staff, among others. Authors are also encouraged to share the published article through email lists, research groups and personal contacts.

«Alteridad» has a Metric Measurement System (PlumX) that allows verifying the compliance with this commitment. For the submission of future articles by authors of «Alteridad», the impact of previous works will be taken into account.

\section{Structure of the manuscripts}

The manuscripts shall be submitted in typeface Arial 10, simple spacing, fully justified and without tabs or white space between paragraphs. Only large blocks (title, authors, abstracts, key words, credits, and captions) will be separated with white space. The page must be 2 centimeters in all its margins. Manuscripts must be submitted in Microsoft Word document (.doc or .docx), requiring the file to be anonymized in File Properties to avoid the information related to the identification of the author/s.

\subsection{Cover page}

Title (Spanish and English): Concise but informative, in Spanish on the first line and in English in the second, consisting of as many significant terms as possible. The title is not only the responsibility of the authors, and changes can be proposed by the Editorial Board. A maximum of 80 characters with space are accepted.

Abstract (Spanish and English): It must be presented in a concise way and in this order: Justification, objectives, methodology used (approach and scope), more relevant results, discussion and main conclusions. It must be written impersonally "The present work analyzes.... In the case of the Abstract, the use of automatic translators will not be accepted because of their poor quality. It will be between 220/230 words.

Key words (Spanish and English): 6 keywords must be presented for each language version directly related to the topic of the manuscript. The use of the keywords presented in UNESCO's Thesaurus will be positively valued (http://bit.ly/2kIgn8I) or the controlled vocabulary of IRESIE (http://bit.ly/2mgg4m8). 


\subsection{IMRDC Structure}

For those works involving empirical research, the manuscripts will strictly respect the IMRDC structure, with the headings of Economic Supports and Notes being optional. The works involving Literature Studies and Revisions may be more flexible under their headings, especially in Methodology, Results and Discussion. In all types of works, bibliographic references are mandatory.

1. Introduction and state of the play: It should include the theoretical foundations and purpose of the study, using bibliographic citations, as well as the review of the most significant literature of the topic at the national and international level. The use of high-impact references (JCR and Scopus) will be positively valued.

2. Methodology: It must be written in a way that the reader can easily understand the development of the research. It should contain the explanation on the approach (quantitative, qualitative or mixed) and the scope (exploratory, descriptive, correlational or explanatory). When appropriate, it shall describe the sample and the sampling form, as well as it must refer to the type of statistical analysis applied. If it is an original methodology, it is necessary to set out the reasons that have led to its use and describe the possible limitations.

3. Results: Efforts will be made to highlight the most relevant results and observations of the investigation, describing, without making judgments, the material and methods used for the analysis. The results will be presented in figures or/and tables according to the journal's standards (See section 4.4). They will appear in a logical sequence in the text, tables or figures, avoiding data redundancy.

4. Discussion and conclusions: Discussion and conclusions: It will summarize the most important findings, relating the observations with interesting studies, pointing to contributions and limitations, without resulting in data already commented in other sections. In addition, the discussion and conclusions section should include deductions and lines for future research.

\subsection{Economic support and notes}

Economic support (optional): Council Science Editors recommends that authors specify the source of funding for the research. Works on the endorsement of competitive national and international projects will be considered a priority. In any case, for the scientific assessment of the manuscript, it must be anonymized with XXXX only for its initial evaluation, in order not to identify authors and research teams, which must be set out in the Presentation Letter and subsequently in the final manuscript.

Notes (optional) will go, only if necessary, at the end of the article (before references). They should be used to clarify terms or make marginal annotations. Note numbers are placed in superscript, both in the text and in the final note. Notes collecting simple bibliographic citations (without comments) are not allowed, as these should be in the references. If it contains a cite, the reference must also be found in the Bibliography section.

\subsection{Bibliography}

Bibliographical citations should be reviewed in the form of references to the text. Bibliography that is not cited should not be included in the text. Its number must be sufficient and necessary to contextualize the theoretical framework, methodology used and research results in an international research space: Minimum 35 for empirical research manuscripts, and around 70 for literature studies and reviews. 
They will be presented alphabetically by the author's first last name (adding the second one only in case the first one is very commonly used, and joined with a hyphen). The quote should be extracted from the original documents, preferably journals and to a lesser extent books. Given the significance of citation indices and impact factor calculations, the use of references from indexed publications in JCR and/or Scopus and the correct citation following APA 6 norms is valued (http:// bit.ly/2meVQcs).

It is mandatory that quotes with DOI (Digital Object Identifier System) be reflected in the References (can be obtained on https://search.crossref.org/). All journals and books without DOI must contain a link (in its online version, if applicable, and in a shorten version using Bity: https:// bitly.com/), and the websites must include the consultation date using the format provided.

Journal articles must be presented in English, with the exception of those in Spanish and English, in which case they will be presented in both languages using square brackets.

\section{Norms for the references}

\section{a) Periodic publications}

- Journal article (one author): Ochoa, A. (2019). The type of participation promoted in schools is a constraint factor for inclusive education. [El tipo de participación que promueve la escuela, una limitante para la inclusión]. Alteridad, 14(2), 184-194. https://doi.org/10.17163/alt. v14n2.2019.03

- Manuscript from a journal (until twenty authors): Guarderas, P., Larrea, M., Cuvi, J., Vega, C., Reyes, C., Bichara, T., Ramírez, G., Paula, Ch., Pesantez, L., Iñiguez, A., Ullauri, K., Aguirre, A., Almeida, M., \& Arteaga, E. (2018). Sexual harassment in Ecuadorian universities: Content validation for instrument development. [Acoso sexual en las universidades ecuatorianas: Validez de contenido de un instrumento de medición]. Alteridad, 13(2), 214-226. https://doi.org/10.17163/ alt.v13n2.2018.05

- Manuscript from a journal (without DOI): López, L., \& Ramírez-García, A. (2014). Medidas disciplinarias en los centros educativos: ¿Suficientes contra el acoso escolar? Perfiles Educativos, 36(145), 32-50. https://bit.ly/37Xd5mw.

\section{b) Books and chapters of books}

- Complete books: Cuéllar, J.C., \& Moncada-Paredes, M.C. (2014). El peso de la deuda externa ecuatoriana. Abya-Yala.

- Chapter of books: Padilla-Verdugo, J. (2014). La Historia de la Educación desde los enfoques del conocimiento. In E. Loyola (Ed.), Ciencia, Tecnología y Sociedad (CTS). Miradas desde la Educación Superior en Ecuador (pp. 107-128). Abya-Yala. https://bit.ly/3etRnZH

\section{c) Electronic means}

- Aunión, J. (2011, marzo 12). La pérdida de autoridad es un problema de toda la sociedad, no es específico del aula. $t$. https://bit.ly/2NlM9Dp 


\section{Guidelines for headings, tables and figures}

The headings of the article shall be numbered in Arabic. These will be without full case of capital letters, no underscores, no bold ones. The numbering must be at most three levels: 1. / 1.1. / 1.1.1. A carriage return will be established at the end of each numbered heading.

Tables and figures must be presented in the text in Microsoft Word ${ }^{\circledR}$ located on the place where the authors consider they should be. They shall be used only when necessary and suitable, their use should be limited for reasons of spaces (maximum 6 between tables and figures). Both must be listed in Arabic and titled with the description of their content. If the source of the table or figure is not of its own elaboration, the authors must incorporate the source consulted below the table [for example, Source: Romero-Rodríguez (2016, p. 32)].

Tables must be elaborated in Microsoft Word document, thus tables cut and pasted from other documents that cannot be edited in the diagramming process will not be accepted. The figures, in addition to being incorporated in the Microsoft Word document ${ }^{\circledR}$, must be sent as supplementary material during the submission in the «Alteridad» OJS, with a quality greater than $600 \mathrm{dpi}$, in TIFF, JPEG or PNG files.

\section{Fees and APC}

«Alteridad» is an Open Access journal, included in the Directory of Open Access Journals (DOAJ) that offers all its production online for the entire scientific community. It also does not set any economic fees throughout the editorial process for the publication of the articles, including scientific review, layout and translation thereof. There is no publication fee, no Article Processing Charge (APC) associated with this publication, neither for authors nor for readers. The journal is also licensed by Creative-Commons Attribution-Non-Commercial-Share Equal (RoMEO blue journal), which allows free access, download and archive of published articles. All expenses, inputs and financing of «Alteridad» come from the contributions made by the Salesian Polytechnic University.

\section{Ethical responsibilities}

Each author shall submit a responsible statement of authorship and originality, as well as their ethical responsibilities.

- Originality: The works must be original and should not be evaluated simultaneously in another publication, being the responsibility of the authors to comply with this standard. The opinions expressed in the published articles are the responsibility of the author/s «Alteridad» as CrossRef ${ }^{\circledR}>$ s international partner, uses the CrossCheck $^{\circledR}$ and iThenticate ${ }^{\circledR}$ anti-plagiarism tool to ensure the originality of the manuscripts.

- Authorship: The list of signatory authors should include only those who have contributed intellectually to the development of the work. Collaborating in data collection is not sufficient criteria of authorship. «Alteridad» rejects any responsibility for possible conflicts arising from the authorship of the manuscripts published.

- Transmission of copyright: the transfer of rights of the manuscript published in «Alteridad» will be included in the cover letter. The Salesian Polytechnic University (the publisher) has the copyright of published articles; it favors and allows the reuse of these under the license of use indicated above. 